\title{
OCCURRENCE OF CRITICAL HEAT FLUX DURING BLOWDOWN WITH FLOW REVERSAL
}

by

J. C. M. Leung

\section{MASTER}

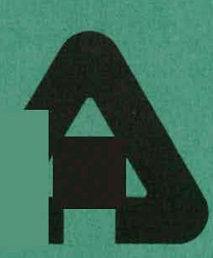

ARGONNE NATIONAL LABORATORY, ARGONNE, ILLINOIS

Prepared for the U. S. NUCLEAR REGULATORY COMMISSION under Contract W-31-109-Eng-38 


\section{DISCLAIMER}

This report was prepared as an account of work sponsored by an agency of the United States Government. Neither the United States Government nor any agency Thereof, nor any of their employees, makes any warranty, express or implied, or assumes any legal liability or responsibility for the accuracy, completeness, or usefulness of any information, apparatus, product, or process disclosed, or represents that its use would not infringe privately owned rights. Reference herein to any specific commercial product, process, or service by trade name, trademark, manufacturer, or otherwise does not necessarily constitute or imply its endorsement, recommendation, or favoring by the United States Government or any agency thereof. The views and opinions of authors expressed herein do not necessarily state or reflect those of the United States Government or any agency thereof. 


\section{DISCLAIMER}

Portions of this document may be illegible in electronic image products. Images are produced from the best available original document. 
The facilities of Argonne National Laboratory are owned by the United States Government. Under the terms of a contract (W-31-109-Eng-38) between the U. S. Energy Research and Development Administration, Argonne Universities Association and The University of Chicago, the University employs the staff and operates the Laboratory in accordance with policies and programs formulated, approved and reviewed by the Association.

\section{MEMBERS OF ARGONNE UNIVERSITIES ASSOCIATION}

The University of Arizona

Carnegie-Mellon University

Case Western Reserve University

The University of Chicago

University of Cincinnati

Illinois Institute of Technology

Univer sity of Illinois

Indiana University

Iowa State University

The University of Iowa
Kansas State University The University of Kansas Loyola University

Marquette University Michigan State University The University of Michigan University of Minnesota University of Missonri Northwestern University University of Notre Dame
The Ohio State University Ohio University.

The Pennsylvania State University

Purdue University

Saint Louis University

Southern Illinois University

The University of Texas at Austin Washingtur University

Wayne State University

The University of Wisconsin

\section{NOTICE}

This report was prepared as an account of work sponsored by the United States Government. Neither the United States nor the United States Energy Research and Development Administration, nor any of their employees, nor any of their contractors, subcontractors, or their employees, makes any warranty, express or implied, or assumes any legal liability or responsibility for the accuracy, completeness or usefulness of any infuimation, apparatus, product or process disclosed, or represents that its use would not infringe privately-owned rights. Mention of commercial products, their manufacturers, or their suppliers in this publication does not imply or connote approval or disapproval of the product by Argonne National Laboratory or the U. S. Energy Research and Development Administration.

Printed in the United States of America Available from

National Technical Information Service

U. S. Department of Commerce 5285 Port Royal Road

Springfield, Virginia 22161

Price: Printed Copy $\begin{gathered}\$ 6.00 ; \text { Microfiche } \$ 3.00 \\ 6.50\end{gathered}$ 
Distribution Category:

Water Reactor Safety Research--

Systems Engineering (NRC-2)

ANL-77 - 4

\section{ARGONNE NATIONAL LABORATORY \\ 9700 South Cass Avenue \\ Argonne, Illinois 60439}

OCCURRENCE OF CRITICAL HEAT FLUX

DURING BLOWDOWN WITH FLOW REVERSAL

\section{by}

J. C. M. Leung

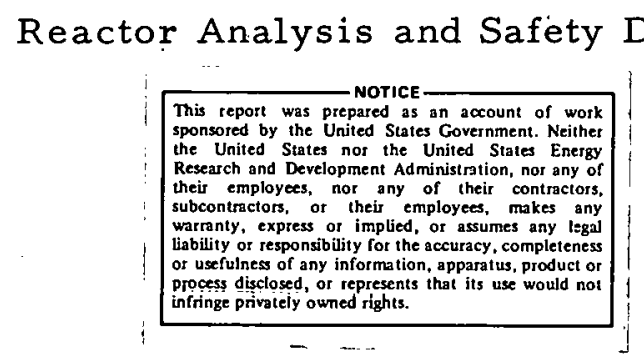

January 1977

Based on a the sis submitted to the Graduate School of Northwestern University in partial fulfillment of the requirements for the degree Master of Science in Chemical Ingineering 
THIS PAGE

\section{WAS INTENTIONALLY LEFT BLANK}


TABLE OF CONTENTS

$\underline{\text { Page }}$

NOMENCLATURE ........................ 10

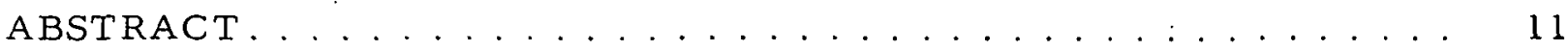

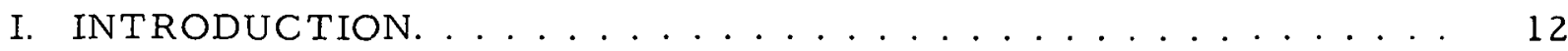

A. Background and Definitions................ 12

1. Two-phase Flow Regimes of Heat Transfer. . . . . . . . 12

2. Boiling Crisis .................. 13

B. Critical-heat-flux Models. . . . . . . . . . . . . . 14

1. Subcooled Critical Heat Flux. . . . . . . . . . . . 14

2. "Dryout" CHF in High-quality Flow Regimes......... 15

C. LOCA and Associated Phenomena in a PWR ......... 16

II. CRITICAL HEAT FLUX UNDER TRANSIENT CONDITIONS:

A LITERATURE SURVEY .................... 17

A. Pool-boiling CHF under Transient Conditions. . . . . . . 17

B. Flow-boiling CHF under Transient Conditions . . . . . . 18

1. United Kingdom: AEEW. . . . . . . . . . . . . . 18

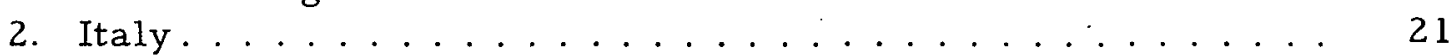

3. USSR: Moscow Power Institute. . . . . . . . . . . 22

4. Germany ..................... 22

5. Japan . . . . . . . . . . . . . . . . . . 23

6. Canada: AECL, Pinawa................ 25

7. USA ............................. 25

8. Summary. ........................... 31

III. EXPERIMENTAL INVESTIGATION . . . . . . . . . . . 33

A. Outline of Experimental Technique............. 33

1. Choice of Working fluid. . . . . . . . . . . . 33

2. Measurement of Flow during Transient. . . . . . . . 33

3. Measurement of Void during Transient............ 34

B. Description of Experimental Apparatus. . . . . . . . . . . . 34

1. Freon-11 Test Facility .................. 34

2. Test Section. . . . . . . . . ......... 36

3. Instrumentation . . . . . . . . . . . . 39 
TABLE OF CONTENTS

Page

C. Experimental Procedure .................. 40

1. Calibration..................... 40

2. Refilling Operation. ................. 40

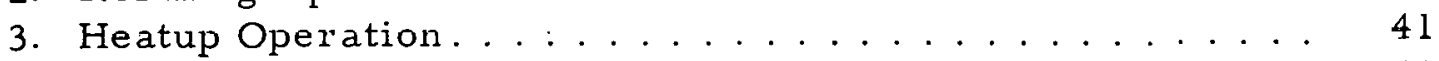

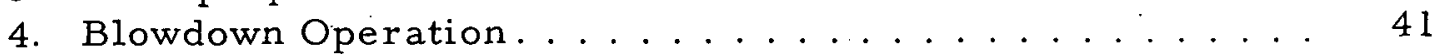

IV. EXPERIMENTAL RESULTS . . . . . . . . . . . . . 42

A. Adiabatic Blowdown Tests ................. 42

B. Preliminary Diabatic Blowdown Tests ............ 42

1. $\operatorname{Run} 4 / 22 \ldots \ldots . \ldots \ldots 4 . \ldots \ldots \ldots \ldots$

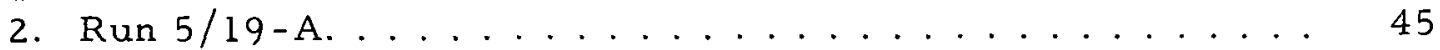

3. $\operatorname{Run} 5 / 29 \ldots \ldots \ldots \ldots$

L. Niabatic Blowdown with High-speed Hhotography:

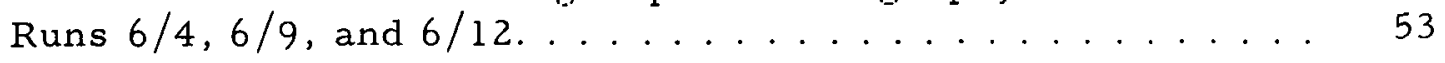

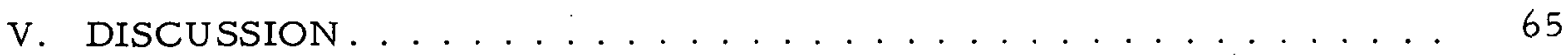

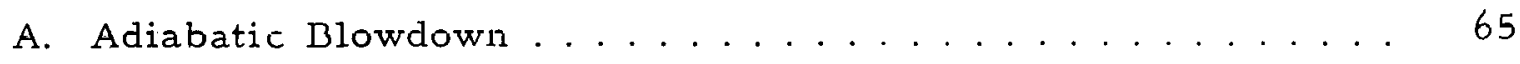

1. $\operatorname{Run} 4 / 4-\mathrm{A} \ldots \ldots \ldots \ldots 6$

2. Run $4 / 9-B \ldots \ldots 66$

B. Effect of Dissolved Gás.................... 67

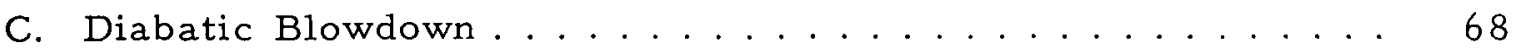

1. Preliminary Diabatic Tests.............. 68

2. Effect of Bubble Growth in the Decompression Process . . 69

3. Diabatic Tests with High-speed Photography. ........ 71

VI. SUMMARY AND CONCLUSIONS. . . . . . . . . . . . . . . . 74

VII. RECOMMENDATIONS FOR FUTURE STUDIES. . . . . . . . 75

APPENDIXES

A. Data for Single-phase Friction Pressure Drop . . . . . . . 76

B. Data for Single-phase Liquid Heat Transfer. . . . . . . . . 82

C. Evaluation of Outside-surface Temperature......... 85

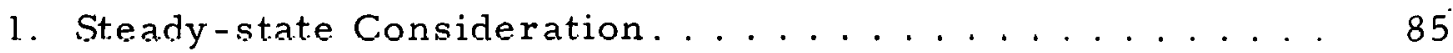

2. Unsteady-state Consideration .............. 85 


\section{TABLE OF CONTENTS}

$\underline{\text { Page }}$

D. Determination of Thermocouple Response .......... 87

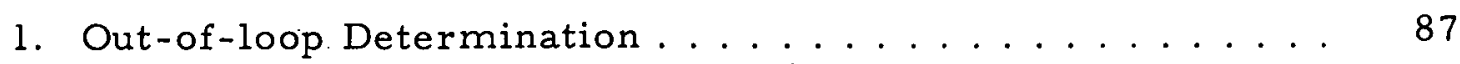

2. In-loop Determination . . . . . . . . . . . . 88

E. Calibration of Capacitance-void Meter ............ 91

1. Void-measurement Instrumentation ............ 91

2. Interpretation of Void Measurement. . . . . . . . . . . 91

3. Temperature Sensitivity in Void Measurement....... 96

F. Void Estimation during Adiabatic Blowdown. . . . . . . . 97

G. Void Estimation from Turbine and Weight Measurements . . . 98

H. Measurement of the Power Factor ...............999

I. Instrument Calibration. ................ 102

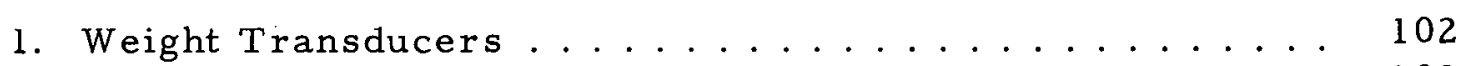

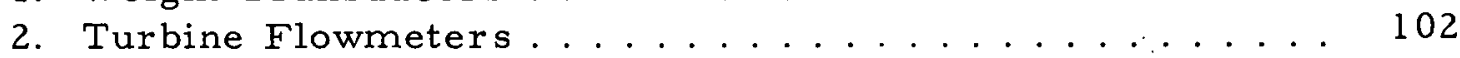

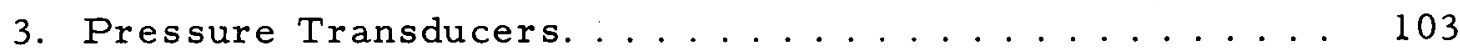

J. Freon-1 l-to-Water Scaling.............. 104

1. Zuber and Ishii................... 104

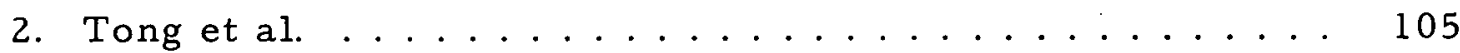

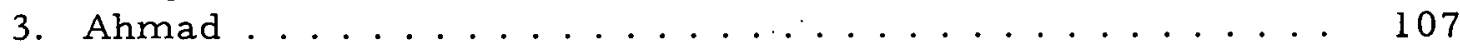

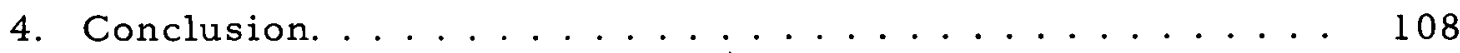

K. Calculation of Critical Flow Rate............. 109

L. Calculation of Critical Heat Flux .............. 113

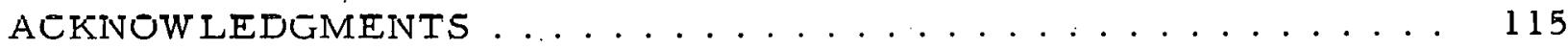

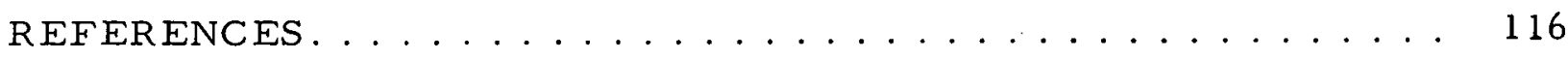




\section{LIST OF FIGURES}

No.

1. Two-phase Flow Regime.................... 13

2. Schematic of a PWR System. . . . . . . . . . . . . 16

3. Dimensionless Density during Various Transients......... 21

4. Effect of Power-excursion Time on CHF . . . . . . . . . 22

5. Time to CHF vs Excess Heat Flux . . . . . . . . . . . . 24

6. Measured and Predicted Wall Temperature for Semiscale

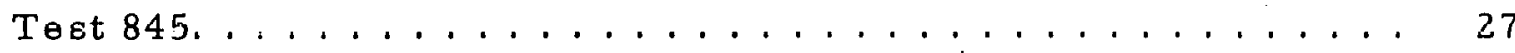

7. Wall Temperature for Babcock and Wilcox Blowdown Test . . . 27

8. Wall 'I'emperature and L'ressure for UKNL Blowdown 'l'est . . . . L8

9. Pressure History for ORNL Single-rod Test. . . . . . . . . . 29

10. MIT Results for Double Flow Reversal . . . . . . . . . . . . . 31

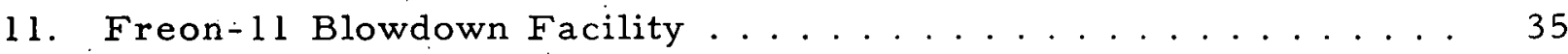

12. Schematic Showing Refrigeration Unit and Receiving Vessel . . . 36

13. Isometric of Transient CHF Test Section . . . . . . . . . . 37

14. Thermocouple Locations................... 39

15. Pressure and Void Measurement for Adiabatic Blowdown

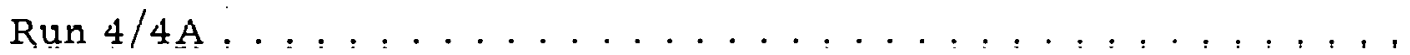

16. Fluid Temperature during Blowdown Run 4/4-A .........443

17. Pressure and Weight Measurement for Adiabatic Blowdown Run 4/9B .......................... 44

18. Void Fraction and Turbine Flowmeter Measurement for Adiabatic Blowdown Run 4/9B ................ 44

19. Pressure History for Diabatic Blowdown Run 4/22. . . . . . . 45

20. Temperature History for Run 4/22 . . . . . . . . . . . . 46

21. Turbine Flow Measurement for Run $4 / 22 \ldots \ldots 46$

22. Void-fraction Measurement for Run 4/22 . . . . . . . . . . 47

23. Pressure History for Diabatic Blowdown Run 5/19A. . . . . . . 47

24. Temperature History for Run 5/19A . . . . . . . . . . 48

25. Void-fraction Measurement for Run 5/19A ........... 49

26. Time to CHF vs Axial Location for Run 5/19A . . . . . . . . 4 49 


\section{LIST OF FIGURES}

No.

Title

$\underline{\text { Page }}$

27. Pressure History for Diabatic Blowdown Run 5/29. . . . . . . 49

28. Temperature History for Run 5/29 . . . . . . . . . . . 50

29. Void-fraction Measurement for Run 5/29............. 51

30. Flow Measurement during Blowdown for Run 5/29........ 51

31. Mass in Blowdown Vessel for Run 5/29 ............. 51

32. Time to CHF vs Axial Location for Run 5/29 .......... 52

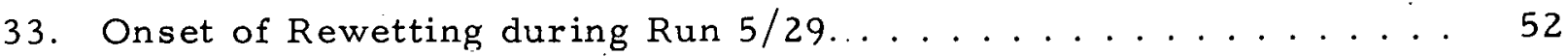

34. Pressure History for Diabatic Blowdown Run 6/4 . . . . . . . 53

35. Temperature History for Run 6/4 . . . . . . . . . . . 54

36. Void-fraction Measurement for Run 6/4............ 55

37. Turbine Flow Measurement for Run 6/4............. 55

38. Mass in Blowdown Vessel for Run 6/4............. 55

39. Pressure-differential Measurement for Run 6/4 ........ 55

40. Pressure History for Diabatic Blowdown Run 6/9 . . . . . . . 56

41. Temperature History for Run 6/9.............. 56

42. Void-fraction Measurement for Run 6/9............. 57

43. Turbine Flow Measurement for Run 6/9............. 57

44. Mass in Blowdown Vessel for Run 6/9............. . 57

45. Pressure-differential Measurement for Run 6/9 . . . . . . . . 57

46. Axial Pressure Profile during Diabatic Blowdown Run 6/9 . . . 58

47. Pressure History for Run 6/12. . . . . . . . . . . . 58

48. Temperature History for Run $6 / 12 \ldots \ldots 59$

49. Void-fraction Measurement for Run 6/12 . . . . . . . . 60

50. Turbine Flow Measurement for Run 6/12 . . . . . . . . . 60

51. Pressure-differential Measurement for Run 6/12 ........660

52. Selected Prints for Run 6/4.................61

53. Selected Prints for Run $6 / 9 \ldots \ldots \ldots 1$

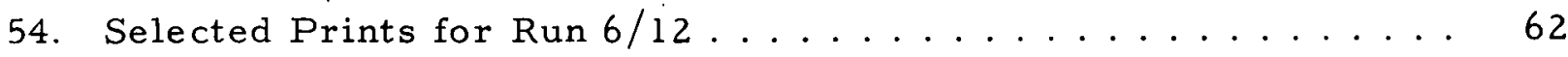

55. Velocity Observed in High-speed Photography during Run 6/4 . . 63 


\section{LIST OF FIGURES}

No.

Title

$\underline{\text { Page }}$

56. Velocity Observed in High-speed Photography during Run 6/9. . . 63

57. Velocity Observed in High-speed Photography during Run 6/12. . 63

58. Pressure Histories for Adiabatic and Diabatic Blowdowns . . . . 70

59. Void Fractions for Adiabatic and Diabatic Blowdowns . . . . . 70

A.1. Friction-factor Results Based on Hydraulic-equivalent

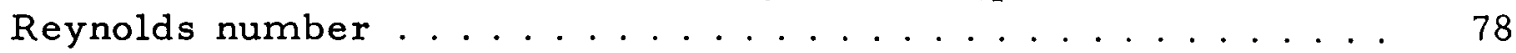

A.2. Friction-factor Plot Based on Modified Reynolds number. . . . . 79

A.3. Isothermal Freon-11 Friction Data .............. 81

B. 1. Results for Single-phase Heat Balance . . . . . . . . . . . . . . 82

B. L. Results for Single-phase Heat Transfer .............. 83

D.1. Temperature Response for Lower-half Test-section Thermocouples.................... 88

D.2. Temperature Response for Upper-half Test-section

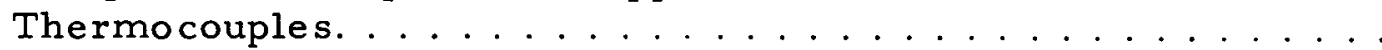

D.3. Temporal Voltage, Current, and Resistance Measurement. during Rapid Joulc Hcating. . . . . . . . . . . . . . . 8y

E.1. Vertical Calibration Using Impedance Bridge. . . . . . . . . . 91

E.2. Horizontal Calibration Using Impedance Bridge . . . . . . . . . . 91

E.3. Capacitance Bridge for Transient Void Measurement . . . . . . 92

E.4. Vertical Calibration Using Capacitance Bridge. . . . . . . . 92

E.5. Horizontal Calibration Using Capacitance Bridge . . . . . . . . 92

E.6. Output-voltage Characteristic of Capacitance Bridge...... 93

E.7. Void-fraction Determination Using Capacitance Bridge...... 93

E.8. Various Idealized Two-phase-flow Models. . . . . . . . . . . . 94

E.9. Theoretical Void vs Apparent Void. . . . . . . . . . . . . 94

F.1. Generalized Temperature-Entropy Diagram . . . . . . . . . 97

H. 1. Determination of Phase Angle Using Lissajous Figure. . . . . . 99

H.2. Measured Phase Angle vs Test-section Voltage.......... 99

H.3. Amplitude of Ripple vs Test-section Voltage ........... 101

H.4. Power Correction Factor vs Test-section Voltage ........ 101 


\section{LIST OF FIGURES}

No.

Title

$\underline{\text { Page }}$

I. 1. Calibration of Supply-vessel Weight Transducer......... 102

I.2. Calibration of Blowdown-vessel Weight Transducer. ....... 102

I.3. Agreement between Two Types of Flow Measurements. . . . . . 103

I.4. Calibration of a 100-psid (689.5-kPa) Transducer ....... 103

J.1. Density Ratio for Freon-11 and Water............ 105

J.2. Density Ratio vs Reduced Pressure ................ 105

\section{LIST OF TABLES}

No.

$\underline{\text { Title }}$

Page

I. Experimental Conditions for Studies of Transient Critical Heat Flux ......................... 19

II. Dimensions of Test Section ................... 38

III. Transient CHF Test Instrumentation . . . . . . . . . . 40 40

IV. Initial Steady-state Conditions in Test Section before Blowdown . 42

V. Time to $\mathrm{CHF}\left(\mathrm{t}_{\mathrm{CHF}}\right)$ for Diabatic Blowdown . . . . . . . . . . 64

VI. Effect of Prolonged Nitrogen Contact with Freon-11 at Elevated

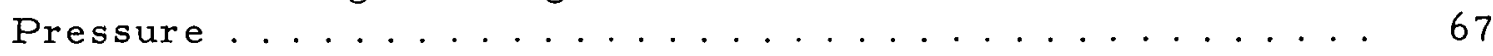

VII. Frictional Pressure Drop for Water in Test Section No. 1. . . . 79

VIII. Frictional Pressure Drop for Freon-11 in Test Section No. 2. . . 81

IX. Time Constant of Thermocouples . . . . . . . . . . . 88

X. Overall Time Response of Test Section and Thermocouples... . 89

XI. Thermodynamic and Transport Properties ........... 106

XII. Results of Freon-11 Water Scaling ............. 106

XIII. Summary of Estimations of Critical Heat Flux. . . . . . . . . 114 


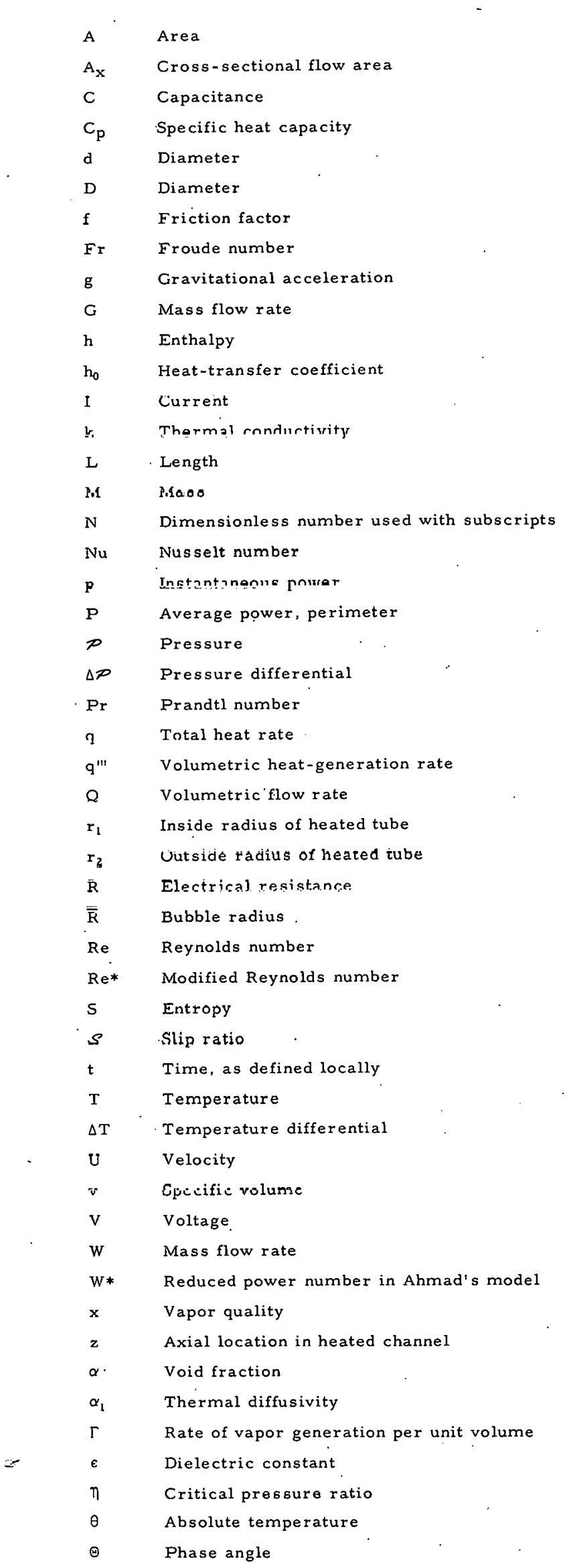

NOMENC LATURE

\begin{tabular}{|c|c|c|}
\hline & $x$ & Radius or diameter ratio \\
\hline & $\mu$ & Viscosity \\
\hline & $\nu$ & Kinematic viscosity \\
\hline & $\xi$ & Tube thickness \\
\hline & $\rho$ & Density \\
\hline & $\rho_{r}$ & Electrical resistivity \\
\hline & $\sigma$ & Surface tension \\
\hline & $\top$ & Response time as defined locally \\
\hline & $\varphi$ & Surface heat flux \\
\hline & $\Phi$ & Laminar coefficient defined in Eq. A.2. \\
\hline & $\psi$ & Power factor \\
\hline & $\omega$ & Angular rotation \\
\hline & Subscript & ts \\
\hline & a & Annarent \\
\hline & ave & Average value \\
\hline & h & Rn \\
\hline & bd & Bead of thermocouple \\
\hline & DD & Blowdown \\
\hline & $r$ & rinntinunus phase. sritical sondition \\
\hline & $\mathrm{CHF}$ & Critical-heat-flux condition \\
\hline & d & Dispersed phase \\
\hline , & e & Equivalent \\
\hline & $\mathbf{E}$ & Empty \\
\hline & f & Liquid phase \\
\hline & $\mathbf{F}$ & Full \\
\hline & fric & Friction \\
\hline & fg & Difference between vapor and liquid quantities \\
\hline & $\mathbf{g}$ & Oasevus pliase \\
\hline 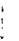 & $\mathrm{h}$ & Hèàted \\
\hline ; & $\mathrm{i}$ & Inlet, inside, interface \\
\hline & jn & Junction \\
\hline & $\max$ & Maximum \\
\hline$i$ & méas & Measured value \\
\hline & $\mathbf{M}$ & Momentum \\
\hline 1 & 0 & Outlet, outside, single phase \\
\hline 4 & 0 & Initial conditions. \\
\hline 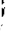 & $\mathbf{r}$ & Reduced property \\
\hline 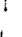 & $\mathbf{s}$ & Steady state \\
\hline$\because$ & $02 t$ & Situratod value \\
\hline i & SAT & Saturation \\
\hline 1 & sub & Subcooled, subcooling \\
\hline & $\mathbf{t}$ & Transient \\
\hline & $\mathbf{T}$ & Total \\
\hline & TC & Thermocouple \\
\hline & TS & Test section \\
\hline & $\mathbf{v}$ & Vaporization \\
\hline & $\mathbf{w}$ & Wall \\
\hline & w & Wetted \\
\hline & $\mathbf{z}$ & Hydrostatic head \\
\hline & $2 \varphi$ & Two phase \\
\hline
\end{tabular}




\author{
OCCURRENCE OF CRITICAL HEAT FLUX \\ DURING BLOWDOWN WITH FLOW REVERSAL \\ by \\ Joseph C. Leung
}

\begin{abstract}
A small-scale experiment using Freon- 11 at $130^{\circ} \mathrm{F}\left(54.4^{\circ} \mathrm{C}\right)$ and 65 psia $(0.45 \mathrm{MPa})$ in a well-instrumented, transparent annular test section was used to study the occurrence of critical heat flux (CHF) during blowdown with flow reversal. The inner stainless steel tube of the annulus was uniformly heated over its $61-\mathrm{cm}$ length. Inlet and exit void fractions were measured by a capacitance technique. Flow-regime transition was observed with highspeed photography.
\end{abstract}

A 1 -hr contact time between Freon-11 and nitrogen at $130^{\circ} \mathrm{F}\left(54.4^{\circ} \mathrm{C}\right)$ and $60 \mathrm{psig}(0.517 \mathrm{MPa})$ was found to greatly affect the steady-state subcooled-boiling initial conditions.

Delay in bubble growth was observed in adiabatic blowdown runs. This was caused by the conditions of thermodynamic nonequilibrium required for the unstable bubble growth. For the diabatic runs, equilibrium was more closely approached in the test section during the early phase of blowdown.

Critical heat flux did not occur immediately during the flow decay in an approximately $60-\mathrm{ms}$ reversal period. The first or early CHF, which occurred at about $400 \mathrm{~ms}$, was independent of the blowdown volume and did not propagate upward. An annular flow pattern appeared at the onset of this CHF which occurred only at the lower 8 in. $(20.3 \mathrm{~cm})$ of the heated zone.

For some cases, the early. CHF was rewet and a second CHF was observed at near depletion of liquid in the heated channel. This CHF, however, propagated smoothly upward, and the time scale for this event was dependent on the system blowduwir volume. 


\section{INTRODUCTION}

Since both boiling-water reactors (BWR's) and pressurized-water reactors (PWR's) operate at elevated temperatures and pressures [ 1200 and 2250 psia (8.273 and $15.51 \mathrm{MPa}$ ) respectively], ${ }^{1}$ if a major rupture of the primary-coolant pipe occurred, commonly called a loss-of-coolant accident (LOCA),* the coolant would be lost from the core region. ${ }^{1,2}$ Current safety research is centered about specific phenomena relating to the two-phase behavior of the water following this transient. These experiments concentrate on areas such as critical flow, which determines the rate at which the coolant is discharged from the core; transient boiling heat transfer crisis or critical heat flux (CHF), which determines when the fuel rods will exreed the local critical values; and emergency-core-cooling-system (ECCS) performance, whirh investigates the reentry of cooling water into the core.

In a PWR, a guillntine rupture of the inlet-coolant pipe results in fast depressurization, known as blowdown. A number of core flow directions may result, depending on the relative thermodynamic conditions of the coolant inside the core and at the plenums. Possible configurations are flov revereal, bidirectional flow, and countercurrent flow. Current numerical analyses generally assume that steady-state CHF correlations apply to this transient system. Consequently, as flow goes through stagnation, the onset of CHF is predicted immediately. Experiments indicate that CHF does not occur as the flow reverses, but in fact is delayed by at least several hundred milliseconds. The peak fuel-cladding temperature reached during the accident is strongly affected by the time delay t $\mathrm{CHF}$ to $\mathrm{CHF}{ }^{4}$ Accordingly, this CHF prediction has a significant impact on reported reactor performance with respect to acceptance criteria on clad temperature and metal-to-water reactions among others.

Current research on water-reactor safety sponsored by the U. S. Nuclear Regulatory Commission consists of integral test programs such as Juss-ofFluid Test (LOFT) and Semiscale at the Idaho National Engineering Laboratory, and Blowdown Heat T'ransfer (BDHT) program at Oak Ridge National Laboratory. To interpret these test results; one must be able to measure the inctan." taneous flow, void fraction, and heater-surface temperature to understand the basic mechanisms involved. Such is the objective of the present study.

A. Background and Definitions

1. Two-phase Flow Regimes of Heat Transfer

Consider a flow of subcooled liquid (e.g., water) into the bottom of a long, uniformly heated vertical tube. Figure 1 shows, in diagrammatic form, the various flow patterns encountered over the length of the tube, together with

*A loss-of-coolant accident is a postulated accident that results from the loss of reactor coolant at a rate in excess of the capability of the reactor-coolant-makeup system from breaks in the reactor-coolant pressure boundary, up to and including a break equivalent in size to the double-ended rupture of the largest pipe of the reactor coolant system (AEC definition, Ref. 3). 
the corresponding heat-transfer regions. When the temperature remains below that necessary for nucleation, the mode of heat transfer is single-phase (liquid) convection (region A). Further downstream, the superheated boundary layer is thick enough to support bubble growth at many nucleation sites. The mode

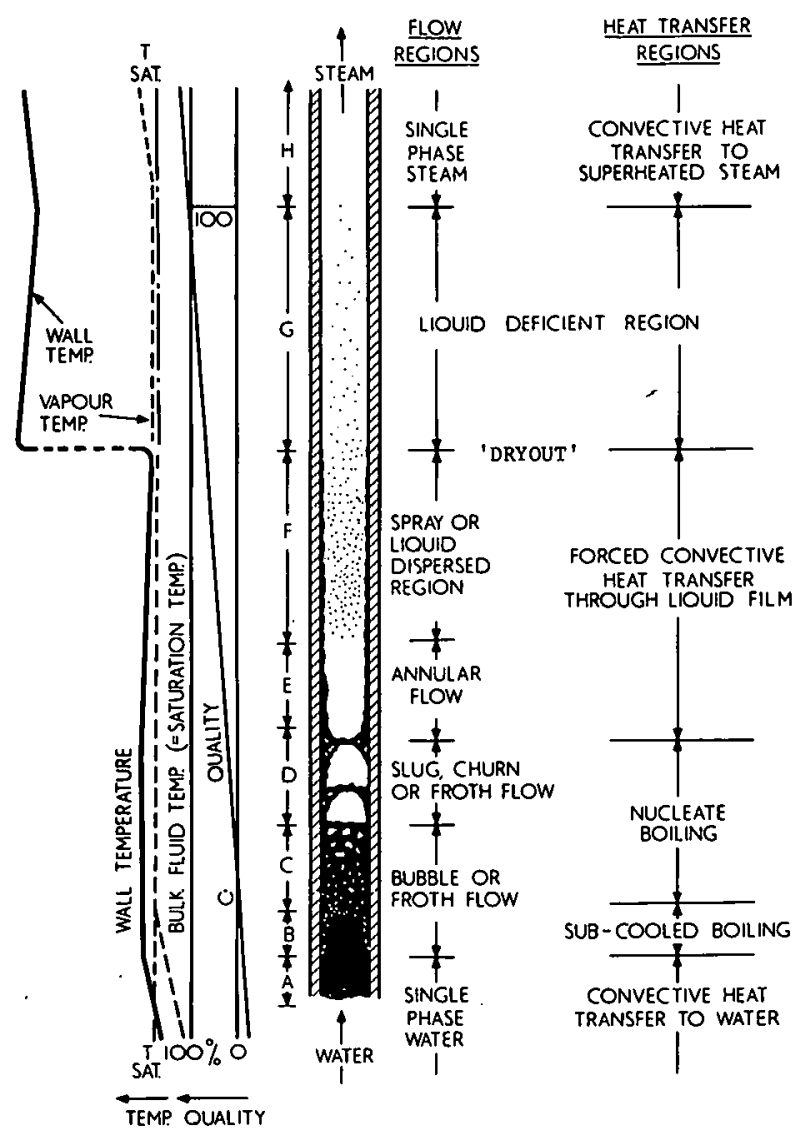

Fig. 1. Two-phase Flow Regime. 5 ANL Neg. No. 900-75-14. of heat transfer in the presence of subcooled liquid (region $B$ ) is known as subcooled nucleate boiling. The region of saturated nucleate boiling starts when the bulk liquid temperature reaches saturation. Slug flow (region D) results when bubbles agglomerate and coalesce in the bulk stream. Annular flow occurs further down the channel (region $E$ ). In this region, heat is mostly carried away from the wall by forced convection in the film to the liquid-vapor interface, where evaporation takes place. Complete evaporation of the liquid film results in "dryout" and is accompanied by a rise in wall temperature. The liquiddeficient region (region G) consists of high-velocity vapor with entrained droplets, and a single-phase (vapor) heat transfer (region $H$ ) results when all liquid droplets disappear by evaporation.

\section{Boiling Crisis}

In forced convective boiling, the boiling crisis is characterized by a sudden reduction. in the heat-transfer coefficient due to the change of heat-transfer mechanisms as indicated by a temperature oscillation ${ }^{6}$ or excursion of the heated surface. ${ }^{7,8}$ The maximum heat flux just before the boiling crisis occurs is called the critical heat flux. At least two mechanisms of boiling crisis have been differentiated.

a. Departure from Nucleate Boiling (DNB) occurs in a bubbly flow pattern. When the bubbly boundary layer becomes thick enough to prevent liquid from contacting the hot surface, boiling changes from nucleate boiling to film boiling, resulting in an insulating vapor film covering the heating surface. ${ }^{7}$ Due to the low thermal conductivity of the vapor coupled with the relatively high values of heat flux required to initiate film boiling, this process is characterized by an excursive temperature behavior.

b. "Dryout" occurs in an annular-flow pattern. The liquid film that normally covers and cools the heating surface becomes too thin, and dry patches form and spread as a result of breakdown of the film. Unlike the 
conditions at DNB, the higher heat-transfer coefficients associated with highvelocity vapor flow and lower critical heat fluxes cause only modest tempera1 ture excursion at "dryout." 8

\section{B. Critical-heat-flux Models}

Although many subcooled CHF models have been proposed, the mechanism is still not fully understood and the hypotheses involved still remain to be confirmed. Considerably more is known about the mechanism of "dryout" in the regions of higher quality. Various models proposed in the past are summarized below.

\section{Subcooled Critical Heat Flux}

Chang, ${ }^{y}$ formulating a model based on the hydrodynamic stability of bubbles, considered the bubbles to reach a critical velocity normal to the surface at CHF. This velocity is determined by taking a force balance on the bubble, and the CHF is calculated based on an enthalpy balance.

Bankoff ${ }^{10}$ presented the Sequential Rate Process model based on a turbulent bubble layer at the wall and a single-phase turbulent liquid core. CHF occurs when the core is unable to remove heat as fast as it is transmitted by the wall layer, resulting in a marked increase in bubble size and population, which in turn results in bubble coalescence and wall dryout.

Kirby et al. ${ }^{11,12}$ suggested that CHF corresponds to the drying up of a liquid film under one of the large vapor bubbles. They later tested the validity of this mechanism by measuring the electrical conductance between the heating surface and the flowing liquid. The results were inconsistent with the proposed mechanism, and CIF was found to occur in the absence of large vapor bubbles in the nucleate-boiling region. The spreading of a dry patch following microlayer evaporation under.a nucleate-boiling bubble was suggested as a possible alternative mechanism. ${ }^{13}$

Flori and Bergles ${ }^{14}$ observed in a low-pressure water system that near the CHF condition the flow pattern is either slug or froth flow. Their model, similar to Kirby's, assumes that when a vapor clot passes near the wall, the nucleation bubbles disrupt the superheated liquid film and a dry spot appears on the wall. This dry spot is quickly quenched by the liquid following the bubble. CHF will occur when the temperature increase due to the dry spot is greater than the temperature drop resulting from quenching. The authors suggested that when the Leidenfrost temperature is reached, a continuous vapor patch covers the surface locally, leading to CHF.

Another model, proposed by Kutateladze ${ }^{15}$ and modified by Tong, ${ }^{16}$ considers the subcooled CHF to be the result of separation of the hydrodynamic boundary layer, analogous to that induced by the injection of gas into a flowing 
liquid through a porous wall. Dean et al. ${ }^{17}$ measured the CHF on a porous plate while various amounts of vapor were being injected into the flow stream. Their study showed that CHF was reduced with vapor injection, which tends to support Kutateladze's and Tong's model.

The separation model was developed further by Purcupile and Gouse. ${ }^{18}$ They postulated that CHF occurs when the vapor injection into the flow stream reduces the velocity gradient near the wall; as the vapor bubbles become almost stagnant, a transition is made from nucleate to film boiling. By defining CHF to be the sum of the heat transferred by vapor generation and by liquid displacement at CHF point, they were able to use the developed correlation to scale CHF between water and Freons.

\section{2. "Dryout" CHF in High-quality Flow Regimes}

A significant contribution to the understanding of the mechanism of dryout was the model proposed by Isbin and his co-workers. ${ }^{19,20}$ This model assumes an annular film thickness on the wall resulting from the processes of liquid entrainment, evaporation, and deposition. Dryout was assumed if the film thickness reduced to zero. Later Grace ${ }^{21}$ suggested that droplet deposition was negligible in most situations of practical interest.

Becker and Persson ${ }^{22}$ further simplified Isbin's solution and showed that dryout was a local phenomenon independent of inlet subcooling and $L / D$ ratio.

Goldmann et al. ${ }^{23}$ assumed a fog- or mist-flow pattern in which the existence of a liquid film can be neglected. The wall was assumed to be cooled by evaporation of droplets deposited, and the droplet diffusion through a vapor boundary layer was suggested as the controlling mechanism for dryout.

Stein ${ }^{24}$ considered a flowing liquid film from which entrainment is negligible. Thus dryout occurs when the rate of evaporation exceeds the rate of droplet supply to the film. He further simplified it to the case proposed by Goldmann et al., but proposed a different mathematical approach to the droplet transport problem.

Tippets ${ }^{25}$ extended Isbin's model to include the effect of film stability. By assuming the film could be represented by a potential flow scheme, he determined from perturbation methods when the interface would become unstable due to the forces resulting from entrainment and deposition, but not from evaporation.

Chung ${ }^{26}$ proposed a theoretical model for liquid mass transfer between the core of the annular flow and the film, and used it to predict CHF due to film depletion. Results indicated that the liquid entrainment was the controlling mechanism, and the local entrainment rate was governed by the Weber number associated with the upstream liquid film. 
Hewitt et al. ${ }^{27,28}$ demonstrated that indeed the $\mathrm{CHF}$ condition occurred when the flow rate of the liquid film on the heated wall fell to zero. - They suggested that bubble nucleation observed within the film could enhance entrainment at high heat flux and cause film breakdown.

The study of the stability of liquid film flow has recently received much attention. Not only is the stability related to the dryout process, but it is also of great interest in the rewetting of a hot, dry surface in emergency core cooling (ECC). The purely fluid-mechanical problem in the absence of heat transfer is well known, having been studied by $\mathrm{Yih}^{29}$ and Benjamin. ${ }^{30}$ Bankoff ${ }^{31}$ extended their analyses to the case with heat addition and showed that evaporation from the surface of a falling liquid film has a destabilizing effect.

The effects of uneven heating and surface tension forces on film breakdown were reported by Norman and McIntyre, ${ }^{32}$ Hallett, ${ }^{33}$ Simon and $\mathrm{Hsu},{ }^{34}$ and Dubrovskii et al. ${ }^{35}$

Hence there appear to be at least two important analytical approaches to dryout: the film thickness and its stability, and the liquid-mass transfer between the core and the film. It is uncertain at this time which model more accurately reflects the physical processes involved.

\section{LOCA and Associated Phenomena in a PWR}

One of the unlikely events considered in safety analysis of a PWR is a hypothetical rupture of the primary piping system, producing a loss-of-coolant accident (LOCA). ' Preliminary results of an AEC study (the Rasmussen study) have shown that the probability of a large-break LOCA is once in

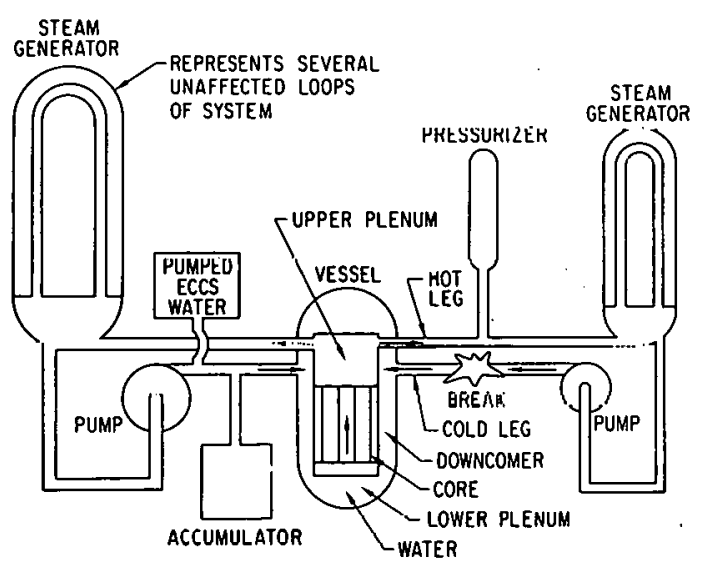

Fig. 2. Schematic of a PWR System.2 Arrows indicate normal operating flow direction. ANL Neg. No. 900-75-364. $10,000 \mathrm{yr}$ for a PWR, " and his liypulletical LOCA generally becomes the design-basis accident (DBA) because it presents the mosl extreme accident conditions. A schematic of a PWR system is shown in Fig. 2. The largest break is taken as though the pipe scparated to permit flow out of each end--a double-ended guillotine pipe break. The fluid initially undergoes decompression from a subcooled state and reaches saturated or two-phase conditions rapidly. This decompression is controlled by the discharge of fluid from the system, which is, in turn, controlled by the compressibility of the flashing, two-phase mixture.

The cold leg or inlet break allows rapid decompression of the lower plenum in the reactor vessel because the fluid path from the break to the 
lower plenum is short and unobstructed in comparison to the path from the break to the upper plenum through the steam generator (see Fig. 2). As a result, flow is caused to change from upflow to stagnation and possibly to downflow.

A major parameter in LOCA analyses is the time to critical heat flux, that is, the time from initiation of the break to the time CHF occurs in the core. Presently the steady-state correlations accepted for use in LOCA transients ${ }^{36}$ include the $W-3,{ }^{37} \mathrm{~B} \& \mathrm{~W}-2,{ }^{38}$ and Macbeth ${ }^{39}$ correlations. Slifer's ${ }^{40}$ transient CHF correlation is also accepted. During the initial flow decay in the core, the CHF is assumed to be exceeded when the coolant flow rate becomes zero for a few milliseconds. Further, it was stated by the $\mathrm{AEC}^{3}$ that "After $\mathrm{CHF}$ is first predicted at an axial fuel rod location during blowdown, the calculation shall not use nucleate boiling heat transfer correlations at that location subsequently during the blowdown even if the calculated local fluid and surface conditions would apparently justify the reestablishment of nucleate boiling." Rewetting is only permitted to occur during the reflood period of a LOCA.

\section{CRITICAL HEAT FLUX UNDER TRANSIENT CONDITIONS:}

\section{A LITERATURE SURVEY}

The present review covers the investigation of $\mathrm{CHF}$ under the following transient conditions:
$\mathrm{CHF}$ in power transients.
$\mathrm{CHF}$ in flow-decay transients.
$\mathrm{CHF}$ in pressure transients.
$\mathrm{CHF}$ in reverse flow and stagnation.

Pool-boiling experiments will be briefly summarized, followed by an up-todate review on flow-boiling transients.

\section{A. Pool-boiling CHF under Transient Conditions}

Almost all pool-boiling transients were tested under power excursion conditions. Cole ${ }^{41}$ and Graham ${ }^{42}$ studied stepwise power input with thin-ribbon test sections. Using an exponential power input, Rosenthal and Miller ${ }^{43}$ observed temperature overshoot and delay time occurring during incipient boiling. The effects of the excursion period and subcooling were studied, and the authors concluded that transient $\mathrm{CHF}$ does not differ much from the corresponding steady-state CHF. The same conclusion was reached by Borishansky and Fokin. ${ }^{44}$. 
Hall and Harrison ${ }^{45}$ found that, in a rapid exponential power transient with $\Delta t<1 \mathrm{~ms}$, film boiling was always preceded by a short burst of nucleate boiling at heat fluxes about 5-10 times the steady-state values.

Tachibana et al. ${ }^{46}$ found that the transient CHF increases as the power impulse time decreases. They explained that higher $\mathrm{CHF}$ may be due to delays in bubble growth and microlayer evaporation. The liquid layer adjacent to the heater is rapidly superheated, and nucleation occurs at many sites. The time period is such that all bubbles are in their early growth phase; rapid evaporation of a thin liquid film at the base of the bubble occurs, provoking effective cooling.

Johnson ${ }^{47}$ summarized an extensive experimental investigation ${ }^{48,49}$ for transient boiling in water subject to exponential heat inputs. The transient $\mathrm{CHF}$ was as much as four times the steady-state $\mathrm{CHF}$.

Sakuiai et al. ${ }^{50}$ suggested an exprcooion rolating traneiont $\mathrm{CH}$ steady-state $\mathrm{CHF}$ by including a term involving the period of the exponential heat input, $p$, i.e.,

$$
\varphi_{\mathrm{tCHF}}=\varphi_{\mathrm{s}} \mathrm{CHF}+\mathrm{kp}^{-\mathrm{m}}
$$

where $k$ and $m$ are strong functions of the pool subcooling.

Howell and $\mathrm{Bell}{ }^{51}$ studied the effect of depressurization rates of $5-10 \mathrm{psi} / \mathrm{s}(35-70 \mathrm{kPa} / \mathrm{s})$ on $\mathrm{CHF}$ in the pool boiling of water. They found that the time to CHF increases with decreasing rate of depressurization and is longer than that predicted by steady-state correlations. This tirnedelidy was explained in terms of the diminishing thickness of the thermal-boundary layer caused by violent convective currents in rapid bulk nucleation.

\section{B. Flow-boiling CHF under Transient Conditions}

'l'his section covers the important results in flow-boiling lransienl CHF studies being conducted in many countries. The pertinent experimental conditions are listed in Table $I$.

\section{United Kingdom: AEEW}

Moxon and Edwards ${ }^{54}$ studied flow and power transients for tubes with uniform and nonuniform heat-flux profiles, and with a 37-rod bundle with uniform heat flux. Fast transients were studied with the inlet-flow halving in less than $500 \mathrm{~ms}$ and power rising to $130 \%$ of its initial value in $200 \mathrm{~ms}$. The experimental and theoretical predictions of the time to CHF were compared. The theoretical predictions were based on a local-condition hypothesis, which states that CHF is a local phenomenon, governed by the local mass velocity, quality, and heat flux. The results of the comparison showed that, in all cases, the CHF occurred later than that predicted by the SLIP code, ${ }^{83}$ and the discrepancy varied between 0 and $400 \mathrm{~ms}$. 
TABLE I. Experimental Conditions for Studies of Transient Critical Heat Flux ${ }^{a}$

\begin{tabular}{|c|c|c|c|c|c|c|}
\hline Reference & Test Section & Test Fluid & $\begin{array}{l}\text { Pressure } \\
\text { psia }\end{array}$ & $\begin{array}{l}\text { Initial Mass } \\
\text { Velocity } \\
10^{6} \mathrm{lb} \mathrm{m} / \mathrm{hr} \cdot \mathrm{ft}^{2}\end{array}$ & $\begin{array}{c}\text { Initial } \\
\text { Heat Flux, } \\
10^{5} \mathrm{Btu} / \mathrm{hr} \cdot \mathrm{ft}^{2}\end{array}$ & Type of Transient Operation \\
\hline $47-49$ & $\begin{array}{l}0.004 \times 0.25-\text { in. ribbon heater } \\
\text { in a rectangular channel }\end{array}$ & Water & $15-2000$ & $0-3.0$ & $0.15-0.20$ & Exponential power increase \\
\hline 52 & 19 -rad bundle, $4.5 \mathrm{ft}$ long & Water & 1500 & $2.0-4.0$ & $5.0-10.0$ & Power ramps; flow coastdown \\
\hline 53 & $\begin{array}{l}19 \text { - ard } 21 \text {-rod bundles, } \\
5 \mathrm{ft} \text { long }\end{array}$ & Water & 1500 & $1.0-3.0$ & $3.0-6.4$ & $\begin{array}{l}\text { Power ramps at } 13 \% / \mathrm{s} \\
\text { maximum; flow coastdown }\end{array}$ \\
\hline 54 & $\begin{array}{l}\text { One tube and } 37 \text {-rod bundle; } \\
\text { both } 12 \mathrm{ft} \text { long }\end{array}$ & Water & 1000 & $1.5-2.0$ & - & $\begin{array}{l}\text { Power ramps at } 150 \% / s \\
\text { flow coastdown }\end{array}$ \\
\hline 55 & $\begin{array}{l}0.08 \times 2.25 \times 66-i n \\
\text { rectangular channel }\end{array}$ & Water & 1100 & 1.0 & 1.6 & Inlet break; outlet break \\
\hline 56 & One-tube, 13 ft long & Water & 860 & $1.0-2.0$ & $1.3-2.0$ & $\begin{array}{l}\text { Inlet break; outlet break; } \\
\text { flow decay }\end{array}$ \\
\hline 57 & 21-rot bundle, $5 \mathrm{ft}$ long & Water & $750-1500$ & $1.0-3.0$ & $5.0-10.0$ & Outlet break \\
\hline 53,59 & $\begin{array}{l}\text { One rod in annular channel and } \\
7 \text {-rod bundle, both } 2 \mathrm{ft} \text { and } \\
\text { heated }\end{array}$ & Water & 1500 & 1.0 & 3.5 & Outlet break \\
\hline 60,61 & $\begin{array}{l}\text { One rod in annular channel and } \\
12 \mathrm{ft} \text {, heated }\end{array}$ & Water & 1500 & 1.0 & $\begin{array}{l}3.7 \text { ave } \\
\text { chopped cosine }\end{array}$ & Inlet break \\
\hline 62 & One annulus, inner tube heated & Water & 15 & $0.35-1.4$ & 6.3 & Exponential power increase \\
\hline 40 & One rod in annular channel, $9 \mathrm{ft}$ long & Water & 1000 & $0.25-1.0$ & $2.0-5.0$ & Outlet break and/or flow decay \\
\hline 63 & $\begin{array}{l}\text { One rod in annulus, } \\
9 \mathrm{ft} \text { heated }\end{array}$ & Water & 1000 & $\begin{array}{r}0.2-1.0 \\
0.25-1.0\end{array}$ & $\begin{array}{l}2.1-5.7 \\
3.8-8.3\end{array}$ & $\begin{array}{l}\text { High-low-high flow } \\
\text { Outlet break }\end{array}$ \\
\hline 64 & $\begin{array}{l}\text { Nine-rod bundle, } \\
6 \mathrm{ft} \text { həated }\end{array}$ & Water & 1000 & $\begin{array}{r}0.5-1.0 \\
0.6-1.0 \\
0.24-1.0\end{array}$ & $\begin{array}{r}2.5-5.0 \\
0.27-1.0 \\
1.8-6.6\end{array}$ & $\begin{array}{l}\text { Flow decay } \\
\text { ON/OFF/ON flow } \\
\text { Outlet break }\end{array}$ \\
\hline 65 & $\begin{array}{l}16-\text { rod bundle, } \\
12 \mathrm{ft} \text { ieated }\end{array}$ & Water & 1000 & $\begin{array}{l}0.6-1.0 \\
0.6-1.0\end{array}$ & $\begin{array}{l}1.7-3.1 \text { ave } \\
0.2-2.0 \text { ave } \\
\text { chopped cosine }\end{array}$ & $\begin{array}{l}\text { Flow decay } \\
\text { ON/OFF/ON flow }\end{array}$ \\
\hline 66 & One tube, $3 \mathrm{ft}$ long & Water & 2250 & $1.0-2.5$ & $6.3-11.0$ & $\begin{array}{l}\text { Outlet break with and } \\
\text { without flow decay }\end{array}$ \\
\hline 67 & Nine-rod bundle, $6 \mathrm{ft}$ heated & Water & 2200 & 2.5 & 3.0 & $\begin{array}{l}\text { Outlet break and inlet break } \\
\text { with programmed power }\end{array}$ \\
\hline 68 & One tabe & Water & 1400 & $0.74-2.2$ & $0.9-1.07$ & Flow decay \\
\hline
\end{tabular}


TABLE I (Contd.)

\begin{tabular}{|c|c|c|c|c|c|c|}
\hline Reference & Tes: Section & Test F-uid & $\begin{array}{c}\text { Pressure } \\
\text { psia }\end{array}$ & $\begin{array}{c}\text { Initial Mass } \\
\text { Velocity, } \\
10^{6} \mathrm{lb} \text { m } / \mathrm{hr} \cdot \mathrm{t}^{2}\end{array}$ & $\begin{array}{c}\text { Initial } \\
\text { Heat Flux } \\
10^{5} \mathrm{3tu} / \mathrm{hr} \cdot \mathrm{ft}^{2}\end{array}$ & Type of Transient Operation \\
\hline 69 & One tube $9.8 \mathrm{ft}$ heated & Water & $1090-2030$ & - & 4.4 & Outlet break \\
\hline 70 & $\begin{array}{l}\text { One tube, } 1 \text { annulus, } 4 \text { - and } \\
9 \text {-rod bundles }\end{array}$ & $\begin{array}{l}\text { Freon-12: } \\
\text { water }\end{array}$ & $\begin{array}{l}155 \\
1000,2000\end{array}$ & $\begin{array}{l}0.37-2.58 \\
\sim 1.0\end{array}$ & $\begin{array}{l}0.0-1.0 \\
0.0-4.5\end{array}$ & $\begin{array}{l}\text { Flow and power transient } \\
\text { Flow and power transient }\end{array}$ \\
\hline 71 & One tube, $9.8 \mathrm{ft}$ heated & Water & 1300 & - & 5.23 & $\begin{array}{l}\text { Inlet break, outlet break, and } \\
\text { double-ended break }\end{array}$ \\
\hline 72 & $\begin{array}{l}28-\text { rod bundle in one pressure } \\
\text { tube, } 12 \mathrm{ft} \text { hested }\end{array}$ & Water & 1070 & $\because$ & C.13 & $\begin{array}{l}\text { Downcomer rupture and } \\
\text { inlet break }\end{array}$ \\
\hline 73 & $\begin{array}{l}\text { Single-loop, } 120 \text {-rod bundle, } \\
9 \text { in., uniformly hea }=d\end{array}$ & Water & 2250 & 0.12 & $3.0-3.8$ & Outlet break; inlet break \\
\hline 74,75 & $\begin{array}{l}\text { One-annulus guter tube hea ied, } \\
\text { One tube, botk } 13 \mathrm{ft} \text {, with } \\
\text { uniform heating }\end{array}$ & Water & 710 & $\begin{array}{l}0.1-2.0 \\
0.5-2.0 \\
0.5-1.1\end{array}$ & $\begin{array}{r}0.75-2.63 \\
0.1-2.63 \\
1.1-2.64\end{array}$ & $\begin{array}{l}\text { Flow stoppage } \\
\text { Outlet break } \\
\text { Exponential power increase }\end{array}$ \\
\hline 76 & $\begin{array}{l}\text { Nine-rod bundle, } 6-\mathrm{ft} \text { keated } \\
\text { length, radial and axial uniform } \\
\text { leating }\end{array}$ & Water & - & $1.0-3.0$ & - & $\begin{array}{l}\text { Flow decay and power ramp } \\
\text { at } 5 \% \text { in } \sim 2 \mathrm{~s}\end{array}$ \\
\hline 77 & $\begin{array}{l}\text { One annulus; } \text { :nly insice rod } \\
\text { heated }\end{array}$ & Water & $300-1010$ & $\mathrm{Up}$ to 1.55 & 0.0 & $\begin{array}{l}\text { Rampwise and stepwise power } \\
\text { to } \max \sim 1.9 \times 10^{6} \mathrm{Btu} / \mathrm{hr} \cdot \mathrm{ft}^{2}\end{array}$ \\
\hline 78 & $\begin{array}{l}\text { One annulus, =nly inner tube, } \\
3.6 \text { in. heated. with out } 2 \text { r Frrex } \\
\text { tabe }\end{array}$ & Water & 43 & $0.37-1.58$ & 9.2 & Outlet break \\
\hline 79,80 & One tube, $8 \mathrm{ft}$ reated & Freon-113 & 200 & 2.50 & 0.24 & $\begin{array}{l}\text { Flow reversal, inlet-flow } \\
\text { stoppage, and combined at } \\
\text { constant pressure }\end{array}$ \\
\hline 81 & Cine tube, $6.6 \mathrm{ft}$ heated & $\begin{array}{l}\text { Organic } \\
\text { coolant }\end{array}$ & 250 & - & 4.35 & Inlet break \\
\hline 82 & Cne tube, $13 \mathrm{ft}$ uniformly heated. & Water & 1450 & 1.13 & $2 . \equiv 4$ & Inlet break \\
\hline
\end{tabular}

aConversion factors: 1 psia $=6.895 \times \mathrm{Pa}_{1} 10^{6} \mathrm{lb} \mathrm{m} / \mathrm{hr} \cdot \mathrm{ft}^{2}=1356 \mathrm{~kg} / \mathrm{m}^{2} . \mathrm{s} ; 1 \mathrm{Btu} / \mathrm{hr} \cdot \mathrm{ft}=3.155 \mathrm{~W} / \mathrm{m}^{2} ; 1 \mathrm{ir} .=2.54 \mathrm{~cm} ; 1 \mathrm{ft}=0.305 \mathrm{~m}$. 


\section{Italy}

a. CISE. Premoli ${ }^{56}$ studied the effect of blowdown following simulated ruptures upstream and downstream, and loss of flow at constant pressure. Transient mass holdup in the test section, as indicated by the ratio $\rho(t) / \rho(t=0)$, was measured by quick-acting closing valves. Therefore, to perform a complete transient, several measurements were performed at different sampling times during repeated runs. Transients performed were less than $3 \mathrm{~s}$, and occurrence of CHF was not mentioned. From the result shown in Fig. 3, Premoli concluded that voidings due to inlet break were most severe and that density decrease was sharp because flow reversal caused the inlet, high-density, subcooled water to be lost from the test section sooner than under other break conditions.

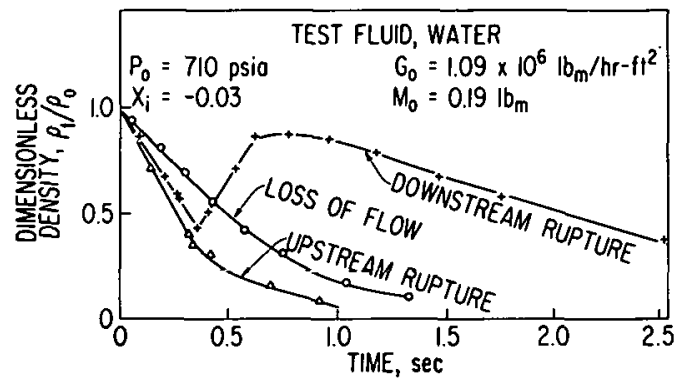

Fig. 3

Dimensionless Density during Various Transients. 56 Conversion factors: $1 \mathrm{psia}=6.895 \mathrm{kPa} ; 1 \mathrm{lbm}=0.4536 \mathrm{~kg}$; $106 \mathrm{lbm} / \mathrm{hr} \cdot \mathrm{ft}^{2}=1356 \mathrm{~kg} / \mathrm{m}^{2} \cdot \mathrm{s}$. ANL Neg. No. 900-75-782.

Gaspari et al. ${ }^{74,75}$ carried out loss-of-flow, power-surge, and outlet-break blowdown studies with both annular and tubular test sections, related to $1 / 14$ th and $1 / 40$ th scaled-down configurations of the CIRENE reactor channel. Experimentally, CHF occurred at the outlet during blowdown and propagated smoothly upstream. The code TILT ${ }^{84}$ was used to analyze the transient behavior. Theoretical predictions were based on a "hydrodynamiccondition hypothesis," which states that CHF is a hydrodynamic phenomenon governed by the hydrodynamic conditions existing in the saturated region of the channel. This and the "local-condition hypothesis" are related to each other through the heat-balance equation.

These two hypotheses were compared by Hassid and Rychlicki ${ }^{85}$ for channels with nonuniform axial heat-flux distribution; they found the hydrodynamic hypothesis to be better. Therefore Gaspari et al. assumed that, in both steady-state and transient conditions, the hydrodynamic critical quantities, i.e., $G, x$, and $P$, do not depend on how they vary along the channel and with time, or on how the heat flux varies along the length and with time, but depend on the boiling length traveled by the liquid that finally reaches the $\mathrm{CHF}$ point. Times to CHF for flow stoppage and power-surge tests were predicted within $150 \mathrm{~ms}$ ( $\mathrm{t} \mathrm{CHF}$ was $0.5-3 \mathrm{~s}$ ) using TILT together with steady-state $\mathrm{CHF}$ correlation.

For blowdown transients, the computed tCHF values were systcmatically lower than experimental values in the annular test section. 
The accuracy of prediction was strongly affected by the range of validity of the steady-state CHF correlation and the accuracy of the blowdown code. Gaspari et al. noted that significant differences exist between the phase distributions in steady state and during blowdown, where the liquid phase is subject to flashing and violent acceleration. In particular, liquid redistribution between the heated and unheated wall or between droplets and film may be strongly affected due to these effects. Time to CHF decreased with the increasing depressurization rate accomplished by variable break areas.

b. Euratom. Fritz and Riebold ${ }^{69}$ investigated the hot-leg rupture of a PWR subchannel by diaphragms of $0.315-, 0.236-$, and $0.157-$ in. (0.800-, $0.599-$, and $0.399-\mathrm{cm}$ ) diameter. Tests were conducted at initial pressure and water temperature of $2000 \mathrm{psia}(14 \mathrm{MPa})$ and $600^{\circ} \mathrm{F}\left(316^{\circ} \mathrm{C}\right)$. The onset of CHF occurred over the outlet portion of the channel at $\sim 500 \mathrm{~ms}$ and was nearly independent of rupture size, and hence of depressurization rate. However, the upstream half of the test section did not experience CHF until $4 \mathrm{~s}$.

\section{USSR: Moscow Power Institute}

Smornov et al. ${ }^{68}$ conducted flow-transient tests in a single tube with flow decreased by $40-70 \%$ of the steady-state value within 0-3 s. Local mass velocity and quality at inception of CHF were determined by calculation

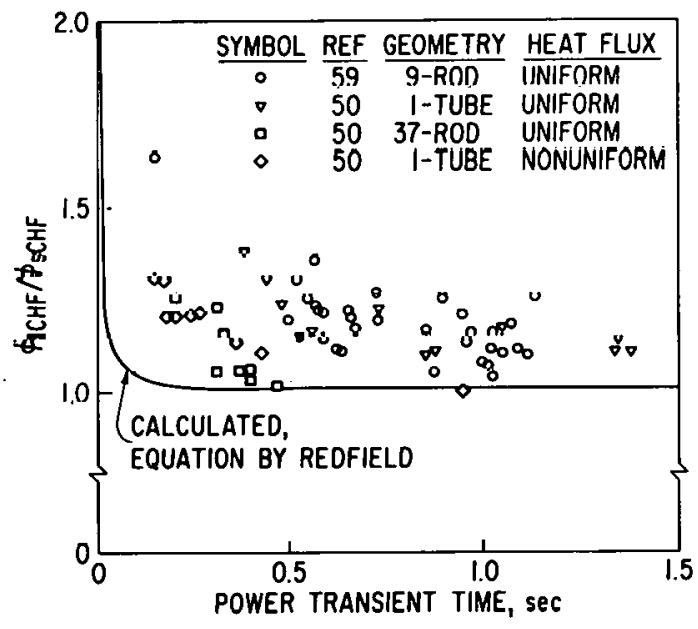

Fig. 4. Effect of Power-excursion Time on CHF.70 ANL Neg. No. 900-75-781 Rev. 3. of the transient process. Steady-state CHF correlation was obtained with the same test section. With a sharp decrease in mass velocity, the computed t $\mathrm{CHF}$ values were lower than those observed experimentally.

\section{Liermany}

Hein and Mayinger ${ }^{70}$ summarized the power- and flow-transient test results conducted at M.A.N. (Masrhinenfabrik Augsiürg Nürnlexg) in a single tube, an annulus, and four - and nine-rod bundles. Figure 4 shows an improvement in $\mathrm{CHF}^{\circ}$ with linear power-excursion time of a few seconds. The equation for power transients proposed by Redfield ${ }^{55}$ underestimates CHF values. In some tests, Freon-12 was used as the modeling fluid, and it was claimed that Boure or Steven's scaling laws were also valid for these slower transients. The results also indicated that improvement in $\mathrm{CHF}$ for tests with uniform heat flux was higher than for nonuniform ones. 
The explanation for the improvement was obscure as Hein and Marjinger did not know whether CHF occurred in bubbly or annular flow. For flow transients, good agreement was observed between transient and steadystate CHF. Unlike the power transients, a nonuniform heat-flux profile did not change this result. However, at very low mass flow improvement did occur, and they attributed this to the finite time required for complete evaporation of liquid film on the heated wall.

Hicken et al. ${ }^{71}$ studied the effect of break area, the ratio in upstream to downstream break area, and the heat flux in a single tube at 1300 psia (9 MPa). Pressure decay was faster with larger breaks and different at various locations in the loop. For small breaks, a rise in system pressure was observed because the volumetric vapor-generation rate in the heated section exceeded that which could be discharged at the break. The following generalizations were made for $t_{\mathrm{CHF}}$ :

$\mathrm{t}_{\mathrm{CHF}}$ decreases with increasing $\varphi$.

${ }^{t}$ CHF decreases downstream for large $\varphi$, but this dependency is small at low $\varphi$.

With large upstream breaks, ${ }^{\mathrm{CHF}}$ is large for low $\varphi$ but short for large $\varphi$.

With large upstream breaks, the upper region of test section did not experience CHF.

$t_{\mathrm{CHF}}$ for double-ended breaks was intermediate between the times for single-ended breaks.

\section{Japan}

a, General. Kawamura et al. ${ }^{62}$ studied pool and flow boilings of water under power-surge conditions at atmospheric pressure. With motion pictures taken at 5,000-10,000 frames/s, they observed the formation of vapor blanketing as a result of bubble coalescence at the CHF point in subcooled pool boiling. They also found that, at the CHF point, $N\left(\overline{\mathrm{R}}_{\max }\right)^{2} \simeq 1$, where $N$ is the nucleation site density and $\bar{R}_{\max }$ is the maximum bubble radius, which is proportional to the thickness of the thermal-boundary layer. This postulate indicated that a high-flux DNB was possible even with many nucleation sites if $\overline{\mathrm{R}}_{\max }$ was kept small, i,e., thin thermal-boundary layer. For pool-boiling transients, they showed that the transient CHF is reduced with increasing initial heat flux as. is expected from above postulate.

Tokumitsu ${ }^{72}$ conducted LOCA studies on a full-scale mockup of the FUGEN reactor, which is a heavy-water-moderated 165-MW BWR. However, the power level was only maintained at $5 \%$ of full power in FUGEN, 
simulating the decay heat, and only three of 25 pressure tubes were electricall heated. In the downcomer-rupture experiment, the CHF was observed half a minute later at the top of the heated length. Single-inlet pipe-rupture tests were performed with one of the pressure tubes, each of which contained 28 heated rods. CHF was observed to start from the top of the pin in nonruptured channels and from the bottom in ruptured ones. In general, ${ }^{\mathrm{CHF}}$ reported was rather long, corresponding to the complete depletion of coolant in the channels.

b. Tokyo Institute of Technology. Aoki and his co-workers. ${ }^{77,78}$ made extensive studies of power excursion and blowdown with inlet quality, power ramp rate, mass velocity, and heat flux as the parameters. For transient heat input, the observed dependency of transient $\mathrm{CHF}$ on the parameters was explained qualitatively according to three regions of flow conditions. At high flow $\left[\mathrm{G} \approx 1.5 \times 10^{6} \mathrm{lbm} / \mathrm{hr} \cdot \mathrm{ft}^{2}\left(2.5 \times 10^{3} \mathrm{~kg} / \mathrm{m}^{2} \cdot \mathrm{s}\right)\right]$ and large subcooling,

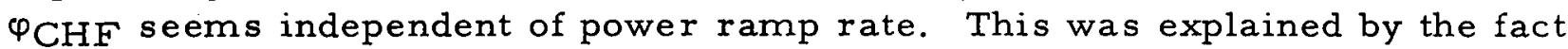
that the CHF mechanism by bubble coalescence is a very localized phenomenon, happening only near the heater surface. The bulk conditions are therefore of secondary importance.

In the second region, where CHF occurred at 50-70\% void, the transient CHF followed the steady-state curve closely. Because of the moderate void fraction, the bulk conditions do affect the transport process at the surface. As for the third region, where annular flow persists at high quality and void, CHF caused by "dryout" occurs rather slowly; hence the term "slow burnout" had been used by some researchers. Under this condition, $\varphi \mathrm{CHF}$ appears to increase as power ramp rate.

'l'he blowdown tests simulating hot-leg break conducted by this group at a water pressure of 65 psia $(448 \mathrm{kPa})$ indicated that the CHF did

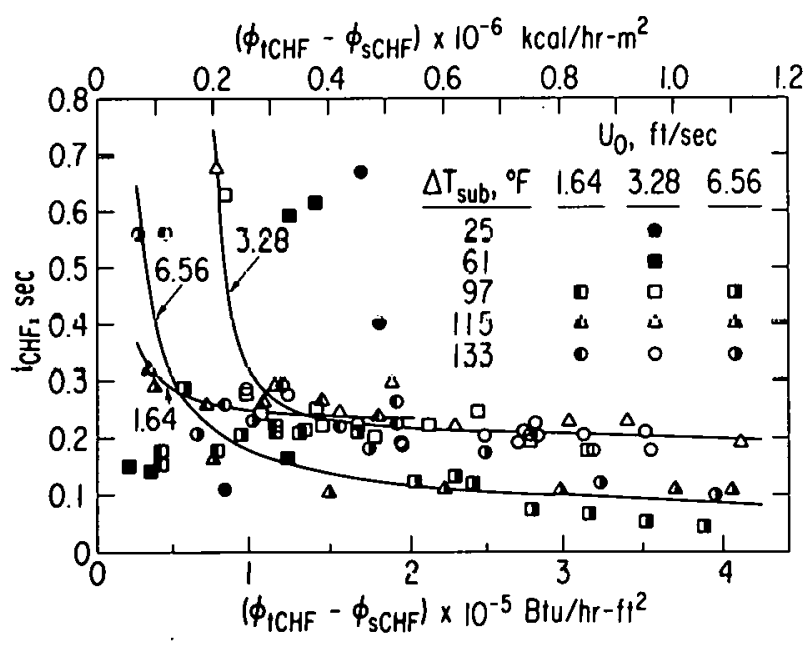

Fig. 5. Time to CHF vs Excess Heat Flux. 78 Conversion factors: $1 \mathrm{kcal} / \mathrm{hr} \cdot \mathrm{m}^{2}=$ $1.163 \mathrm{~W} / \mathrm{m}^{2} ; 1 \mathrm{ft} / \mathrm{sec}=0.305 \mathrm{~m} / \mathrm{s}$; $1 \mathrm{Btu} / \mathrm{hr} \cdot \mathrm{ft}^{2}=3.155 \mathrm{~W} / \mathrm{m}^{2}$. ANL Neg. No. 900-75-784 Rev. 1. not occur at the sudden vaporization just after blowdown, and their observed $\mathrm{CHF}$ values were higher than steady-state CHF. In Fig. 5, the excess heat flux, i.e., $\varphi_{t C H F}-\varphi_{s} \mathrm{CHF}$, was plotted agaimst t $\mathrm{CH} L$. Tor large subcooling, the experimental data were correlated by a curve for each flow velocity.

Interesting results were observed in the high-speed photographs taken with the transparent test section. To quote, "just after depressurization, (1) vigorous boiling-like sudden vaporization occurred, and then (2) there was a period in which the bubble disappeared or boiled only on the surface of the heater. After 
a while, (3) vigorous boiling including coalesced bubbles began again and then CHF occurred ... . The reason why CHF never occurred in region (1) seemed to be due to the large growth velocity of sudden vaporized bubble and also owing to that the stable liquid layer was kept on the heater surface through the bubble growth because steam was supplied to the bubble not only from the heater surface side but also from the superheated layer in bulk liquid." The collapse of bubbles in region (2) was apparently caused by subcooled water on the unheated wall (glass shroud) or from upstream. No flow reversal was studied.

\section{Canada: AECL, Pinawa}

Banerjee et al. ${ }^{81}$ conducted blowdown studies of an organic coolant in a single heated tubular channel. Continuity, momentum, and energy equations were solved by the method of characteristics, and the predictions of various parameters during transients were satisfactory. The report of the occurrence of CHF was not included.

More recently, Banerjee et $21 .^{82}$ reported some initial diabatic blowdown tests conducted at the CISE high-pressure water loop. For $100 \%$ inlet break area, $\mathrm{CHF}$ occurred at 3 and $7 \mathrm{~s}$, respectively, for inlet subcooling of 104 and $240^{\circ} \mathrm{C}$, whereas no CHF was observed for the $5 \%$ inlet break. From the mass decay curve of the coolant reported, onset of CHF corresponded to $10-15 \%$ of initial mass remaining.

\section{USA}

a. Westinghouse and Columbia University. Both power and flow transients were reported by Tong and hisco-workers. ${ }^{52,53}$ For ramp power excursions, transient CHF levels were approximately equal to the corresponding steady-state values. In their simulated flow-coastdown tests, no CHF was observed when a $2-s$ delay in the effective control-rod insertion was simulated by appropriatc control of the power.

Cermak et al. ${ }^{57}$ studied the behavior of transient CHF during blowdown in rod bundles at high pressure. Steady-state CHF tests, conducted with the same bundle, were used to predict the transient CHF. The localconditions hypothesis was used with calculations based on the CHICKIN computer code ${ }^{55}$ developed at Westinghnuse. The time to CHF was reported to be affected by the rate of pressure decay, qualitatively in agreement with Gaspari's findings. The calculation using the above procedure underestimated ${ }^{\mathrm{CHF}}$ by 0-4.2 $\mathrm{s}$ for actual observed $\mathrm{t}_{\mathrm{CHF}}$ of 1-7 s. Hence, CHF during blowdown could be predicted on the basis of steady-state data, but the prediction was a conservative one.

Farman and Cermak ${ }^{66}$ studied the CHF and beyond-CHF heat transfer during blowdown in a $3-\mathrm{ft}(0.9-\mathrm{m})$ tubular test section. Outlet-pipe 
rupture was. simulated by discharging the system coolant to atmosphere. However, two-phase critical flow through the discharge valve was prevented by placing a tank of subcooled water in the line upstream of the valve to ensure single-phase exit at the discharge location. Transient CHF occurred at the exit, but no mention was made of its propagation upstream. Steady-state correlation developed by Tong $^{37}$ at Westinghouse was conservative in predicting transient CHF results.

b. Bettis Atomic Power Laboratory. Redfield et al. ${ }^{86}$ conducted blowdown studies for a rectangular heated channel, simulating both cold- and hot-leg breaks of different sizes. The loop was not geometrically similar to a typical PWR, but it did contain the essential elements: a pressurizer, a canned rotor pump, and a heat exchanger. The test results were compared with predictions using the FLASH code ${ }^{87}$ Although instantaneous flow reversal was predicted in the cold-leg breaks, DP cells across the test section showed an oscillatory behavior about zero during the initial $1 \mathrm{~s}$. Temperature measurement indicated good heat transfer during the initial part of the transient, for the wall temperature followed the falling saturation temperature of the coolant. Time to CHF was measured at 155,182 , and $280 \mathrm{~s}$ for the three tests reported, the corresponding FLASH-predicted values being 108, 160 , and $380 \mathrm{~s}$.

c. Babcock and Wilcox. Morgan et al. ${ }^{67}$ presented some simulation tests for cold-leg break using the Babcock and Wilcox Boiling Heat Transfer Loop. 'T'he test section consisted of a nine-rod PWR bundle, $6 \mathrm{ft}$ $(1.8 \mathrm{~m})$ long. The Babcock and Wilcox evaluation model CRAFT ${ }^{88}$ was used to calculate the fuel temperature by first assuming one of three modes of heat transfer (forced convection, nucleate boiling, or stable film boiling) exists at the surface. When the computed heat flux exceeds the corresponding CHF determined by the W-3 correlation, ${ }^{37}$ CRAFT switches to stable film boiling. With criteria according to the USAEC's Interim Policy Statement, ${ }^{3}$ where this transition is assumed to occur almost instantaneously after the inlet break, the cladding temperature is calculated to rise sharply and continue to rise until power trips.

The prediction by CRAFT was done on the Semiscale Test 845 , and the result was highly conservative (see Fig. 6). However, delaying CHF until dryout, when quality in the core is close to 1.0 , resulted in much better agreement (hence termed the CKAFT Best Estimate). The same conclusion was made in the ORNL blowdown data reported by Lawson; ${ }^{58}$ i.e., the reported hot- and cold-leg break simulations were again in reasonable agreement with the best-estimate calculation (see Fig. 7). It was concluded that flow reversal occurring in the first few seconds after a large, cold-leg break was not expected to give rise to a thermally identifiable flow stagnation. This tends to support the view that the early blowdown phase is dominated by a high degree of turbulence created by vigorous nucleation, rather than by a flow-boundarylayer phenomenon such as film boiling. 


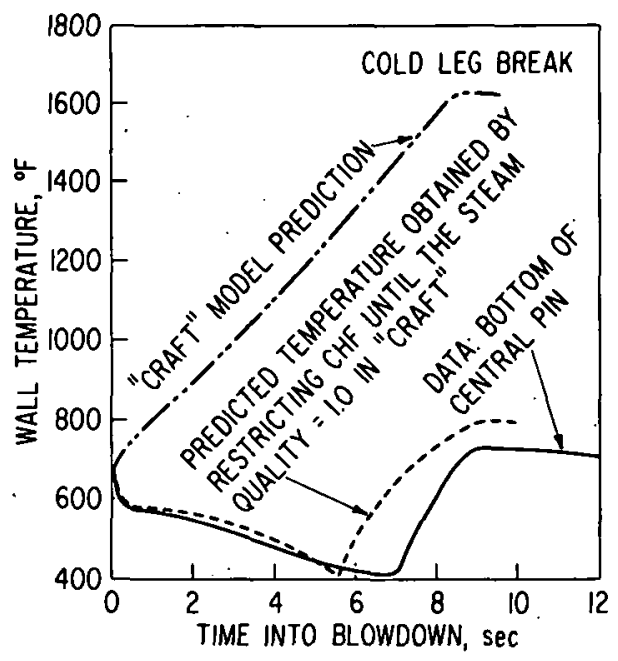

Fig. 6

Measured and Predicted Wall Temperature for Semiscale Test 845.67 Conversion factor: $t\left({ }^{\circ} \mathrm{C}\right)=\left[\mathrm{t}\left({ }^{\circ} \mathrm{F}\right)-32\right] / 1.8$. ANL Neg. No. 900-75-780 Rev. 2.

Fig. 7

Wall Temperature for Babcock and Wilcox Blowdown Test 67 Conversion factor: $t\left({ }^{\circ} \mathrm{C}\right)=\left[\mathrm{t}\left({ }^{\circ} \mathrm{F}\right)-32\right] / 1.8$. ANL Neg. No. 900-75-785 Rev. 1.

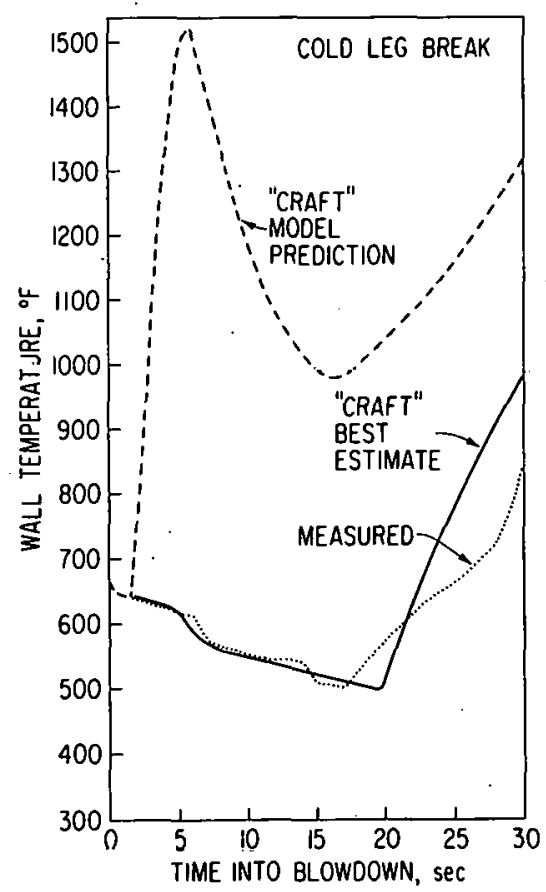

Flow and power transients were performed on a $6-\mathrm{ft}(1.8-\mathrm{m})$ long, nine-rod bundle by Zielke and Wilson. ${ }^{76}$ Typical reactor coolant-pump coastdown and $5 \%$ power ramp were simulated. Transient CHF values were compared with the Babcock and.Wilcox-2 steady-state CHF correlation, ${ }^{38}$ and all data points except two had an experimental-to-predicted CHF ratio $>1.0$.

d. Oak Ridge National Laboratory. Lawson ${ }^{58,59}$ had reported blowdown results for both single- and seven-rod bundles with an outlet break. Blowdown times of 7-60 s were achieved by varying the diameter of a critical flow orifice located near the rupture disks. Results from one of the representative single-rod tests are shown in Fig. 8, with power reduced to $10 \%$ at $3 \mathrm{~s}$ 
into blowdown. No CHF was observed until the loop was at, or near, atmospheric pressure, when the coolant was almost entirely discharged. For the $15-\mathrm{s}$ seven-rod-bundle test reported, ${ }^{59} \mathrm{CHF}$ occurred at $\sim 9.5 \mathrm{~s}$, when loop pressure was $\sim 215$ psia (1.5 MPa).

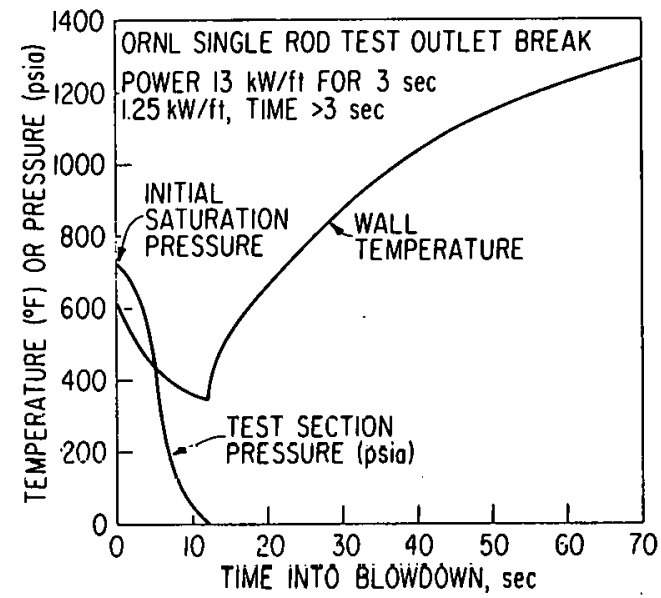

Fig. 8

Wall Temperature and Pressure for ORNL Blowdown Test. 58 Conversion factors: 1 psia $=6.895 \mathrm{kPa} ; \mathrm{t}\left({ }^{\circ} \mathrm{C}\right)=\left[\mathrm{t}\left({ }^{\circ} \mathrm{F}\right)-32\right] /$ $1.8 ; 1 \mathrm{~kW} / \mathrm{ft}=3.281 \mathrm{~kW} / \mathrm{m}$. ANL Ncg. No. $200-75-779$ Rev. 2 .

The effect of flow reversal resulting from an inlet-pipe rupture was included in the more recent ORNL Blowdown Heat Transfer program. ${ }^{60,61}$ The first test was in the FCTF (Forced Convection Test Facility), which consisted of a single heated $12-\mathrm{ft}(3.66-\mathrm{m})$-long rod in annular geometry, installed in the same loop as that used in Lawson's tests. The heat-generation profile was that of a chopped cosine with maximum heat flux of 610,000 Btu/ $\mathrm{hr} \cdot \mathrm{ft}^{2}\left(1.9 \times 10^{6} \mathrm{~W} / \mathrm{m}^{2}\right)$ in the middle section. The first six blowdown tests simulating a single-ended inlet break showed that $\mathrm{t} C \mathrm{HF}$ varied from 4.0 to $9.5 \mathrm{~s}$, as shown in Fig. 9. CHF occurred downstream of the highest heat-flux zone and propagated along the heater in both directions. The Thermal Hydraulic Test Facility (THTF) will study blowdown with and without flow reversal in a 49-pin, electrically heated FWR bundle.

e. Aerojet Nuclear Company (ANC). The Semiscale Blowdown facility has a primary objective of providing an experimental data base to help assess the capability and adequacy of analytical models during a hypothetical LOCA. By 1970 , single-loop semiscale testing with a $9-$ in. $(22.86-\mathrm{cm})$ heated core was completed. ${ }^{73}$ One of the findings was that the coolant in the lower (inlet during steady state) and upper plenums did not simultaneously decompress to the saturation pressures corresponding to the individual plenum temperature following a hot-leg break. Rather, the coolant decompressed to a pressure corresponding to the saturation temperature in the upper plenum within $0.2 \mathrm{~s}$. Coolant in the lower plenum remained subcooled for $2-3 \mathrm{~s}$. For the hot-leg-break test (Test 825$)^{73}$ with full power on for $14 \mathrm{~s}$ into blowdown, $\mathrm{CHF}$ occurred only at the top of the heated length at $12.5 \mathrm{~s}$. The depressurization rate during the saturation blowdown was slow, $\sim 27 \mathrm{psia} / \mathrm{s}$. The heattransfer coefficient was calculated to rise up to $10,000 \mathrm{Btu} / \mathrm{hr} \cdot \mathrm{ft}^{2} \cdot{ }^{\circ} \mathrm{F}(57 \mathrm{~kW} /$ $\mathrm{m}^{2} \cdot{ }^{\circ} \mathrm{C}$ ) within $100 \mathrm{~ms}$ after rupture. 


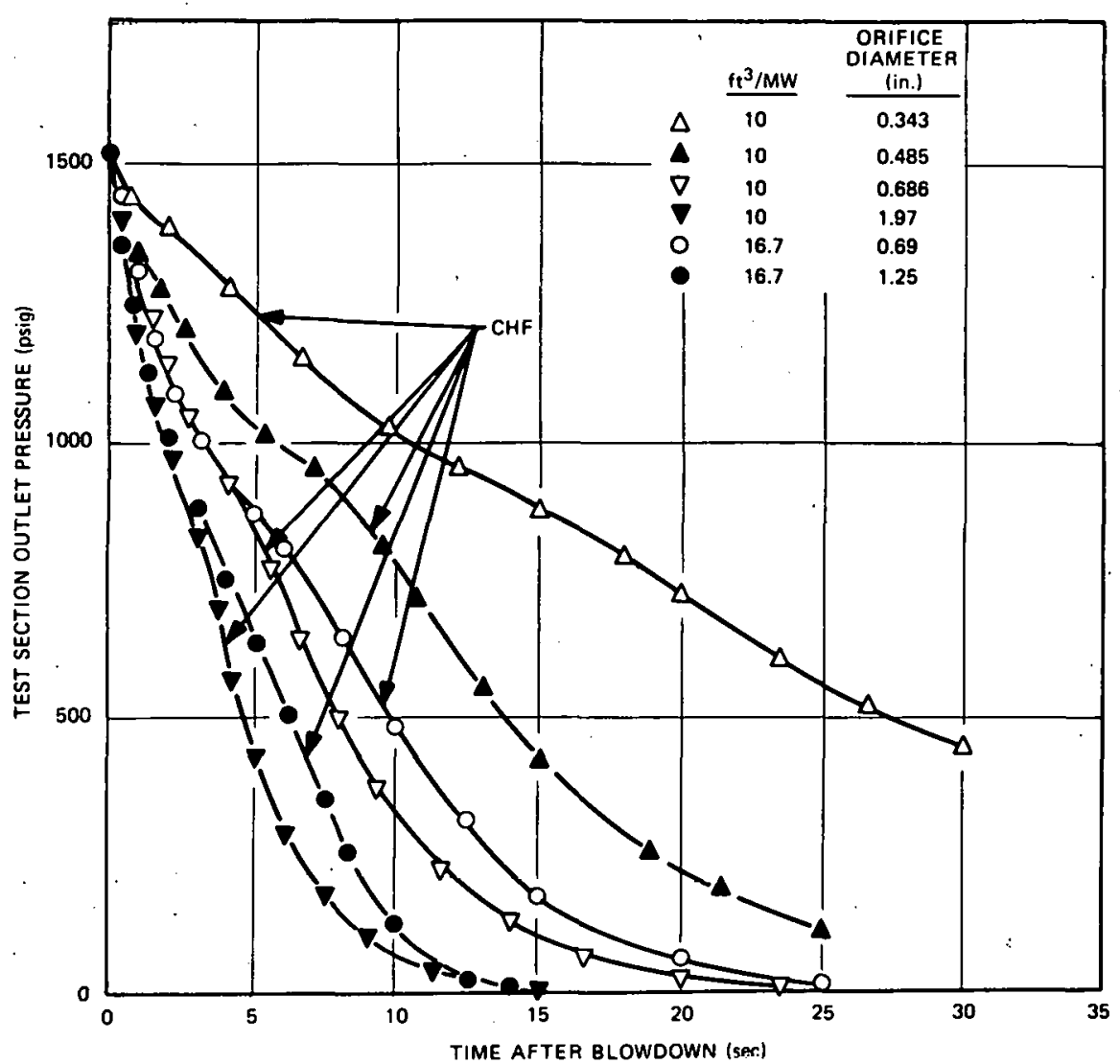

Fig. 9. Pressure History for ORNL Single-rod Test.61 Conversion factors; $1 \mathrm{ft}^{3}=0.02837 \mathrm{~m}^{3} ; 1$ in. $=2.54 \mathrm{~cm} ; 1 \mathrm{psi}=6.895 \mathrm{kPa}$. ANL Neg. No. 900-75-576.

The first test (Test 845 ). involving ECC injection was reported in 1972. ${ }^{89}$ Major observations for this cold-leg-rupture test were:

(1) The reversed flow through the core carried a two-phase fluid at high enthalpy, causing the lower-plenum temperature to rise.

(2) Occurrence of CHF was delayed until 2.1 s at the top location on the central pin, but the cladding was rewetted at $3.7 \mathrm{~s}$. The rewetting was attributed to increased downflow. Subsequently, CHF occurred at all monitored core locations between 5 and $7 \mathrm{~s}$.

(3) Following the transition from subcooled to saturated blowdown, the system decompressed at essentially fluid-saturation temperature for the rest of the transient.

(4) A mass balance indicated that $\sim 25 \%$ of the fluid mass was ejected through the pump and cold-leg side of the break, and $75 \%$ was ejected through the vessel inlet and out of the break.

(5) Vessel fluid qualities were $>60 \%$ within 2 s after rupture. 
f. General Electric (GE). Slifer ${ }^{40}$ reported on GE models for BWR performance in a LOCA. Using the GE Heat Transfer Loop at San Jose, he studied the following transients using both single- and nine-rod squarearray geometry:

(1) Depressurization at $50-100 \mathrm{psi} / \mathrm{s}(344.7-689.5 \mathrm{kPa} / \mathrm{s})$ with constant flow showed that use of the GE steady-state correlations (Janssen-Levy for single tube and Hench-Levy for rod bundles) to predict the onset of CHF in transient was conservative.

(2) Flow-decay tests also indicated the same conservatism.

(3) Combined depressurization and flow-decay tests also showed that CHF did not occur earlier than steady-state prediction.

Lahey and his co-workers s3-65 $^{6 e p o r t e d ~ r e s u l t s ~ f r o m ~ a n ~ e x-~}$ perimental transient CHF program in single-, 9-, and 16-rod test sections. A simplified analysis based on the method of characteristics was developed that allowed prediction of the transient flow and quality in a heated channel. Computer code $\mathrm{MAYU}^{61}$ was generated for transient CHF predictions. For. flow-decay transients, CHF occurred above the critical value corresponding to the quasi-steady-state predictions. Flow ON/OFF/ON transients were conducted such that the inlet flow was suddenly stalled for a time and then turned back on. Time to CHF ranged from $2.3 \mathrm{~s}$ for $\varphi=149,000 \mathrm{Btu} / \mathrm{hr} \cdot \mathrm{ft}^{2}$ $\left(3 \times 10^{6} \mathrm{~W} / \mathrm{m}^{2}\right)$ in a $16-\operatorname{rod}$ bundle to $21 \mathrm{~s}$ for $\varphi=51,000 \mathrm{Btu} / \mathrm{hr} \cdot \mathrm{ft}^{2}(1.6 \mathrm{x}$ $\left.10^{5} \mathrm{~W} / \mathrm{m}^{2}\right)$.

These tests indicated that pool builing is an effective mode of heat transfer. In many cases, the rods were rewet with no apparent difficulties vince the flow was reestablished. For the depressurization tests with rates of $50-100 \mathrm{psi} / \mathrm{s}(344.7-689.5 \mathrm{kPa} / \mathrm{s})$ no immediate onset of CHF took place. In general, the quasi-steady-state and MAYU method of prediction. overestimated $t_{C H F}$, and, in some cases, CHF was not experimentally observed.

g. Massachusetts Institute of Technology (MIT). Using Freon-113 at 200 psia, Griffith and his students ${ }^{79,80}$ studied transient CHF during flow reversal, inlet-flow blockage, and a combination of the two For initial uniform heat flux and subcooled upflow, the transient consisted of two flow reversals bounding a period of downflow, $T d$. The results showed that CHF did not occur at flow reversal, but depended on the history of the peak enthalpy fluid. In Fig. 10, the heat flux marking the CHF boundary for the corresponding downflow duration $\tau_{d}$ is plotted. For negligibly small $\tau_{\mathrm{d}}(<100 \mathrm{~ms})$, no CHF was ubserved until the heat flux was at the $\varphi_{\mathrm{S}}$ CHF level, in which case the disturbance would trigger an incipient $C H F$. At a $\tau_{d}$ of about one channel transport time ( $\sim \mathrm{s}$ in their runs), the $\varphi \mathrm{CHF}$ value observed was lowest. 


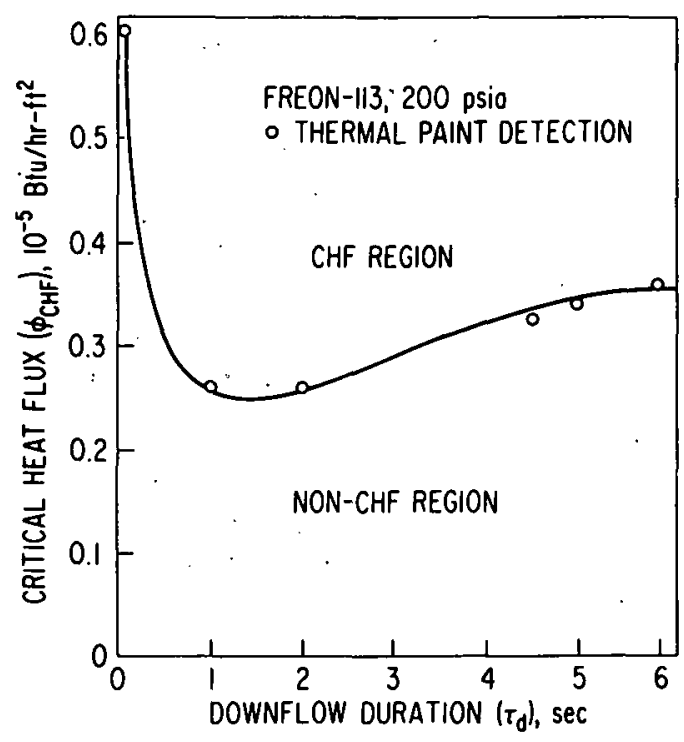

Fig. 10

MIT Results for Double Flow Reversal. 80 Conversion factors: $1 \mathrm{Btu} / \mathrm{hr} \cdot \mathrm{ft}^{2}=$ $3.155 \mathrm{~W} / \mathrm{m}^{2} ; 1$ psia $=6.895 \mathrm{kPa}$. ANL. Neg. No. 900-75-783 Rev. 2.

This result was explained by the fact that the enthalpy peak traversed three full passes through the heated section. For transients with longer ${ }^{\tau} d$, the dependency of $\varphi_{t} C H F$ on ${ }^{\top} d$ was small, since these transients were essentially single reversals from initially steady downflow to upflow. They also postulated that, if $\mathrm{CHF}$ did not occur during flow reversal, complete voiding due to incipient bulk boiling of Freon from the heated channel could occur in 1-2 s under the test conditions. A small but versatile computer program BACTRAC3 was successfully developed ${ }^{80}$ to predict the occurrence of CHF during rapid flow-reversal transients.

\section{Summary}

To conclude, then, CHF in a flow-decay transient without reversal and in a power excursion can be predicted, but often conservatively, using steady-state CHF correlations with local parameters calculated by means of computer codes. $54,70,74,76,77$ Caution has to be exercised at low flow, since only some correlations are suitable in this range. The concept of flooding heat flux has recently been introduced, ${ }^{90}$ and flooding phenomenon was experimentally observed in the low-velocity, countercurrent-flow, CHF studies conducted at MIT. ${ }^{91}$ Time to CHF for flow and power transients depends on a number of parameters, particularly on the critical-heat-flux ratio (CHFR) at the steady-state condition. (The critical-heat-flux ratio is defined as the ratio of the predicted critical heat flux to the initial local heat flux before the transient.) Flow-stagnation experiments indicated that heat flux at low flow can be quite high, as in pool boiling. ${ }^{65}$ At this low flow, CHF was found to depend on void fraction 91 (generally unknown in pool-boiling experiments).

A major finding in blowdown studies is that time to $\mathrm{CHF}$ decreases as the rate of depressurization increases. ${ }^{57,75}$ The same conclusion was arrived at in a pool-boiling depressurization study. ${ }^{51}$ High-speed photos showed vigorous bulk nucleation, in agreement with the findings in flow-boiling 
depressurization. ${ }^{78}$ Vigorous nucleation, acceleration, ${ }^{74}$ turbulence, ${ }^{67}$ and stability of the liquid film ${ }^{78}$ on the heater wall during the initial phase of blowdown have all been proposed as plausible explanations for the time delay to CHF. But for time well into blowdown, annular flow with liquid film on the wall was suggested as the major mode of efficient heat transfer observed. ${ }^{58}$ In general, $\mathrm{CHF}$ during blowdown occurred at a very late time, corresponding to near or complete loss of the coolant mass in the test section. ${ }^{58,67,82}$ A.t such a point where high-quality flow was experienced, "dryout" is probably the cause of the temperature excursion. For a hotleg break, CHF was usually reported to occur first at the exit and then propagate upstream, 66,69,71,74,89 for nonuniform heat flux, bidirectional propagation of the CHF front which occurred originally at the maximum heat-flux location was observed. ${ }^{61}$ 


\section{EXPERIMENTAL INVESTIGATION}

A. Outline of Experimental Technique

1. Choice of Working Fluid

In the study of steady-state CHF, the water system has been scaled down successfully by using a liquid having a lower latent heat of vaporization and operating at pressure having the same liquid/vapor density ratio as the water system. Such liquids reported in the literature are Freon-11, ${ }^{92,93}$ Freon-12 $2^{94,95}$ Freon-113, ${ }^{96}$ Freon- $114,{ }^{97}$ Freon-22, ${ }^{98}$ and $\mathrm{CO}_{2} \cdot{ }^{99}$ Freons are usually chosen because of their very low latent heat, relatively low hazard, and well-established fluid properties. Freon-1l at 260 psia $(1.8 \mathrm{MPa})$ and $237^{\circ} \mathrm{F}\left(114^{\circ} \mathrm{C}\right)$ has been used to scale $\mathrm{CHF}$ of steam-water mixtures at $1500 \mathrm{psia}(10.3 \mathrm{MPa})$ and $500^{\circ} \mathrm{F}\left(260^{\circ} \mathrm{C}\right) .{ }^{100}$ At this lower pressure, visualization studies can be conducted. Furthermore, heater failures, which frequently result in post-CHF operation in water, have not been reported in Freon studies. However, Freon-to-water scaling during a pressure transient has not been explored, and it is uncertain that scaling can be achieved. A discussion of scaling appears in Appendix $\mathrm{J}$.

The experiment described here used Freon-ll as the boiling fluid in a transparent annular test section so that direct photographic observations could be made of the fluid behavior before, during, and after local CHF resulting from a depressurization transient. Because of the transparent glass section, the experiment was conducted at 65 psia $(0.45 \mathrm{MPa})$, corresponding to a water-equivalent pressure of 450 psia $(3.1 \mathrm{MPa})$ based on density ratio.

\section{Measurement of Flow during Transient}

Accurate flow measurements during two-phase transients are difficult because of the various flow configurations that can be obtained. A turbine flowmeter is commonly used in single-phase flow. Based on Grey's analysis ${ }^{101}$ for the transient response of a turbine flowmeter, Pupper ${ }^{102}$ found that the turbine will respond very closely to the liquid velocity, even in the presence of two-phase mixture, and the error is represented by

$$
\frac{(1-\alpha) \rho_{f}+\alpha \rho_{g} \mathcal{S}^{2}}{(1-\alpha) \rho_{f}+\alpha \rho_{g} \mathcal{S}} \text {. }
$$

The error is small for low and intermediate void fractions as either slip ratio $s \rightarrow 1$ or $\rho_{g} \ll \rho_{f}$. Later Rouhani ${ }^{103}$ cautioned that only for low quality will the response of the turbine be proportional to liquid velocity alone.

Hutcherson ${ }^{104}$ used weight-transducer measurement to estimate mass flow rate during blowdown. The blowdown vessel in his study was suspended from a weight transducer, and the mass flow rate was determined by 
differentiating the mass-decay signal. A similar arrangement was used in the present study to measure the mass flow for comparatively long transients. In addition, turbine meters were located in the inlet and outlet legs of the test section, and used mainly to detect significant changes in flow velocity.

\section{Measurement of Void during Transient}

Most of the void-measuring techniques are based on the attenuation of a radiation beam such as gamma and $X$ rays. Among the nonnuclear methods of void measurement, one of the most important is the impedance method, ${ }^{105,106}$ which is based on the difference between liquid and vapor electrical conductivity and dielectric constant. The impedance method again can be divided into conductivity ${ }^{107}$ and capacitance ${ }^{108}$ measurements.

Dukler ${ }^{109}$ reported using a capacitance probe for measurement of falling-film thickness. A commercially available capacitance void meter, manufactured by Ikor, Inc: (Burlington, Mass.). has heren mrressfilly tested for Freon and water at three different laboratories. ${ }^{6,110,111}$ However, this commercial void meter is tubular and therefore only suitable for mounting in a circular channel.

The first attempt to measure void in an annulus by a capacitance probe used a brass electrode surrounding the outside of the glass tube and measured the capacitance between the inside heater tube and the electrode. ${ }^{112}$ In the present study, a similar void probe was used because of its simplirity in design and low cost. Appendix E contains information on the elertronic circuit for dynamic void measurement as well as the calibration test.

B. Description of Experimental Apparatus

\section{Freon-11 Test Facility}

This experiment was conducted in the Freon Test Loop of the Reactor Analysis and Safety Division, Argonne National Laboratory. The apparatus, shown in Fig. 11, was a once-through loop and consisted of three main vessels: a supply vessel, a variable-volume blowdnwn vessel, and a receiving vessel. The vessels are described below.

a. Supply Vesss.1. A 5.5-kW, 14-in. (35.56-cm) Watlow immersiun heater was used for heating $\sim 600 \mathrm{lb}$ of Freon to the desired operating temperature inside this $8-\mathrm{ft}^{3}\left(2.4-\mathrm{m}^{3}\right)$ vessel. Four immersed thermocouples (Type K) were installed at four vertical locations, and the temperatures were monitored on a multichannel recorder during heating. The rlnse agreement among thc four thermocouples indicated that no significant stratification occurred. 


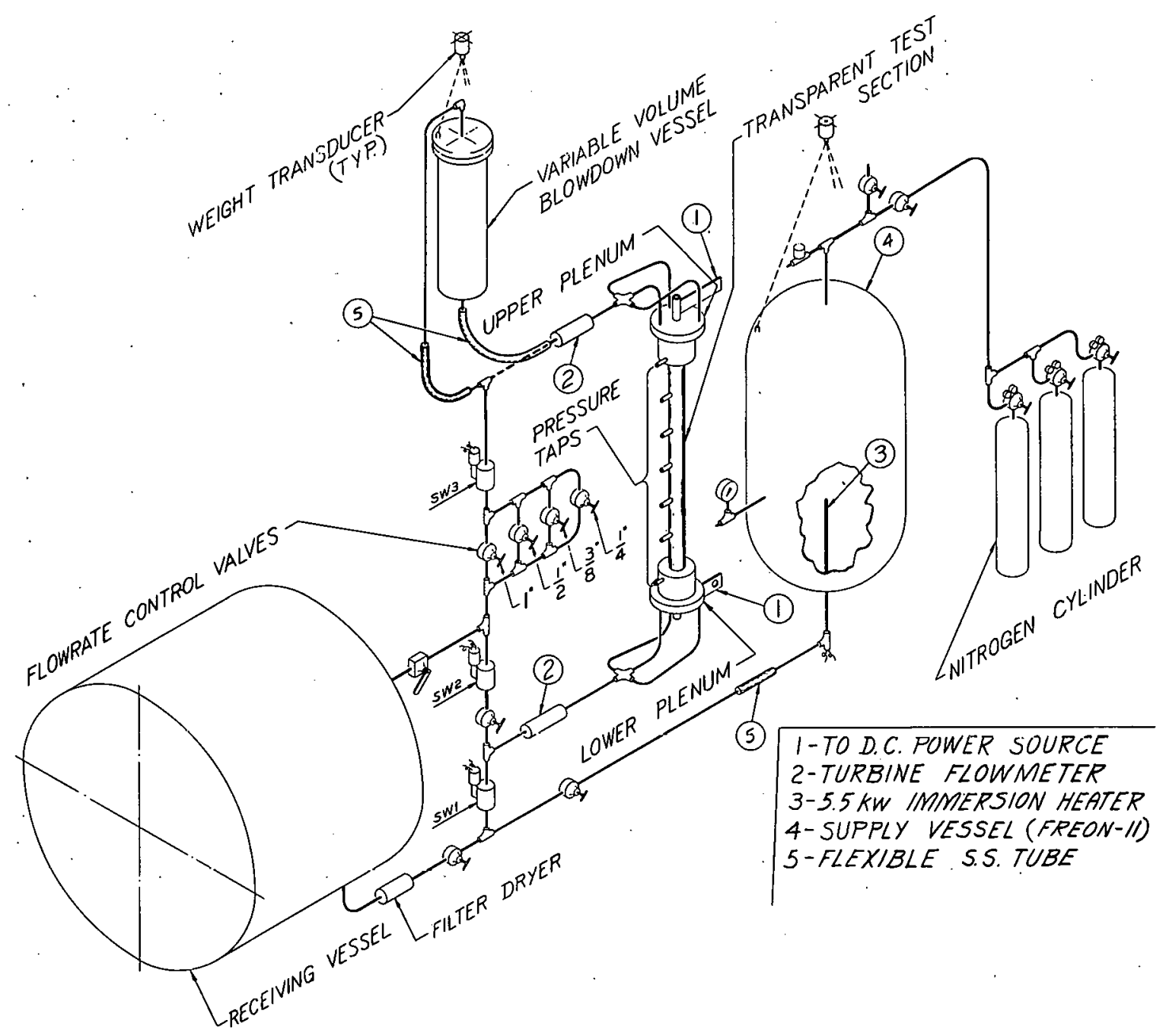

Fig. 11. Freon-11 Blowdown Facility. ANL Neg. No. 900-4557 Rev. 2.

The vessel and its contents were suspended from a weight transducer that was a Statham, UC3, unbonded-type strain gauge, Universal Transducing Gell. The rell was mounted in a Statham, UL4, $1000-1 b_{f}(4448-N)$ load-cell accessory head, which permitted the cell to detect a maximum of $1250 \mathrm{lb}_{\mathrm{f}}(5560 \mathrm{~N})$ of total suspended weight. The weight transducer was calibrated with dead weights, and the results are shown in Appendix I.

As a safety precaution against overpressurization of the supply vessel, a pressure switch was installed to cut off the heater power and open a solenoid valve located at the top of the vessel.

During the test, the supply vessel was maintained at a constant pressure above the liquid saturation value by three nitrogen cylinders to ensure that Freon flowing in the loop was subcooled: 
b. Blowdown Vessel. The blowdown vessel was a 30-in.

(76.2-cm)-long Type 304 stainless steel cylinder with an inside diameter of 4 in. $(10 \mathrm{~cm})$ and a wall $0.237 \mathrm{in} .(0.6 \mathrm{~cm})$ thick. It had a dome end cap on the bottom, and a flange connection on the top. Both ends had $1-i n .(2.54-\mathrm{cm})$ pipe connections. The volume was altered as desired by inserting a cylindrical displacement vessel through the flanged end.

The vessel was wrapped with a $30-\mathrm{ft}$ shielded Nichrome heater wire on the outside and covered with about 1 in. $(2.54 \mathrm{~cm})$ of Fiberglas insulation. Four immersed thermocouples (Type K) were installed at four vertical locations, continuously monitored on a multichannel recorder. The empty vessel was brought to the operating temperature before the test so that the heat loss to the vessel wall was minimal.

Similar to the supply vessel, the blowdown vessel was suspended from an identical type of weight transducer. A 500-1b $(2224-N)$ loadcell accessory head was used in this case, with the calibration curve shown in Appendix. I.

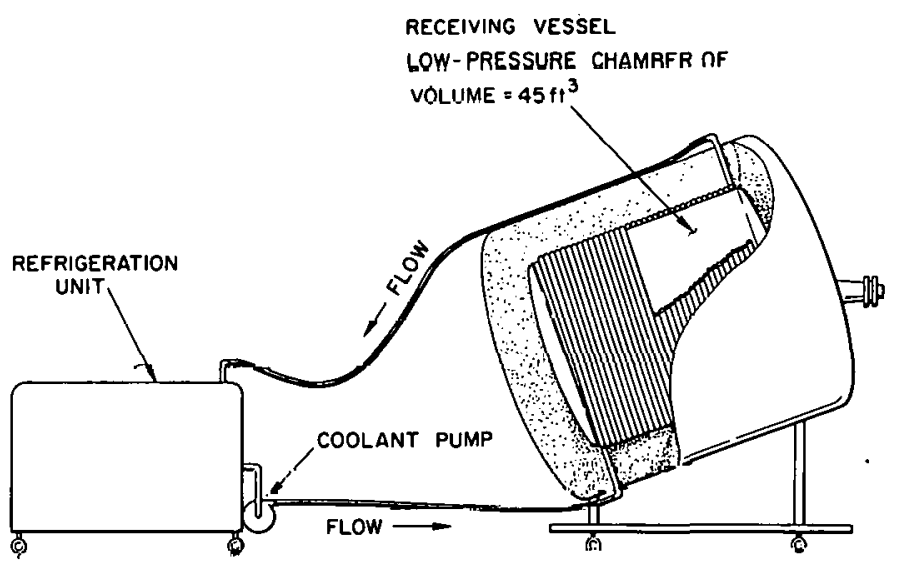

Fig. 12. Schematic Showing Refrigeration Unit and Receiving Vessel. Conversion factor: $1 \mathrm{ft}^{3}=0.02837 \mathrm{~m}^{3}$. ANL Neg. No. 900-75-13 Rev. 2. c. Receiving Vessel This large vessel of $-45 \mathrm{ft}^{3}\left(13.7 \mathrm{~m}^{3}\right)$ with cooling capability supplied from a refrigeration unit, is shown in Fig. 12. The refrigeration unit consisted of a tank containing a $50 \%$ water $-50 \%$ ethylene glycol mixture to which 100-150 lb $(45-68 \mathrm{~kg})$ of dry ice was added to increase the cooling capacity. A closed-circuit cooling coil was wrapped around the receiving ves sel and formed a helix inside the cooling tank. Ethylene glycol solution was continuously circulated by a 1/2-hp (373-W) pump inside this coil. The $10001 \mathrm{~b}$ of Frcon-l1

in the vessel was typically maintained at $10^{\circ} \mathrm{F}$; a vacuum pump maintained the pressure inside at $10 \mathrm{psia}(68.95 \mathrm{kPa})$ fnr a ronsiderable interval befere llue test. Thus the Freon was kept cold and prevented from prolongcr rontact with air or nitrogen. The vessel was well insulated by a 2 -in. $(5.08-\mathrm{cm})$ inner layer of asbestos and 8 in. of Fiberglas material.

\section{Test Section}

The test section, shown isometrically in Fig. 13, consisted of a 24-in. (86-cm)-long, 0.752-in. (1.9-cm)-ID, 0.805-in. (2.045-cm)-OD, directly heated, Type 304 stainless steel tube, silver-brazed at both ends to two 


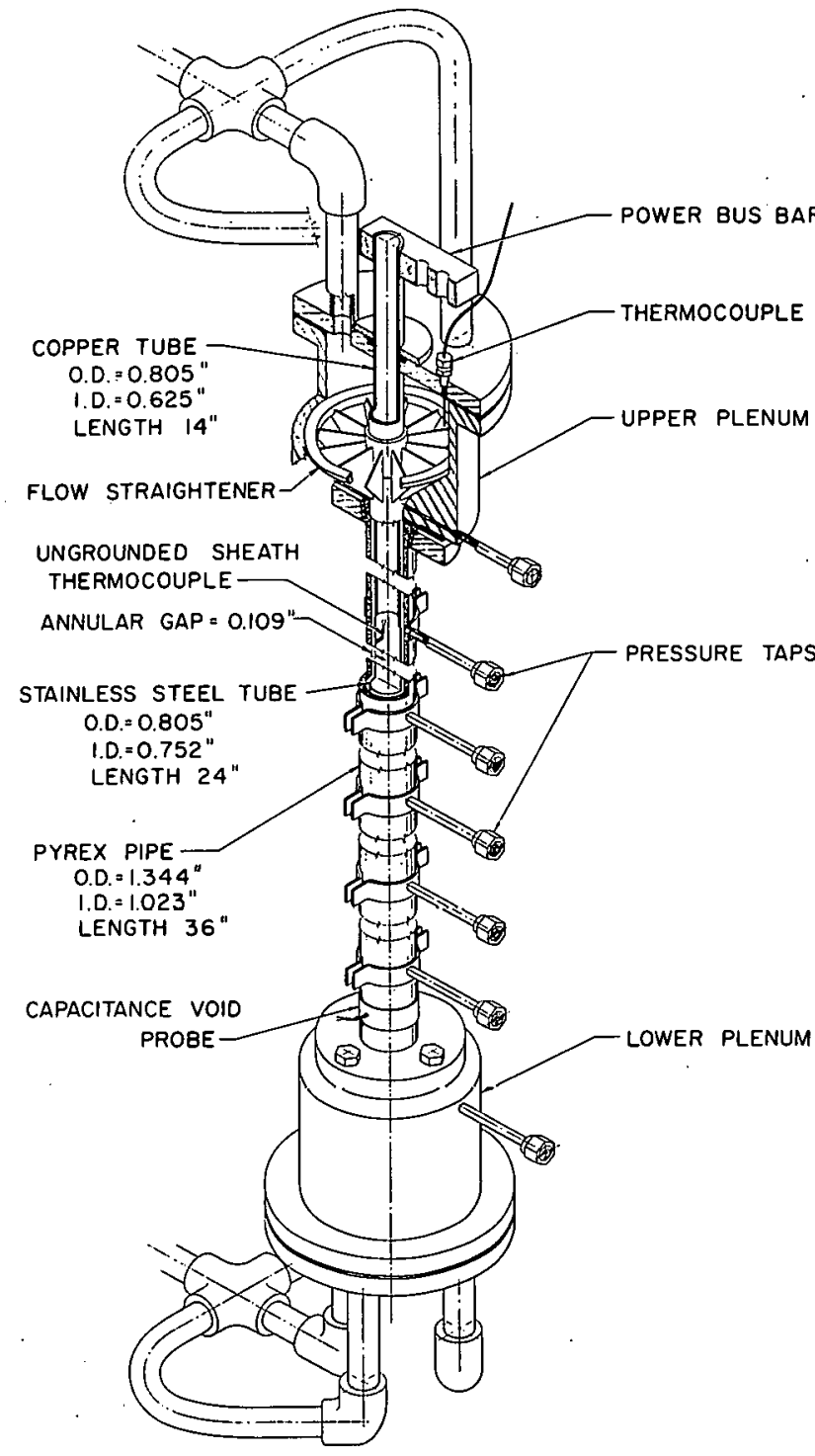

Fig. 13. Isometric of Transient CHF Test Section. Conversion factor: 1 in. $=2.54 \mathrm{~cm}$. ANL Neg. No. $900-5597$. 14-in. (35.56-cm)-long copper leads of low electrical resistance. The circumferential variation of the Type 304 stainless steel tube thickness, measured at both ends using a tubing $\mathrm{mi}$ crometer, was \pm 0.001 in. $(0.0254 \mathrm{~mm})$. Hence, radial variation in heat flux was minimal. The resistance of this $0.0265-$ in. $(0.67-\mathrm{mm})$ wall tube was calculated to be $0.0103 \Omega$, which agreed closely with Kelvin-bridge measurement of $0.0104 \Omega$. Dimensional information is listed in Table II.

The outer $3-\mathrm{ft}(0.9-\mathrm{m})$ transparent Pyrex pipe had five $1 / 8$-in. $(0.3175-\mathrm{cm})$ holes drilled at $6-$ in. $(15-\mathrm{cm})$ intervals for measurements of differential pressure. Copper clamps with Viton gaskets tightly fitting over the Pyrex pipe were used to secure the pressure taps and prevent leakage of fluid at the test pressure. The Pyrex pipe was made with flared conical ends to take a specially designed metal flange, which was cushioned from the glass by a molded asbestos insert. The flat Type 304 stainless steel surface of the plenum had been tap drilled at the proper locations to take three 5/16-in. $(0.79-\mathrm{cm})$ flange bolts. A Teflon gasket was gripped between the grooved pipe end and the plenum surface when the flange bolts were tightened.

To ensure that the heated tube was properly centered with respect to the Pyrex pipe, the following assembling procedure was used. Two carefully machined brass collars were made to slipfit in the annular channel at both ends. Two rods with diameters smaller than the annular gap were attached to each collar so that the collar could be pushed into or pulled out of the channel. Flow straighteners, as shown in Fig. 13, were made to center the heated tube with respect to the plenums. First, the two collars were pushed into the annular gap at both ends, followed by the flow straighteners. This resulted in proper centering of the Pyrex pipe with respect to the two plenums and the inner tube so that the flange bolts at both ends could be tightened. The flow straighteners and the collars were slid out of the assembly and the former put back in the original position inside the plenums. 
TABLE II. Dimensions of Test Section

\begin{tabular}{|c|c|}
\hline Stainless steel-heater OD & 0.805 in. $(2.0447 \mathrm{~cm})$ \\
\hline Stainless steel-heater ID & 0.752 in. $(1.9101 \mathrm{~cm})$ \\
\hline Copper-tube OD & 0.805 in. $(2.0447 \mathrm{~cm})$ \\
\hline Copper-tube ID & 0.625 in. $(1.5875 \mathrm{~cm})$ \\
\hline Outer-wall Pyrex OD & 1.344 in. $(3.4138 \mathrm{~cm})$ \\
\hline Outer-wall Pyrex ID & 1.022 in. $(2.5959 \mathrm{~cm})$ \\
\hline Heated length & $23.5 \mathrm{in} .(59.69 \mathrm{~cm})$ \\
\hline Heated-length $L / D$ ratio & 108 \\
\hline Galming length & 60 in $(152.4 \mathrm{rm})$ \\
\hline Calming-length L/D ratio & 28 \\
\hline Hydraulic diameter & $0.217 \mathrm{in} .(0.5512 \mathrm{~cm})$ \\
\hline Heated equivalent diameter & 0.492 in. $(1.2497 \mathrm{~cm})$ \\
\hline Annular flow area & 0.311 in. $^{2}\left(2.006 \mathrm{~cm}^{2}\right)$ \\
\hline Annular-section volume & 11.210 in. $^{3}\left(183.699 \mathrm{~cm}^{3}\right)$ \\
\hline Upper-plenum volume & $29.360 \mathrm{in}^{3}\left(74.574 \mathrm{~cm}^{3}\right)$ \\
\hline Lower-plenum volume & 29.360 in. $^{3}\left(74.574 \mathrm{~cm}^{3}\right)$ \\
\hline
\end{tabular}

Twenty-two 0.032-in. (0.762-mm)-OD, Type-K (Chromel-Alumel), ungrounded, sheathed thermocouples were spot-welded onto the inside wall of the stainless steel tube (see Fig. 14). Nine of these were used for CHF detection by means of temperature controllers. The measurements from the rest of the thermocouples were recorded as primary data. Connections were made to flexible leads where the sheathed thermocouples emerged from the ends of the copper leads. Two 0.0625-in. (1.5875-mm)-OD, ungrounded, sheathed, Type-K the rmocouples were inserted through the plenums into each end of the annular channel to measure bulk fluid temperatures.

Void fraction in the annular channel was evaluated by measuring the electrical capacitance between the heater tube and an electrode wrapped around the outer surface of the Pyrex tube. The electrode was a $0.001-$ in. $(0.025-\mathrm{mm})$-thick, $1-$ in. $(2.54-\mathrm{cm})$-wide stainless steel foil, which surrounded the tube completely. There were two such electrodes located 3 in. upstream and downstream of the heated region, as shown in Fig. 13. The electronic circuit and calibration technique are presented in Appendix $E$.

To maintain the lowest possible resistance at bus-bar connections, the contact surfaces were coated with a layer of silver by electroplating. The test section was isolated electrically from the rest of the piping and tubing by flanges with Viton gaskets wherever appropriate. 


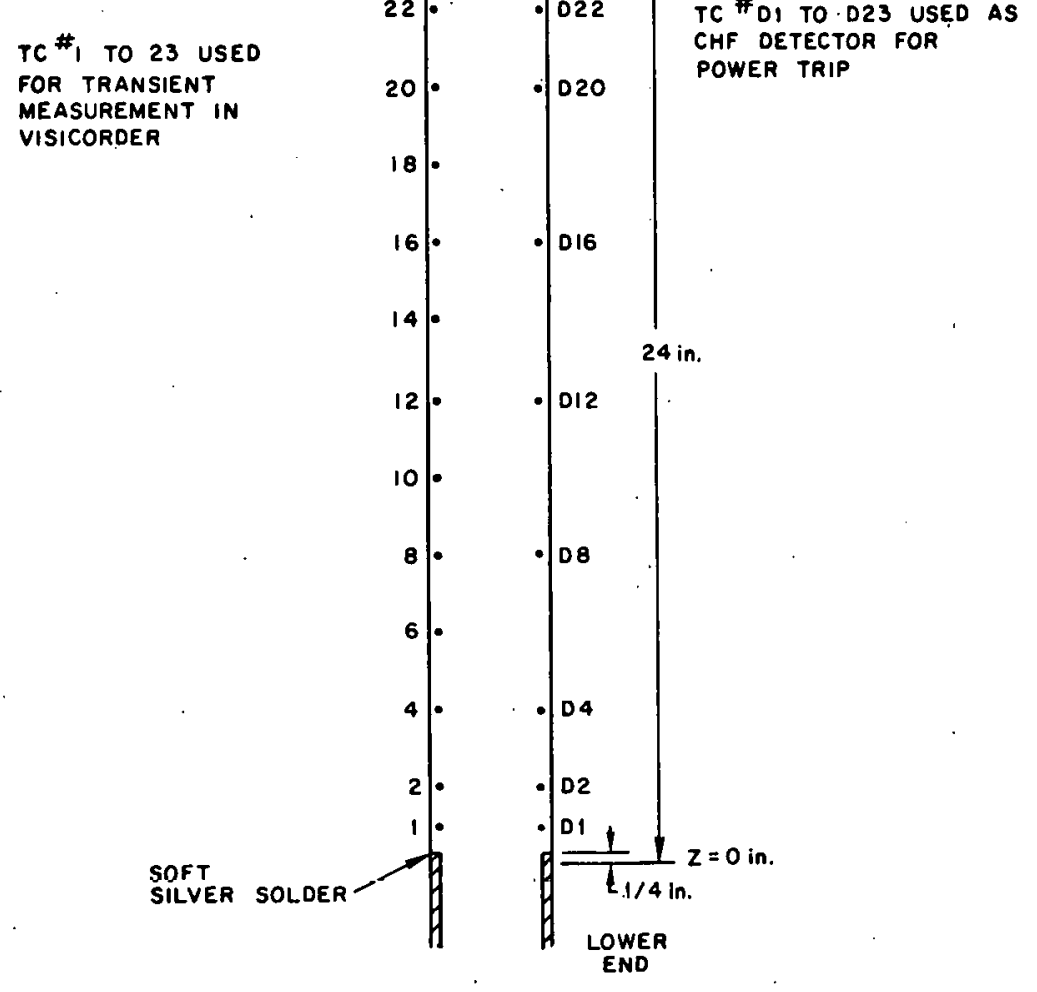

Fig. 14. Thermocouple Locations. Conversion factor: 1 in. $=2.54 \mathrm{~cm}$. ANL Neg. No. 900-75-387.

\section{Instrumentation}

Power to the test section was supplied by a $20-\mathrm{V}, 1500-\mathrm{A}$, dc power supply (Mode1 815 rectifier, manufactured by Crown Rheostat). To protect the test section from physical burnout and to avoid chemical decomposition of Freon-11, the nine temperature controllers were set to trip the test-section power at a heated-wall temperature of $300^{\circ} \mathrm{F}$. The response time of the controller (manufactured by Weather Measure, TPC-1 Type K) as measured by the time lag between the input and output signals, was about $300 \mathrm{~ms}$. If the heated tube was suddenly insulated, an average temperature rise of $\sim 90^{\circ} \mathrm{F} / \mathrm{s}$ $\left(\sim 32^{\circ} \mathrm{C} / \mathrm{s}\right)$ at a heat flux of $45,000 \mathrm{Btu} / \mathrm{hr} \cdot \mathrm{ft}^{2}$ would be experienced. Thus it was believed safe to run power tests without causing physical failure of the test section.

The test-section power was obtained from two measurements: voltage drop across the test section and voltage drop across an on-line shunt rated at $50 \mathrm{mV} / 2000 \mathrm{~A}$.

Table III contains a summary list of instruments and the corresponding recording devices. 
TABLE III. Transient CHF Test Instrumentation

\begin{tabular}{|c|c|c|}
\hline Parameter & Instrument & Recorder \\
\hline Wall temperature & $\begin{array}{l}\text { Thirteen Chromel-Alumel } \\
\text { thermocouples }\end{array}$ & $\begin{array}{l}\text { Visicorder Honeywell, } \\
\text { Model } 1508\end{array}$ \\
\hline Fluid temperature & $\begin{array}{l}\text { Four Chromel-Alumel } \\
\text { thermocouples }\end{array}$ & Honeywell strip chart \\
\hline Test-section pressure & $\begin{array}{l}\text { Two strain-gauge } \\
\text { Statham transducers }\end{array}$ & Visicorder \\
\hline Blowdown-vessel pressure & Statham transducer & Honeywell strip chart \\
\hline Receiving-vessel pressure & Statham transducer & Visicorder \\
\hline Test-section pressure drop & $\begin{array}{l}\text { Six strain-gauge Statham } \\
\text { and CEC DP cells with } \\
5-15 \text { psid }(34-103 \mathrm{kPa})\end{array}$ & Visicorder \\
\hline \multirow[t]{2}{*}{ Test-section flow } & $\begin{array}{l}\text { Inlet and outlet Cox turbine } \\
\text { fonwmeters (bidirectional); } \\
2.5-608 \mathrm{pm}^{-1.6 \times 10^{-4}}= \\
\left.3.8 \times 10^{-3} \mathrm{~m}^{3} / 8\right) \text { usgd with } \\
\text { two Cux flow converters }\end{array}$ & Honeywell strip chart \\
\hline & $\begin{array}{l}\text { Weight transfiurers nn } \\
\text { supply vessel and blow- } \\
\text { down voasol; bulh Slilliain } \\
\text { unbonded-type strain } \\
\text { gauges }\end{array}$ & $\begin{array}{l}\text { Hewlett-Backard otrip } \\
\text { chart }\end{array}$ \\
\hline Void fraction & $\begin{array}{l}\text { Capacitance void probes } \\
\text { with detection circuit }\end{array}$ & Honeywell strip chart \\
\hline Test-section power & $50-\mathrm{mV} / 2000-\mathrm{A}$ shunt & Honeywell strip chart \\
\hline Photographic measurement & Hycam camera & $\begin{array}{l}800-1000-\mathrm{fps} \\
(244-305-\mathrm{m} / \mathrm{s}) \\
\text { Kodak Ektachrom film }\end{array}$ \\
\hline
\end{tabular}

\section{Experimental Procedure}

\section{Calibration}

Pressure transducers, weight transducers, and turbine, flowmeters were calibrated at an early stage before any tests were conducted in the loop. Later calibration showed that the drift was insignificant. The calibration procedure, together with the calibration curves, is presented in Appendix I.

Amplifiers were used to raise transducer and thermocouple signals to the required input level for visicorder galvanometers, but the drifts in these amplifiers gain were found to be significant. To minimize the effect of such drift, the amplifiers were calibrated by inputting a known millivolt signal from a standard dc voltage supply just before each test.

\section{Refilling Operation}

The supply vessel was filled with Freon-l l from the receiving vessel. First a vacuum was pulled on the supply vessel through the line at its top while the vent on the receiving vessel was opened to atmosphere. The two valves on the bottom line of the loop in Fig. 11 were opened to allow Freon flow into the supply vessel. At the same time, the Freon was allowed to pass through a coarse copper gauge filter and then a filter-dryer assembly, similar to the one used in the AECL Chalk River Freon Loop. ${ }^{113}$ 


\section{Heatup Operation}

The temperature controller for the immersion heater in the $\sim 85 \%$ full-supply tank was first set at $100^{\circ} \mathrm{F}\left(38^{\circ} \mathrm{C}\right)$ with the heater on. When the controller started to operate, the vent was opened slightly to bleed off any dis solved gas that had come out of the bulk solution for $1 \mathrm{hr}$. Dissolved gases had been found to play a significant role in two-phase-flow heat transfer, 111,114 and the common degassing procedure used here was to boil the system at its saturation temperature. ${ }^{10,111}$ After degassing in a two-phase state, the vent was closed, and the controller was set at the higher operating temperature $\left[\sim 135^{\circ} \mathrm{F}\left(57^{\circ} \mathrm{C}\right)\right]$. A four-fifths-full vessel of Freon-ll would attain stable and uniform temperature as indicated by the four immersed thermocouples after $1 \frac{1}{2} \mathrm{hr}$.

AC power to the blowdown-vessel heating wire was turned on to bring the vessel wall up to operating temperature while the vessel was still empty. Nichrome heater wires were also used for heating the loop piping to the desired temperature.

\section{Blowdown Operation}

The following checkout procedure was performed before each run:

a. Air at 45 psig was supplied to the three air-operated solenoid valves SW 1, SW 2, and SW 3 shown in Fig. 11. Valves SW 1 and SW 3 were opened by a manually operated switch, while SW 2 remained closed.

b. The loop was purged with hot Freon, and the pressure transducers were bled for trapped gases.

c. Various readout devices were checked for proper recording conditions, and photographic equipment was made ready.

d. The supply vessel was pressurized by nitrogen, resulting in subcooled Freon.

e. Single-phase upflow in the test section was established by opening the flow-control valves.

f. Desired power level to the test section was turned on, and the flow and inlet pressure were set to the desired values by adjusting the flowcontrol valves and the throttle-line valve located just upstream of valve SW 1 .

g. After steady-state upflow with subcooled boiling was established and maintained for $\sim 1$ min to ensure steady loop-component temperatures, all recording and photographic systems were actuated.

h. The manually operated switch in step a was then quickly turned to the opposite position to initiate the blowdown transient. This caused solenoid valves SW 1 and SW 3 to close and SW 2 to open, closing the path from the top of the test section to the receiving vessel, shutting off the supply vessel from the test section, and opening a path to the receiving vessel. 


\section{EXPERIMENTAL RESULTS}

The data from two adiabatic and six diabatic (i.e., with power input to the test section) blowdown tests are reported in this study. The initial steadystate conditions prior to blowdown are indicated in the figures showing the pressure-decay curves, and also in Table IV for the diabatic tests. The original analog data signals, however, are not presented, due to the enormous number of traces involved.

TABLE IV. Initial Steady-state Conditions in Test Section hefore Rlowdown ${ }^{a}$

\begin{tabular}{|c|c|c|c|c|c|c|c|}
\hline $\begin{array}{l}\text { Run } \\
\text { No. }\end{array}$ & $\begin{array}{c}\text { Pressure } \\
\text { Po, psia }\end{array}$ & $\begin{array}{c}\text { Temperature } \\
\mathrm{T}_{0},{ }^{\circ} \mathrm{F}\end{array}$ & $\begin{array}{l}\text { Subcooling } \\
\Delta \mathrm{T}_{\text {sub }}{ }^{\circ} \mathrm{F}\end{array}$ & $\begin{array}{l}\text { Velocity } \\
\text { in TS, } \\
\mathrm{U}_{0}, \mathrm{ft} / \mathrm{s}\end{array}$ & $\begin{array}{c}\text { Mass } \\
\text { Velocity } \\
\mathrm{G}, 1 \mathrm{~b}_{\mathrm{m}} / \mathrm{hr} \cdot \mathrm{ft}^{2}\end{array}$ & $\begin{array}{c}\text { Heat Flux } \\
\varphi, \text { Btu/hr} \cdot \mathrm{ft}^{2}\end{array}$ & $\begin{array}{l}\text { Blowdown } \\
\text { Volume } \\
\text { V } \\
\text { BD }, \mathrm{ft}^{3}\end{array}$ \\
\hline $4 / 22$ & 67.5 & 127.1 & 40.8 & 3.28 & $1.04 \times 10^{6}$ & 38,500 & 0.080 \\
\hline $5 / 19-A$ & 65.7 & 132.8 & 33.2 & 8.05 & $2.53 \times 10^{6}$ & 46,340 & 0.072 \\
\hline $5 / 29$ & 66.0 & 132.8 & 3.3 .5 & 7.54 & $2.37 \times 10^{6}$ & 45.520 & 0.318 \\
\hline $6 / 4$ & 64.8 & 1.32 .8 & 32.2 & 7.54 & $2.37 \times 10^{6}$ & 45,460 & 0.318 \\
\hline $6 / 9$ & 64.5 & 133.9 & 30.7 & 7.54 & $2.37 \times 10^{6}$ & 46,300 & 0.201 \\
\hline $6 / 12$ & 65,1 & 133,3 & $3 ? .0$ & 7.54 & $2.37 \times 10^{6}$ & 46,570 & 0.072 \\
\hline
\end{tabular}

${ }^{\mathrm{a}}$ Conversion factors: $1 \mathrm{psia}=6.895 \mathrm{kPa} ; \mathrm{t}\left({ }^{\circ} \mathrm{C}\right)=\left[\mathrm{t}\left({ }^{\circ} \mathrm{F}\right)-32\right] / 1.8 ; 1 \mathrm{ft} / \mathrm{s}=0.305 \mathrm{~m} / \mathrm{s} ; 10^{6} 1 \mathrm{bm} /$ $\mathrm{hr} \cdot \mathrm{ft}^{2}=1356 \mathrm{~kg} / \mathrm{m}^{2} \cdot \mathrm{s} ; 1 \mathrm{Btu} / \mathrm{hr} \cdot \mathrm{ft}^{2}=3.155 \mathrm{~W} / \mathrm{m}^{2} ; \mathrm{l} \mathrm{ft}^{3}=0.0284 \mathrm{~m}^{3}$.

${ }^{b}$ Blowdown volume is defined to be the system volume between the lower plenum and the SW 3 valve.

\section{A. Adiabatic Blowdown Tests}

A number of adiabatic blowdown tests were conducted with Freon at nominal conditions of $65 \mathrm{psia}(448 \mathrm{kPa})$ and $145^{\circ} \mathrm{F}\left(63^{\circ} \mathrm{C}\right)$. The tests were performed by establishing a steady upflow and then initiating a decompression that produced flow reversal within the system. Results for two typical blowdown transients are presented in Figs. 15-18. The shortest transient was obtained with the blowdown vessel isolated from the loop; the system required about $15 \mathrm{~s}$ to reach ambient pressure. For the long transient, Run 4/9-B, the fluid for blowdown was at two different initial temperatures. The stagnant fluid stored in the blowdown vessel was at a lower temperature $\left[138^{\circ} \mathrm{F}\left(59^{\circ} \mathrm{C}\right)\right]$ than that of the flowing liquid in the turbine legs and test section $\left[151^{\circ} \mathrm{F}\left(66^{\circ} \mathrm{C}\right)\right]$.

\section{B. Preliminary Diabatic Blowdown Tests}

Three diabatic blowdown runs are presented here. They were performed in order to check system behavior under various sonditions. The. main features of each run are described below, the corresponding, initial, ronditions being summarized in Table IV.

\section{1. $\operatorname{Run} 4 / 22$}

For Run 4/22, the transient was initiated with solenoid valves SW 1 and SW3 closed about 1 s before SW 2 opened. As a result, the fluid in the test section was stagnant, and because of the continuous energy input, the pressure in the test section began to rise, as shown in Fig. 19, until decompression 

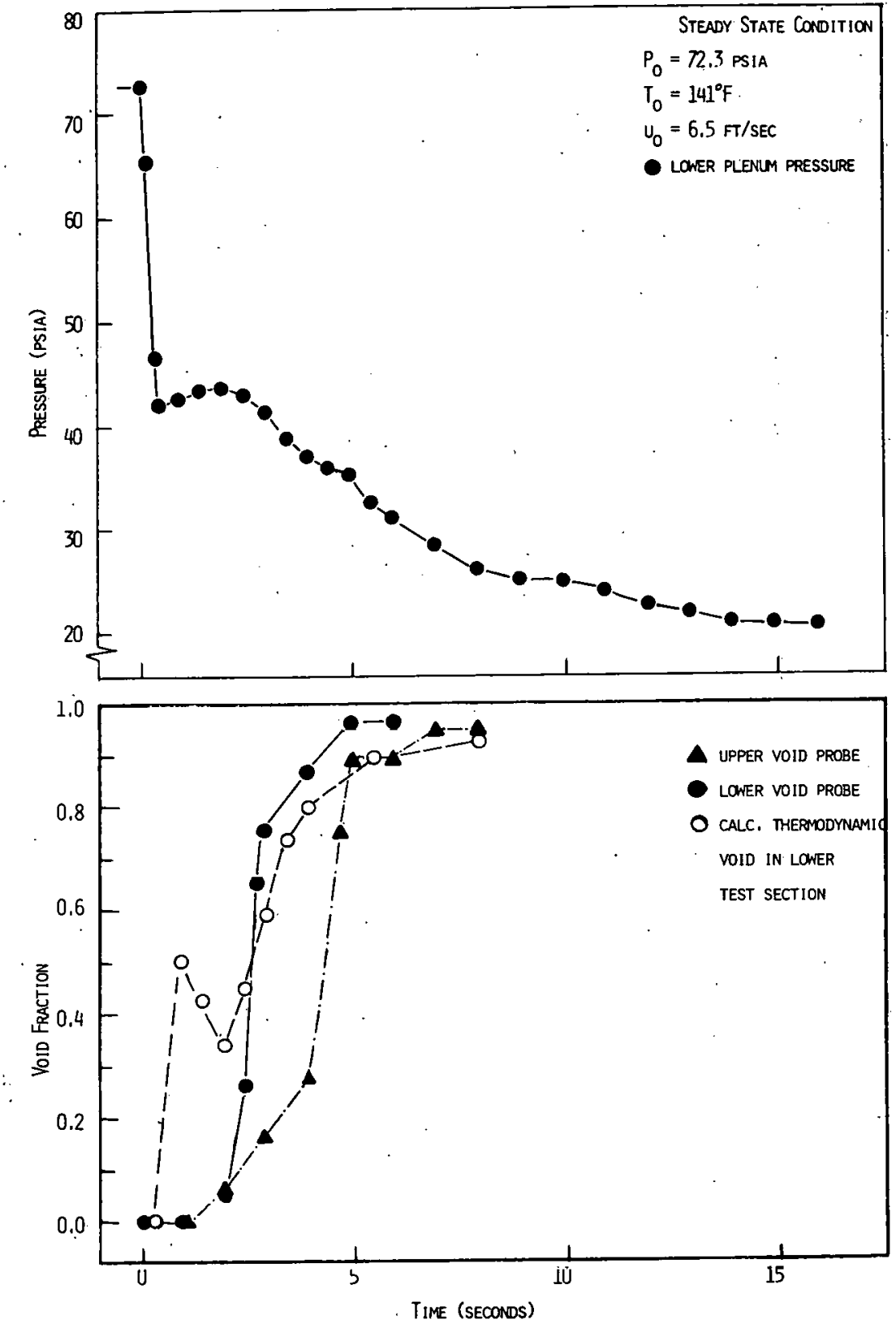

Fig. 15

Pressure and Void Measurement for Adiabatic Blowdown Run 4/4A. Blowdown volume $\simeq 0.08 \mathrm{ft}^{3}$. Conversion factors: 1 psia $=$ $6.895 \mathrm{kPa}$; t. $\left({ }^{\circ} \mathrm{C}\right)=\left[\mathrm{t}\left({ }^{\circ} \mathrm{F}\right)-32\right] /$ 1.8: $1 \mathrm{ft} / \mathrm{sec}=0.305 \mathrm{~m} / \mathrm{s}$. ANL Neg. No. 900-75-43I Rev. 1.

Fig. 16

Fluid Temperature during Blowdown Run 4/4-A. Conversion factor: $t\left({ }^{\circ} \mathrm{C}\right)=\left[\mathrm{t}\left({ }^{\circ} \mathrm{F}\right)-32\right] /$ 1.8. ANL Neg. No. 900-75-947.

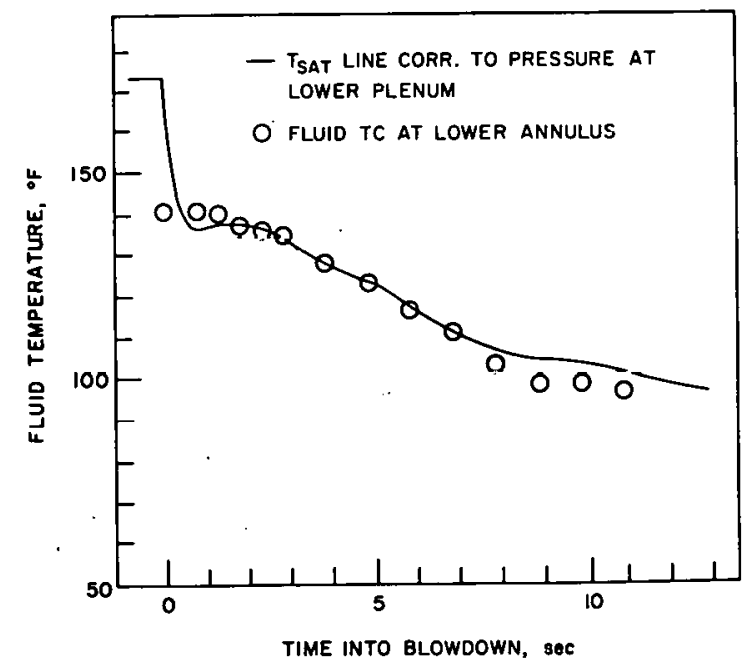



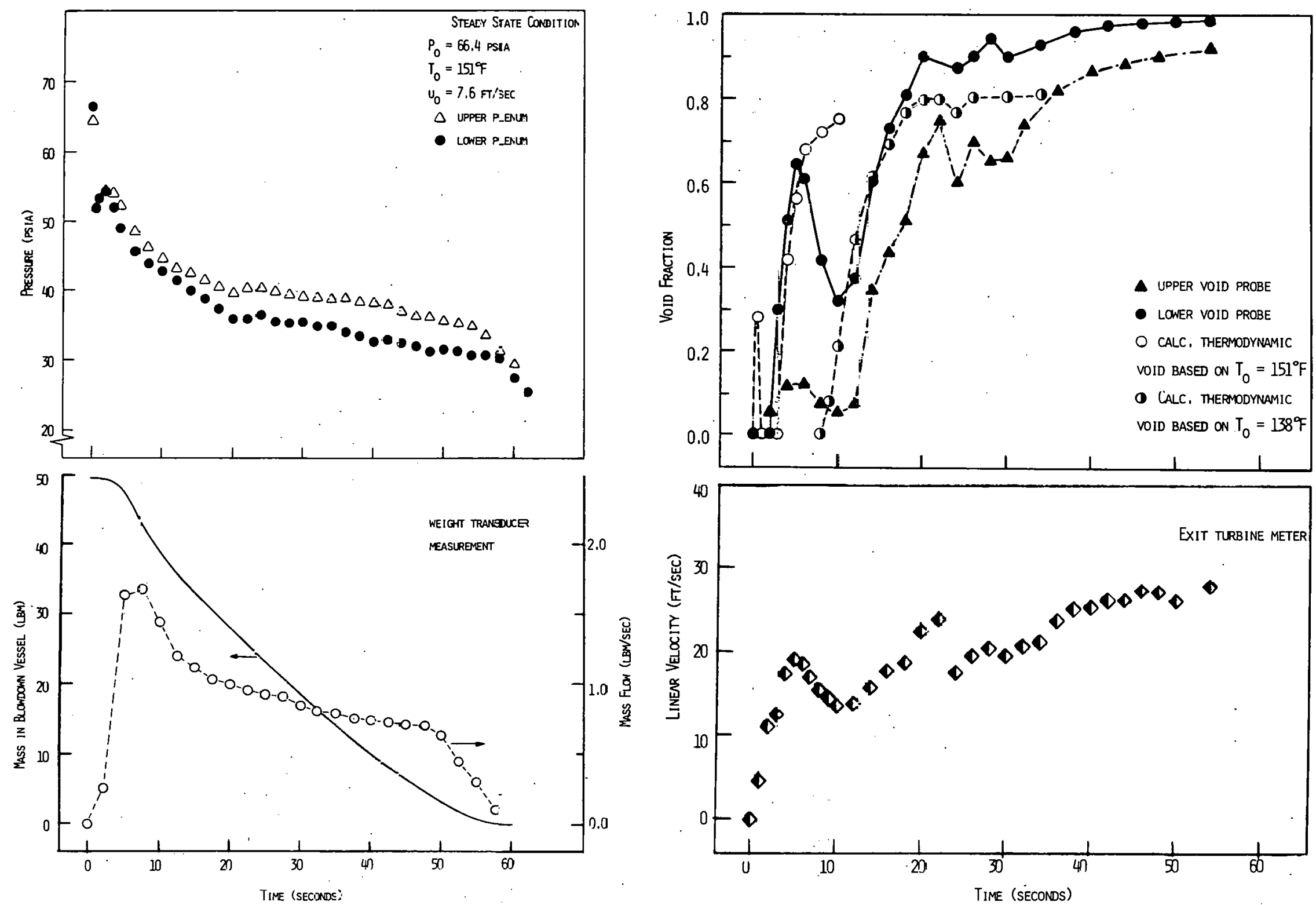

Fig. 17. Pressure and Weight Measurement for Adiabatic Blow Jown Run 4/9B. Blowdown volume $\approx 0.532 \mathrm{ft}^{3}$. Conversion factors: $1 \mathrm{psic}=6.895 \mathrm{kPa} ; 1 \mathrm{ib}=0.4536 \mathrm{~kg} ; \mathrm{t}\left({ }^{\circ} \mathrm{C}\right)=\left[\mathrm{l}\left({ }^{\circ} \mathrm{F}\right)-3 \tilde{c}\right] /$ $1.8 ; 1 \mathrm{ft} / \mathrm{sec}=0.305 \mathrm{~m} / \mathrm{s}$. ANL Ne.3. No. $900-75-430$.

Fig. 18. Void Fraction ard Turbine Flowmeter Measurement for Adiabatc. Blowdown Run 4/9B. Conversion factor: $1 \mathrm{ft} / \mathrm{sec}^{-}=0.305 \mathrm{~m} / \mathrm{s}$. ANL Neg: No. 900-75-429. 


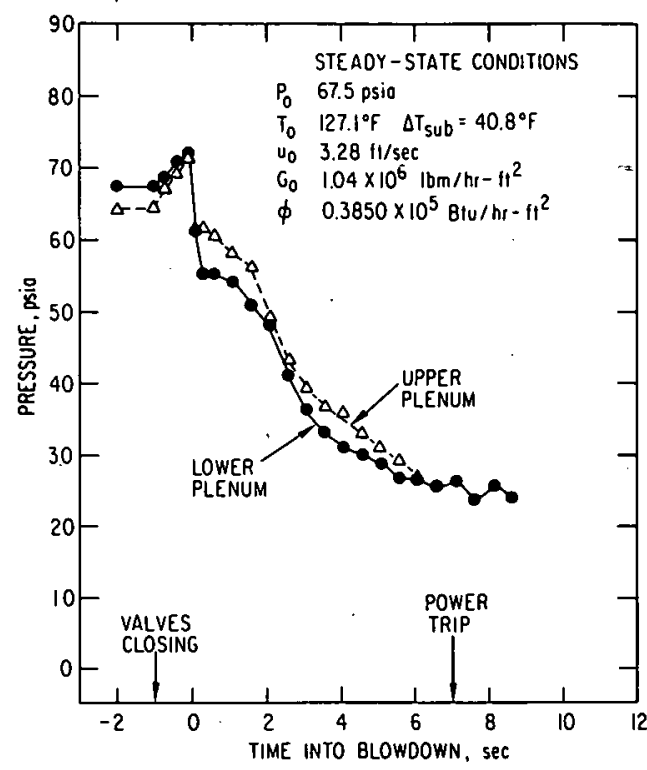

Fig. 19

Pressure History for Diabatic Blowdown Run $4 / 22$. Blowdown volume $\simeq 0.08 \mathrm{ft}^{3}$. Conversion factors: $1 \mathrm{psia}=6.895 \mathrm{kPa}$; $\mathrm{t}\left({ }^{\circ} \mathrm{C}\right)=\left[\mathrm{t}\left({ }^{\circ} \mathrm{F}\right)-32\right] / 1.8 ; 1 \mathrm{ft} / \mathrm{sec}=$ $0.305 \mathrm{~m} / \mathrm{s} ; 10^{6} \mathrm{lb} \mathrm{m} / \mathrm{hr} \cdot \mathrm{ft}^{2}=1356 \mathrm{~kg} /$ $\mathrm{m}^{2} \cdot \mathrm{s} ; 1 \mathrm{Btu} / \mathrm{hr} \cdot \mathrm{ft}^{2}=3.155 \mathrm{~W} / \mathrm{m}^{2}$. ANL Neg. No. 900-75-342.

occurred on opening valve SW2. Figure 20 shows the wall temperature and the fluid temperature. Figures 21 and 22 show the flow and void-fraction measurements, respectively. Time zero is taken to be the start of depres surization. The time at power trip is indicated on the figures.

\section{Run 5/19-A}

Like Run 4/22, Run 5/19-A was performed with the blowdown vessel removed from the loop and replaced by a flexible stainless steel tube as shown in Fig. 11. Subcooled flow boiling was visually observed all along the heated length during steady-state operation. Time zero for the transient was again taken to be the instant at which the plenum pressures started to drop (see Fig. 23). Temperature and void-fraction measurements are shown in Figs. 24 and 25. Figure 26 shows the time to $C H F, t_{C H F}$, at various locations along the heated section. The inception of $\mathrm{CHF}$ is defined as

$$
{ }^{t}{ }_{C H F}=t_{T C}-T_{T S},
$$

where $t_{\mathrm{TC}}$ is the point at which the thermocouple begins to rise and $\mathrm{T}_{\mathrm{TS}}$ is the overall time response of the heated tube and thermocouples. The latter is determined by a separate test, as described in Appendix D.

\section{3. $\operatorname{Run} 5 / 29$}

Run 5/29 was performed with the full volume of the blowdown vessel, which produced a transient lasting almost $1 \mathrm{~min}$. The experimental results are shown in Figs. 27-33. Heater-wall temperatures on the bottom 8 in. rose without power trip, the most severe rise occurring at the extreme end. Rewetting of this dried-out region was observed as the wall temperature at this location dropped before any physical damage was done on the heater surface. Power trip subsequently occurred at $\sim 40 \mathrm{~s}$ as the whole test section went into CHF condition. Figure 31 shows that the blowdown vessel was essentially empty at $40 \mathrm{~s}$. 

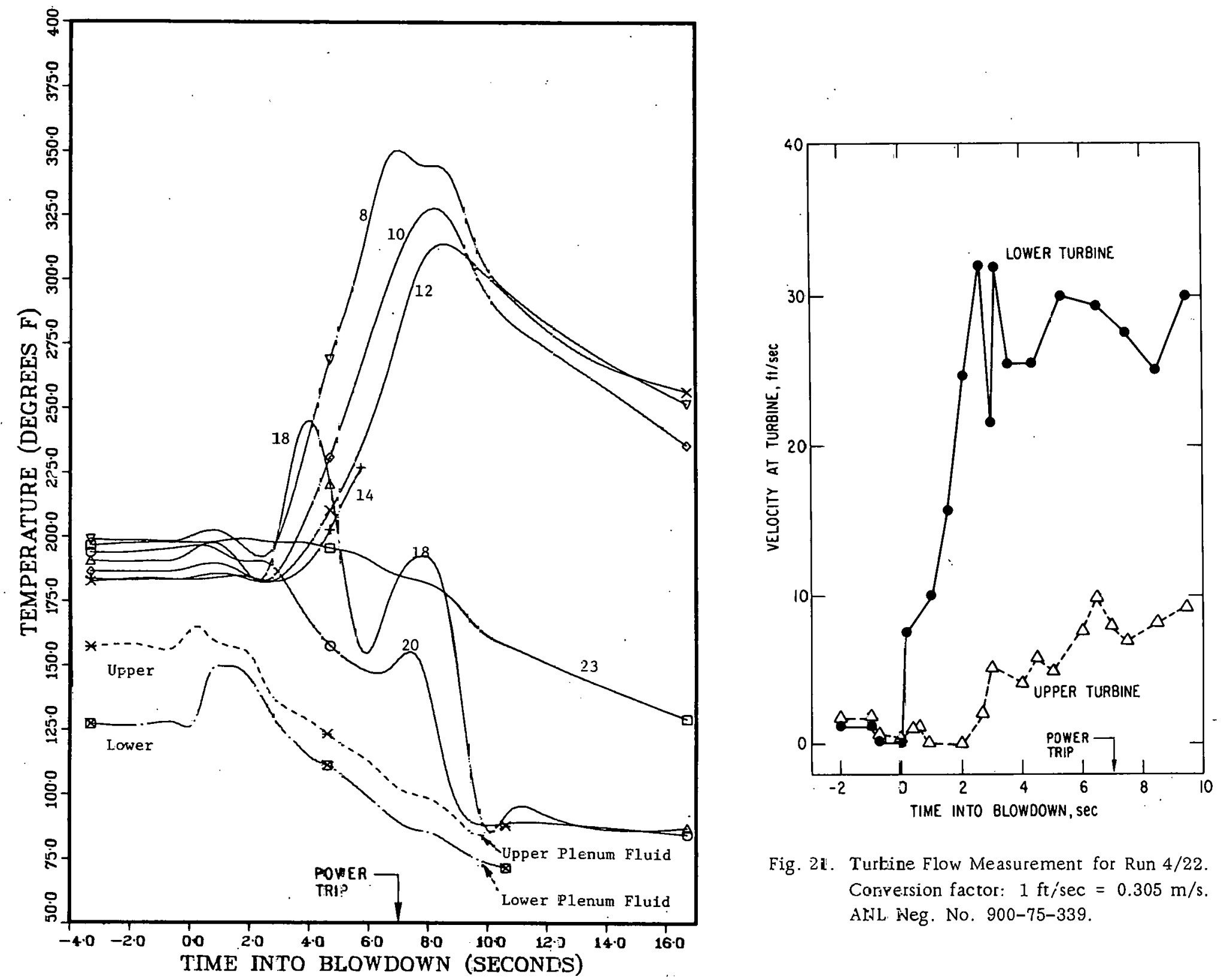

Fig. 21. Turtine Flow Measurement for Run $4 / 22$. Corrersion factor: $1 \mathrm{ft} / \mathrm{sec}=0.305 \mathrm{~m} / \mathrm{s}$. AIL Weg. No. 900-75-339.

Fig. 20. Temperature History for Run 4/22. Conversion factor: $\mathrm{t}\left({ }^{\circ} \mathrm{C}\right)=\left[\mathrm{t}\left({ }^{\circ} \mathbb{F}\right)-32\right]: 1.8$. ANL Neg. No. 900-75-346. 


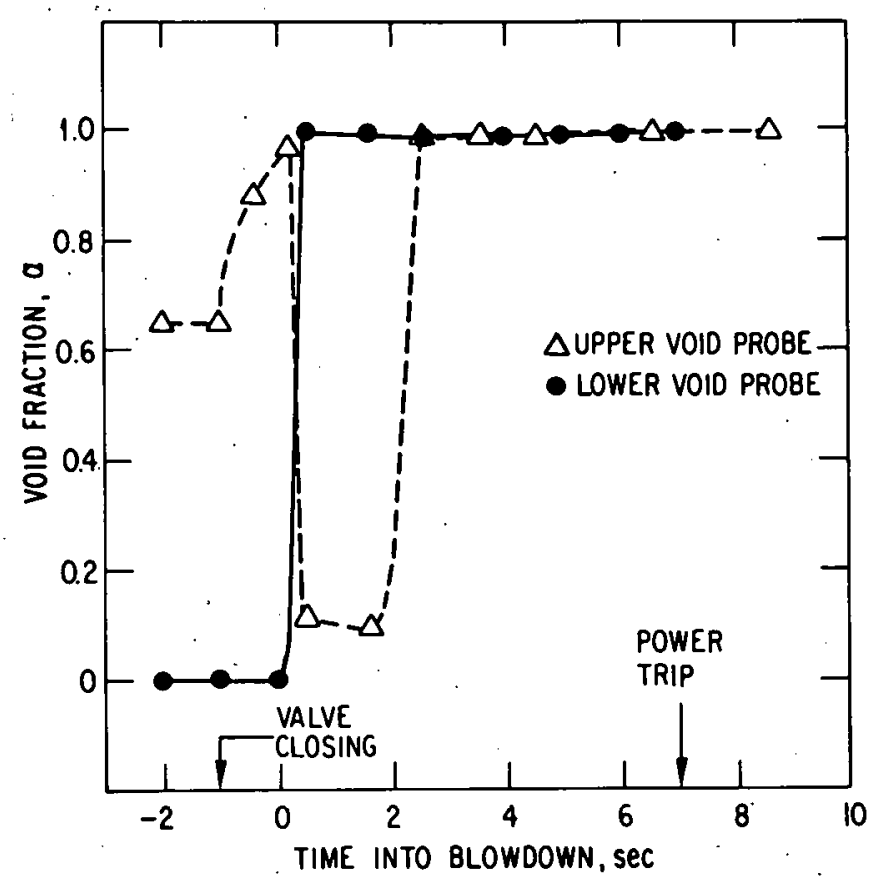

Fig. 22

Void-fraction Measurement for Run $4 / 22$. ANL Neg. No. 900-75-341.

Fig. 23

Pressure History for Diabatic Blowdown Run 5/19A. Blowdown volume $\simeq$ $0.072 \mathrm{ft}^{3}$. Conversion factors: $1 \mathrm{psia}=$ $6.895 \mathrm{kPa} ; \mathrm{t}\left({ }^{\circ} \mathrm{C}\right)=\left[\mathrm{t}\left({ }^{\circ} \mathrm{F}\right)-32\right] / 1.8$; $1 \mathrm{ft} / \mathrm{sec}=0.305 \mathrm{~m} / \mathrm{s} ; 10^{\theta} \mathrm{lb} / \mathrm{hr} \cdot \mathrm{ft}^{2}=$ $1356 \mathrm{~kg} / \mathrm{m}^{2} \cdot \mathrm{s} ; 1 \mathrm{Btu} / \mathrm{hr} \cdot \mathrm{ft}^{2}=3.155 \mathrm{~W} /$ $\mathrm{m}^{2}$. ANL Neg. No. 900-75-389.

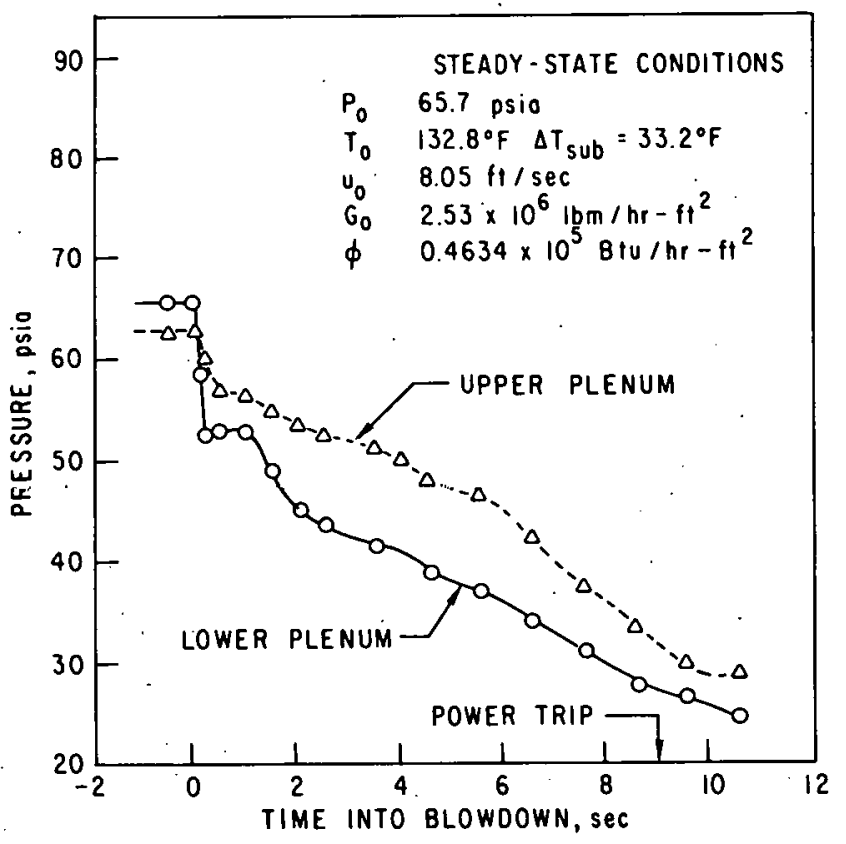




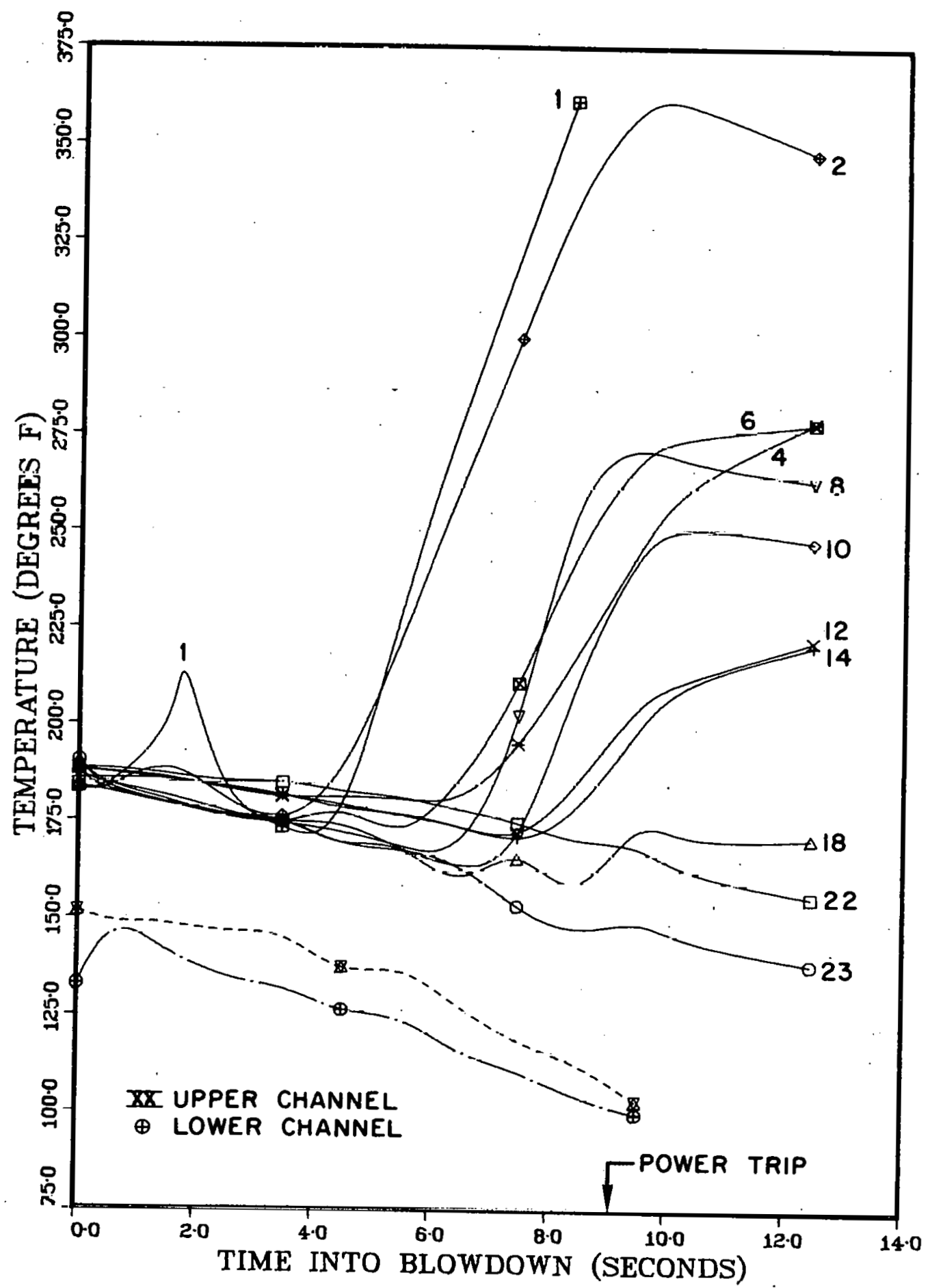

Fig. 24. Temperature History for Run 5/19A. Conversion factor: $\mathrm{t}\left({ }^{\circ} \mathrm{C}\right)=\left[\mathrm{t}\left({ }^{\circ} \mathrm{F}\right)-32\right] / 1.8$. ANL Neg. No. 900-75-801. 


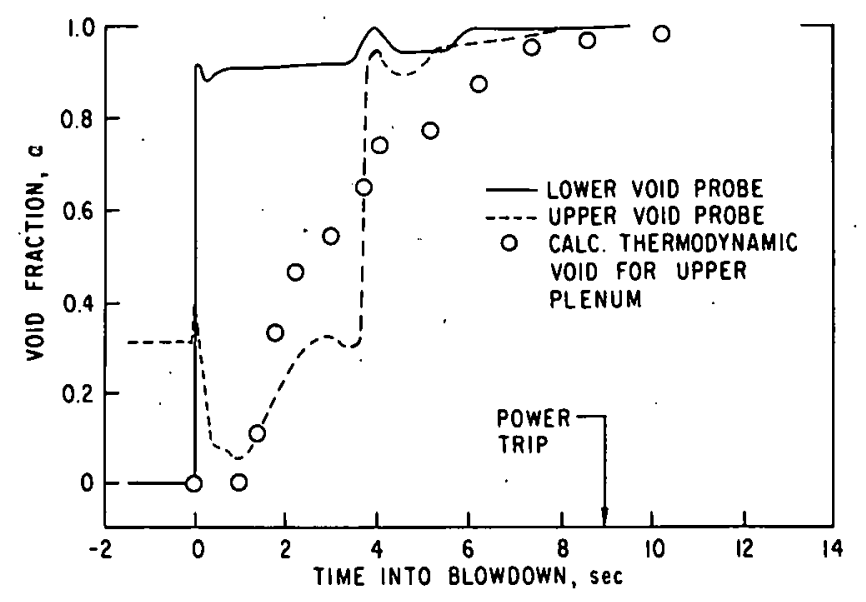

Fig. 25

Void-fraction Measurement for Run 5/19A.

ANL Neg. No. 900-75-388 Rev. 1.

Fig. 26

Time to CHF vs Axial Location for Run 5/19A. Conversion factor: 1 in. $=2.54 \mathrm{~cm}$. ANL. Neg. No. 900-75-394.
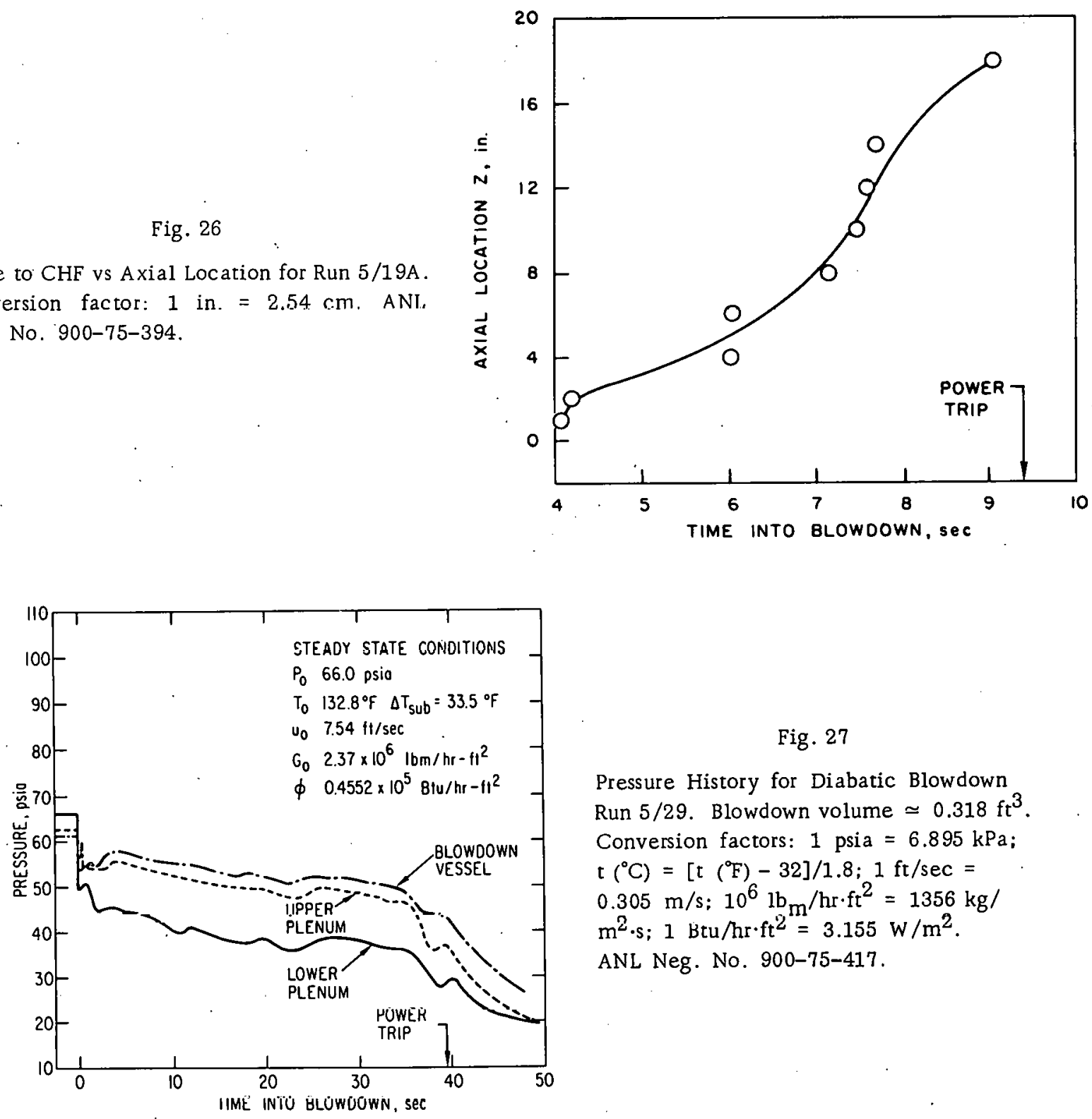

Fig. 27

Pressure History for Diabatic Blowdown Run $5 / 29$. Blowdown volume $\simeq 0.318 \mathrm{ft}^{3}$. Conversion factors: 1 psia $=6.895 \mathrm{kPa}$; $\mathrm{t}\left({ }^{\circ} \mathrm{C}\right)=\left[\mathrm{t}\left({ }^{\circ} \mathrm{F}\right)-32\right] / 1.8 ; 1 \mathrm{ft} / \mathrm{sec}=$ $0.305 \mathrm{~m} / \mathrm{s} ; 10^{6} \mathrm{lb} / \mathrm{mr} \cdot \mathrm{ft}^{2}=1356 \mathrm{~kg} /$ $\mathrm{m}^{2} \cdot \mathrm{s} ; 1 \mathrm{Btu} / \mathrm{hr} \cdot \mathrm{ft}^{2}=3.155 \mathrm{~W} / \mathrm{m}^{2}$.

ANL Neg. No. 900-75-417. 


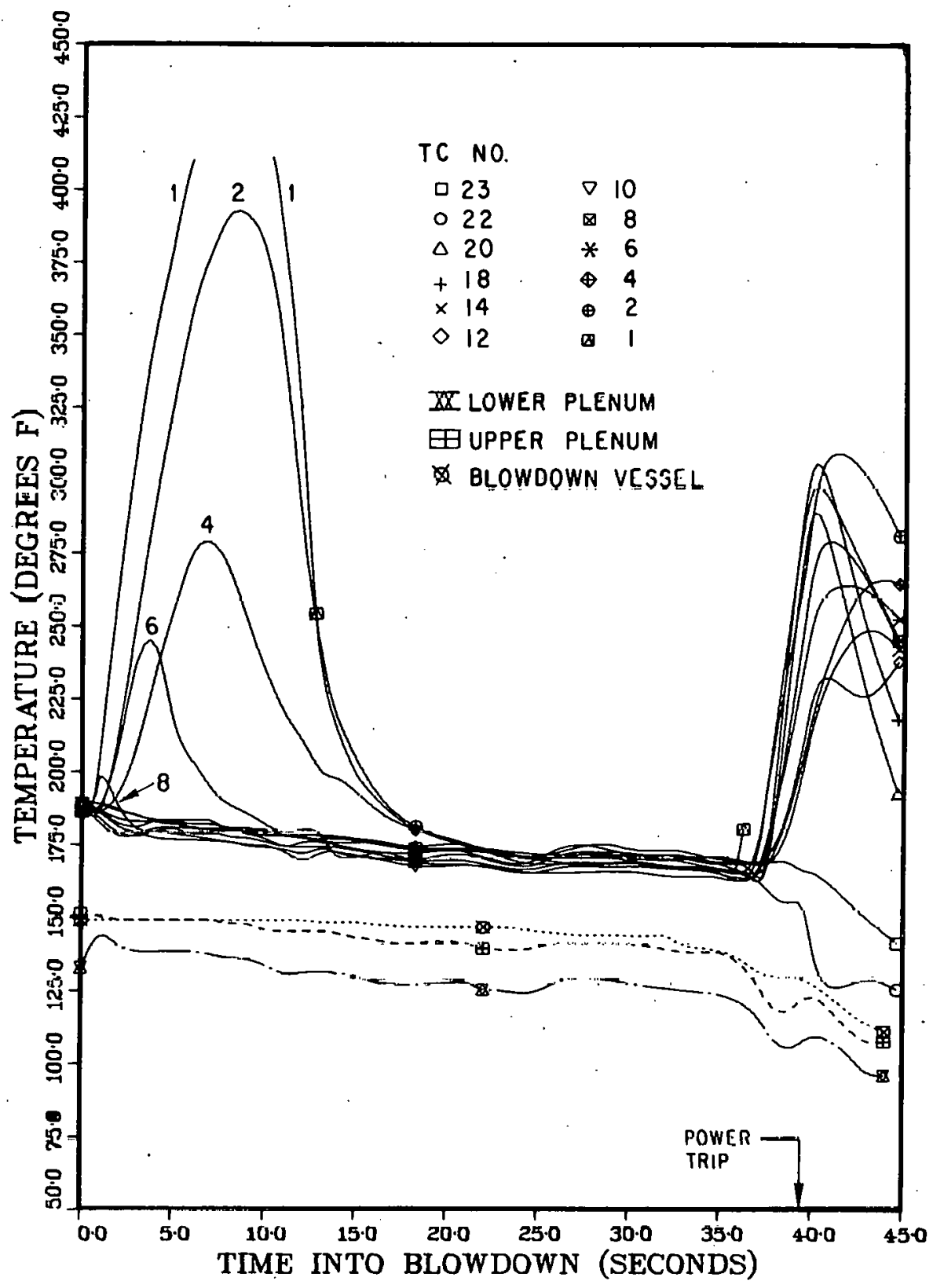

Fig. 28. Temperature History for Run 5/29. Conversion factor: $\mathrm{t}\left({ }^{\circ} \mathrm{C}\right)=\left[\mathrm{t}\left({ }^{\circ} \mathrm{F}\right)-32\right] / 1.8$. ANL Neg. No. 900-75-412. 


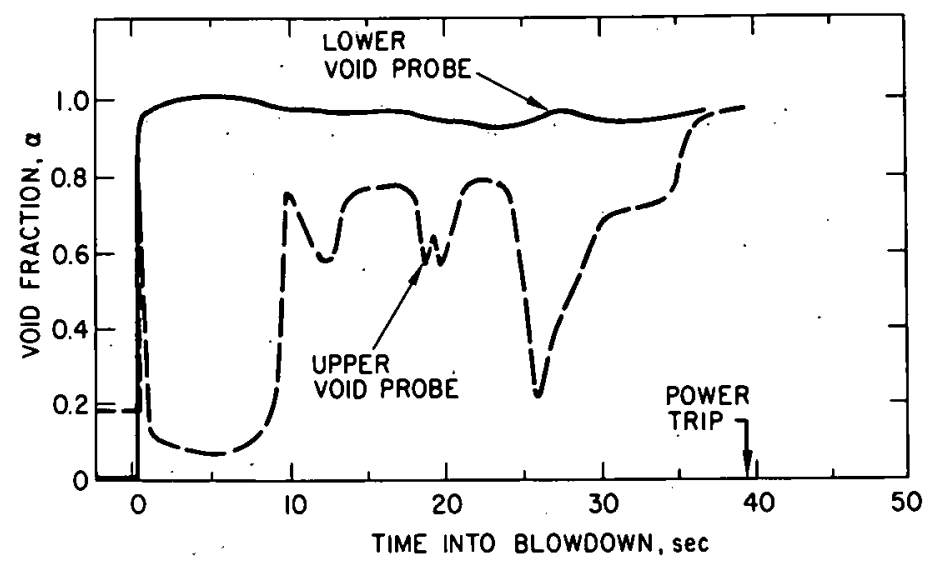

Fig. 29

Void-fraction Measurement for Run 5/29. ANL Neg. No. 900-75-418.

Fig. 30

Flow Measurement during Blowdown for Kun 5/29. Conversion factor: $1 \mathrm{ft} / \mathrm{sec}=$ $0.305 \mathrm{~m} / \mathrm{s}$. ANL Neg. No. $900-75-420$.
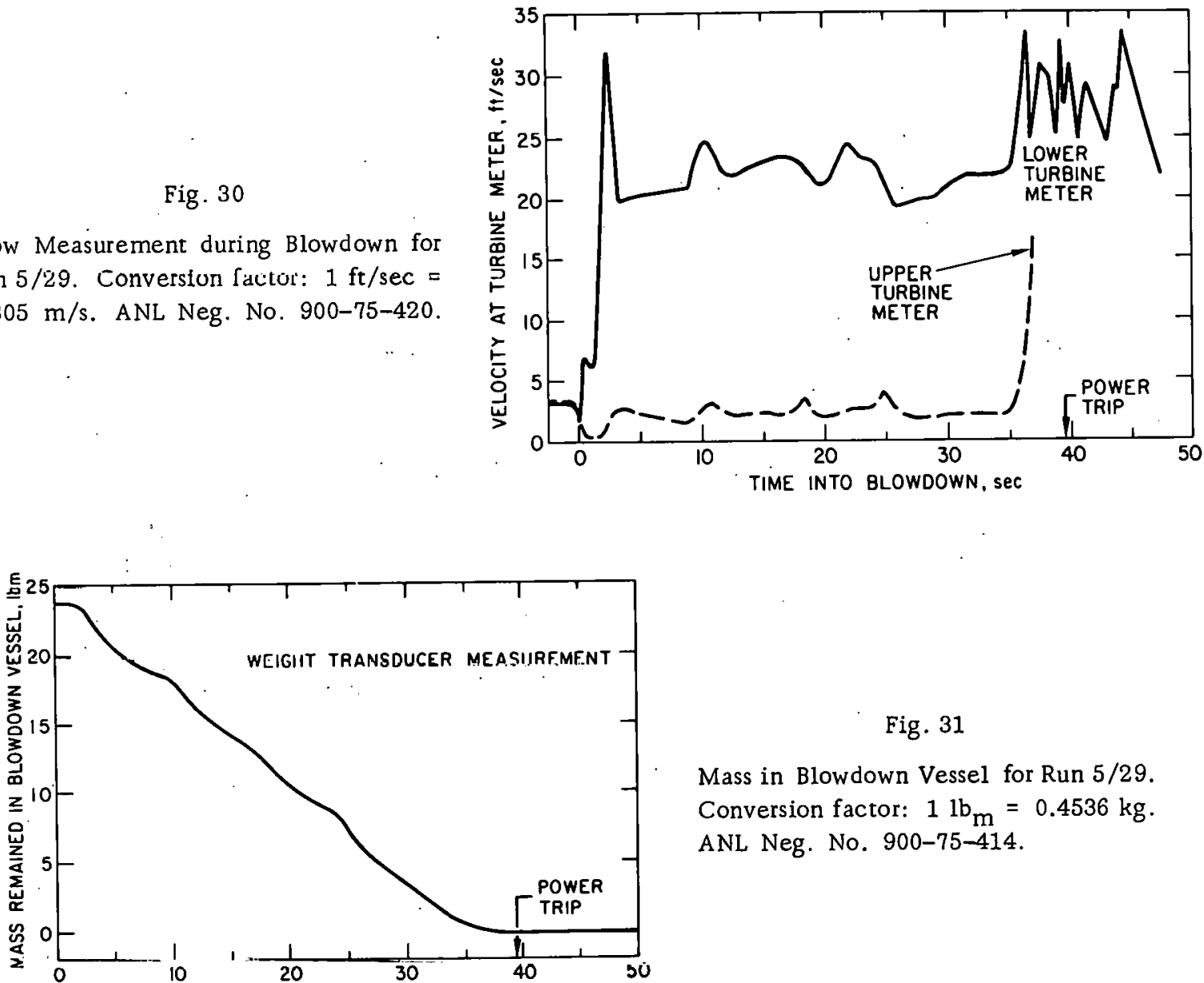

Fig. 31

Mass in Blowdown Vessel for Run 5/29. Conversion factor: $1 \mathrm{lb} m=0.4536 \mathrm{~kg}$. ANL Neg. No. 900-75-414.

TIME INTO BLOWDOWN, SeC 


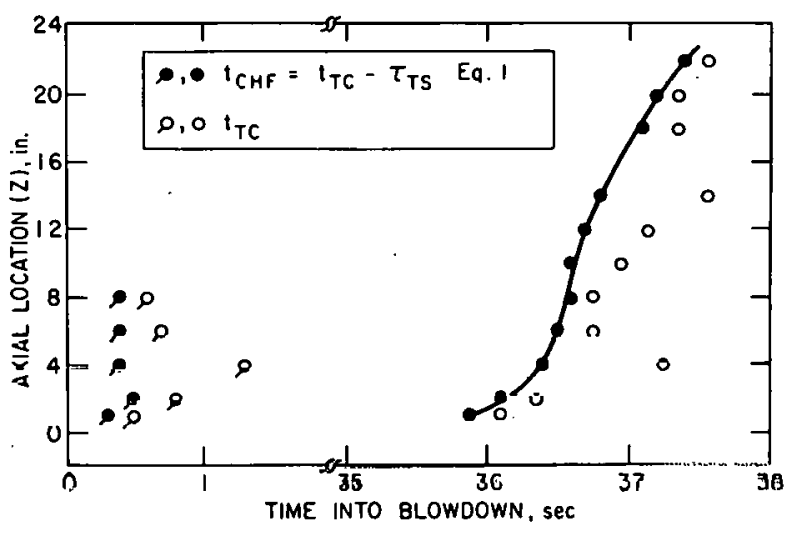

Fig. 32

Time to CHF vs Axial Location for Run $5 / 29$. Conversion factor: 1 in. = $2.54 \mathrm{~cm}$. ANL Neg, No. 900-75-41.3.

Fig. 33

Onset of Rewetting during Run $5 / 29$. Conversion factor: 1 in. $=2.54 \mathrm{~cm}$. ANL Neg. No. $900-75-419$.

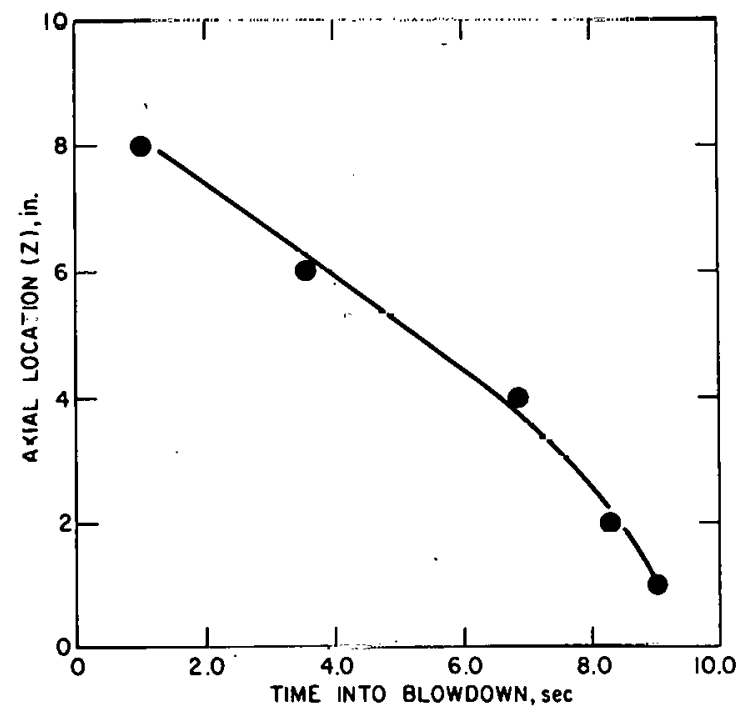


C. Diabatic Blowdown with High-speed Photography: Runs 6/4,6/9, and $6 / 12$

The following tests were performed after the following minor change. During the preliminary diabatic blowdown tests (Runs $4 / 22,5 / 19-A$, and 5/29), the three air-operated solenoid valves did not close or open at the same time. To minimize this effect, small globe valves were used to meter the airflow to individual solenoid valves. This allowed a finer tuning of the system response, and produced repeatable and satisfactory operation.

Three tests were conducted with high-speed photography (800-1000 frames $/ \mathrm{sec}$ ) taken at the bottom 6 in. $(15 \mathrm{~cm})$ of the heated section. A neon lamp was used as a coincidence mark on both the pictures and the visicorder chart so that correlation in time could be made between recording traces and the high-speed photographs. This series of tests (Runs $6 / 4,6 / 9$, and $6 / 12$ ) was aimed at studying the effect of blowdown volume on time to CHF. Hence the initial steady-state conditions were maintained unchanged as shown in Table IV. The results are shown in Figs. 34-51.

The pressure profile obtained from DP cell measurement for Run 6/9 is shown in Fig. 45. Some pressure traces were lost in the other two runs; the signals did not appear on the visicorder paper. Results of high-speed photography are also shown as selected prints at various times into blowdown in Figs. 52-54. The transient coolant velocities; obtained with a motion-picture analyzer, are presented in Figs. 55-57. The velocity shown is more indicative of the liquid phase when significant slip occurs as in annular flow.

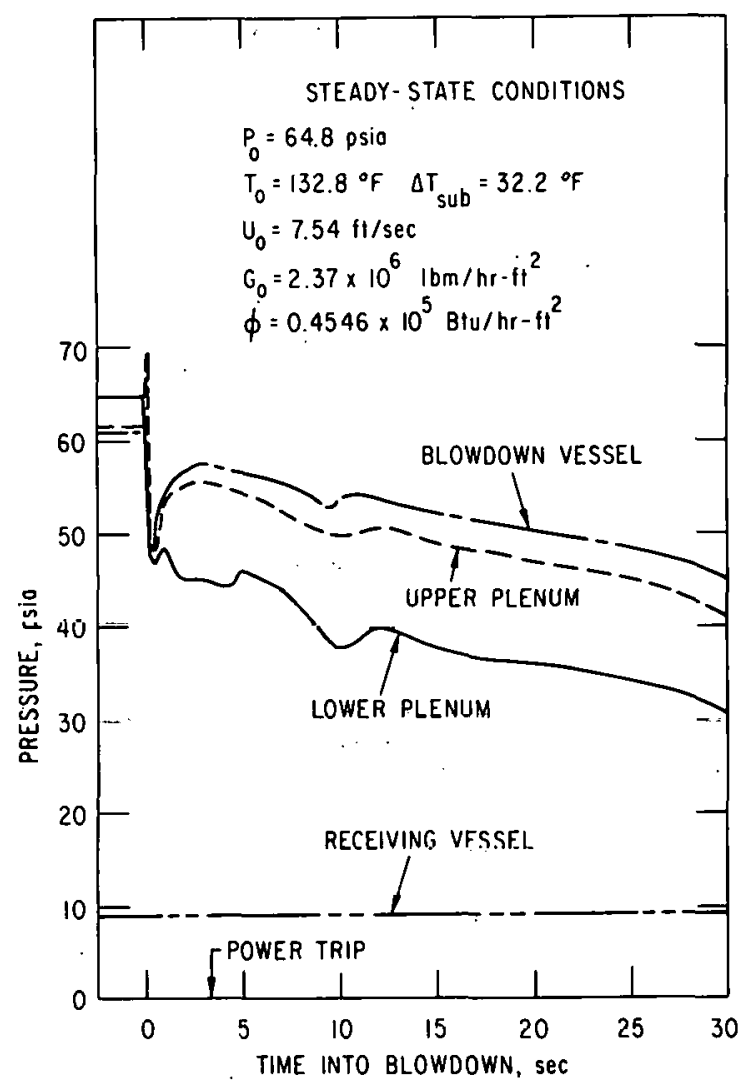

Fig. 34

Pressure History for Diabatic Blowdown Run 6/4. Blowdown volume $\simeq 0.318 \mathrm{ft}^{3}$. Conversion factors: $1 \mathrm{psia}=6.895 \mathrm{kPa} ; \mathrm{t}\left({ }^{\circ} \mathrm{C}\right)=\left[\mathrm{t}\left({ }^{\circ} \mathrm{F}\right)-32\right] / 1.8$; $1 \mathrm{ft} / \mathrm{sec}=0.305 \mathrm{~m} / \mathrm{s}: 10^{6} \mathrm{lb} \mathrm{m} / \mathrm{hr} \cdot \mathrm{ft}^{2}=1356 \mathrm{~kg} /$ ${ }_{111^{2}}{ }^{2} ; 1 \mathrm{Btu} / \mathrm{hr}^{2} \cdot \mathrm{ft}^{2}=3.155 \mathrm{~W} / \mathrm{m}^{2}$. ANL Neg. No. $900-75-498$. 


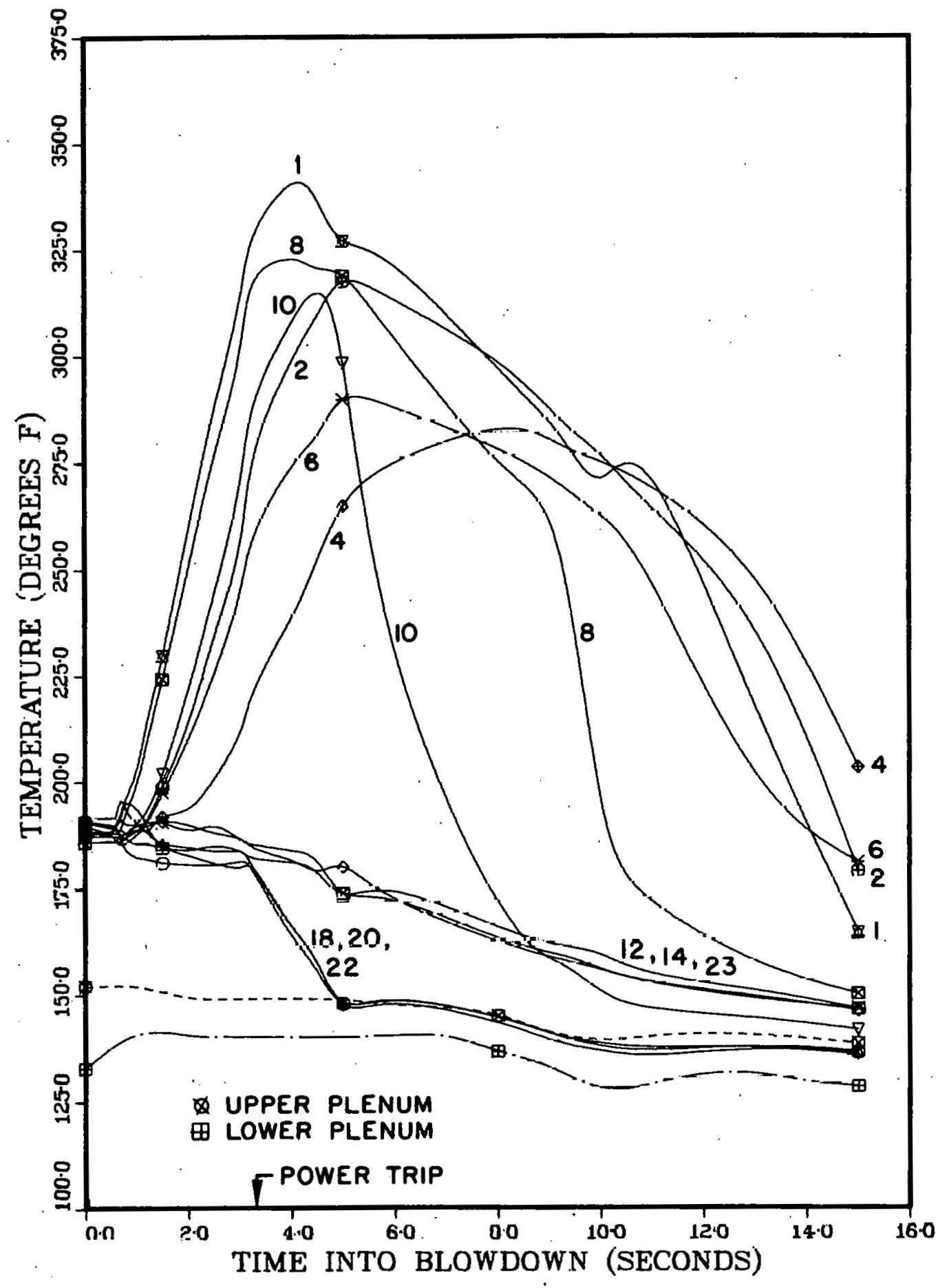

Fig. 35. Temperature History for Run 6/4. Conversion factor: $\mathrm{t}\left({ }^{\circ} \mathrm{C}\right)=\left[\mathrm{t}\left({ }^{\circ} \mathrm{F}\right)-32\right] / 1.8$. ANL Neg. No. 900-75-804. 


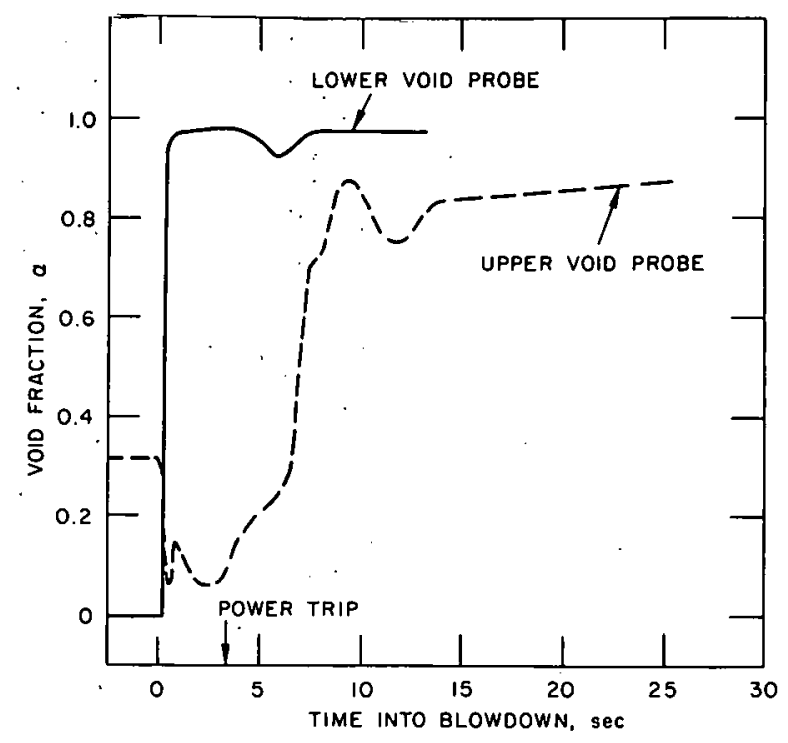

Fig. 36. Void-fraction Measurement for Run 6/4. ANL Neg. No. 900-75-501.

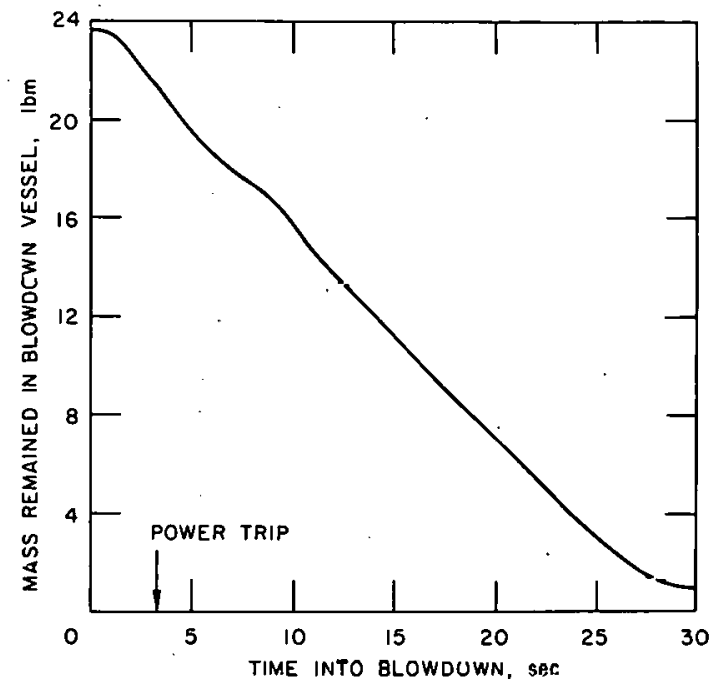

Fig. 38. Mass in Blowdown Vessel for Run $6 / 4$. Conversion factor: $1 \mathrm{lb} m=0.4536 \mathrm{~kg}$. ANL Neg. No. 900-75-497.

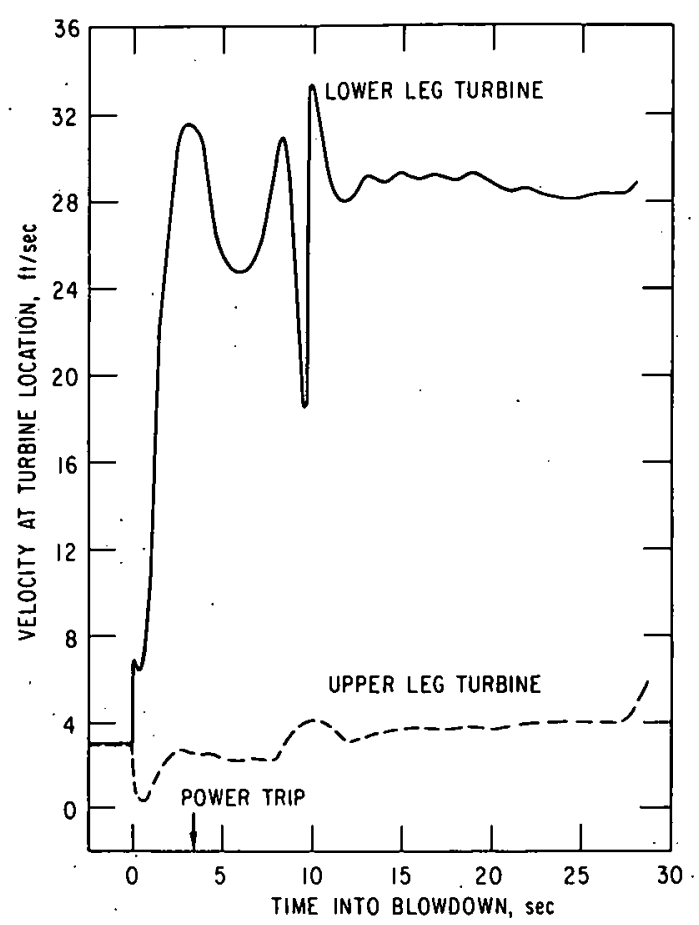

Fig. 37. Turbine flow Measurement for Run $6 / 4$. Conversion factor: $1 \mathrm{ft} / \mathrm{sec}=0.305 \mathrm{~m} / \mathrm{s}$. ANL Neg. . No. $900-75-500$.

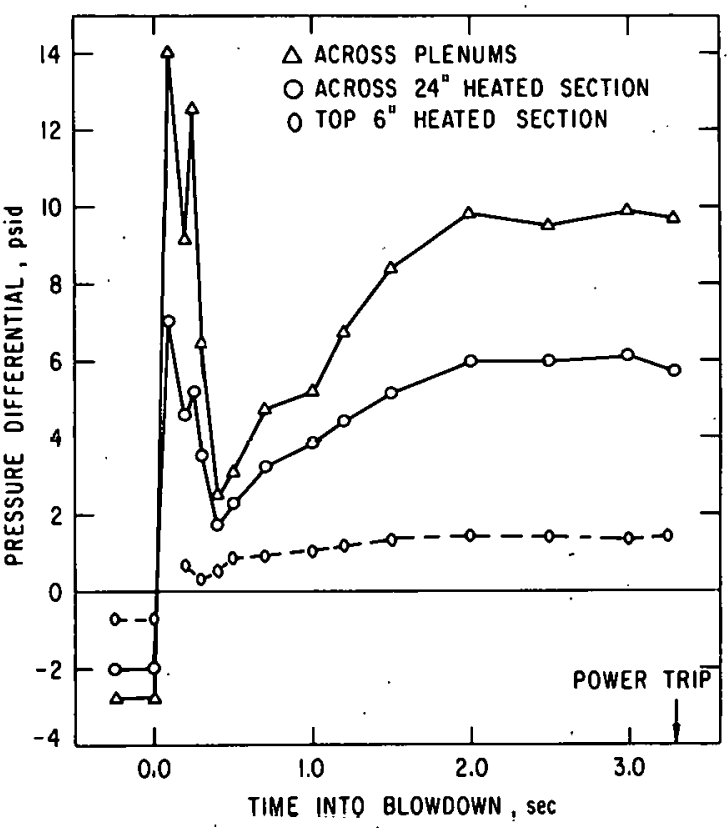

Fig. 39. Pressure-differential Measurement for Run 6/4. Conversion factors: 1 psia $=$ $6.895 \mathrm{kPa} ; 1 \mathrm{in} .=2.54 \mathrm{~cm}$. ANL Neg. No. 900-75-921. 


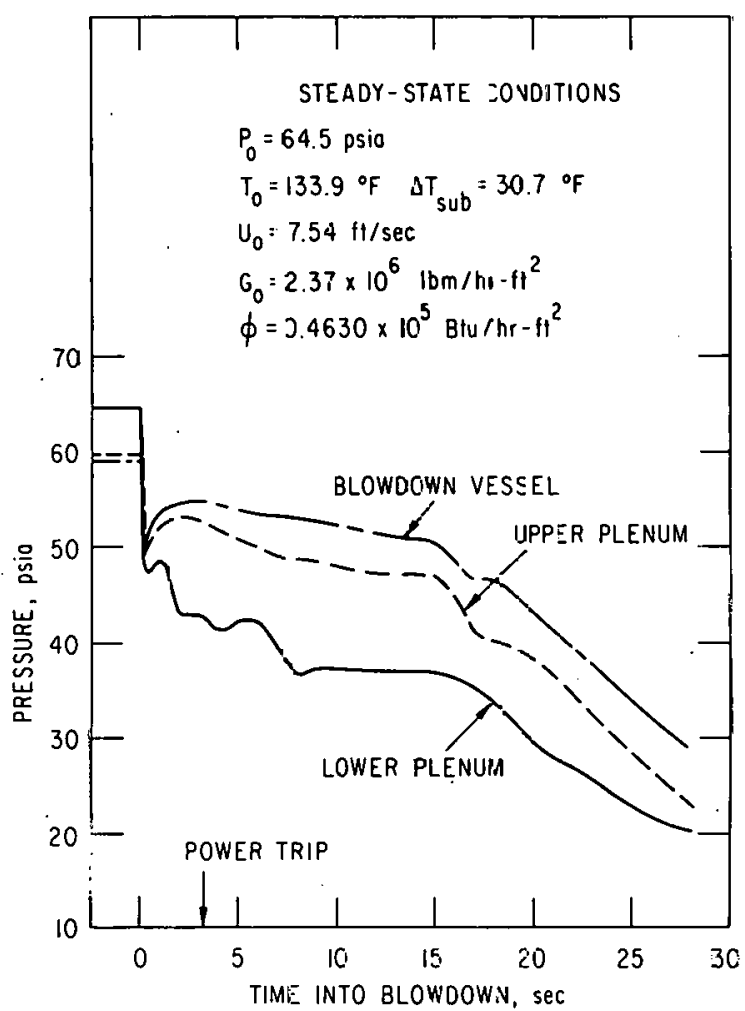

Fig. 40. Pressure History for Diabatic Blowdown Run 6/9. Blowdown Volime $\simeq 0.201 \mathrm{f}=3$ Conversion factors: 1 psia $=6.895 \mathrm{kPa}$; $\mathrm{t}\left({ }^{\circ} \mathrm{C}\right)=\left[\mathrm{t}\left({ }^{\circ} \mathrm{F}\right)-32\right] / 1.8 ; 1 \mathrm{ft} / \mathrm{sec}=$ $0.305 \mathrm{~m} / \mathrm{s} ; 10^{6} \cdot 1 \mathrm{~b}_{\mathrm{m}} / \mathrm{hr} \cdot \mathrm{ft}^{2}=1356 \mathrm{~kg} !$ $\mathrm{m}^{2} \cdot \mathrm{s} ; 1 \mathrm{E} \cdot \mathrm{zu} / \mathrm{hr} \cdot \mathrm{ft}^{2}=3.155 \mathrm{~W} / \mathrm{m}^{2}$. ANL Neg. No. 9010-75-495.

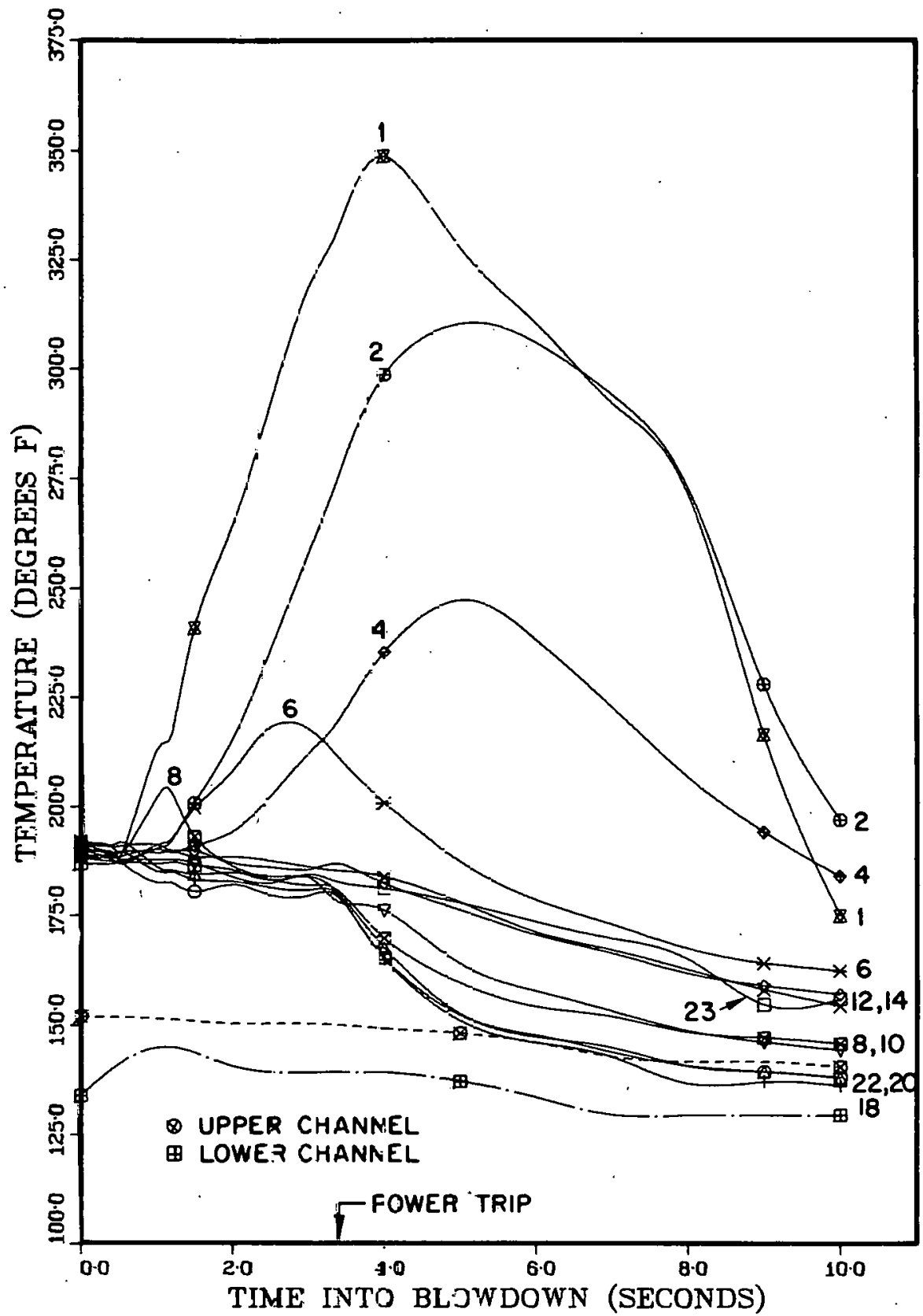

Fig. 41. Temperature History for Rin 6/9. Conversion factor: $\mathrm{t}\left({ }^{\circ} \mathrm{C}\right)=\left[\mathrm{t}\left({ }^{\circ} \mathrm{F}\right)-32\right] / 1.8$. fNL Neg. No. 900-75-803. 


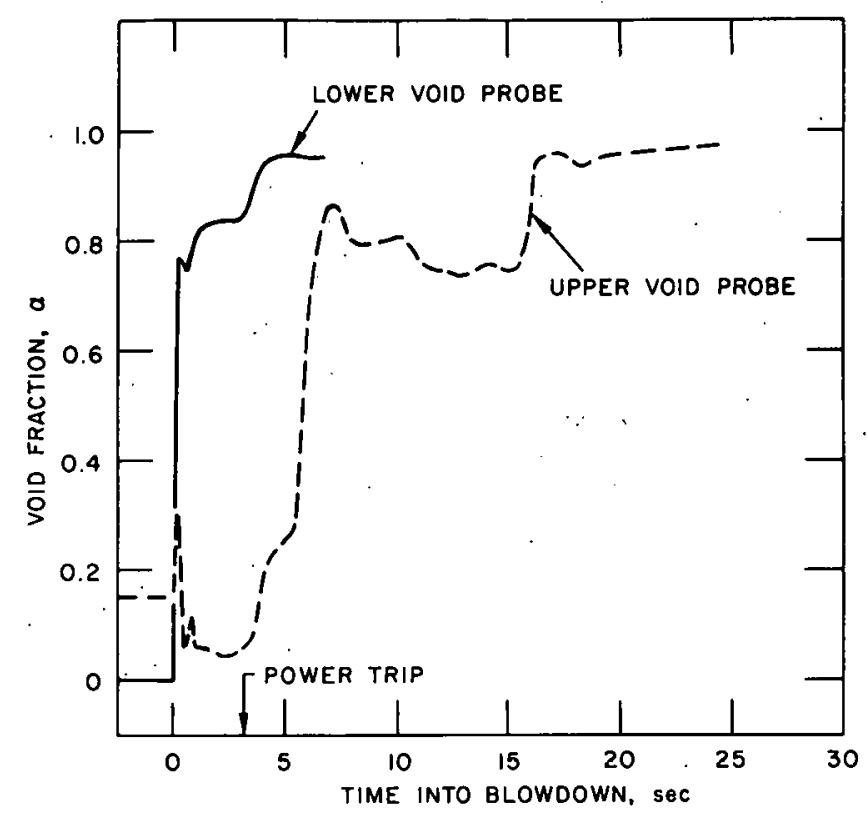

Fig. 42. Void-fraction Measurement for Run 6/9. ANL Neg. No. 900-75-502.

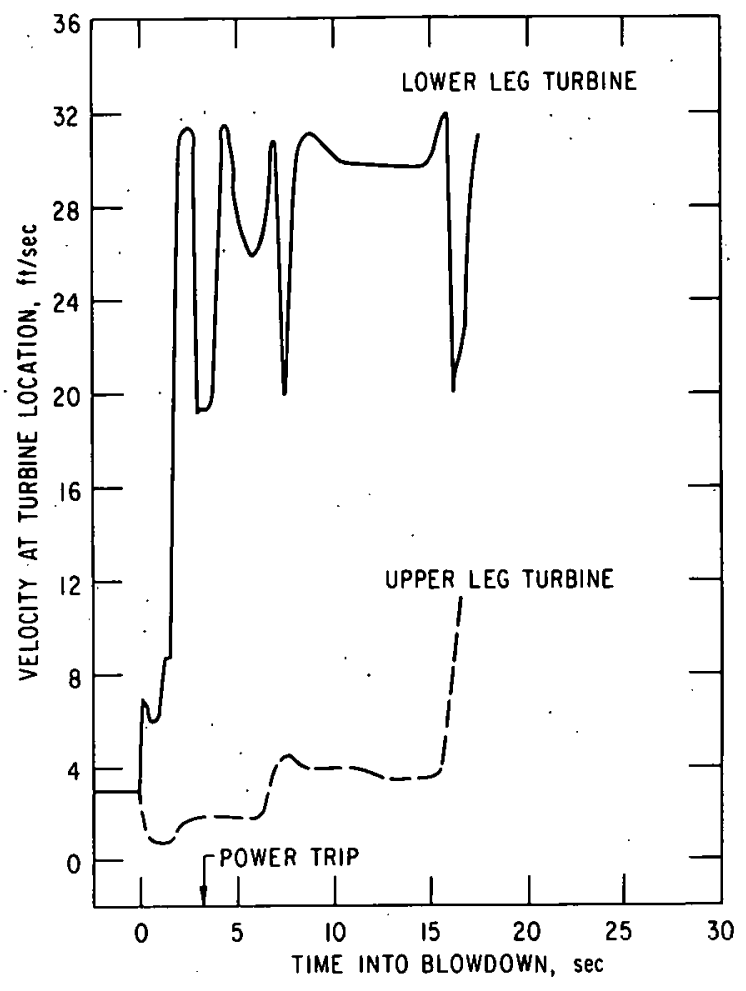

Fig. 43. Turbine Flow Measurement for Run $6 / 9$. Conversion factor: $1_{\mathrm{ft}} \mathrm{\textrm {sec }}=0.305 \mathrm{~m} / \mathrm{s}$. ANL Neg. No. 900-75-499.

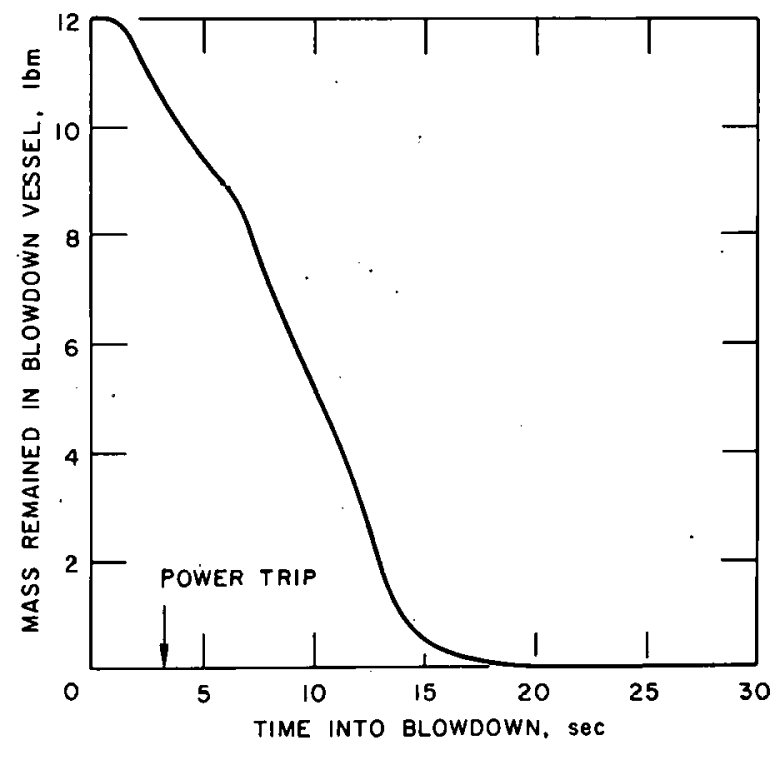

Fig. 44. Mass in Rlnwdnwn Vessel for Run $6 / 9$. Conversion factor: $1 \mathrm{lb} m=0.4536 \mathrm{~kg}$. ANL Neg. No. 900-75-496.

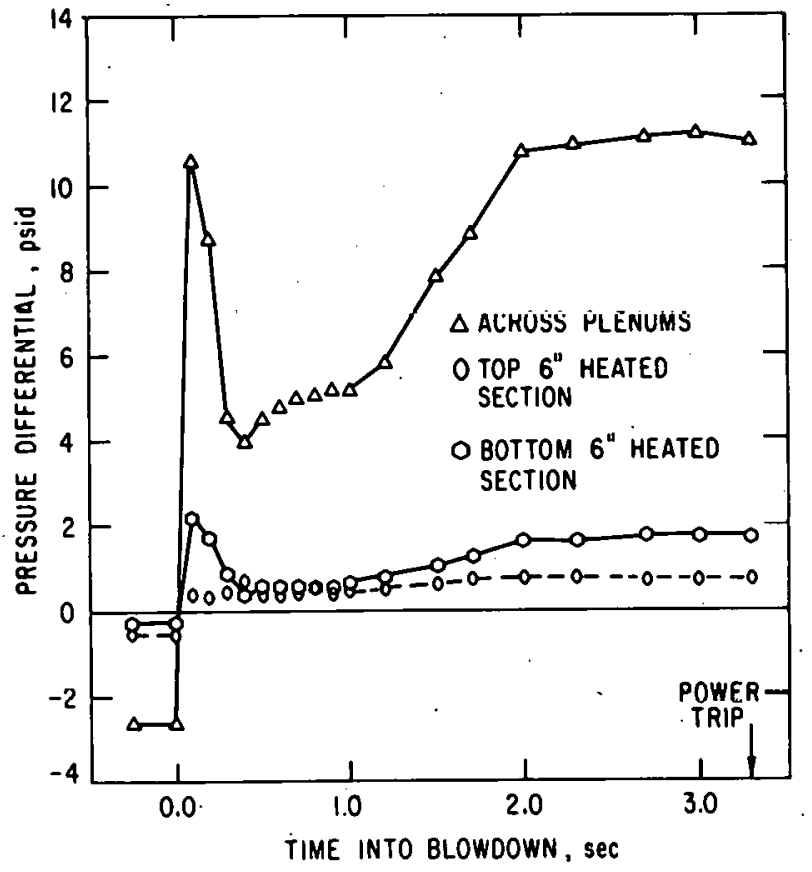

Fig. 45. Pressure-differential Measurement for Run 6/9. Conversion factors: 1 in. $=2.54 \mathrm{~cm} ; 1 \mathrm{psi}=6.895 \mathrm{kPa}$. ANL Neg. No. 900-75-920. 


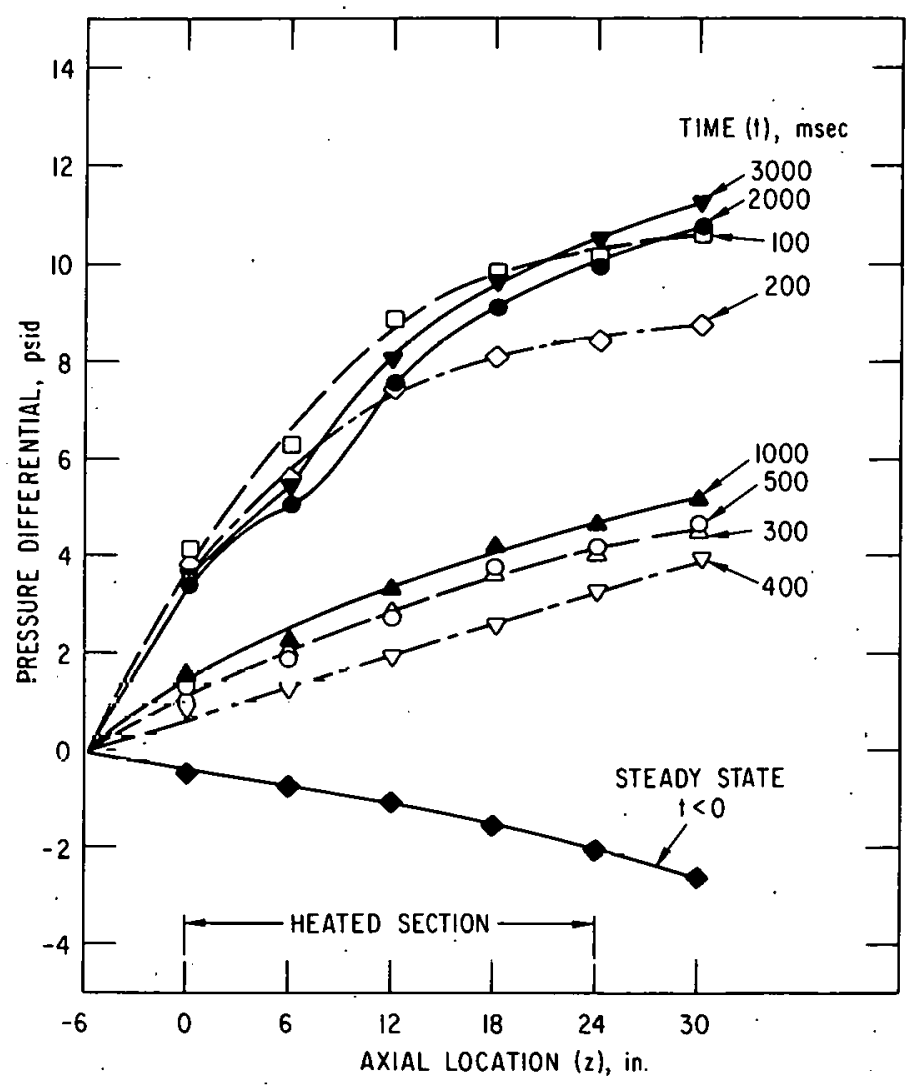

Fig. 46

Axial Pressure Profile during Diabatic Blowdown Run $6 / 9$. Conversion factors: 1 psi $=6.895 \mathrm{kPa} ; 1$ in. $=2.54 \mathrm{~cm}$. ANI Neg. No. 800-75-503.

Fig. 47

Pressure History for Run 6/12. Blowdown volume $\simeq 0.072 \mathrm{ft}^{3}$. Conversion factors: 1 psia $=6.895 \mathrm{kPa} ; \mathrm{t}\left({ }^{\circ} \mathrm{C}\right)=\left[\mathrm{t}\left({ }^{\circ} \mathrm{F}\right)-32\right] /$ $1.8 ; 1 \mathrm{ft} / \mathrm{sec}=0.305 \mathrm{~m} / \mathrm{s} ; 10^{6} \mathrm{lb} \mathrm{m} / \mathrm{hr} \cdot \mathrm{ft}^{2}=$ $1356 \mathrm{~kg} / \mathrm{m}^{2} \cdot \mathrm{s} ; 1 \mathrm{Btuh} \mathrm{hr} \cdot \mathrm{ft}^{2}=3.155 \mathrm{~W} / \mathrm{m}^{2}$. ANL Neg. No: 900-75-416.

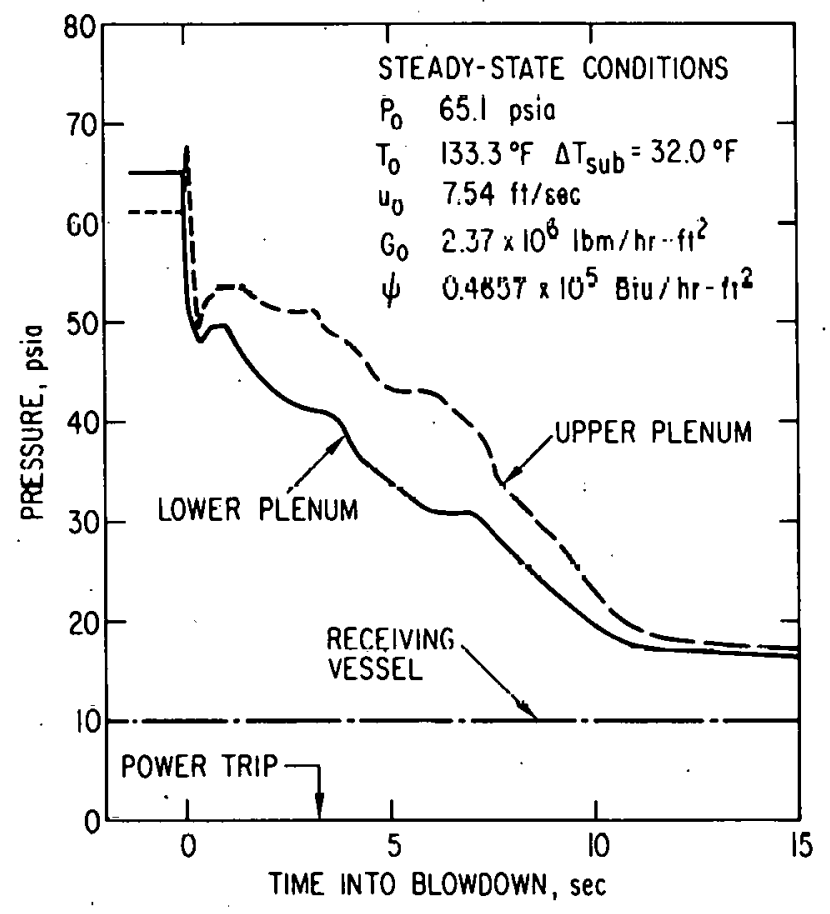




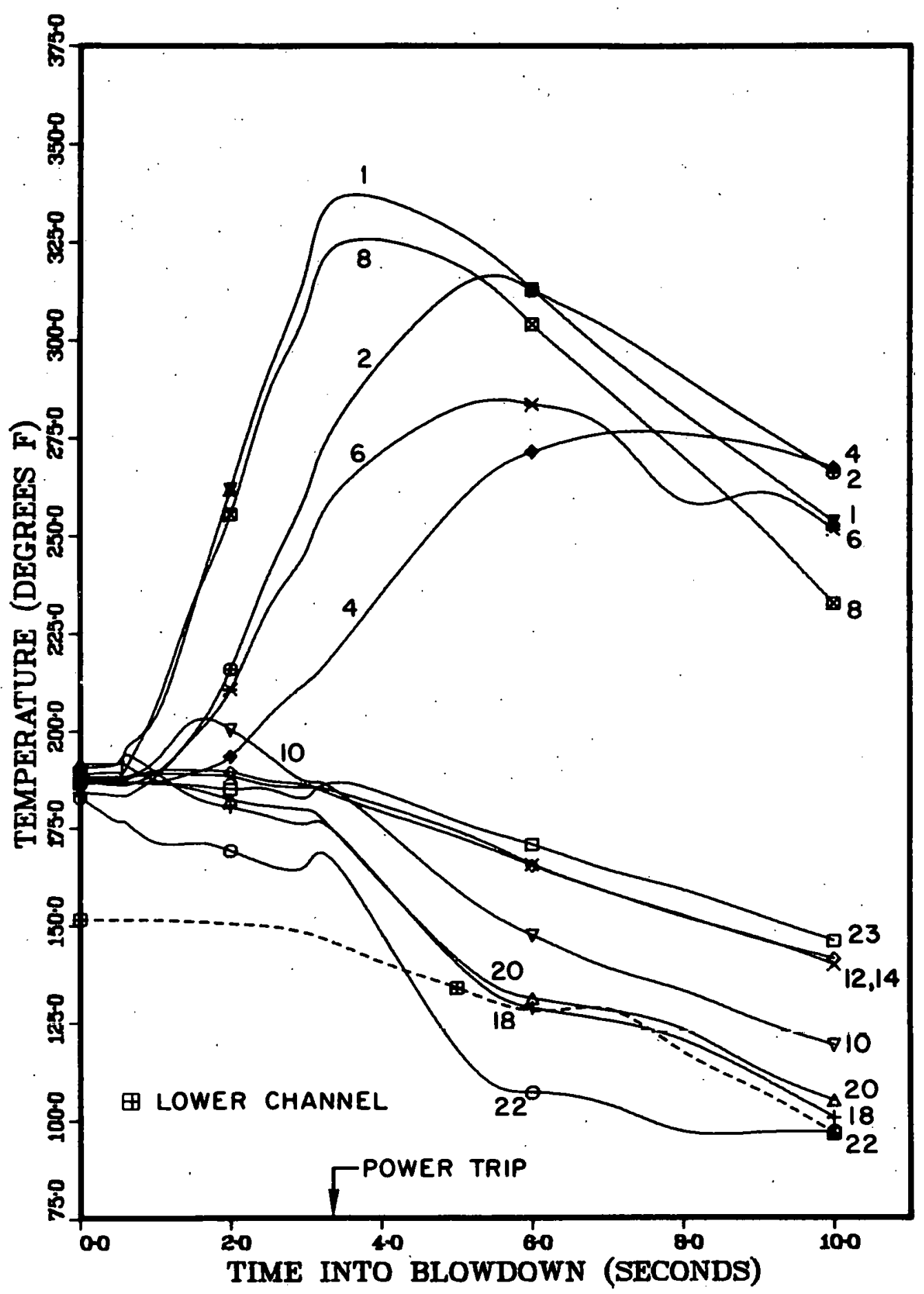

Fig. 48. Temperature History for Run 6/12. Conversion factors: $\mathrm{t}\left({ }^{\circ} \mathrm{C}\right)=\left[\mathrm{t}\left({ }^{\circ} \mathrm{F}\right)-32\right] / 1.8$. ANL Neg. No. 900-75-802. 


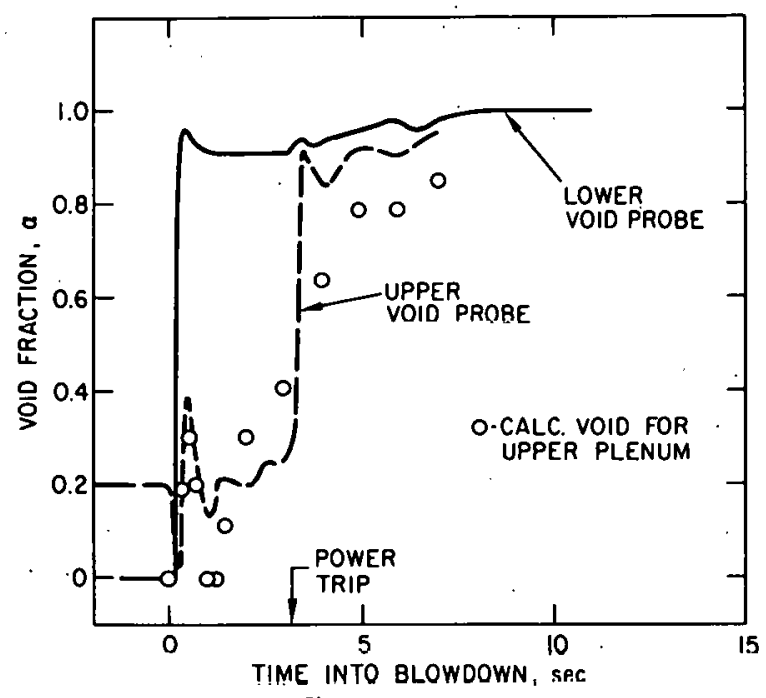

Fig. 49

Void-fraction Measurement for Run 6/12. ANL Neg. No. 900-75-415.

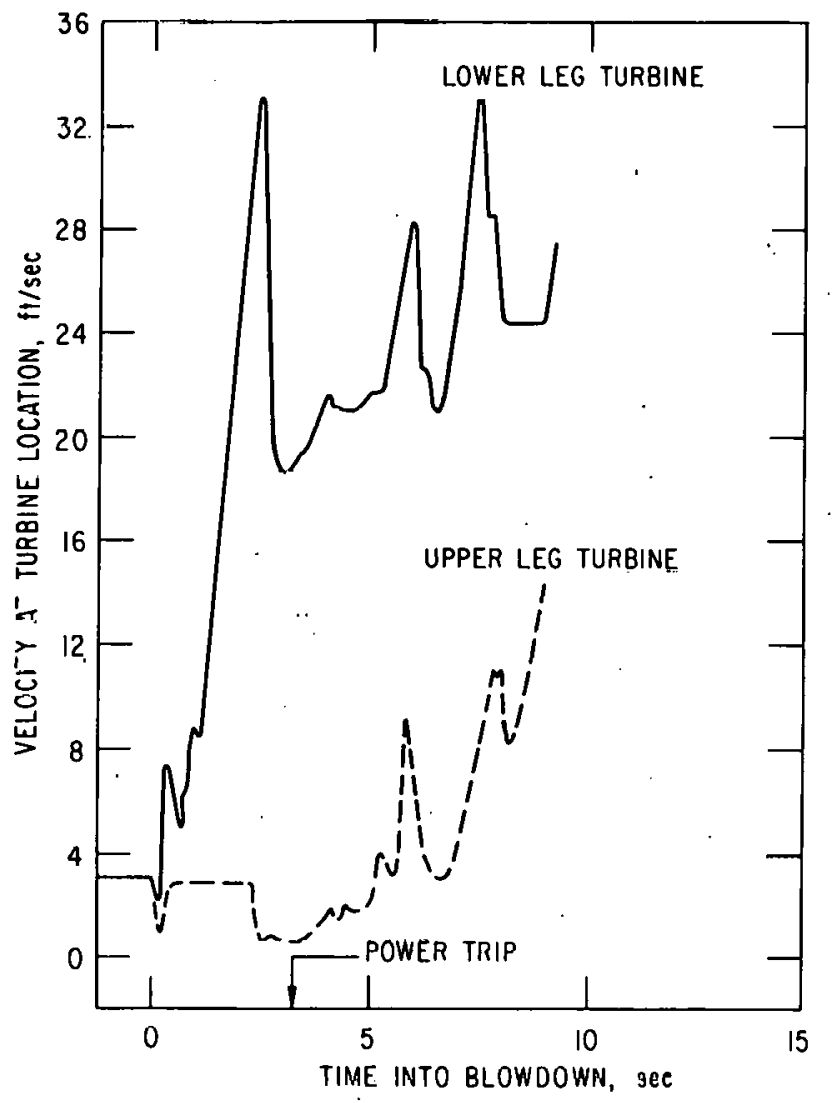

Fig. 50. Turbine Flow Measurement for Run $6 / 12$. Conversion factor: $1 \mathrm{ft} / \mathrm{sec}=0.305 \mathrm{~m} / \mathrm{s}$. ANL Neg. No. $900-75-494$.

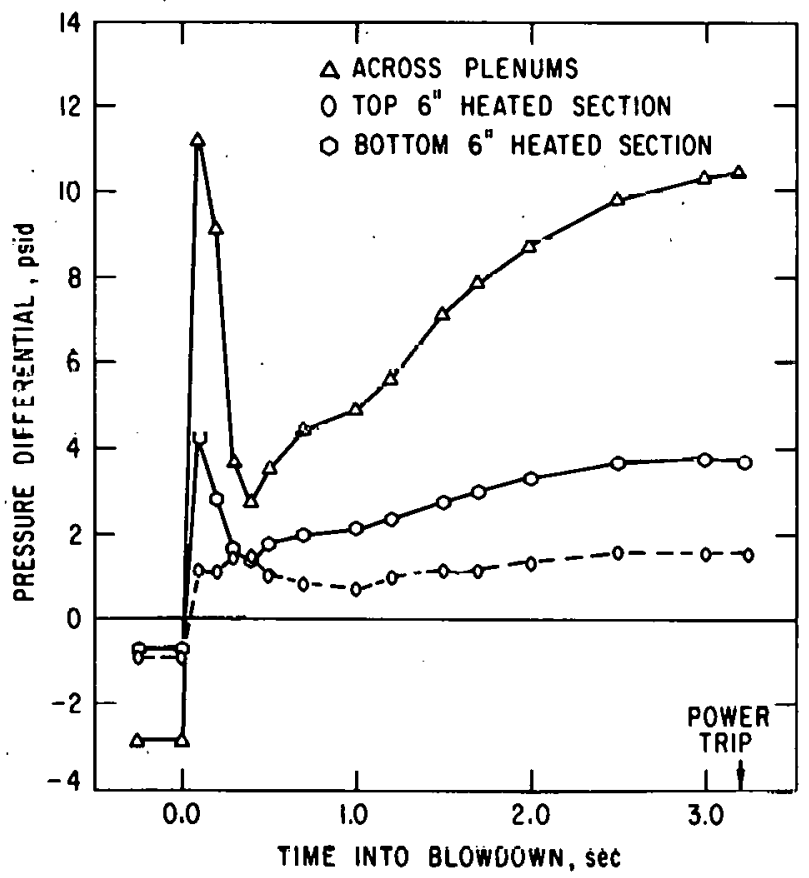

Fig. 51. Pressure-differential Measurement for Run $6 / 12$. Conversion factors: 1 psi $=6.895 \mathrm{kPa} ; 1$ in. $=2.54 \mathrm{~cm}$. ANL Neg. No. 900-75-922. 

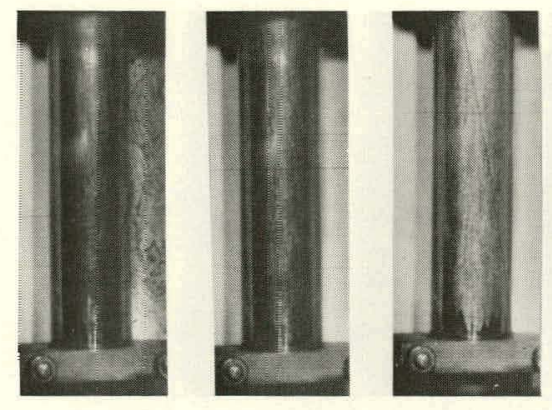

$20 \mathrm{~ms}$
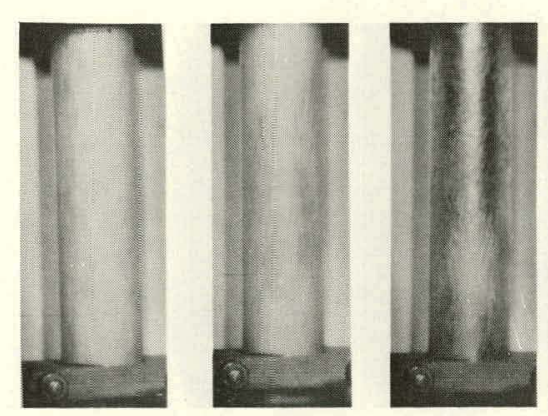

$300 \mathrm{~ms}$

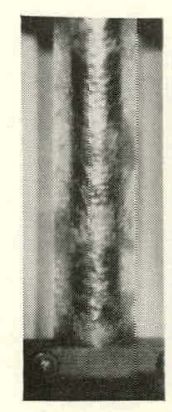

$500 \mathrm{~ms}$
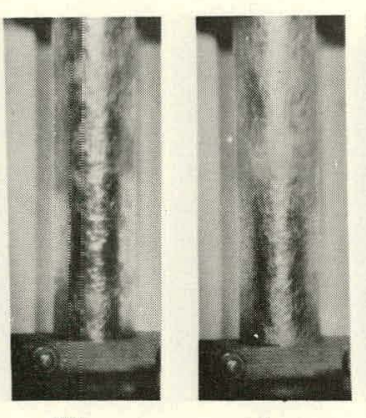
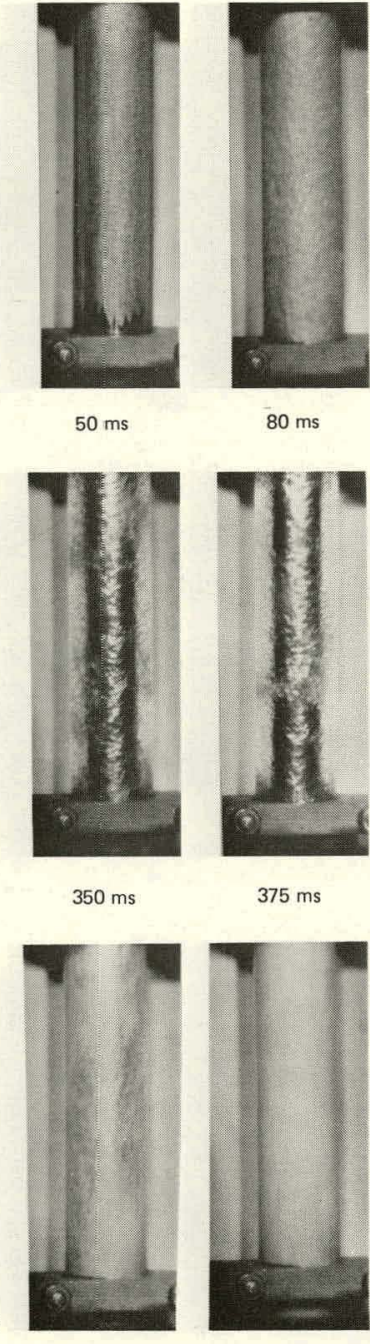

$350 \mathrm{~ms}$

$2 \mathrm{~s}$
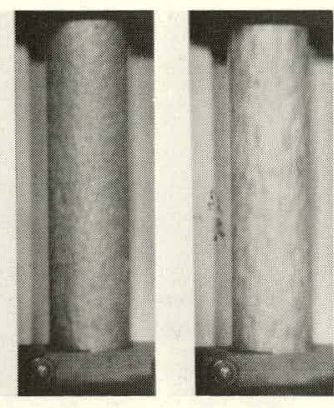

$120 \mathrm{~ms}$
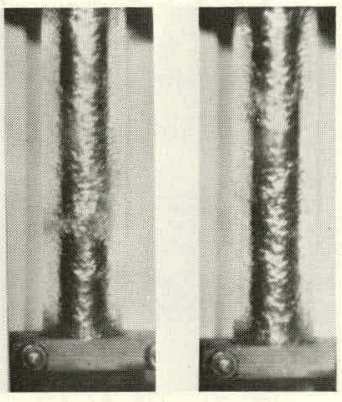

$400 \mathrm{~ms}$

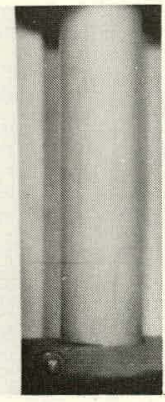

$5 \mathrm{~s}$
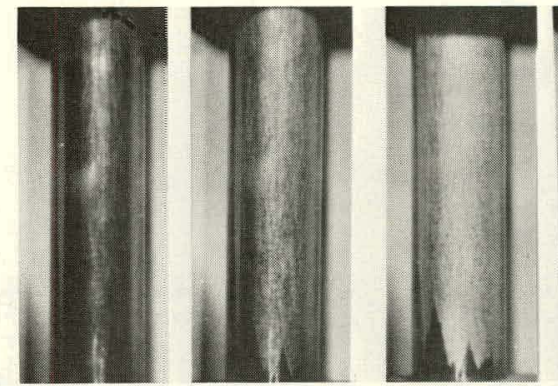

$40 \mathrm{~ms}$

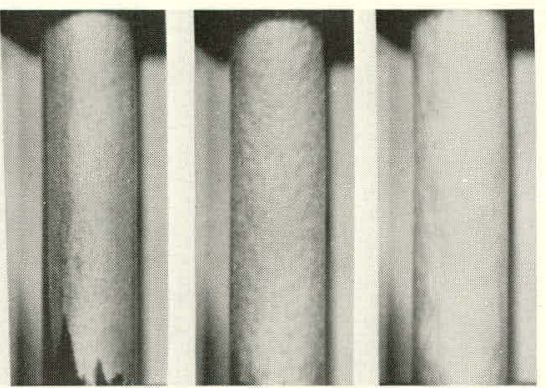

$0 \mathrm{~ms}$

$20 \mathrm{~ms}$
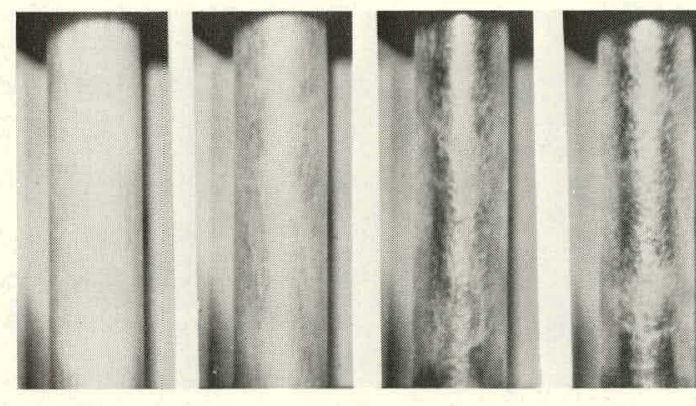

$80 \mathrm{~m}$

$120 \mathrm{~ms}$

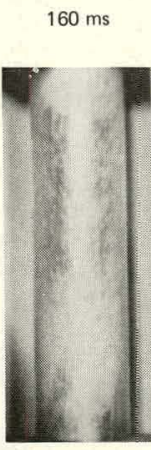

$500 \mathrm{~ms}$

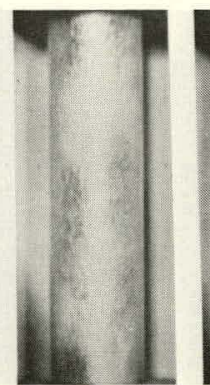

$600 \mathrm{~ms}$

$300 \mathrm{~ms}$

$350 \mathrm{~ms}$

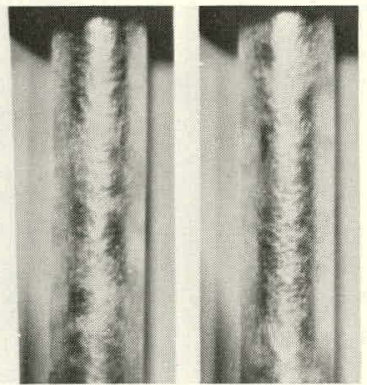

$375 \mathrm{~ms}$

$400 \mathrm{~ms}$

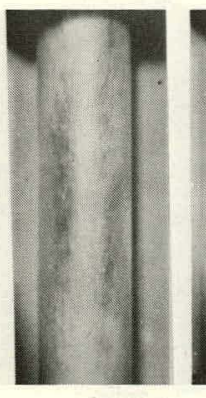

$1 \mathrm{~s}$

$2 \mathrm{~s}$

$5 \mathrm{~s}$

Fig. 53. Selected Prints for Run 6/9. ANL Neg. No. 900-75-325.

Fig. 52. Selected Prints for Run 6/4. ANL Neg. No. 900-75-326. 

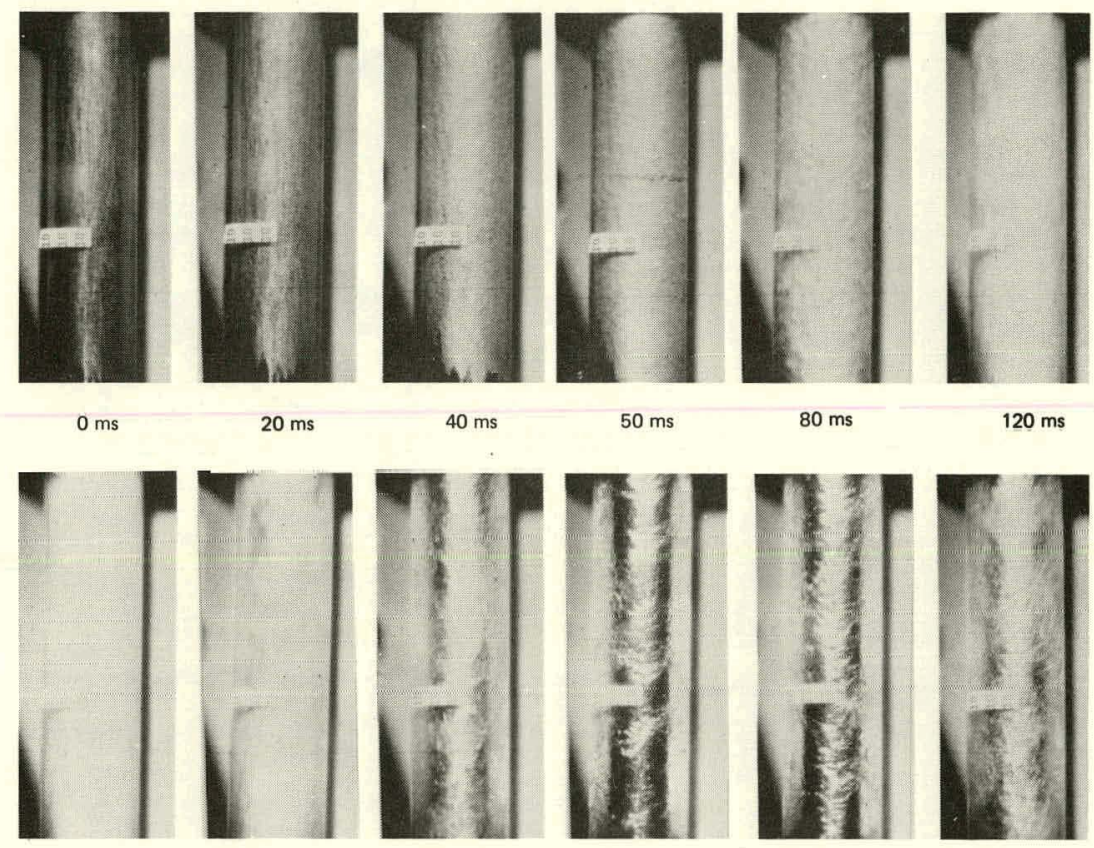

$20 \mathrm{~ms}$

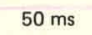

$80 \mathrm{~ms}$

$120 \mathrm{~ms}$

$160 \mathrm{~ms}$
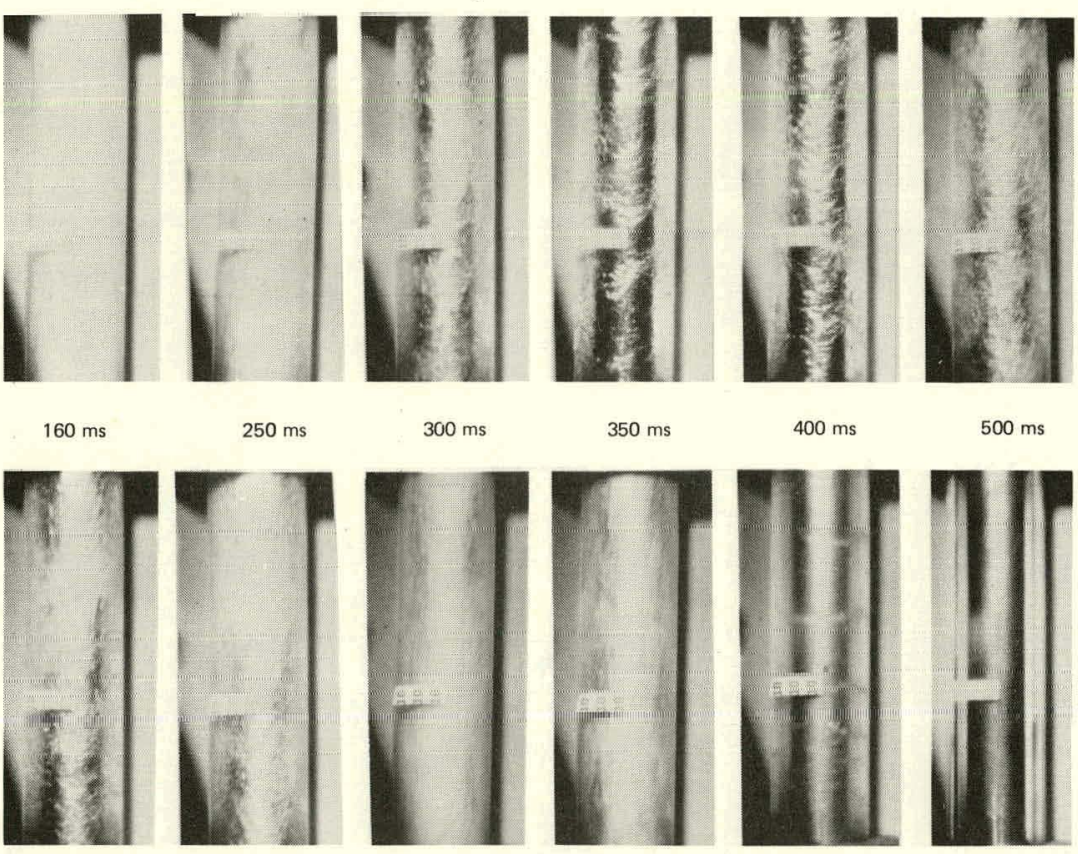

$250 \mathrm{~ms}$

$300 \mathrm{~ms}$

$350 \mathrm{~ms}$

$400 \mathrm{~ms}$

$500 \mathrm{~ms}$

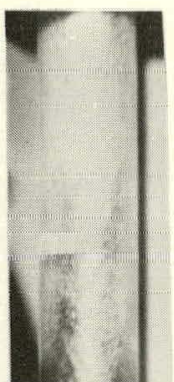

$1 \mathrm{~s}$

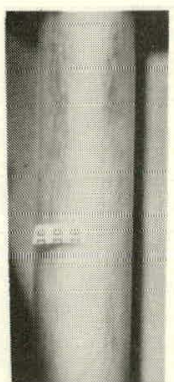

$3 \mathrm{~s}$

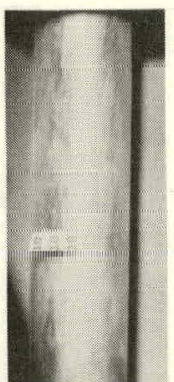

$5 \mathrm{~s}$

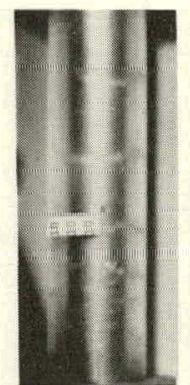

$7.5 \mathrm{~s}$

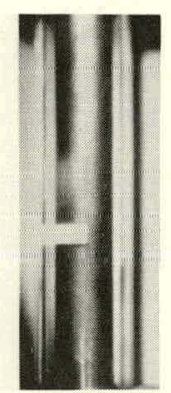

$9 \mathrm{~s}$

Fig. 54. Selected Prints for Run 6/12. A.NL Neg. No. 900-75-327 Rev. 1. 


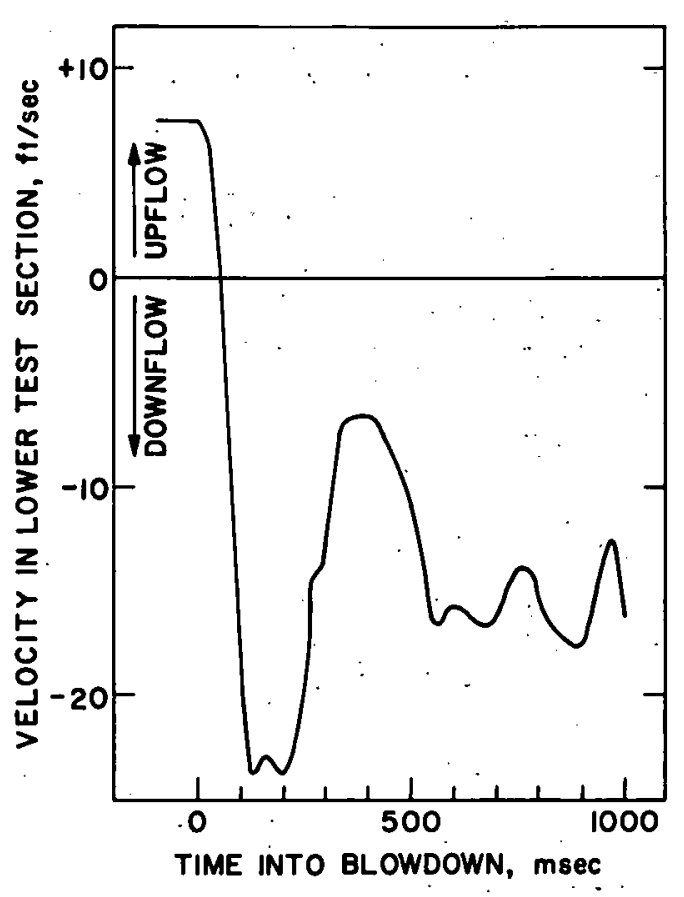

Fig. 55. Velocity Observed in Highspeed Photography during Run $6 / 4$. Conversion factor: $1 \mathrm{ft} / \mathrm{sec}=0.305 \mathrm{~m} / \mathrm{s}$. ANL Neg. No. 900-75-988.

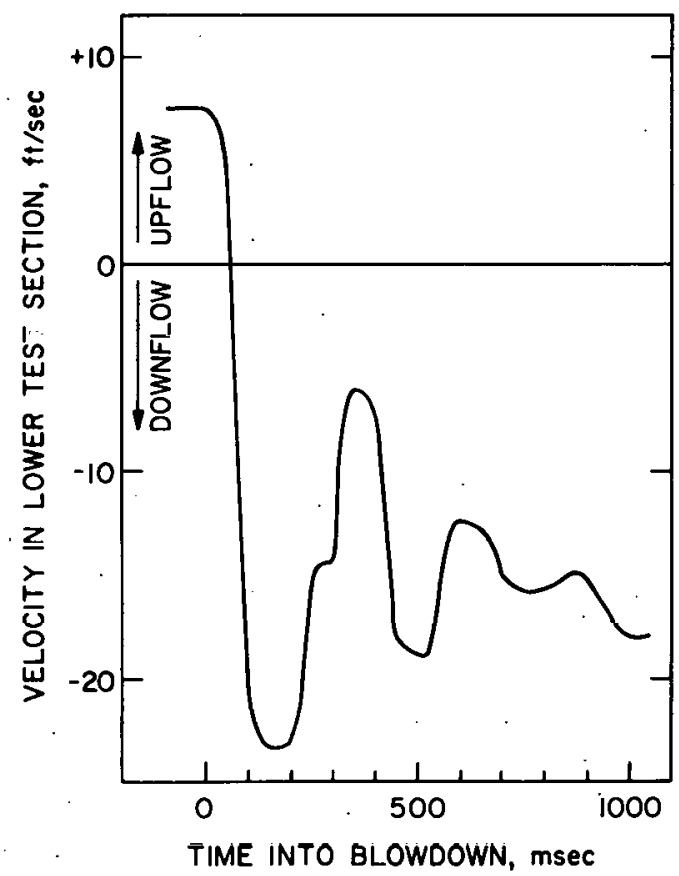

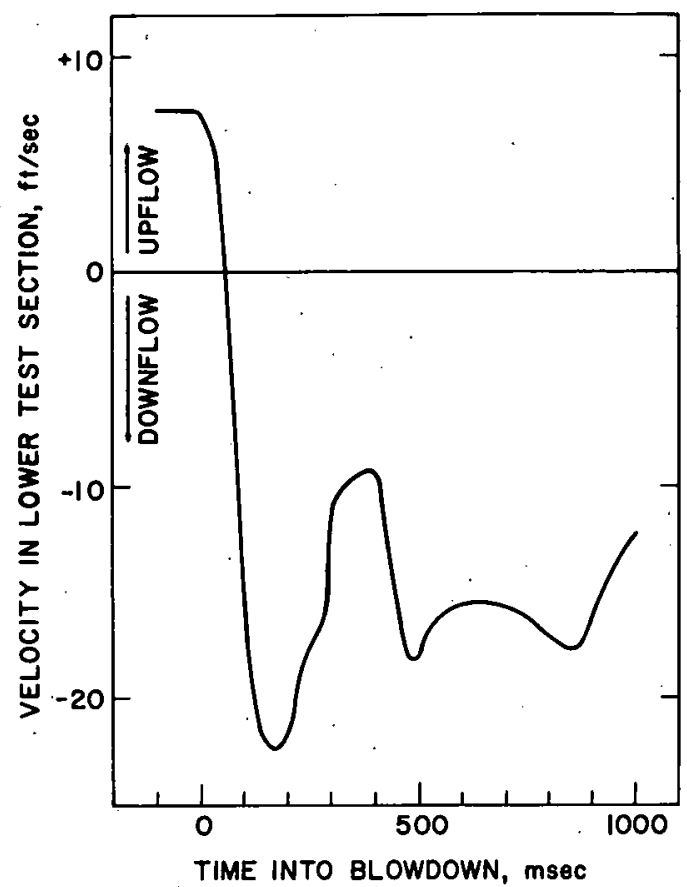

Fig. 56. Velocity Observed in Highspeed Photography during Run $6 / 9$. Conversion factor: $1 \mathrm{ft} / \mathrm{sec}=0.305 \mathrm{~m} / \mathrm{s}$. ANL Neg. No. 900-75-944.

Fig. 57

Velocity Observed in Highspeed Photography during Run $6 / 12$. Conversion factor: $1 \mathrm{ft} / \mathrm{sec}=0.305 \mathrm{~m} / \mathrm{s}$. ANL Neg. No. 900-75-987. 
For all these runs, time to CHF was short ( $400 \mathrm{~ms})$, as shown in Table V. Similar to Run $5 / 29$, temperature excursion was observed only at the bottom $8-10$ in. $(20-25 \mathrm{~cm})$.

TABLE V. Time to $\mathrm{CHF}^{\mathrm{a}}\left(\mathrm{t}_{\mathrm{CHF}}\right)$ for Diabatic Blowdown

\begin{tabular}{|c|c|c|c|c|c|c|c|}
\hline \multirow[b]{2}{*}{ Run } & \multicolumn{7}{|c|}{ Thermocouple Location, in. (cm) } \\
\hline & Jo.: 1 & 2 & 4 & 6 & 8 & 10 & 12 \\
\hline & \multicolumn{7}{|c|}{ Time to $\mathrm{CHF}, \mathrm{s}$} \\
\hline $6 / 4$ & $0.4(1.0)$ & $0.5(1.3)$ & $0.4(1.0)$ & $0.5(1.3)$ & $0.4(1.0)$ & 0.5 & b \\
\hline $6 / 7$ & $0.3(0.8)$ & $0.5(1.3)$ & $0.1 \cdot(1.0)$ & $0.5(1.3)$ & $0.1(1.0)$ & b & b \\
\hline $6 / 12$ & $0.3(0.8)$ & $0.4(1.0)$ & $0.4(1.0)$ & $0.2(0.5)$ & $0.2(0.5)$ & $0.3(0.8)$ & $\mathrm{b}$ \\
\hline
\end{tabular}

$a_{t_{C H F}}$ is defined by Eq. $1 . \therefore$

bNo CHF. 


\section{DISCUSSION}

The experimental results presented in Sec. IV are discussed here. The critical-flow and critical-heat-flux calculations accompanying the discussion are detailed in Appendixes $K$ and $L$. The discussion here is divided into the adiabatic blowdowns, the effect of dissolved gas, and the diabatic blowdowns.

A. Adiabatic Blowdown

$$
\text { 1. Run 4/4-A }
$$

Figure 15 shows the inlet and exit void as measured by the capacitance probes for this short transient. The present interpretation of void fraction from capacitance measurement is simply based on the slug-flow model (see Appendix E). A more advanced calibration will be undertaken to determine the effect of flow patterns on void measurement, but will not be considered in this report. The calculated void, assuming an isentropic expansion based on the measured pressure history with no slip between phases (see Appendix F), is also plotted for comparison. Interestingly enough, the initial peak indicated by the equilibrium calculation was not measured experimentally.

During the initial stage of the unstable growth of a bubble., the inertia of the surrounding liquid and the surface tension control the process, ${ }^{8}$ however, this period is short compared to the thermally controlled stage for the Freon-l1 system under investigation. The latter is limited by the rate of thermal conduction to the bubble liquid-vapor interface. The above observed discrepancy is attributed to the nonequilibrium conditions required for unstable bubble growth. ${ }^{104}$

The measured and calculated void in the lower test section reached $50 \%$ at $\sim 2.5 \mathrm{~s}$, at which time the pressure started to drop and the bulk fluid temperature agreed with the saturation temperature predicted from pressure measurement (see Fig. 16). At such a void fraction, transition to slug-annular flow was evident from the high-speed movies, resulting in a large increase in the liquid-vapor interfacial area. Thus the liquid configuration changed from vapor bubbles growing in a superheated liquid toward a dispersed liquid-vapor mixture that closely approached thermodynamic equilibrium. In other words, the liquid mass or droplet surface temperature was essentially in equilibrium with the vapor because of the large interfacial area available for interphase mass transfer.

Agreement between measured and calculated void fraction is encouraging in this region. Because of the present interpretation, the measured void can be overestimated by as much as $15 \%$ in the annular flow (high-voidfraction) regime (see Fig. E.9 in Appendix E). However, the calculated void is also overestimated, because the actual slip ratio is greater than unity in dispersed flow. 
Figure 16 shows that, after the very short period of subcooled decompression, the fluid was superheated during the pressure recovery period; that is, the system pressure had dropped below the local saturation pressure. The recovery rate was determined by the relative rate of vapor generation and discharge choked flow. A bubble-growth model was suggested to describe this period. ${ }^{104}$ The saturation blowdown that followed lasted until $8 \mathrm{~s}$, at which time the fluid temperature seemed to indicate significant subcooling. Physically this is not possible. Since the flow was adiabatic, the generation of a two-phase mixture at a pressure greater than the saturation pressure could not be due to subcooled boiling. ${ }^{115}$ Rather, nitrogen gas coming out of solution probably occurred. The continued lowering in system pressure facilitated the diffusion of the dissolved gas towards the liquid-vapor interface and its subsequent evaporation. As noted in Sec. V.B below, the contact time between Freon and nitrogen inside the supply vessel at $130^{\circ} \mathrm{F}\left(54^{\circ} \mathrm{C}\right)$ and 75 psia $(0.5 \mathrm{MPa})$ had to be limited to a very short period $(10 \mathrm{~min})$ to eliminate appreciable dissolution of nitrogen. However, this precaution was not observed for the adiabatic and the first two reported diabatic blowdown tests ( $R$ uns $4 / 22$ and $5 / 19 A$ ).

\section{2. $\operatorname{Run} 4 / 9-B$}

For Run 4/9-B, the initial peak in void indicated by the equilibrium calculation was again not measured by the void probe (see Fig. 18), and the same reasoning applies here.

As mentioned in Sec. IV.A, the blowdown fluid was initially al two different temperatures. In this earlier version of the test-loop design, ${ }^{116}$ the blowdown vessel had only one flexible tube joining the flowing loop; as a result, the fluid had to be stored in a stagnant condition. Attempting to maintain the same fluid temperature inside the blowdown vessel and the rest of the flowing loop was difficult. This version of the facility was subsequently modified to the present design, as shown in Fig. 11, after this test. Continuous fluid flow inside the blowdown vessel was allowed during the initial steady-state operation.

The early rise in the measured void resulted from the flashing of hotter fluid $\left[151^{\circ} \mathrm{F}\left(66^{\circ} \mathrm{C}\right)\right]$ in the test section and upper turbine leg. Figure 18 shows that this rise was well predicted by the equilibrium calculation. The void fraction dropped when the colder fluid $\left[138^{\circ} \mathrm{F}\left(59^{\circ} \mathrm{C}\right)\right]$ from the blowdown vessel entered the test section. The later rise in void-fraction development was again well predicted by an equilibrium calculation, based on the initial temperature of the fluid in the blowdown vessel.

Measurements at the lower turbine meter (see Fig. 18) showed a trend similar to that of the lower void probe. If the meter is indicative of the liquid velocity for a two-phase mixture, then a knowledge of the mass flow rate during blowdown enables one to calculate the local void fraction, as described in Appendix G. Figure 17 shows that the mass flow can be found by differentiai ing the mass-decay curve. The void fraction at the turbine estimated using the 
above-mentioned approach was more than $75 \%$ during the period from 5 to $20 \mathrm{~s}$. This is considerably higher than the measured values within the test section, because choking is thought to have existed at the piping immediately downstream of the lower plenum. The associated pressure drop resulted in additional flashing before the two-phase fluid reached the turbine meter.

\section{B. Effect of Dissolved Gas}

With subcooled boiling before blowdown, the vapor will condense as it leaves the heated surface and comes into contact with the bulk fluid. But the presence of a noncondensible gas has been demonstrated to prolong, and in the present case eliminate, the collapse of subcooled bubbles. ${ }^{11,117}$ Dissolved gases affect two-phase-flow heat transfer. ${ }^{114,118,119}$ The presence of gas increases the heat transfer in subcooled boiling. ${ }^{8}$ Gas bubbles can form at the surface and agitate the liquid in the same manner that vapor bubbles do. The first evolution of bubbles occurred at a much lower wall superheat in the presence of dissolved gas for a water-air system. ${ }^{120}$ In fact, bubble evolution had been observed during steady adiabatic flow in the present system while the test loop pressure was still above the saturation value. This phenomenon stimulated the following investigation.

During each run the Freon in the supply vessel was pressurized by nitrogen; thus the rate of nitrogen going into solution had to be examined. Table VI shows the effect of a 1 -hr contact interval between nitrogen and Freon in the supply vessel at $130^{\circ} \mathrm{F}\left(54^{\circ} \mathrm{C}\right)$ and $75 \mathrm{psia}(0.5 \mathrm{MPa})$. It is apparent that nitrogen was exiting from solution in the heated zone, since the exit turbine meter showed a much higher flow than the inlet one under all liquid-equilibrium conditions, indicating the presence of an uncondensed two-phase mixture. Therefore the following precaution was taken to ensure the dissolved gas was kept to a minimum.

TABLE VI. Effect of Prolonged Nitrogen Contact with Freon-11

$\left[130^{\circ} \mathrm{F}\left(54^{\circ} \mathrm{C}\right)\right]$ at Elevated Pressure $[75 \mathrm{psia}(0.5 \mathrm{MPa})]^{\mathrm{a}}$

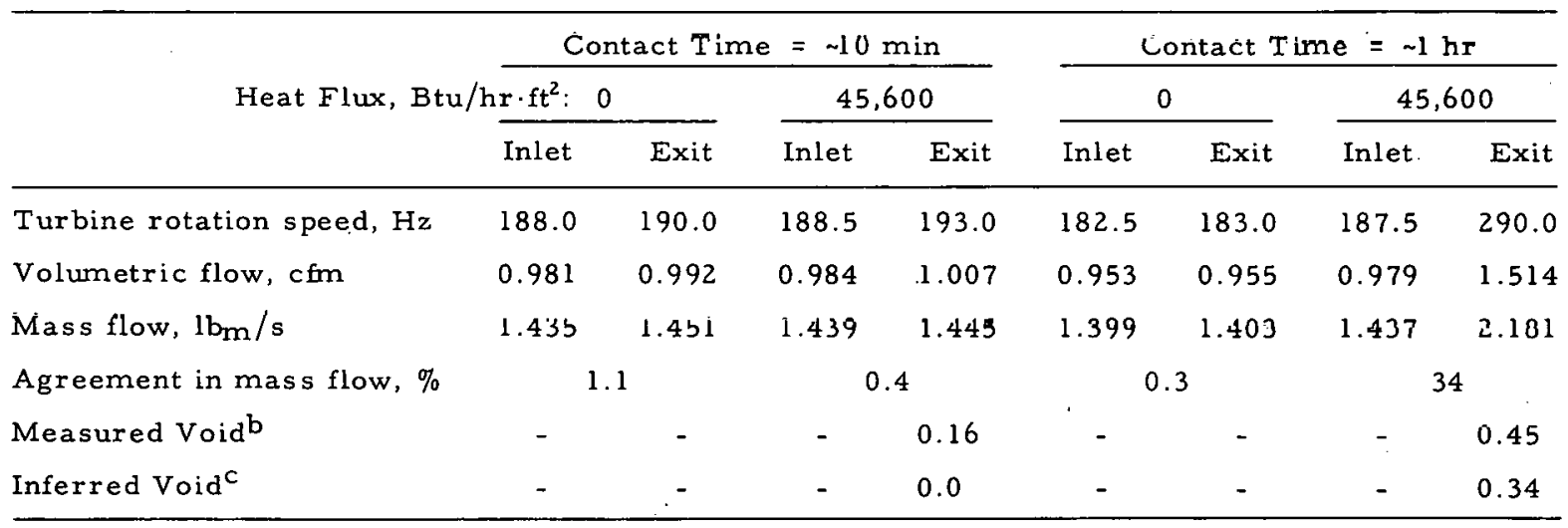

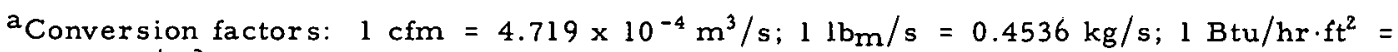
$3.155 \mathrm{~W} / \mathrm{m}^{2}$.

b Capacitance void measurement made $3 \mathrm{in.}(7.6 \mathrm{~cm})$ downstream of heated section.

${ }^{c}$ Calculated void from turbine measurement according to $\alpha_{0}=1-\left(\rho_{i} Q_{i}\right) /\left(\rho_{0} \Omega_{0}\right)$, where subscripts $i$ and o stand for inlet and outlet locations. 
First, the Freon was stored in the receiving vessel under saturation conditions at 10 psia $(68.95 \mathrm{kPa})$ so that the Freon was not in contact with air during the storage period. Second, the Freon was boiled at or above ambient pressure in the supply vessel for $1 / 2$ to $1 \mathrm{hr}$ while constantly vented to atmosphere, thus bleeding off any noncondensible gas coming out of solution before each run. ${ }^{110,111}$ Third, the contact time with nitrogen at operating pressure was kept to a minimum, normally $10 \mathrm{~min}$ before each run. The agreement be tween the inlet and exit flowmeter measurements for this case, as illustrated in Table VI, demonstrates the success of these measures.

C. Diabatic Blowdown

\section{Preliminary Diabatic Tests}

a. Run $4 / 22$. Run $1 / 22$ was conducted with an almost $1-8$ inlet flow stoppage before blowdown initiation. However, efficient cooling was maintained all during this very-low-flow period, as indicated by the heater-wall. temperature. During the inlet flow stoppage, if the fluid in the heated section remained close to saturation in the liquid phase only, the calculated temperature rise of the average bulk fluid was about $40^{\circ} \mathrm{F} / \mathrm{s}\left(22^{\circ} \mathrm{C} / \mathrm{s}\right)$. and if any part of the heater surface was experiencing $\mathrm{CHF}$, a temperature excursion of $80^{\circ} \mathrm{F} / \mathrm{s}$ $\left(44^{\circ} \mathrm{C}\right)$ would result. The measured temperature rise of $7^{\circ} \mathrm{F}\left(3.9^{\circ} \mathrm{C}\right)$ indicates that CHF did not occur and the fluid did not remain in an all-liquid state. But part of the heat was used in raising the bulk temperature of the fluid and the rest as latent heat of vaporization.

The observed pressure rise in the test section resultcd in an increase of about $8^{\circ} \mathrm{F}\left(4.4^{\circ} \mathrm{C}\right)$ in the saturation temperature, which lends support to the above argument. Vapnr generation was ovidont from the uppel vuid probe, which indicated a continuous rise to almost $100 \%$ void just before te pressurization. The existence of countercurrent flow during the low-flow period was inferred.

The above observation tends to support the fact that the heat flux at low flow can be quite high without experiencing $\mathrm{CHF}$ as in pool boiling. ${ }^{65,80}$ For a horizontal flat plate in an unconfined pool boiling, 7.uber.121 Eug gested the following critical-heat-flux correlation:

$$
\varphi_{\mathrm{CHF}}=\frac{\pi}{24} h_{f g} \rho_{g}^{1 / 2}\left[\sigma g\left(\rho_{f}-\rho_{g}\right)\right]^{1 / 4}\left(\frac{\rho_{f}}{\rho_{f}+\rho_{g}}\right)^{1 / 2}
$$

where for $\varphi_{\mathrm{CHF}}$ is $1.2 \times 10^{5} \mathrm{Btu} / \mathrm{hr} \cdot \mathrm{ft}^{2}\left(3.8 \times 10^{5} \mathrm{~W} / \mathrm{m}^{2}\right)$ for Freon-11 al 65 psia $(0.45 \mathrm{MPa})$ and $1.2 \times 10^{6} \mathrm{Btu} / \mathrm{hr} \cdot \mathrm{ft}^{2}\left(3.8 \times 10^{6} \mathrm{~W} / \mathrm{m}^{2}\right)$ for water at $1500 \mathrm{psia}$ (10 MPa).

As shown above, this heat flux is at least three times as large as the operating heat flux. Even though the above equation is not applicable to 
the present confined geometry, Walkush ${ }^{122}$ and Avedisian et al. ${ }^{91}$ have shown that a value of $85-90 \%$ of Zuber's prediction can be expected at low flow and low void fraction in an internally heated annulus with small $\mathrm{L} / \mathrm{D}$.

The heater -wall temperature shown in Fig. 20 indicates that CHF occurred at about $2 \mathrm{~s}$ into blowdown, at which time the upper void measurement had a sharp rise to $100 \%$, indicative of a fluid-depletion condition. Many wall thermocouples were defective due to improper installation and were therefore replaced. The most severe temperature rises were at the lower end, where CHF seemed to occur first, although an equally early CHF onset was found at $\mathrm{TC} 18$ [6 in. $(15 \mathrm{~cm})$ from the top], but this was rewet after $\sim 1 \mathrm{~s}$.

b. Runs 5/19A and 5/29. For Runs 5/19A, 5/29, and all others, no CHF was observed upon flow reversal. The flow-reversal period is defined as the time from the initiation of decompression until the start of downflow. In the three runs taken with high-speed photography, this reversal period was observed to last 50-60 ms. Efficient cooling was maintained during this time, as the heater wall thermocouples showed a slight drop in temperature.

Similar to Run $4 / 22$, the start of temperature excursion in Run 5/19A coincided with the sharp rise in upper-channel void development (see Fig. 25). A void fraction of over $90 \%$ indicated that the channel was nearly depleted of liquid coolant, and as a result, "dryout" occurred. The propagation of the dryout front for $R$ un 5/19A was quite smooth, as shown in Fig. 26.

In $\mathrm{R}$ un 5/19A, a very small temperature excursion appeared at $\mathrm{TC} 1$ [ $1 \mathrm{in} .(2.54 \mathrm{~cm})$ from the lower end] shortly after flow reversal, but rewetting occurred in $\sim 1 \mathrm{~s}$. In Run 5/29, inception of CHF occurred twice (see Fig. 28). The early temperature excursion was more pronounced as temperatures above $400^{\circ} \mathrm{F}\left(204^{\circ} \mathrm{C}\right)$ were measured. However, only the bottom third of the heated zone experienced $C H F$, and rewetting quickly took place at the 8 -in. location and propagated downstream. The time to first CHF was about the same at all the CHF locations ( $400 \mathrm{~ms}$ for Run 5/29), as shown in Fig. 32 . The occurrence of the second $C H F$ agail coincidod with the upper void probe, measuring close to $100 \%$ void. The upper turbine meter also showed a rapid rise (see Fig. 30), indicating flow of high-quality vapor. Further, the mass remaining in the blowdown vessel, as sensed by the weight transducer, was nearly zero at this time. This "dryout" front followed the same kind of locus as in Run 5/19A (see Fig. 32), but the rate of propagation was faster. Unlike the second CHF, the first CHF requites further discussion (see Sec. V.C.3 belnw).

\section{Effect of Bubble Growth in the Decompression Process}

As mentioned in Sec. V.A, the bubble-growth rate affected the initial decompression characteristic. This is understandable, since the system pressure would drop to the ambient pressure if it were not for the inception of vaporization of the hot liquid. For adiabatic blowdown, nucleation sites in the 
form of surface cavities are activated as a result of decompression. With Freon-11 at operating temperatures and pressures, the bubble-growth rate is essentially limited by the heat conduction to the liquid-vapor interface; consequently, the actual pressure must.drop below the PSAT value, causing some superheat to occur. Hence the initial rise in calculated equilibrium void fraction at the lower channel was not experimentally observed.

This phenomenon of bubble growth as a result of the thermodynamic nonequilibrium state of the fluid has been reported in other adiabatic blowdown experiments. ${ }^{82,104}$ But for the diabatic blowdowns, where subcooled bubbles were present initially, thermodynamic equilibrium was more closely approached during the early phase of the blowdown. The different characteristics associated with adiabatic and diabatic blowdown are best illustrated by showing the system pressure and void fraction as in Figs. 58 and 59. For the diabatic case, the system pressure dropped to the saturation pressure corresponding to the exit fluid temperature in the upper plenum, whereas for the adiabatic case, an undershoot in pressure was observed. The immediate jump to $.90 \%$ void in Lhe lower channel was characteristic of the diabatic case. This was due to the large vapor generation during flow reversal accompanying the depressurization. Thermodynamic equilibrium void was estimated at the upper channel for the diabatic blowdown. The isentropic expansion was thought to hold, since the fluid underwent decompression and flow reversal under adiabatic conditions because the upper turbine leg and upper plenum were well insulated. The prediction was encouraging, since a slug-flow model had been used in the interpretation of the measurement.

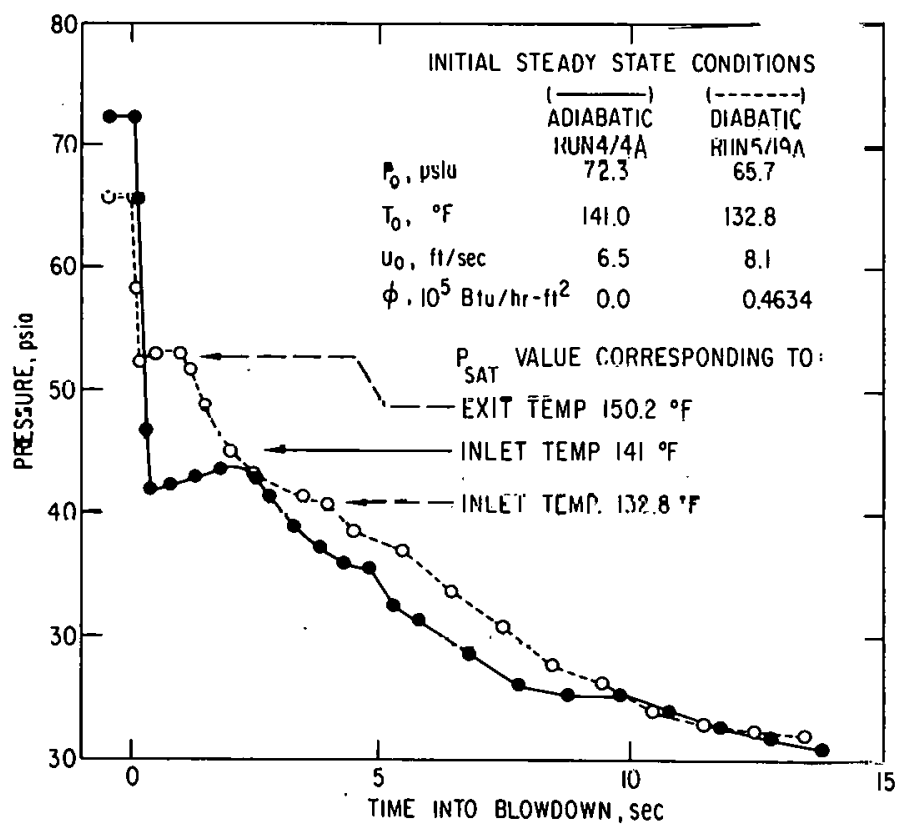

Fig. 58. Pressure Histories for Adiabatic and Diabatic Blowdowns. Conversion factors: $1 \mathrm{psi}=$ $6.895 \mathrm{kPa} ; \mathrm{t}\left({ }^{\circ} \mathrm{C}\right)=\left[\mathrm{t}\left({ }^{\circ} \mathrm{F}\right)-32\right] / 1.8 ; 1 \mathrm{ft} / \mathrm{sec}=$ $0.305 \mathrm{~m} / \mathrm{s}: 1 \mathrm{Btu} / \mathrm{hr} \cdot \mathrm{ft}^{2}=3.155 \mathrm{~W} / \mathrm{m}^{2}$. ANL Neg. No. 900-75-423 Rev. 1.

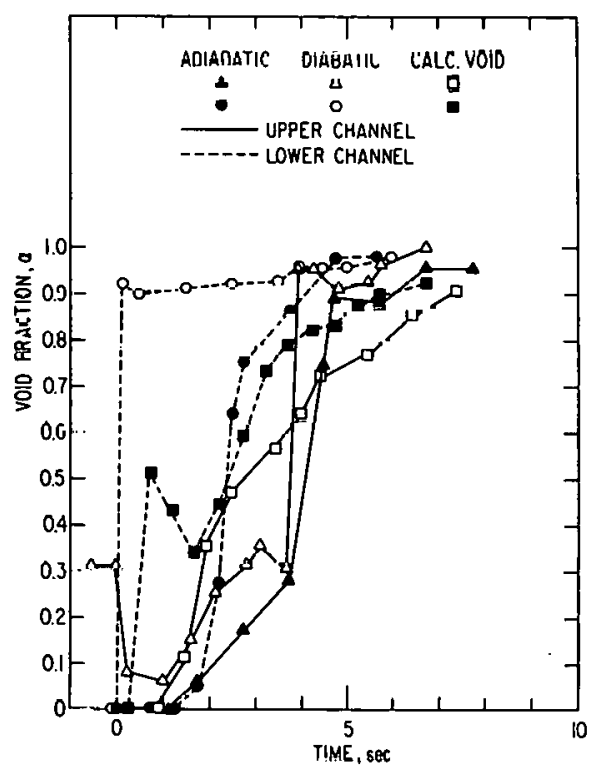

Fig. 59. Void Fractions for Adiabatic and Diabatic Blowdowns. ANL Neg. No. 900-75-421. 
The success of this prediction is further demonstrated in the diabatic blowdown Run 6/12 (see Fig. 49), where the very early void development was well followed by the calculation. This was expected if the system approached thermodynamic equilibrium. The upper-void probe [located 3 in. $(7.6 \mathrm{~cm})$ above the heated zone] indicated the presence of subcooled bubbles in the channel exit during steady-state operation. However, these bubbles were soon condensed before reaching the upper turbine location, most probably in the upper plenum, where more mixing occurred. The existing subcooled bubbles in the upper test-section channel therefore acted as nucleation sites where interphase mass transfer took place during the early phase of blowdown.

\section{Diabatic Tests with High-speed Photography}

The results of the three diabatic blowdown tests were presented in Figs. 34-51. Selected prints showing the flow regime during the early blowdown phase are presented in Figs. 52-54. This series of tests ( $R$ uns 6/4, 6/9, and $6 / 12$ ) was aimed at studying the effect of blowdown volume on time to CHF.

With the help of high-speed photography, the flow-reversal period was observed to last 50-60 ms. The upflow decayed as soon as depressurization started. The selected prints show that, as the flow slowed down, bubble density on the heating surface increased rapidly. Vigorous vaporization oc curred during downflow, as seen from prints at $80 \mathrm{~ms}$, and the high-void mixture was swept out of the heated channel at an accelerating speed, up to $23 \mathrm{ft} / \mathrm{s}$ $(7 \mathrm{~m} / \mathrm{s})$ (see Figs. 55-57). The lower-void probe showed an immediate jump to high void fraction, qualitatively in agreement with the results of high-speed photography. However, this high-velocity flow dropped off at around $250 \mathrm{~ms}$, leading to the development of an annular flow pattern, which, judging from the pictures, lasted until $500 \mathrm{~ms}$ (see Figs. 52-54).

During this period, considerable slip between liquid and vapor phases was observed; roll waves frequently passed along, while a few smaller diuplets travclcd down the sore at a much higher velocity. Wavy liquid films adhered to the outer unheated wall, although it is impossible to judge from the motion pictures whether a liquid film was also present on the heated wall. According to the thermocouples at the heater -wall location, critical-heat flux conditions experienced at around $300 \mathrm{~ms}$ (see Table V) coincided with the time of appearance of annular flow. Thus, the heater wall where pictures were taken was inferred to be dry, and hence the temperature excursion. Considering the uncertainty in determining the time to $\mathrm{CHF}$, we can conclude that no difference was observed among these three runs with different blowdnwn volumes.

The temperature excursion in the se runs continued until the power tripped. The flow pattern after $500 \mathrm{~ms}$ was uncertain when judged from the pictures, due to the presence of liquid film on the inner wall of the transparent shrnil. ' With the measured high void $(>80 \%)$ at the lower end of the channel, dispersed or mist flow is probably predominant. The entrained liquid droplets 
on impinging onto the dry wall could be vaporized, but the heat removal is apparently insufficient to cool the heated surface. Rewetting by axial conduction ${ }^{1}$ occurred during the preliminary test, $R$ un $5 / 29$, as the liquid rewetting front that existed above the 8 -in. $(20-\mathrm{cm}$ ) location propagated downward (see Fig. 33). Rewetting also took place at the 8 - and 6 -in. $(20-$ and $15-\mathrm{cm})$ locations in Run $6 / 9$ and at the $10-\mathrm{in} .(25-\mathrm{cm}$ ) location in Run 6/12 before power trip (see Figs. 41 and 48 ).

At about $100 \mathrm{~ms}$, the upper-plenum pressures all showed spikes. This was observed after the valving adjustment, as mentioned in Sec. IV.C. These pressure spikes are perhaps due to the acoustic phenomena associated with the closing of the downstream valve SW3. The rise is due to the compression wave traveling down the upper turbine leg into the test section, where a rarefaction wave was sent back causing the pressure to drop and the flow to reverse.

The total pressure drop is the summation of the momentum, frictional, and hydrostatic pressure drop: ${ }^{8}$

$$
\Delta \mathbb{P}_{\mathrm{T}}=\Delta \mathbb{P}_{\mathrm{M}}+\Delta \mathbb{P}_{\mathrm{fric}}+\Delta \mathbb{P}_{\mathrm{z}}
$$

Near the lower end of the annular channel, the momentum pressure drop dominates, as shown in Fig. 46. For low-quality flows $(x \simeq 0)$, the momentum pres sure drop in a constant-area channel may be approximated ${ }^{115}$ by

$$
\Delta \boldsymbol{P}_{M}=\frac{G^{2}}{\rho_{f}}\left(\frac{1}{1-\alpha_{2}}-\frac{1}{1-\alpha_{1}}\right),
$$

where $\alpha_{2}$ and $\alpha_{1}$ are the void fractions at axial lucations 2 and 1 .

In the present condition prior to $\mathrm{CHF}$, vigorous vaporization is taking place during the decompression, as indicated by the significant increase in void fraction measured at the lower void probe. As a result, the momentum pressure drop increases as the two-phase mixture moves downstream. Hence the pressure profile exhibits an increasing negative slope (see Fig. 46), indicative of acceleration. Exception was found during the interval 300-500 ms, when a more linear profile was observed. This coincides with the observance of the annular flow of low velocity (see Figs. 55-57).

Because the steepness of the pressure profiles is characteristic of the region upstream from a choking location, ${ }^{115}$ the possibility of choking cannot be overlooked. The results of the critical-flow-rate calculation are presented in Appendix K. The calculation was made at $200 \mathrm{~ms}$, since the velocity then was observed to be highest. The flow decay promoted at about $300 \mathrm{~ms}$ was first thought to be caused by choking at the exit of the test section. But the calculation in Appendix $\mathrm{K}$ indicates that the flow was far away from choking at the lower test section. The choked location was then assumed to be at the lower 
stainless steel cross, where the three outlet tubes from the lower plenum merged. It had a cross-sectional flow area of $1.98 \mathrm{~cm}^{2}$, followed by an abrupt expansion to a $2.22-\mathrm{cm}$-ID tube. The homogeneous, nonequilibrium, compressible-flow equation can be approximated for saturated liquid in terms of the critical pressure ratio $\eta$ as ${ }^{124}$

$$
G=\left[2 \rho_{f} p(1-\eta)\right]^{1 / 2} \text {, }
$$

where $\mathcal{P}$ refers to the stagnation pressure.

The fluid in the lower plenum was discharged first at subcooled condition during blowdown. The critical pressure ratio is about 0.8 at zero quality. ${ }^{124}$ With Eq. 5, a volumetric discharge rate of $0.069 \mathrm{ft}^{3} / \mathrm{s}\left(0.021 \mathrm{~m}^{3} / \mathrm{s}\right)$ was calculated at the throat, i.e., the cross. This may be compared with the vapor generation $r$ ate in the heated channel as given by

$$
Q_{v}=\frac{\varphi \pi D L_{h}}{h_{f g}}\left(v_{g}-v_{f}\right)
$$

A value of $0.066 \mathrm{ft}^{3} / \mathrm{s}\left(0.020 \mathrm{~m}^{3} / \mathrm{s}\right)$ was calculated alone using Eq. 6 , neglecting the effect of flashing caused by pressure drop and possible condensation in the lower plenum. The actual rate of vapor generation was higher and, in fact, exceeded the discharge rate at the throat. Consequently, the sys tem pressure was observed to rise. This has also been reported by Hicken et al. ${ }^{71}$ in the small-break blowdowns. The rise in lower-plenum pressure then caused the flow retardation observed at $300 \mathrm{~ms}$. The accompanying velocity decay was thought to cause the CHF onset in the lower end of the heated section. The local occurrence of CHF then cut off the heat transfer to the fluid, and, hence, the total rate of vapor generation was lowered. Subsequently the velocity picked up, as observed in the high-speed photography, because of the reduced vapor production and the increasing volumetric flow $r$ ate at the limiting area.

During the initial steady-state upflow, the enthalpy profile would increase linearly from bottom $\left(h=h_{i}\right)$ to top $\left(h=h_{i}+\Delta h\right)$. The enthalpy at the top would be slightly higher during the upflow decay period after blowdown initiation. Assuming a linear rate of mass decay during flow reversal, the exit enthalpy at stagnation would only be $\Delta \mathrm{h} / 6$ higher, about $2 \%$ of the local enthalpy. This enthalpy peak is calculated to reach the lower heated zone in about $1 \mathrm{~s}$ based on the integrated velocity curve and measured void, but $\mathrm{CHF}$ had occurred much earlier in time.

Estimation of critical heat fluxes is presented in Appendix L. The results, however, have to be regarded with caution since the CHF correlation used was originally developed at a higher pressure range (in terms of density ratio). Further, the correlation is used in terms of inlet subcooling or quality and not of the local parameters. Table XIII (in Appendix L) shows a number of cases. The critical-heat-flux ratio (CHFR, also known as DNBR) was 1.75 
during steady-state operation (case 1). The occurrence of the early CHF at $\sim 300 \mathrm{~ms}$ was at a CHFR of 0.91 , well within the $\pm 15 \%$ accuracy of the correlation (case 6).

In $R$ un 5/29, where the early CHF was rewet, a higher mass velocity was measured by the weight transducer at $3 \mathrm{~s}$ in comparison with $\mathrm{Runs} 6 / 4$ and 6/9, for which no complete rewetting occurred (case 2 versus case 5). Thc corresponding CHFR's were 1.01 and 0.94 , respectively. A higher mass flow caused the rewetting in Run 5/29. After rewetting, CHF was predicted with a CHFR of 0.91 at $20 \mathrm{~s}$ (case 3), but was not observed. Most probably the inaccuracy of the correlation increases with decrease in pressure and the density ratio decreases sharply with pressure below 50 psia ( $345 \mathrm{kPa}$ ), as shown in Fig. J.1. The late (second) CHF occurred at a CHFR of 0.79 only (case 4). Hence, because of the aforementioned difficulties, we cannot conclude frnm the above discussion that steady-state $\mathrm{CHF}$ correlation is conservative when used in a transient situation.

\section{SUMMARY AND CONCLUSIONS}

Experimental data have been presented for the blowdown of a small scale facility using Freon $-1 \mathrm{l}$ at $130^{\circ} \mathrm{F}\left(54^{\circ} \mathrm{C}\right)$ and $65 \mathrm{psia}(448 \mathrm{kPa})$. A transparent, annular test section, with its inner tube heated, was used to study the onset of critical heat flux during blowdown with flow reversal. Flow-regime transition was observed with high-speed photography.

An analysis of the experimental data leads to the following conclusions.

1. A l-hr contact time betwcen Freon-1 l and nitrogen at $130^{\circ} \mathrm{H}\left(54^{\circ} \mathrm{C}\right)$ and 75 psia $(0.5 \mathrm{MPa})$ greatly affected the steady-state subcooled-boiling initialupflow conditions. Nitrogen gas was exiting from solution in the heated zone. Special precaution had to be taken to ensure that the dissolved gas was kept to a minimum.

2. Delay in bubble growth was observed in the adiabatic blowdown. This was caused by the nonequilibrium conditions required for unstable bubble growth. For the diabatic runs, thermodynamic equilibrium was more closely approached in the test section during the early phase of blowdown.

3. CHF did not occur immediately during the flow decay in an approximately 60 -ms reversal period.

4. The first or early CHF, which occurred at about $400 \mathrm{~ms}$, was not affected by the blowdown volume. An annular-flow pattern (with vapor adjacent to the heated wall and liquid at the unheated wall) appeared at the onset of CHF as best judged by the photographic results. There was no sign of CHF propaga. tion, and its occurrence was restricted to the bottom third of the heated channel. 
5. For some cases, the early CHF was rewet and a second CHF was observed at near depletion of liquid in the channel. This strongly suggests a dryout mechanism, and the dryout front was found to propagate smoothly upward.

\section{RECOMMENDATIONS FOR FUTURE STUDIES}

The following is recommended for further studies in the present facility:

1. Due to the slow-response nature of the strip-chart recorders, the present recording system for void and turbine meter is not adequate. Visicorder or magnetic-tape recording units will be used to record all transient signals.

2. The solenoid valves (SW1, SW2, and SW3) will have to be synchronized to avoid nonrëproducible results. Rupture-disk assemblies may offer good alternatives.

3. Pressure measurement should be made downstream of the test section to determine the exact choking plane during blowdown.

4. The difference between inlet and outlet breaks can be examined. In particular, a simultaneous inlet and outlet break (double-ended break) could result in a flow stagnation located in the heated channel.

5. The effect of break area on time to CHF should be investigated.

6. Other test-section geometries can be studied to determine the effect on flow regime and CHF.

7. A test section capable of operating at higher pressures and temperatures can be installed. 


\section{APPENDIX A \\ Data for Single-phase Friction Pressure Drop}

Pressure drop and fluid friction associated with the isothermal flow of water at $70-190^{\circ} \mathrm{F}\left(21-88^{\circ} \mathrm{C}\right)$ through the present concentric annular test section* with radius ratio of 0.787 was obtaincd by measuring the static pressure drop. Data are presented for laminar, transition, and turbulent flow covering a Reynolds number (based on hydraulic or equivalent diameter) range from 20 to 60,000 . An inclined manometer using 1.75 Meriam fluid (M.F.) was used to give a pressure drop down to $0.0004 \mathrm{psi}(0.003 \mathrm{kPa})$. Two $60-\mathrm{in}$. $(152-\mathrm{cm})$ $\mathrm{U}$-tube manometers using 1.75 and $2.95 \mathrm{M} . \mathrm{F}$. were mounted vertically to measure pressure differential across the $24-\mathrm{in} .(61-\mathrm{cm})$ heated length. Mass flow rate was determined by the weighing-tank. method.

The inside diameter of the commercially available $1-$ in. $(2.54-\mathrm{cm})$ Pyrex pipe was determincd mort prerisely ao descilued below. 'llie pipe was mounted vertically with a stopcock fitted at the bottom end. A piece of copper tubing was made to go through the stopcock at one end and connected to a vertically mounted graduater manometor tube al the uther end. Exactly $25 \mathrm{~mL}$ of water was delivered into the pipe by a burette, and the water level in the manometer was recorded each time. The inside diameter of the pipe was calculated according to

$$
\mathrm{d}_{\mathrm{o}}=\left(\frac{4}{\pi} \frac{\Delta \mathrm{V}}{\Delta \mathrm{h}}-\mathrm{d}_{\mathrm{m}}^{2}\right)^{1 / 2}
$$

where

$$
\begin{aligned}
& r_{111}=\text { ID of manowieler lube (predetermined by volumetric method), } \\
& \Delta V=\text { volume of water added, in. }{ }^{3},
\end{aligned}
$$

and

$$
\Delta h \text { - rise ln water level, in. }
$$

The following results were obtained:

$\begin{array}{llc}\text { TS.No. 1, first pipe } & \frac{d_{0}, \text { in. }(\mathrm{cm})}{1.023(2.598)} & \frac{\text { Standard Deviation, in. }(\mathrm{cm})}{0.007(0.018)} \\ \text { TS No. 2, second pipe } & 1.022(2.596) & 0.007(0.018)\end{array}$

The laminar-flow velocity profile in annuli is well known. ${ }^{125}$ The relationship between the Moody friction factor and Reynolds number is given by

\footnotetext{
*The first Pyrex plpe used in obtaining the single-phase pressure drop broke during the installation in the loop later. Hence a second pipe was used in obtaining single-phase heat transfer and subsequent blowdown tests.
} 


$$
f \cdot=\frac{64}{R e_{h}} \Phi
$$

where

$$
\Phi=\frac{(1-x)^{2}}{1+x^{2}+\frac{1-x^{2}}{\ln x}}
$$

and

$$
x=\mathrm{d}_{\mathrm{i}} / \mathrm{d}_{\mathrm{o}} \text {, diameter ratio. }
$$

The Reynolds number is defined on the basis of the hydraulic or equivalent diameter:

$$
\operatorname{Re}_{\mathrm{h}} \equiv \frac{\rho \mathrm{D}_{\mathrm{e}} \mathrm{U}}{\mu}
$$

and

$$
D_{e} \equiv \frac{4 A_{x}}{P_{w}}=\frac{4 \frac{\pi}{4}\left(d_{o}^{2}-d_{i}^{2}\right)}{\pi\left(d_{o}+d_{i}\right)}=d_{0}-d_{i}
$$

where $P_{w}$ is the wetted perimeter.

The function $\Phi$ has a value of 1.0 at $x=0$ for a circular tube and a value of 1.5 at $x=1$, i.e., parallel plates of infinite width.

Experimentally, the Moody friction factor is evaluated according to 126

$$
f=\frac{2 D_{e}}{\rho U^{2}}\left(-\frac{d P}{d z}\right)
$$

A plot of $f$ versus $R_{h}$ is shown in Fig. A.l; the agreement with theory in the laminar region is excellent. For the present geometry, Eq. A.2 becomes

$$
f=\frac{95.91}{\mathrm{Rc}_{\mathrm{h}}}
$$

the experimental laminar data yielded an average $f \cdot \mathrm{Re}_{\mathrm{h}}$ value of 95.93. The equation obtained by Nikuradse, ${ }^{127}$ applicable over the entire turbulent Reynolds number range for smooth tubes, is

$$
\frac{1}{\sqrt{f}}=2.0 \log _{10}(\operatorname{Re} \sqrt{f})-0.8
$$


which is plotted in Fig. A.1. The experimental data clearly show that, for Reynolds number based on the hydraulic diameter, the friction data lie considerably above the smooth tube, the difference being 10-20\%. Similar results were obtained in a recent survey of past literature, ${ }^{128}$ and it was concluded that the hydraulic diameter is not the proper length dimension to use for the Reynolds number to ensure both geometric and hydrodynamic similarity between circular tubes and annular ducts. Jones ${ }^{129}$ proposed a modified Reynolds number, $\mathrm{Re}^{*}$, which yields a friction-factor relation as identical with that obtained for a round tube in laminar flow:

$$
f=\frac{64}{\mathrm{Re}^{*}} \text {. }
$$

This Reynolds number also provides good similarity in fully developed turbulent flow for smooth rectangular ducts, as demonstrated by Jones. If Eqs. A.8 and A. 2 are compared, the modified Reynolds number is given hy

$$
\mathrm{Re}^{*}=\frac{\mathrm{Re}_{\mathrm{h}}}{\Phi}
$$

A plot of $f$ versus $R^{*}$ is shown in Fig. A.2, the success of this method is readily demonstrated. The turbulent data for $\mathrm{Re}>10^{4}$ yield a mean deviation of $0.9 \%$ and a standard deviation of $2.7 \%$ about the smooth-tube line. All pertinent results are tabulated in Table VII.

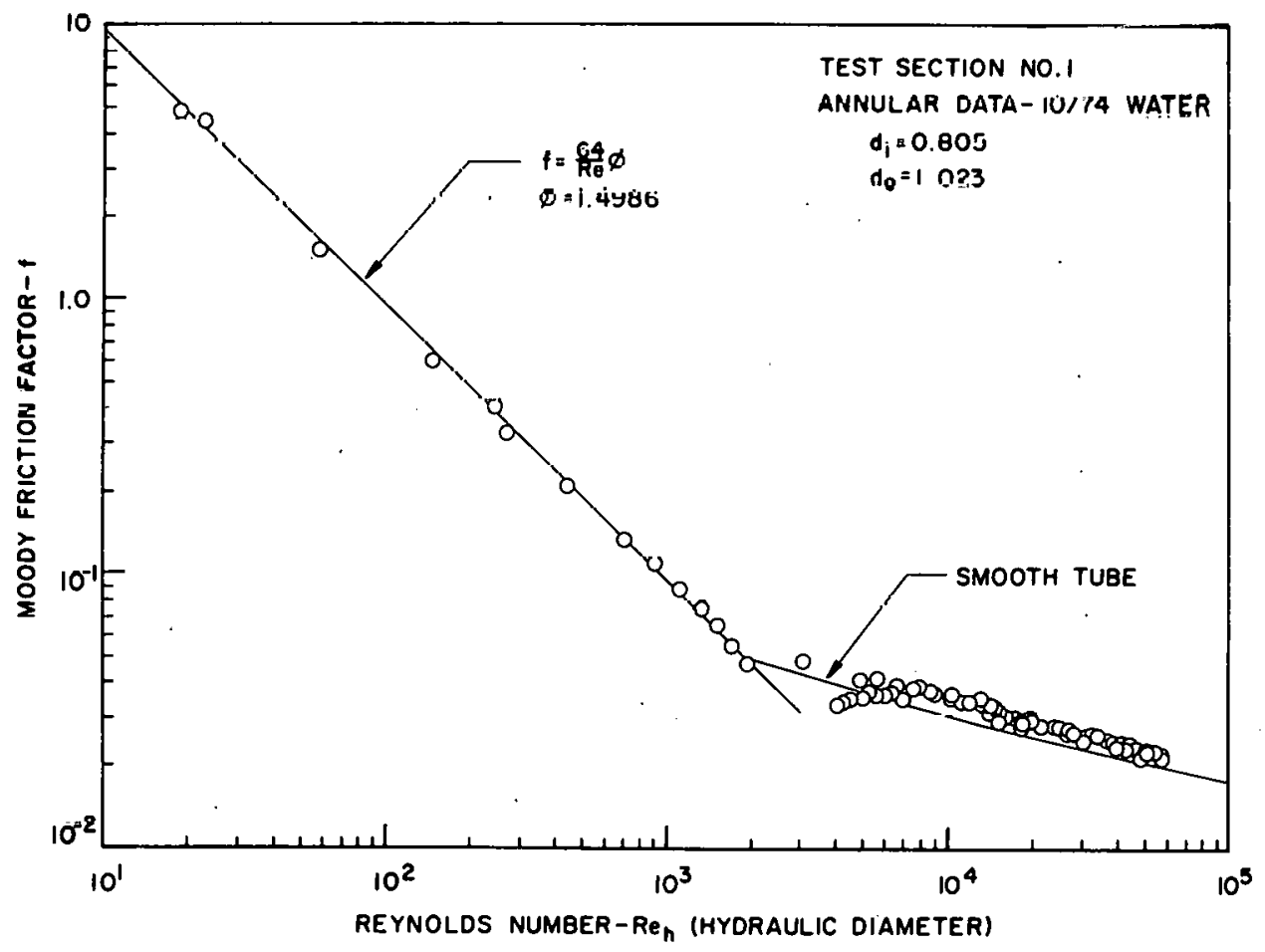

Fig. A.1. Friction-factor Results Based on Hydraulic-equivalent Reynolds Number. $\Lambda$ NL Neg. No. 900-75-806 Rev.1. 


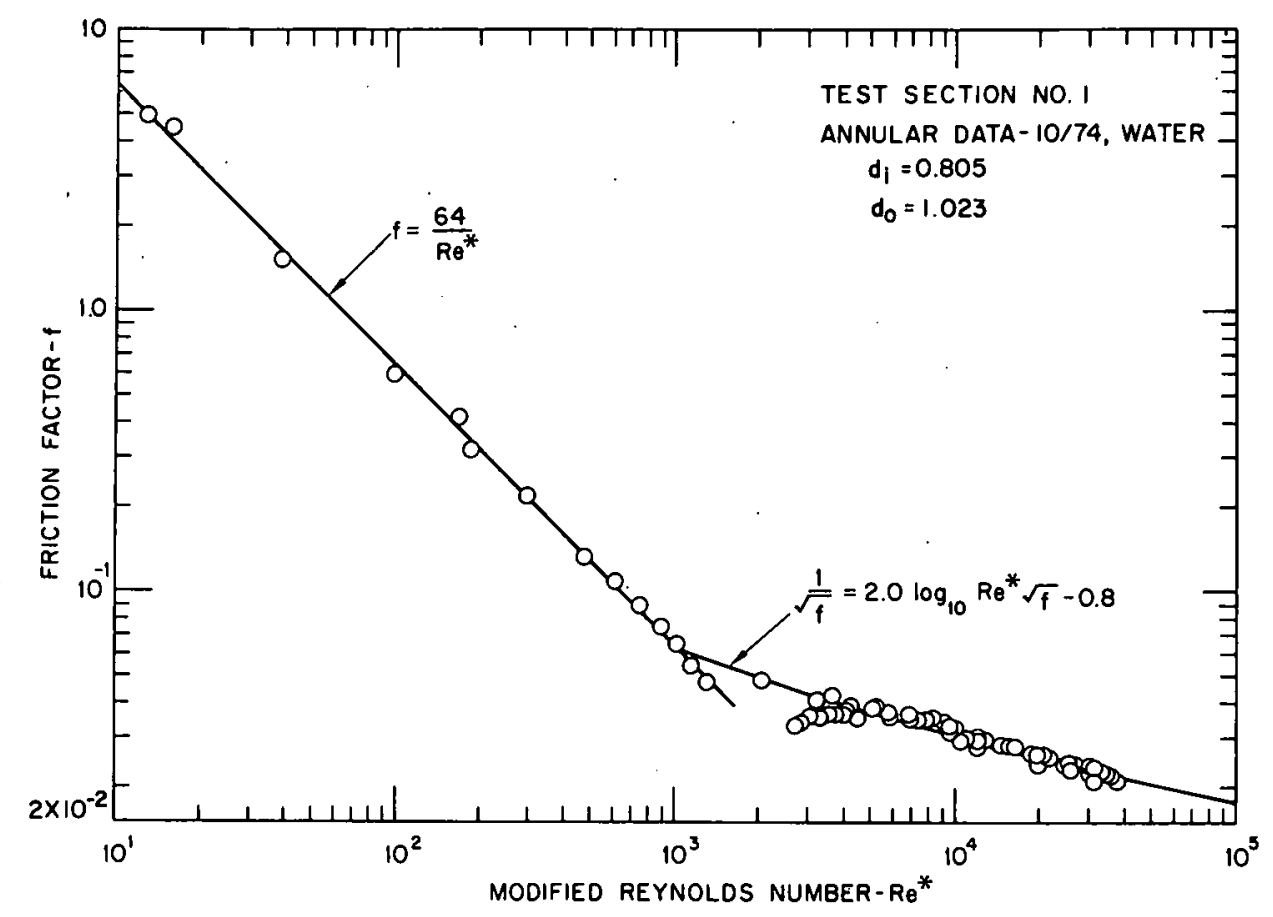

Fig. A.2. Friction-factor Plot Based on Modified Reynolds Number.'ANL Neg. No. 900-4837 Rev. 1.

TABLE VII. Frictional Pressure Drop for Water in Test Section No. $1^{a}$

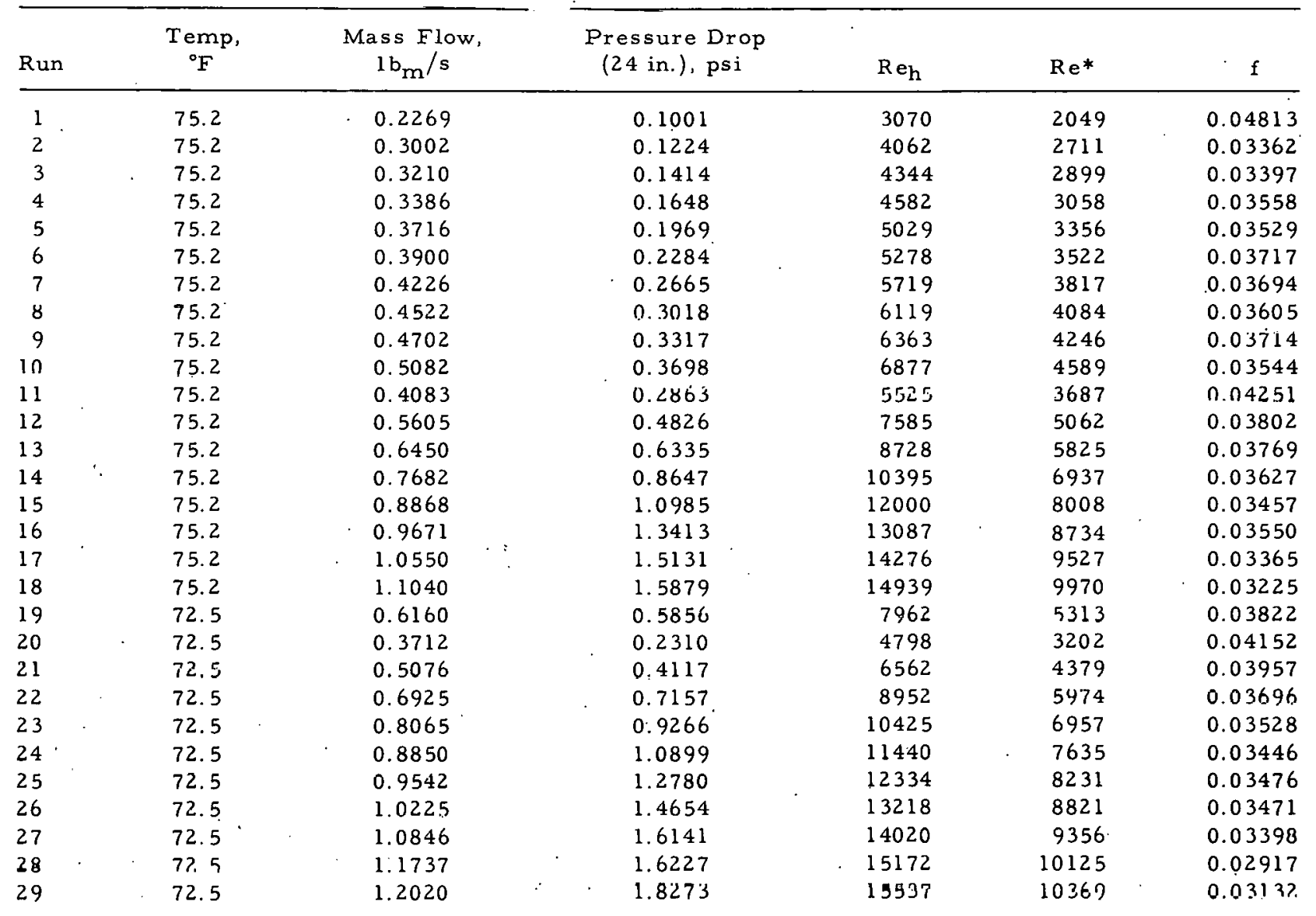


TABLE VII. (Contd.)

\begin{tabular}{|c|c|c|c|c|c|c|c|c|c|c|}
\hline Run & $\begin{array}{l}\text { Temp, } \\
{ }^{\circ} \mathrm{F}\end{array}$ & & & $\begin{array}{c}\text { Mass Flow, } \\
1 \mathrm{~b}_{\mathrm{m}} / \mathrm{s}\end{array}$ & & $\begin{array}{l}\text { Pressure Drop } \\
\text { (24 in.), psi }\end{array}$ & & $\mathrm{Re}_{\mathrm{h}}$ & $\mathrm{Re}^{*}$ & $\mathrm{f}$ \\
\hline 30 & 72.5 & & & 1.2987 & . & 2.0000 & & 16788 & 11204 & 0.02937 \\
\hline 31 & 72.5 & & & 1.4084 & & 2.2091 & & 18206 & 12150 & 0.02758 \\
\hline 32 & 72.5 & & & 1.4368 & & 2.4182 & & 18573 & 12395 & 0.02901 \\
\hline 33 & 72.0 & & & 0.00177 & & 0.000566 & & 23 & 15 & 4.476 \\
\hline 34 & 72.0 & & & 0.00453 & & 0.001274 & & 59 & 39 & 1.538 \\
\hline 35 & 72.0 & & & 0.01146 & & 0.003161 & & 148 & 99 & 0.5961 \\
\hline 36 & 72.0 & & & 0.02130 & & 0.005898 & & 275 & 187 & 0.3220 \\
\hline 37 & 72.0 & & & 0.00146 & & 0.000425 & & 19 & 13 & 4.939 \\
\hline 38 & 72.0 & & & 0.01898 & & 0.005946 & & 245 & 164 & 0.4087 \\
\hline 39 & .72 .0 & & & 0.03438 & & 0.01048 & & 444 & 297 & 0.2195 \\
\hline 40 & 72.0 & & & 0.05529 & & 0.01628 & & 715 & 477 & 0.1319 \\
\hline 41 & 72.0 & . & & 0.07083 & & 0.02213 & & 916 & 611 & 0.1092 \\
\hline 42 & 72.0 & & & 0.08594 & & 0.02661 & & 1111 & 741 & 0.08924 \\
\hline 43 & 72.0 & & & $0.1035 ?$ & & ก 03.211 & & 1339 & 84.3 & 0.07181 \\
\hline 44 & 72.0 & & & 0.11771 & & U. U3681 & & 1522 & 1015 & 0.06578 \\
\hline 45 & 77.0 & & & 0.13333 & & 0.03962 & & 1721 & 1150 & 0.05520 \\
\hline 46 & 72.0 & & & 0.15179 & & 0.04456 & & 1962 & 1309 & 0.04788 \\
\hline 47 & 82.0 & & & 1.4451 & & 1.9767 & & 50960 & 34010 & 0.02281 \\
\hline 48 & 82.0 & & & 1. 5480 & & 2.2355 & & 54190 & 36160 & 0.02249 \\
\hline 49 & 82.0 & & & 1.1390 & & 1.2711 & & 39300 & 26230 & 0.02364 \\
\hline 50 & 82.0 & & & 1.2755 & & 1. 5663 & & 43700 & 29160 & 0.02324 \\
\hline 51 & $82: 0$ & & & $1.42 \cap 5$ & · & 1.7933 & & 48320 & 32250 & 0.02146 \\
\hline 52 & 82.0 & & & 1.5291 & & 2.1612 & & 51650 & 34470 & 0.02233 \\
\hline 53 & 82.0 & & & 0.9025 & & 0.8380 & & 30270 & 20200 & 0.02486 \\
\hline 54 & 82.0 & & & 1.5337 & & 2.2468 & & 51090 & 34090 & 0.02309 \\
\hline 55 & 185.0 & & & 1. 5723 & & 2.2328 & & 58190 & 38840 & 0.02171 \\
\hline 56 & 184.0 & & & 1.5385 & & 2.1658 & & 56550 & 37740 & 0.02201 \\
\hline 57 & 183.0 & & & 1.4706 & & 2.0349 & & 53690 & 35830 & 0.02264 \\
\hline 58 & 182.0 & & & 1.4124 & & 1.9216 & & 51220 & 34190 & 0.02318 \\
\hline 59 & 181.0 & & & 1. 3263 & & 1.7378 & & 17780 & 31890 & 0.02378 \\
\hline 60 & 180.0 & & & 1.2500 & & 1.6105 & & 44730 & 29850 & 0.02482 \\
\hline 61 & 179.0 & & & 1.2225 & & 1. 5043 & & 43430 & 28980 & 0.02425 \\
\hline 62 & 178.0 & & . & 1.1765 & & 14193 & & 41480 & 27640 & $\| n) 454$ \\
\hline 63 & 177.0 & & & 1.1491 & & 1.3505 & & 40210 & 26850 & 0.02465 \\
\hline 64 & 176.0 & & & 1.1111 & & 1.2634 & & 38620 & 25770 & 0.02468 \\
\hline 65 & 175.0 & & & 1.0638 & & 1.1572 & & 36710 & 24500 & 0.02467 \\
\hline 66 & 174.0 & . & & 0.9901 & & 1.0581 & & 33920 & 22640 & 0.02605 \\
\hline 67 & 173.0 & & & 0.9653 & & 1.0154 & & 32830 & 21910 & 0.02631 \\
\hline 68 & 172.0 & & & 0.9259 & & 0.9290 & . & 31280 & 20870 & 0.02617 \\
\hline 69 & 171.0 & & & 0.8977 & & 0.8666 & & 30110 & 20090 & 0.02598 \\
\hline 70 & 170.0 & . & & 0.8160 & & 0.7957 & & 28180 & 188.10 & 0.02687 \\
\hline 71 & $16 \dot{9} .0$ & & & 0.8170 & & 0.7481 & & 27010 & 18030 & 0.02710 \\
\hline 72 & .168 .0 & & & 0.7987 & & 0.70 .34 & & 26220 & 17500 & 0.02667 \\
\hline 73 & 167.0 & & . & 0.7576 & & 0.6678 & . & 24680 & 16470 & 0.02815 \\
\hline 74 & 166.0 & & & 0.7386 & & 0.6358 & & 23890 & 15940 & 0.02821 \\
\hline 75 & 165.0 & & & 0.7321 & & 0.6179 & & 23510 & 15690 & 0.02791 \\
\hline 76 & 164.0 & & & 0.6812 & & 0.5414 & & 2.1720 & 14500 & $0.0<826$ \\
\hline 77 & 163.0 & & & 0.6112 & & 0.4550 & & 19350 & 12920 & 0.02951 \\
\hline 78 & 162.0 & & & 0.5834 & & 0.4159 & & 18340 & 12240 & 0.02961 \\
\hline 79 & 161.0 & & & 0.5192 & & $0.3415^{\circ}$ & & 16210 & 10820 & 0.03071 \\
\hline 80 & 160.0 & & & 0.450 .1 & & 0.2777 & & 13950 & 9310 & 0.03324 \\
\hline 81 & 159.0 & & & 0.4587 & & 0.2755 & & 14110 & 9420 & 0.03176 \\
\hline 82 & 158.0 & & & 04112 & & 0.2447 & & 12550 & 8473 & 0.03512 \\
\hline 83 & 155.0 & & & 0.5247 & & 0.3528 & & 15640 & 10440 & 0.03113 \\
\hline 84 & 154.0 & & . & 0.5814 & & 0.4198 & & 17200 & 11480 & 0.03018 \\
\hline 85 & 154.0 & : & & 0.6188 & & 0.4791 & & 18310 & 12220 & 0.03040 \\
\hline
\end{tabular}

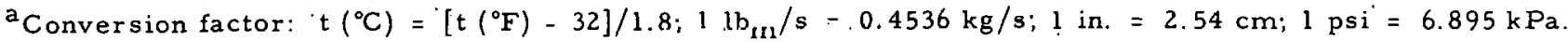


Limited isothermal friction data were obtained for Freon-11 in the second Pyrex pipe. Mass flow rate was determined by turbine flowmeters, and pressure loss was measured by DP cells. Results are tabulated in Table VIII. Agreement with the circular-tube equation based on the modified Reynolds number is good, as shown in Fig. A. 3.

TABLE VIII. Frictional Pressure Drop for Freon-11 in Test Section No. 2a

\begin{tabular}{ccccccc}
\hline & $\begin{array}{c}\text { Temp, } \\
\text { Run }\end{array}$ & $\begin{array}{c}\text { Mass Flow, } \\
1 \mathrm{o}_{\mathrm{m}} / \mathrm{s}\end{array}$ & $\begin{array}{c}\text { Pressure Drop } \\
(24 \mathrm{in} .), \mathrm{psi}\end{array}$ & $\mathrm{Re}_{\mathrm{h}}$ & $\mathrm{Re}^{*}$ & $\mathrm{f}$ \\
\hline 1 & 68.7 & 0.385 & 0.144 & 10920 & 7290 & 0.0353 \\
2 & 69.2 & 0.910 & 0.612 & 26050 & 17380 & 0.0270 \\
3 & 69.6 & 1.601 & 1.676 & 45960 & 30670 & 0.0238 \\
4 & 69.2 & 1.912 & 2.402 & 55010 & 36710 & 0.0239 \\
5 & 67.3 & 2.278 & 3.092 & 65400 & 43640 & 0.0217 \\
\hline${ }^{\mathrm{a} C o n v e r s i o n ~ f a c t o r s: ~} \mathrm{t}\left({ }^{\circ} \mathrm{C}\right)=\left[\mathrm{t}\left({ }^{\circ} \mathrm{F}\right)-32\right] / 1.8 ; 11 \mathrm{bm} / \mathrm{s}=0.4536 \mathrm{~kg} /$
\end{tabular}
$\mathrm{s} ; 1$ in. $=2.54 \mathrm{~cm} ; 1 \mathrm{psi}=6.895 \mathrm{kPa}$.

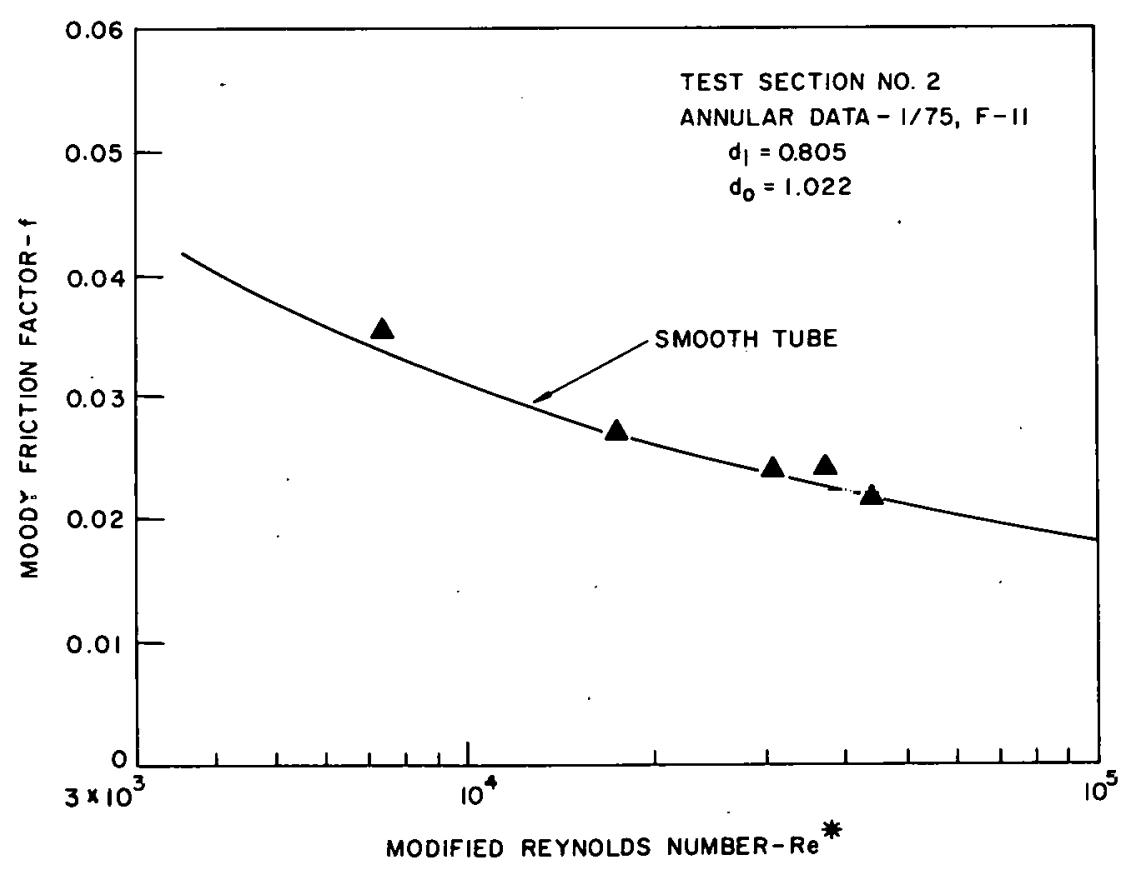

Fig. A.3. Isothermal Freon-11 Friction Data. ANL Neg. No. 900-75-805 Rev. 1. 


\section{A PPENDIX B}

\section{Data for Single-phase Liquid Heat Transfer}

A simple macroscopic heat balance on the heated test section (length $=L_{h}$ ) results in

$$
\varphi \pi D_{i} L_{h}=W_{f} C_{p f}\left[T_{f}\left(L_{h}\right)-T_{f i}\right] .
$$

The term on the left is the total heat input q supplied by the dc rectifier, provided heat loss to the outside is negligible. Figure B.l shows the heatbalance results performed with Freon-11 at close to room temperature. In most cases, agreement is within 5\%, giving good confidence in the instrumentation involved.

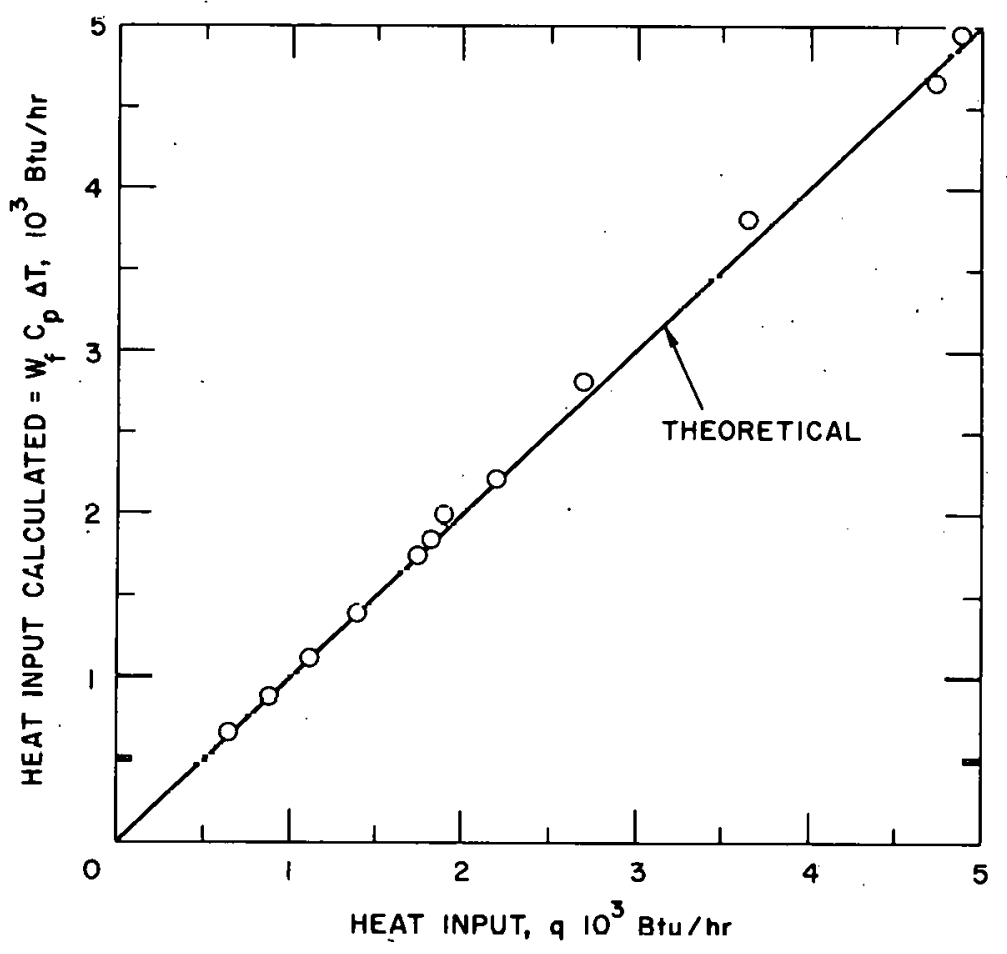

Fig. B.1. Results for Single-phase Heat Balance. Conversion factor: $1 \mathrm{Btu} / \mathrm{hr}=0.293 \mathrm{l} / \mathrm{s}$. ANL Neg. No. $900-75-385 \mathrm{Rev} .1$.

The heat-transfer coefficient to single-phase liquid under forced converstion is given by

$$
\mathrm{h}_{\mathrm{fo}}=\varphi / \Delta \mathrm{T}_{\mathrm{f}}
$$

where

$$
\Delta T_{f}=T_{w o}-T_{f}(z)
$$

is the temperature difference between the heated-tube outside surface (annular geometry) and the bulk liquid temperature at a length $z$ from the inlet. Similar to Eq. B. $1, T_{f}(z)$ is given by 


$$
T_{f}(z)=T_{f i}+\frac{\pi D_{i} z}{W_{f} C_{p f}} \varphi .
$$

The temperature difference between the inside and outside of the heated tube, $T_{w i}-T_{w o}$, is derived in Appendix $C$ and is given by Eq. C. 5.

The laws governing laminar or turbulent convective heat transfer are well established. For turbulent flow the well-known Dittus-Boelter equation has been found to be satisfactory:

$$
\frac{h_{f o} D}{k_{f}}=0.023\left(\frac{\rho U D}{\mu_{f}}\right)^{0.8}\left(\frac{C_{p} \mu_{f}}{k_{f}}\right)^{0.4} \text {. }
$$

However, it was mainly developed for tube geometry.

For an annulus, an additional term is included to account for the geometry of the system. Monrad and Pelton ${ }^{130}$ recommended

$$
\frac{h_{f o} D_{e}}{k_{f}}=0.020\left(\frac{\rho U D_{e}}{\mu_{f}}\right)^{0.8}\left(\frac{C_{p} p^{\mu}}{k}\right)_{f}^{0.33}\left(\frac{D_{o}}{D_{i}}\right)^{0.53}
$$

which is valid for $\mathrm{Re}_{\mathrm{h}}>10^{4}$.

Wiegand ${ }^{131}$ also suggested a correlation that gives results close to Eq. B.6. For the present geometry, the product $0.020\left(D_{0} / D_{i}\right)^{0.53}$ is 0.023 , which is the same constant as in the Dittus-Boelter equation.

The plot of $\mathrm{Nu} / \mathrm{Pr}^{0.33}$ against $\mathrm{Re}_{\mathrm{h}}$ is shown in Fig. B.2; the agreement is good, although the data show discrepancies at higher Reynolds numbers. The variation of $h_{f o}$ along the test section is thought to be mainly due to inaccurate measurement of the thermocouple temperature. Possible errors are mentioned at the end of this appendix.

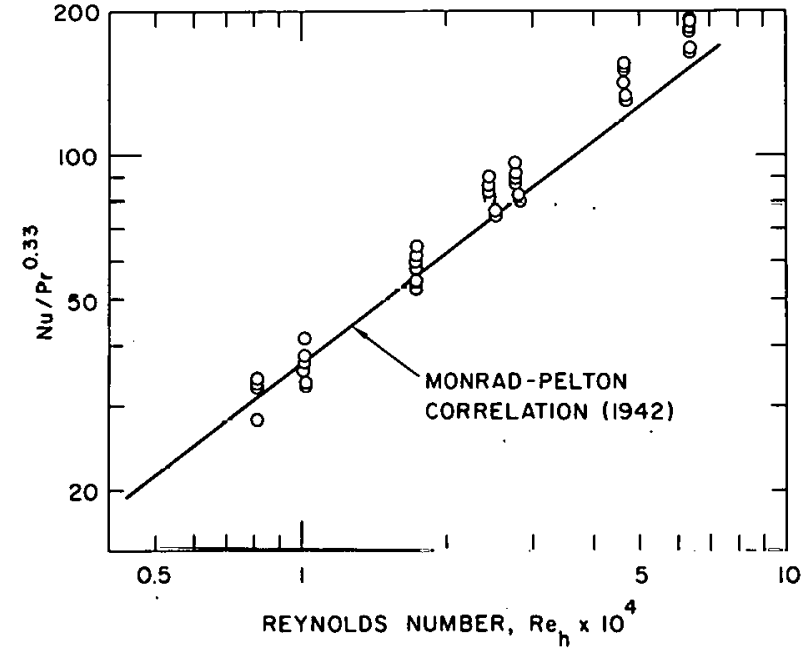

Fig. B.2

Results for Single-phase Heat Transfer. ANL Neg. No. 900-75-393 Rev. 1. 
Finally, some isothermal upward flows of Freon at $135^{\circ} \mathrm{F}\left(57^{\circ} \mathrm{C}\right)$ were performed to get an estimate of the heat loss through the outer Pyrex pipe. Results obtained showed a mean value of $125 \mathrm{Btu} / \mathrm{hr}(37 \mathrm{~J} / \mathrm{s})$ and an overall heat-transfer coefficient of about $2 \mathrm{Btu} / \mathrm{hr} \cdot \mathrm{ft}^{2} \cdot{ }^{\circ} \mathrm{F}\left(11 \mathrm{~W} / \mathrm{m}^{2} \cdot{ }^{\circ} \mathrm{C}\right)$, which compares favorably with the calculated value $0.93 \mathrm{Btu} / \mathrm{hr} \cdot \mathrm{ft}^{2} \cdot{ }^{\circ} \mathrm{F}\left(5.3 \mathrm{~W} / \mathrm{m}^{2} \cdot{ }^{\circ} \mathrm{C}\right)$ based on free convection from the pipe. The presence of copper clamps at each pressure-tap location may conduct some heat away, thus enhancing the heat loss.

Temperatures along the heated test section were measured by 0.031 -in. (0.079-cm)-OD stainless steel, ungrounded, sheathed, Chromel-Alumel (Type K) thermocouples. Some possible errors in temperatures are:

1. Inhomogeneity of thermocouple wires.

2. Stray emf pickup in the leads.

3. Drift of the reference junction units.

4. Inaccuracy of amplifier units, such as calibration drift and nonlinearity output.

5. Inaccuracy in measurement of trace on visicorder paper.

A maximum deviation of $3^{\circ} \mathrm{F}$ in wall-thermocouple readings during is othermal flow of Freon has been observed. 
APPENDIX C

Evaluation of Outside-surface Temperature

1. Steady-state Consideration

In the absence of axial heat conduction, the temperature difference between the inside and outside of the heated tube can be calculated quite straightforwardly. The general differential equation for an infinite heatgenerating cylinder is

$$
\frac{\mathrm{d}^{2} \theta}{\mathrm{dr}^{2}}+\frac{1}{\mathrm{r}} \frac{\mathrm{d} \theta}{\mathrm{dr}}+\frac{\mathrm{q}^{\prime \prime \prime}}{\mathrm{k}}=0
$$

where $\theta=\theta(r)$ only. The boundary conditions are

$$
\theta\left(r_{2}\right)=T_{w i}
$$

and

$$
\left.\frac{d \theta}{d r}\right|_{r_{2}}=0
$$

where $\mathrm{T}_{\mathrm{wi}}$ values are known from thermocouples readings. The second condition is valid in view of the fact that the inside tube was packed with magnesium oxide, which is a good insulator.

The solution in terms of outside-wall temperature $\mathrm{T}_{\text {wo }}$ as a function of inside-wall temperature $T_{w i}$, inside radius $r_{2}$, outside radius $r_{1}$, and heat-generation rate $\mathrm{q}^{\prime \prime}$ is

$$
T_{w o}=T_{w i}-\frac{q^{\prime \prime \prime}}{2 k}\left(\frac{r_{1}^{2}-r_{2}^{2}}{2}-r_{2}^{2} \ln \frac{r_{1}}{r_{2}}\right)
$$

and in terms of the outside-surface heat flux $\varphi$

$$
\mathrm{T}_{\mathrm{wo}}=\mathrm{T}_{\mathrm{wi}}-\frac{\varphi \mathrm{r}_{1}}{\mathrm{k}}\left(\frac{1}{2}-\frac{\mathrm{r}_{2}^{2}}{\mathrm{r}_{1}^{2}-\mathrm{r}_{2}^{2}} \ln \frac{\mathrm{r}_{1}}{\mathrm{r}_{2}}\right) \text {. }
$$

At a heat flux of $50,000 \mathrm{Btu} / \mathrm{hr} \cdot \mathrm{ft}^{2}\left(157.75 \mathrm{~kW} / \mathrm{m}^{2}\right), \Delta \mathrm{T}_{\mathrm{W}}$ is $\sim 6^{\circ} \mathrm{F}\left(\sim 3.3^{\circ} \mathrm{C}\right)$.

2. Unsteady-state Consideration

For the time-dependent case, Eq. C.I has to be written as

$$
\frac{\partial^{2} \theta}{\partial r^{2}}+\frac{1}{r} \frac{\partial \theta}{\partial r}+\frac{q^{\prime \prime \prime}}{k}=\frac{1}{\alpha_{1}} \frac{\partial \theta}{\partial t}
$$


where $\theta=\theta(r, t)$. The boundary conditions are

$$
\theta\left(r_{2}, t\right)=T_{w i}(t)
$$

and

$$
\left.\frac{\partial \theta}{\partial r}\right|_{r_{2}}=0,
$$

and the initial condition is

$$
\theta\left(r_{2}, 0\right)=T_{w i}(0),
$$

where $T_{w i}(0)$ and $T_{w i}(t)$ are known.

The problem above has been referred to as the "inverse-heatconduction" problem in the literature. ${ }^{132-134}$ Any numerical technique that seeks to solve the above equations "exactly" is inherently unstable, as small changes in the input data can cause large changes in the solution. The approaches to the numerical solution have been categorized into four methods:

1: Integral-equation approach. ${ }^{135}$

2. Laplace or Fourier transform. ${ }^{136}$

3. Infinite-series technique. ${ }^{134}$

4. Nonlinear estimation technique. ${ }^{133}$

The above equations cannot be viewed as a good description of the real situation at a CHF location since many parameters are functions of temperature, e.g., $k, \alpha_{1}$, and $q^{\prime \prime \prime}$. (Heat generation varies because of changes in the electrical resistivity of the material due to temperature.) Further, axial conduction cannot be neglected, because it is significant at dryout location. ${ }^{113}$

Therefore the determination of the heater-surface temperature during transients was a difficult task. Furthermore, the measurement of the insidewall temperature $\mathrm{T}_{\text {wi }}$ during transients involves some uncertainty as the wall-thermocouple beads might not be right next to the wall. This is certainly the case for all ungrounded, sheathed thermocouples. As a result (see Appendix $D)$, the surface temperature and the corresponding heat-transfer coefficient calculated could be so uncertain as to make any further analysis or conclusion unreasonable. 


\section{APPENDIX D}

Determination of Thermocouple.Response

1. Out-of-loop Determination

\section{a. Theory}

If a thermometric element is immersed in a constant-temperature $\left(\theta_{\mathrm{b}}\right)$ bath, the temperature of the thermocouple, $\theta_{\mathrm{TC}}(\mathrm{t})$, is related to the temperature of immersion by ${ }^{137}$

$$
\theta_{T C}(t)-\theta_{b}=\left[\theta_{T C}(0)-\theta_{b}\right] \exp [-(1 / \tau) t] .
$$

Equation D. 1 holds when the Biot number is small ( $\left.h_{0} d / k<0.1\right) ;^{138}$ i.e., internal-conduction resistance is negligible in comparison with surfaceconvection resistance.

The time constant $T$ depends not only on the physical size and shape of the thermocouple (TC), but also on the flow conditions in which it is immersed. For a step change in temperature, the time constant is given by the ratio of the thermal capacitance of the TC to the thermal conductance of the environmental film:

$$
\tau=\frac{\left(\rho \vee C_{p}\right)_{j n}}{h_{0} A_{b d}},
$$

where the subscripts $j n$ and bd represent the junction and bead, respectively. Therefore, for a given thermocouple, $T \propto 1 / h_{0}$.

\section{b. Experiment}

The test was conducted using a beaker of boiling water at $212^{\circ} \mathrm{F}$ $\left(100^{\circ} \mathrm{C}\right)$. Heating was supplied by a hot plate, and good agitation was ensured by the boiling process. The test thermocouple was allowed to stabilize at room temperature and then was plunged into the boiling water. Zero time occurred when the thermocouple first entered the fluid, as shown by a steep rise in temperature displayed on the visicorder chart. The time constant was found, knowing the speed of the chart and using Eq. D. 1:

$$
\frac{\theta_{\mathrm{TC}}(\mathrm{T})-\theta_{\mathrm{b}}}{\theta_{\mathrm{TC}}(0)-\theta_{\mathrm{b}}}=\frac{1}{\mathrm{e}}=0.368
$$

Results are shown in Table IX. Because the time constant varied from one thermocouple to another, the approximate range is given. 
TABLE.IX. Time Constant of Thermocouplesa

\begin{tabular}{ccc}
\hline Type & Application & T, ms \\
\hline 0.032 -in.-OD, ungrounded, sheathed & Spot-welded to inside wall of TS & $50-80$ \\
0.0625 -in.-OD, ungrounded, sheathed & Placed in annular flow channel & $150-250$ \\
\hline
\end{tabular}

aConversion factor: 1 in. $=2.54 \mathrm{~cm}$.

2. In-loop Determination

At the occurrence of boiling crisis, the cooling-surface temperature rises rapidly due to the presence of vapor film or dry spots. The heattransfer coefficient at the inception of CHF decreases by at least two orders of magnitude. Therefore one way to determine the overall time response of the heated tube and thermocouples was as follows.

With no coolant on the heat-liasidei side, su dis lu simulite "Arynut" or vapor-blanketing condition, the test section was suddenly subjected to fullpower load as used in the transient. The time response $T_{T S}$ was then taken to be the time delay until the thermocouple temperature began to rise. To avoid physical damage, power to the test section was tripped in less than $2 \mathrm{~s}$. Results are shown in Figs. D. 1 and D.2, and the corresponding time response TTS is given in Table X. The estimated temperature excursion was also plotted based on both the temporal-resistance measurement and an adiabatic-heatup calculation.

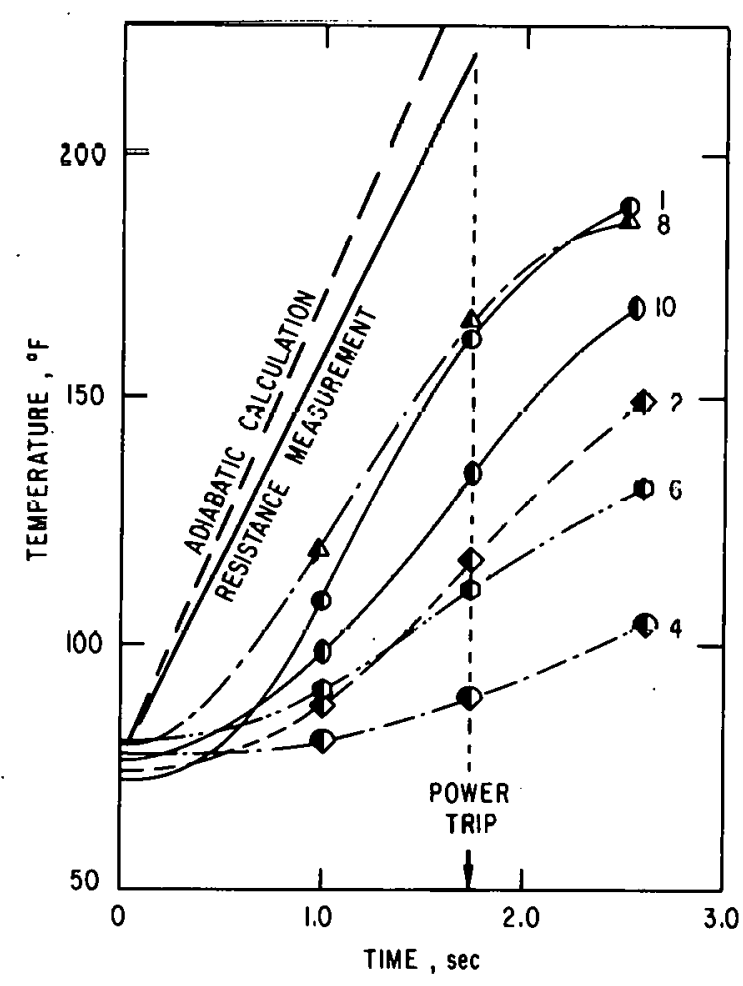

Fig. D.1. Temperature Response for Lower-half Test-section Thermocouples. Conversion factor: $\mathrm{t}\left({ }^{\circ} \mathrm{C}\right)=\left[\mathrm{t}\left({ }^{\circ} \mathrm{F}\right)-32\right] / 1.8$. ANL Neg. No. 900-75-365 Rev. 2.

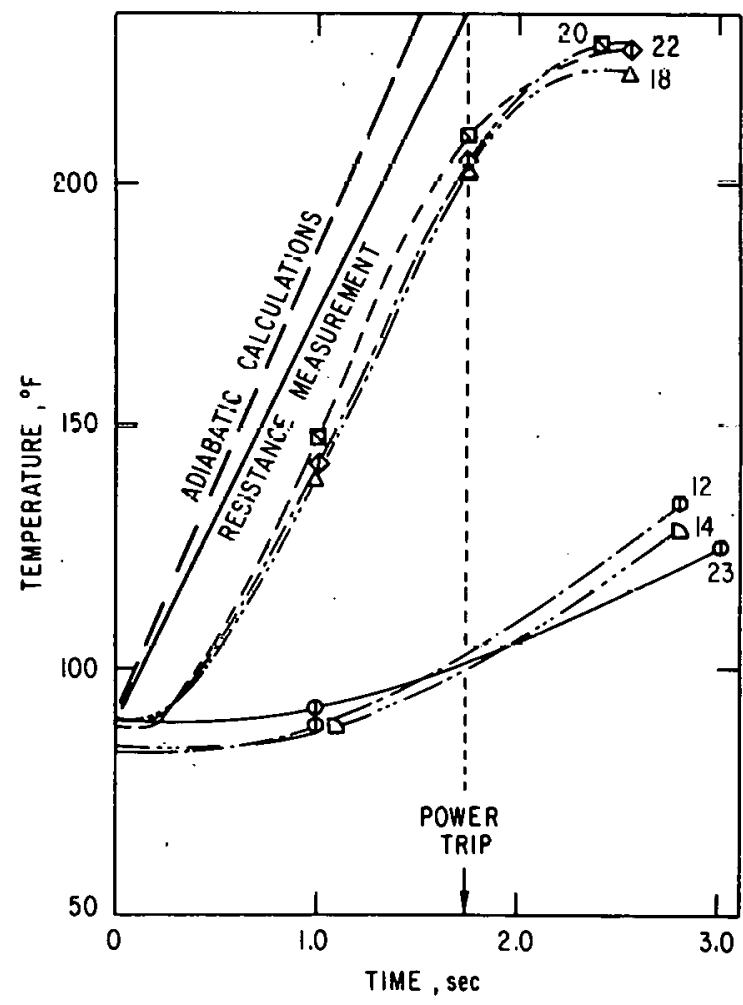

Fig. D.2. Temperature Response for Upper-half T'est-section 'l'hermocouples. Conversion factor: $\mathrm{t}\left({ }^{\circ} \mathrm{C}\right)=\left[\mathrm{T}\left({ }^{\circ} \mathrm{F}\right)-32\right] / 1.8$. ANL Neg. No. 900-75-366 Rev. 1. 
TABLEX. Overall Time Response of Test Section and Thermocouples

[Heat flux $\left.=45,500 \mathrm{Btu} / \mathrm{hr} \cdot \mathrm{ft}^{2}\left(143.55 \mathrm{~kW} / \mathrm{m}^{2}\right)\right]$

\begin{tabular}{|c|c|c|c|}
\hline TC No. & ${ }^{T_{T S}},{ }^{a} \mathrm{~s}$ & TC No. & ${ }^{\mathrm{T}} \mathrm{TS}{ }^{\mathrm{a}} \mathrm{s}$ \\
\hline 1 & 0.2 & 14 & 0.8 \\
\hline 2 & 0.3 & $16^{b}$ & - \\
\hline 4 & 0.9 & 18 & 0.2 \\
\hline 6 & 0.3 & 20 & 0.2 \\
\hline 8 & 0.2 & 22 & 0.2 \\
\hline 10 & 0.3 & 23 & 0.3 \\
\hline 12 & 0.7 & & \\
\hline
\end{tabular}

${ }^{a}$ Due to uncertainty, ${ }^{T}$ TS values rounded off to first-place decimal.

${ }^{\mathrm{b}}$ TC 16 was detached from the wall.

The resistivity of Type 304 stainless steel, $\rho_{\mathrm{r}}$, is a function of temperature, and the following equation was obtained based on the values given in Ref. 139:

$$
\rho_{\mathrm{r}}(\mathrm{ohm} / \mathrm{ft})=2.2755 \times 10^{-6}+0.00128 \times 10^{-6} \mathrm{~T}\left({ }^{\circ} \mathrm{F}\right)
$$

Therefore, from the measured rate of change of resistance in the test section as shown in Fig. D. 3, the rate of temperature rise was found to be $84^{\circ} \mathrm{F} / \mathrm{s}$ $\left(47^{\circ} \mathrm{C} / \mathrm{s}\right)$.

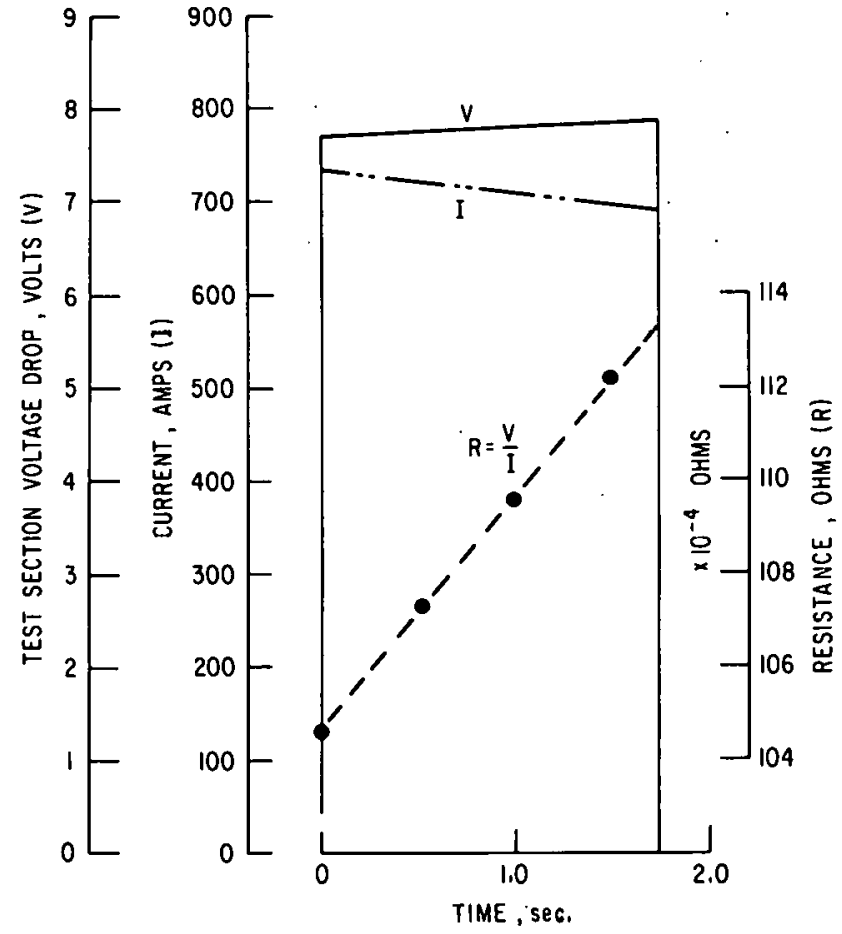

Fig. D.3. Temporal Voltage, Current, and Resistance. Measurement during Rapid Joule Heating. ANL Neg. No. 900-75-367.
If no axial conduction and no radial temperature gradient are assumed, the adiabatic wall analysis yields

$$
\frac{\Delta \theta}{\Delta t}=\frac{\varphi}{\rho C_{p} \xi},
$$

where $\xi$ is the thickness of the tube. This value was calculated to be $96^{\circ} \mathrm{F} / \mathrm{s}\left(53^{\circ} \mathrm{C} / \mathrm{s}\right)$.

As evidenced from Fige. D. 1 and D.2, not all the thermocouples followed the estimated temperature rise. In fact, those with long ${ }^{\top} T S$ rarely follow at all. This large discrepancy observed among the behavior of the thermocouples during rapid temperature excursion is most likely due to the variation in the radial distance of the thermocouple beads from the wall. This variation was 
mainly caused by the spot-welding technique, which did not attempt to place the bead right next to the welding spot. In addition, the exact location of the bead from the thermocouple sheathed end was not known. As a result, some beads were placed further away from the heated wall, giving rise to slower responses due to increased depth and lower temperature measurement due to excessive conduction loss. Hence for transient temperature measurement, the exact location of the thermocouple bead is important, and this fact is more obvious in the discussion of "inverse heat conduction" in Appendix C. 


\section{APPENDIX E}

\section{Calibration of Capacitance-void Meter}

1. Void-measurement Instrumentation

The geometry and dimension of the void probe is outlined in Sec. III. B.2. A bench setup was conducted first to check the linearity of the calibration curve using a mockup test section with similar electrodes. Vertical-slug (plug) and horizontal-stratified flow patterns were created simply by filling the test section vertically and horizontally, respectively, with Freon. Figures E. 1 and E.2 show the results of the bench test using a commercial impedance bridge for capacitance measurement. Measured capacitance is seen to vary linearly with void, except for the vertical-slug pattern; in this case, at both empty and full positions distortion was caused by a fringe effect of the outside electrode.

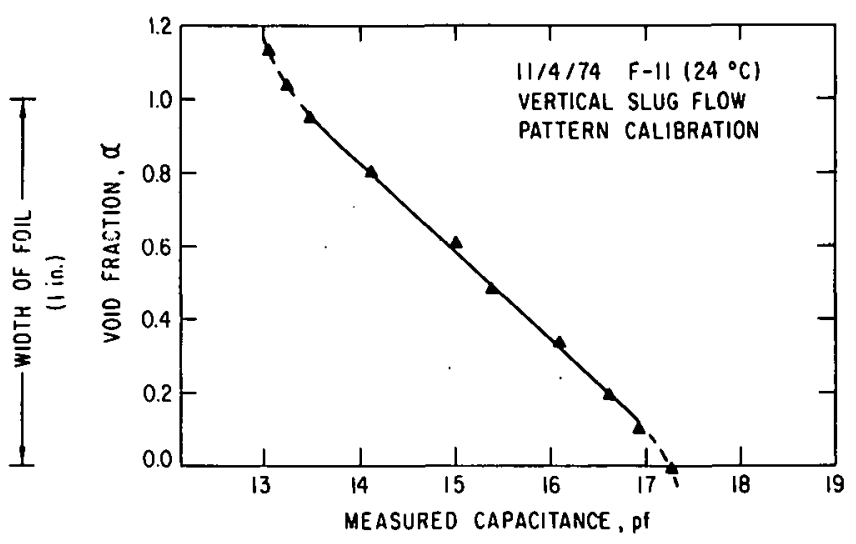

Fig. E.1. Vertical Calibration Using Impedance Bridge. Conversion factor: 1 in. $=2.54 \mathrm{~cm}$. ANL Neg. No. $900-75-510$.

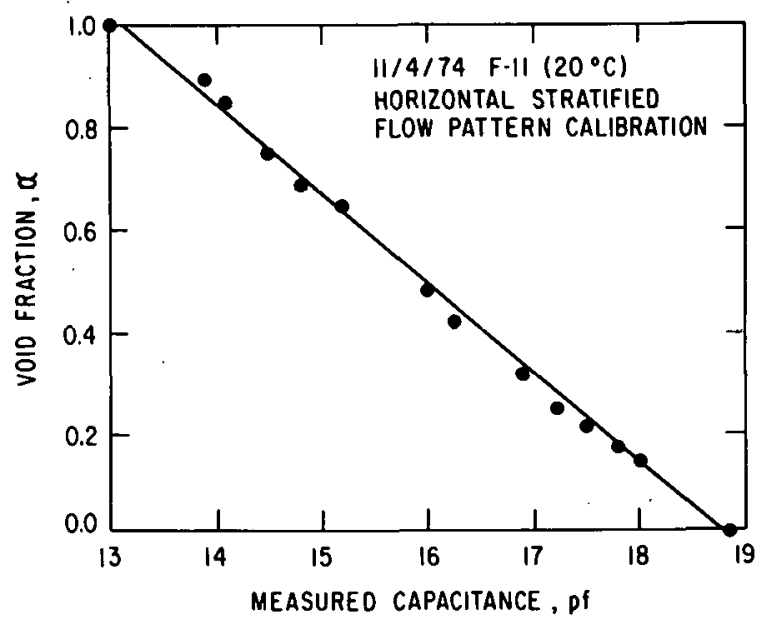

Fig. E.2. Horizontal Calibration Using Impedance Bridge. ANL Neg. No. 900-75-517 Rev. 1.

The dynamic-measurement circuit is shown in Fig. E.3. With the test section empty, the variable capacitor $C_{k}$ was adjusted so that a minimum dc output was obtained. Figures E. 4 and E. 5 show the results of the bench test using the devised circuit. The same linearity was achieved. Next the bridge was calibrated by providing a known capacitance (using a General Radio Precision Capacitor, Type No. 722-MEQ) across the unknown and checking for linearity in the dc output. The result, shown in Fig. E.6, indicates that the bridge did provide linear response as desired in the range of interest.

\section{Interpretation of Void Measurement}

If the dc outputs or capacitance measurements at both empty and full positions are known, and if the calibration is linear as in Fig. E.5, the apparent void fraction. is found from 


$$
\alpha_{a}=\frac{C_{F}-C_{2 \varphi}}{C_{F}-C_{E}}=\frac{V_{F}-V_{2 \varphi}}{V_{F}-V_{E}}
$$

which is a direct result of Eq. E. 4 below by assuming a slug model as shown later. The resulting plot of theoretical void $\alpha$ versus the apparent void $\alpha_{a}$ is shown in Fig. E. 7.

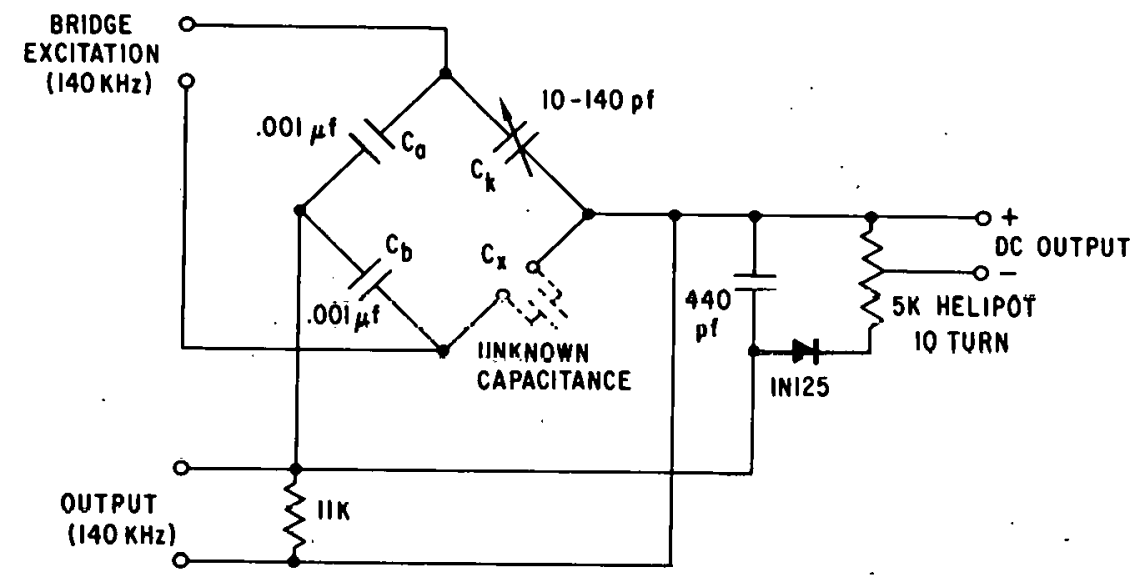

Fig. E.3

Capacitnnes Bridge for Trantslent Vold Measurement. ANL Neg. No. 900-75-514 Rev. 1.

Fig. E.4

Vertiçal Calibration IIsing r.apacitance Bridge. Cinnversinn factor; 1 in. $=2.54 \mathrm{sm}$. ANI. Neg. No. 900-75-512 Rev. 1.
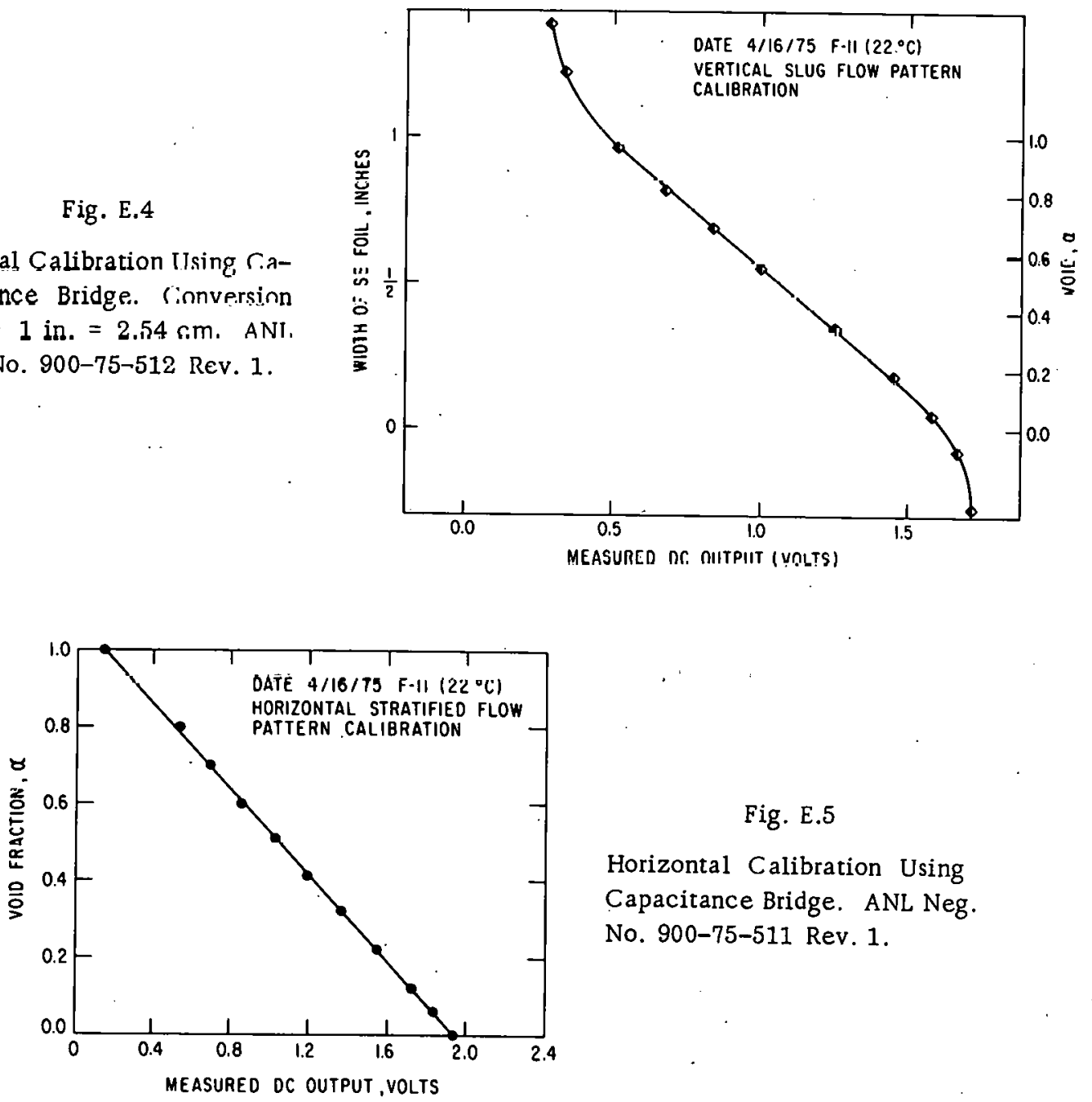

Fig. E.5

Horizontal Calibration Using Capacitance Bridge. ANL Neg. No. 900-75-511 Rev. 1. 


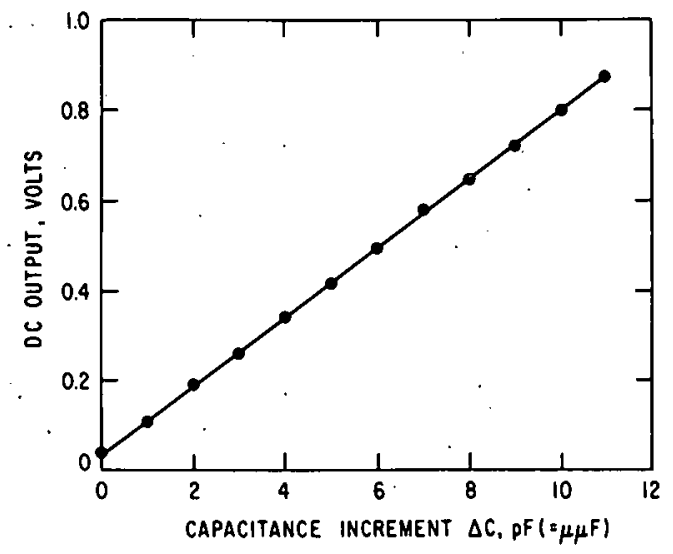

Fig. E.6. Output-voltage Characteristic of Capacitance Bridge. ANL Neg. No. 900-75-516.

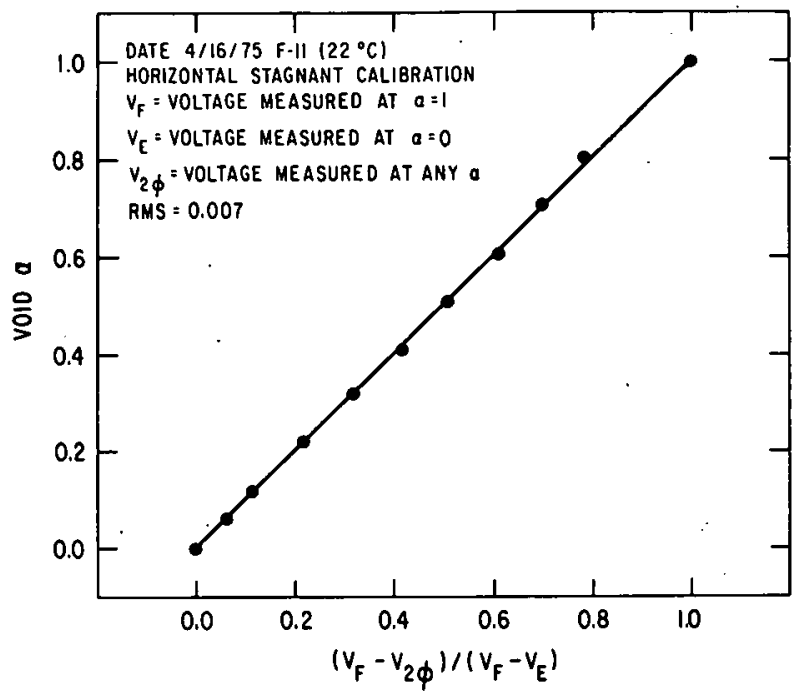

Fig. E.7. Void-fraction Determination Using Capacitance Bridge. ANL Neg. No. 900-75-509 Rev. 1.

But is the apparent void given by Eq. E.l sensitive to flow patterns? Although this was not experimentally tested in this investigation, some estimates of this dependence are made in the rest of this appendix.

The capacitance $C$ is directly related to the dielectric constant $\varepsilon$ of the material between the electrodes according to

$$
\mathrm{C}=\epsilon \frac{\mathrm{A}}{\mathrm{d}},
$$

where

$$
A=\text { total effective area of electrode }
$$

and

$d$ = spacing between electrode plates.

Hence, depending on the flow patterns, the effective dielectric constant of a two-phase mixture can be calculated as a function of the dielectric constants of the two media by the following idealized considerations. ${ }^{140}$

a. Slug-flow Model (see Fig. E. 8)

The two phases are in parallel between the electrodes; therefore

$$
C_{2 \varphi}=C_{f}+C_{g},
$$

which together with Eq. E.2 gives

$$
\varepsilon_{2 \varphi}=(1-\alpha) \varepsilon_{\mathrm{f}}+\alpha \varepsilon_{\mathrm{g}} .
$$


According to Eq. E.1,

$$
\alpha_{\mathrm{a}}=\frac{\varepsilon_{\mathrm{f}}-\varepsilon_{2 \varphi}}{\epsilon_{\mathrm{f}}-\varepsilon_{\mathrm{g}}}
$$

which can be regarded as a change in the dielectric of the medium. After substituting the value of $\varepsilon_{2 \varphi}$, we obtain

$$
\alpha_{\mathrm{a}}=\alpha
$$

which indicates that, for the slug-flow model, the apparent void is identical to the theoretical void, as shown in Fig. E.9. The present study used this slugflow model in the interpretation of void fraction.

$$
\left|\frac{v}{--}-\right|
$$

(a) SLUG MODEL

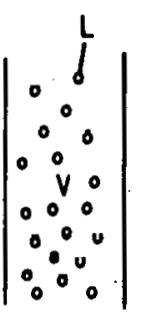

(C) DROPLET MODEL

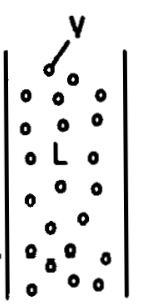

(b) BUBBLE MODEL

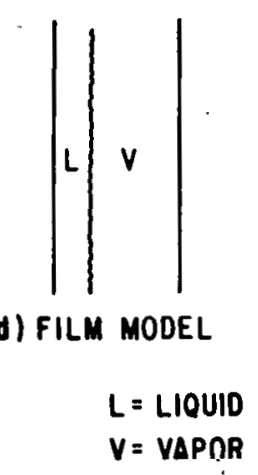

$V=$ VAPOR

Fig. E.8. Various Idealized Two-phase-flow Models. ANL Neg. No. 900-75-506.

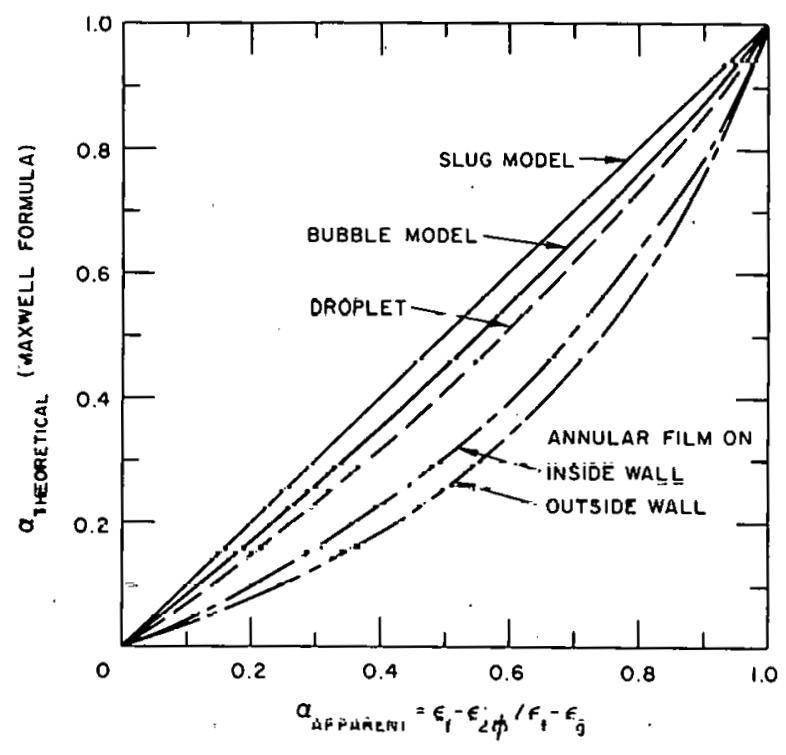

Fig, E.9. Theoretical Void vs A pparent Void. ANL Neg. No. 900-75-340 Rev. 1.

\section{b. Bubbly-flow Model}

To find the total dielectric constant of a two-phase mixture with one phase dispersed as small spheres, Maxwell ${ }^{141}$ derived the approximate formula

$$
\frac{\epsilon_{2 \varphi}-\varepsilon_{c}}{\epsilon_{2 \varphi}+2 \epsilon_{c}}=\beta \frac{\epsilon_{d}-\epsilon_{c}}{\epsilon_{d}+2 \epsilon_{c}},
$$


where

$\beta=$ volume fraction of dispersed phase,

$\epsilon_{c}=$ dielectric constant of continuous phase,

and

$\epsilon_{\mathrm{d}}=$ dielectric constant of dispersed phase.

Equation E. 7 holds if the dispersed spheres are separated by distances large in comparison with their diameters.

In the bubbly-flow model, Eq. E.7 can be written as

$$
\frac{\epsilon_{2 \varphi}-\epsilon_{\mathrm{f}}}{\epsilon_{2 \varphi}+2 \epsilon_{\mathrm{f}}}=\alpha \frac{\epsilon_{\mathrm{g}}-\epsilon_{\mathrm{f}}}{\epsilon_{\mathrm{g}}+2 \epsilon_{\mathrm{f}}}
$$

or

$$
\alpha_{\mathrm{a}}=\alpha\left(\frac{\varepsilon_{2 \varphi}+2 \varepsilon_{\mathrm{f}}}{\varepsilon_{\mathrm{g}}+2 \epsilon_{\mathrm{f}}}\right)
$$

which indicates that the apparent void is overestimated in comparison with the theoretical void, since the quantity in parentheses is greater than one.

c. Dispersed-flow Model

From the discussion in Sec. b, Eq. E. 7 can be written as

$$
\frac{\varepsilon_{2 \varphi}-\epsilon_{\mathrm{g}}}{\epsilon_{\mathrm{f}}-\epsilon_{\mathrm{g}}}=(1-\alpha) \frac{\epsilon_{2 \varphi}+2 \epsilon_{\mathrm{g}}}{\epsilon_{\mathrm{f}}+2 \epsilon_{\mathrm{g}}}
$$

or

$$
\left(1-\alpha_{\mathrm{a}}\right)=(1-\alpha)\left[\frac{\varepsilon_{2 \varphi}+2 \varepsilon_{\mathrm{g}}}{\varepsilon_{\mathrm{f}}+2 \varepsilon_{\mathrm{g}}}\right] \text {, }
$$

which implies that $\left(1-\alpha_{a}\right)<(1-\alpha)$ or $\alpha_{a}>\alpha$. Again the apparent void is overeetimated in comparison with the theoretical void.

\section{d. Film-flow Model}

By considering the liquid and vapor phases as capacitances in series, we obtain 


$$
\epsilon_{2 \varphi}=\frac{\varepsilon_{f} \varepsilon_{g}}{(1-\alpha) \varepsilon_{g}+\alpha \epsilon_{f}}
$$

and

$$
\alpha_{\mathrm{a}}=\alpha \frac{\epsilon_{2 \varphi}}{\epsilon_{\mathrm{g}}}
$$

which says that the apparent void is overestimated in comparison with the the or etical void.

With a concentric electrode configuration, the capacitance measurement is also found to be sensitive to the distribution of the film in the annular channel. Duo to the lengthy derivation, which is uut repeated here, the final results are shown in the plot of $\alpha$ versus $\alpha_{a}$ in Fig. E.9. Dielectric constants at $70^{\circ} \mathrm{F}\left(21^{\circ} \mathrm{C}\right)$ for Freon-l 1 were used in the calculation. Also, the effect of the glass shroud has becn included.

3. Temperature Sensitivity in Void Measurement

Since the dielectric constant is a function of temperature, temperature correction has to be considered in the void measurement. To my knowledge, no complete information has been obtained for Freon-11, although Du Pont ${ }^{142}$ suggested an empirical way of estimating the $\varepsilon_{f}$ and $\varepsilon_{g}$ values at various temperature. Hence, at present, no attempt was made to correct this effert.. 


\section{APPENDIX F}

\section{Void Estimation during Adiabatic Blowdown}

The mass quality and void fraction during an adiabatic blowdown can be estimated as below. When wall shear, heat exchange with the environment,

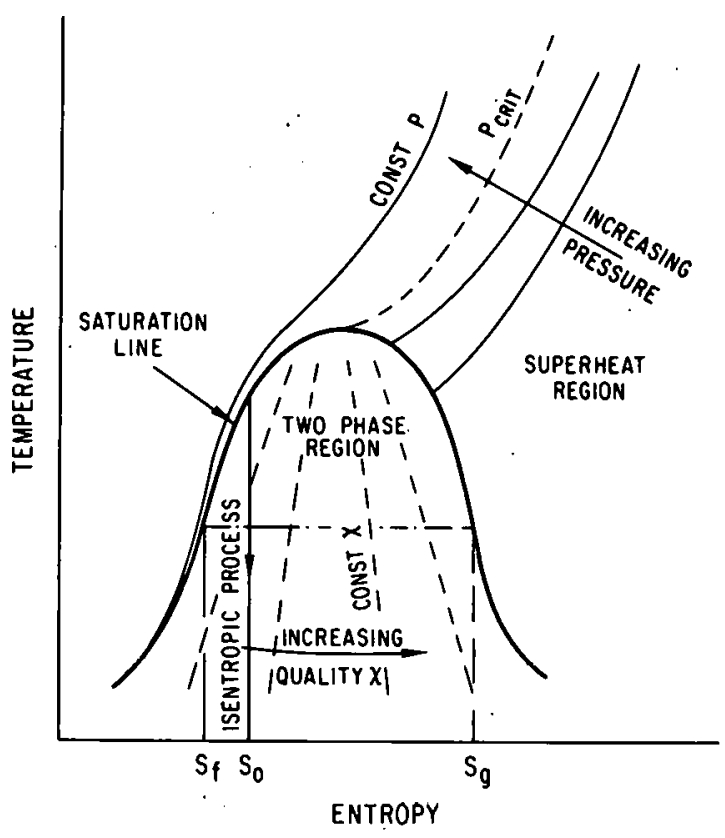

Fig. F.1. Generalized Temperature-Entropy Diagram. ANL Neg. No. 900-75-923.

$$
S_{0}=(1-x) S_{f}+x S_{g}
$$
and interfacial viscous terms are neglected, the system entropy during the blowdown expansion can be assumed constant; ${ }^{124}$ i.e., we have an isentropic process for which

$$
d S_{0}=d\left[(1+x) S_{f}+x S_{g}\right]=0
$$

The blowdown from a subcooled state follows the constant-entropy path as shown in Fig. F.1. As blowdown proceeds, the temperature continues to drop as quality increases. Since liquid is essentially incompressible, the initial subcooled liquid has almost the same entropy as that at the saturation value, $S_{0}$, as shown in Fig. F.1. Therefore, at any time into blowdown, the following equation holds, assuming thermodynamic equilibrium between phases:

or

$$
S_{0}=S_{f}+x S_{f g}
$$

Hence, the quality $x$ can be estimated if the pressure at the location of interest is known. Then the void fraction can be calculated according to

$$
\alpha=\frac{1}{1+\frac{\rho_{g}}{\rho_{f}}\left(\frac{1-x}{x}\right) s}
$$

where

$$
\mathcal{S}=\frac{\mathrm{u}_{\mathrm{g}}}{\mathrm{u}_{\mathrm{f}}} ; \text { slip ratio }=1.0 \text { for homogeneous flow model }
$$

The homogeneous flow model has been assumed for the above calculation in the piesent study. 


\section{APPENDIX G}

Void Estimation from Turbine and Weight Measurements

Flow-measurement technique from turbine and weight transducers was discussed in Sec. III.A.2. The continuity equation can be written as

$$
w_{1}=w_{2}=\left(w_{f}+w_{g}\right)_{2}
$$

where 1 and 2 may be at the test-section exit and turbine location, respectively. For no storage effect in the loop, the mass flow $W$ can be found from the massdecay signal of the weight transducer. At the turbine location, for quality $x$ small compared to 1 ,

$$
\left(W_{f_{2}}\right)_{2}(1-x)(W)_{2} \approx(W)_{2} \text {, }
$$

so that in conjunction with the definition for liquid mass flow

$$
\left(\mathrm{W}_{\mathrm{f}}\right)_{2}=\left[\rho_{\mathrm{f}}(1-\alpha) \mathrm{AU}_{\mathrm{f}}\right]_{2}
$$

where $U_{f}$ is indicated by the turbine meter. The void at the turbine location $c$ an be found after rearranging:

$$
\alpha_{2}=1-\left(\frac{W_{f}}{\rho_{f} A_{f}}\right)_{2}
$$

Therefore the void can be estimated as above if the mass flow and liquid velocity are known. 


\section{APPENDIX H}

Measurement of the Power Factor

The power dissipated by an electric heater is given by

$\mathrm{P}=\mathrm{VI} \cos \Theta$

where $\Theta$ is the phase angle between voltage and current. This phase angle comes about because a hollow tube is not a purely resistive load but has some inductance.

To measure the power factor, the test-section voltage was connected to the $\mathrm{X}$ input of an oscilloscope and the current (which in this case is the voltage drop across the shunt) to the $\mathrm{Y}$ input. Properly adjusting the gain to give equal amplitude input generated a Lissajous figure, as shown in Fig. H.1. The angle $\Theta$ may be calculated from

$$
\sin \Theta=\frac{\text { Horizontal intercept }}{\text { Maximum horizontal deflection }}=\frac{\mathrm{b}}{\mathrm{a}} \text {. }
$$

The results obtained for the present $2-\mathrm{ft}(10.08-\mathrm{cm})$ Type 304 stainless steel tube are shown in Fig. H.2. The average value of $\cos \Theta$ is 0.993 .
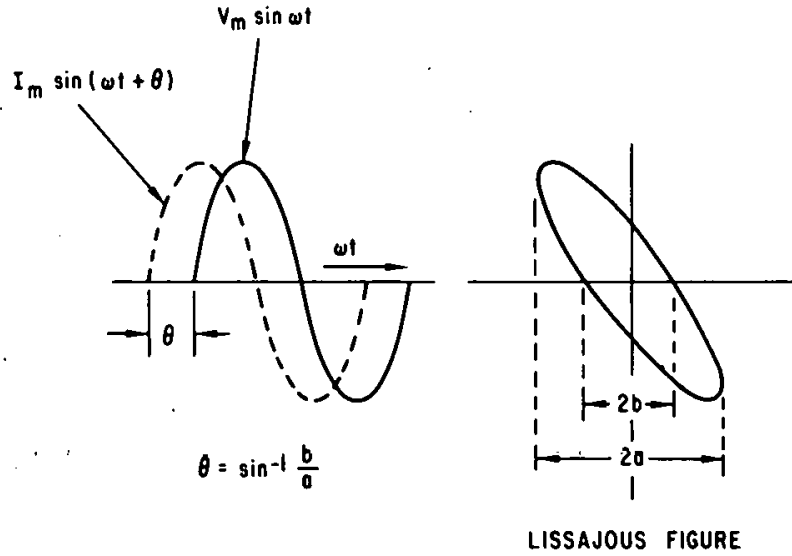

Fig. H.1. Determination of Phase Angle Using Lissajous Figure. ANL Neg. No. 900-75-508.

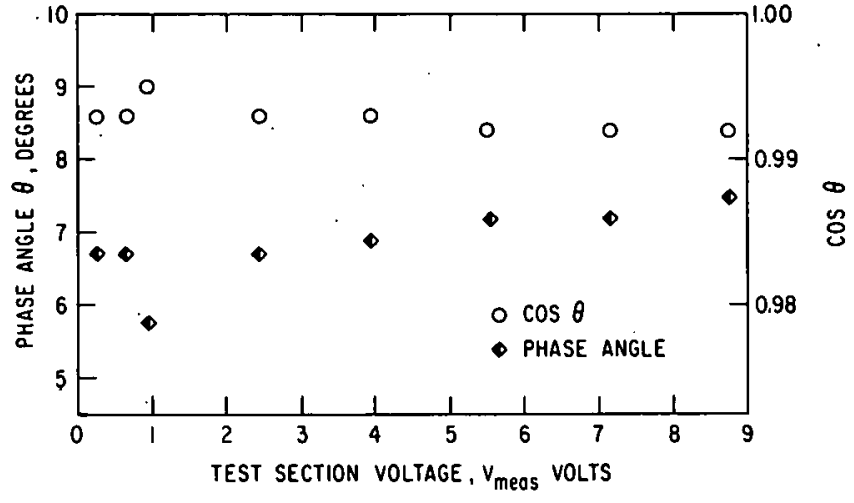

Fig. H.2. Measured Phase Angle vs Test-section Voltage. ANL Neg. No. 900-75-515.

The instantaneous power for ac heating is

$$
\mathrm{p}=\mathrm{I}_{\mathrm{m}} \mathrm{V}_{\mathrm{m}} \sin (\omega \mathrm{t}+\Theta) \sin (\omega \mathrm{t})
$$

where $I_{m}$ and $V_{m}$ are the amplitudes of current and voltage, respectively. The average power can be written as 


$$
P=\frac{1}{\pi} \int_{k}^{k+\pi} p(\omega t) d(\omega t)=\frac{I_{m} V}{2} \cos \Theta .
$$

Hence, with Eq. H.l, root-mean-square ( $\mathrm{rms}$ ) values are to be used. However, measurement by digital voltmeter and Honeywell strip-chart recorder gives the mean or average value.

Since the dc rectifier puts out rippling dc, oscilloscope pictures were taken at various power levels in order to assess the amount of ripple present. The result is shown in Fig. H.3. If the ripples are assumed to be rectified sine waves, then

$$
\mathrm{V}_{\text {ineas }}=\dot{v}_{\text {avc }}=V_{b}+\frac{L}{\pi} v_{\text {mar }}
$$

and

$$
T_{\text {l1eds }}=T_{\text {dve }}=T_{\mathrm{u}}+\frac{2}{\pi} I_{111 d x} .
$$

If the shapes of the ripples and the dc component are known, the average power is given by

$$
\begin{aligned}
P= & V_{b} I_{b}+\frac{V_{\max } I_{\max }}{2}\left(\frac{2 \sin (0) \pi \cos (10-2 \Theta \cos (1)}{\pi}\right) \\
& +\frac{2}{\pi}\left(V_{\text {max }} I_{b}+I_{\max } V_{b}\right),
\end{aligned}
$$

where, for $\Theta<10^{\circ}$,

$$
\frac{2 \sin \Theta+\pi \cos \Theta-2 \Theta \cos \Theta}{\pi}=\cos \Theta=0.993 .
$$

In terms of measured values (average),

$$
\mathrm{P}=\mathrm{V}_{\text {meas }} \mathrm{I}_{\text {meas }}+\left(\cos \Theta-4 / \pi^{2}\right) \mathrm{V}_{\text {max }} \mathrm{I}_{\max }
$$

Define a power factor $\psi$ such that

$$
P=V_{\text {meas }} I_{\text {meas }} \psi .
$$

A plot of $\psi$ versus $V_{\text {meas }}$ is shown in Fig. H.4. 


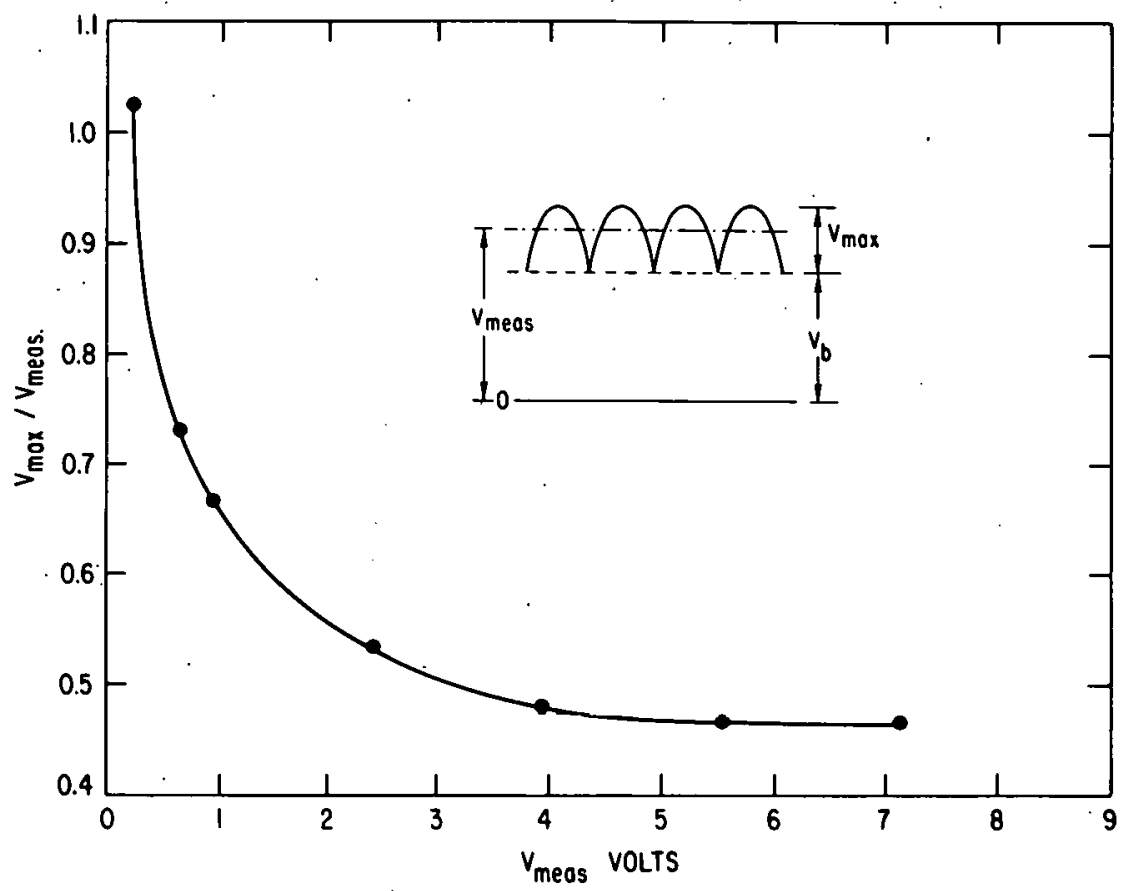

Fig. H.3. Amplitude of Ripple vs Test-section Voltage. ANL Neg. No. 900-75-513.

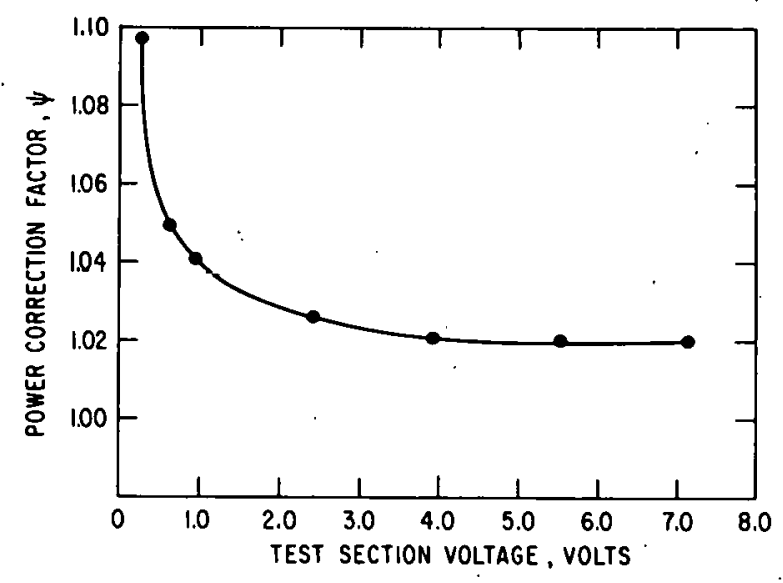

Fig. H.4

Power Correction Factor vs Test-section Voltage. ANL Neg. No. 900-75-507. 


\section{APPENDIX I}

\section{Instrument Calibration}

Calibrations of the weight transducers, turbine flowmeters, and pressure tranducers are discussed in this appendix.

\section{Weight Transducers}

The two Statham UC 3 unbonded-type strain-gauge, Universal Transducing cells were calibrated with dead weights. The millivolt output was read on an HP DVM Mode1 No. 2401C. Hysteresis was less than $0.5 \%$. Calibration results are shown in Figs. I.l and I. 2 .

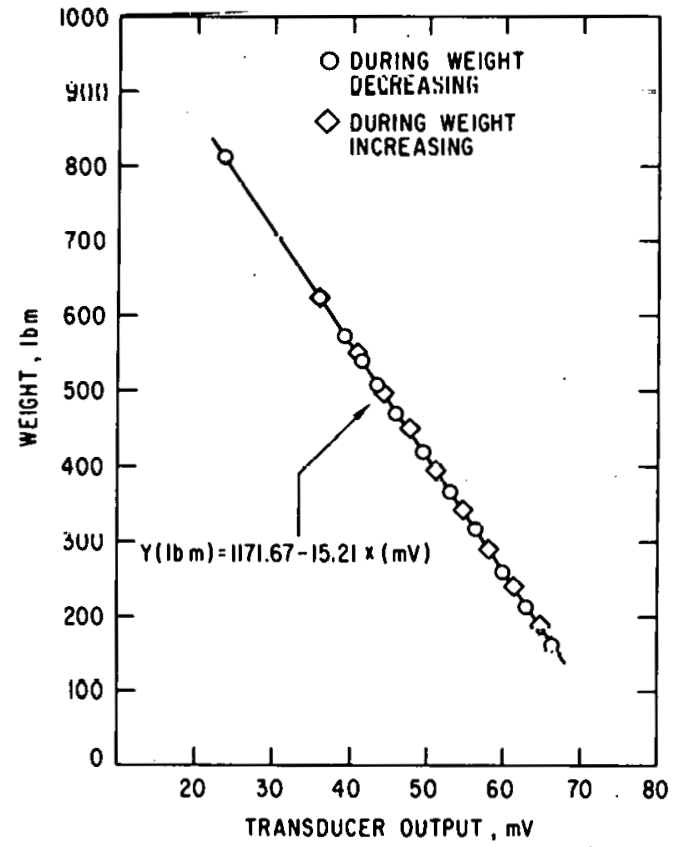

Fig. I.1. Calibration of Eupply-vesse.1 Weight Transducer. Conversion factor: $1 \mathrm{lb} m=0.4536 \mathrm{~kg}$. ANL Neg. No. 900-75-571.

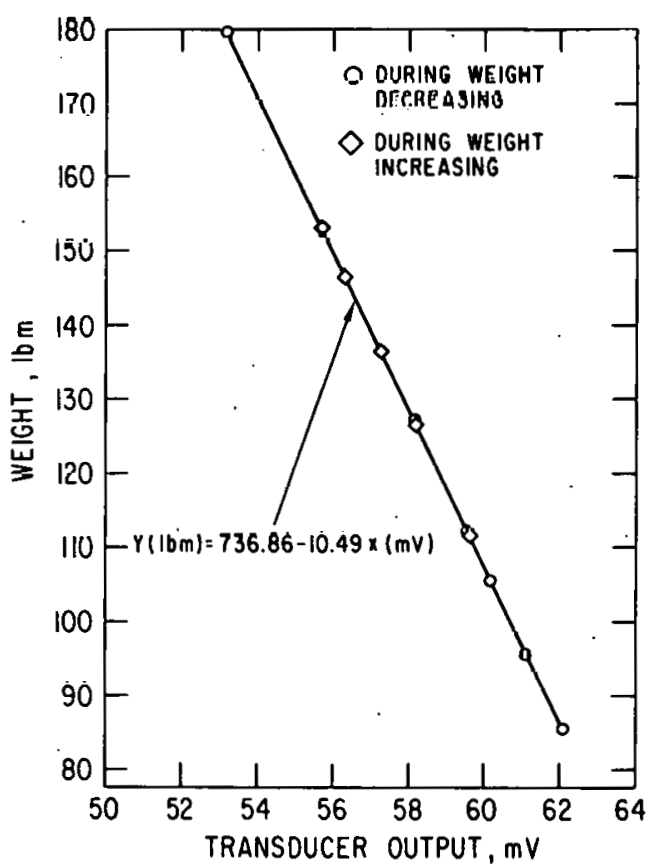

Fig. I.2. Calibration of Blowdown-vessel Weight Transducer. Conversion factor: $1 \mathrm{lb} \mathrm{m}=0.4536 \mathrm{~kg}$. ANL Neg. No. 900-75-575.

\section{Turbine Flowmeters}

Cox Model AN 16 flowmeters were individually calibrated at 12 flow rates using the standard reference fuel, MIL-F-7024A Type 2 at $80^{\circ} \mathrm{F}\left(27^{\circ} \mathrm{C}\right)$ by the manufacturer before shipment. From the data so obtained, the mean cycles/gallon " $\mathrm{K}$ " factor was calculated. A quick check of this $\mathrm{K}$ factor was performed by measuring the flow rate of water using a weight tank. The rotational speed of the turbine was read on an HP Frequency Counter, Model No. $5202 \mathrm{~L}$. Agreement in $\mathrm{K}$ values was within $4 \%$, mainly due to inaccurate experimental measurement. The $\mathrm{K}$ factor for backflow in these bidirectional turbine meters agreed to within $2 \%$ of the value for the designated flow direction. 
These flowmeters were also calibrated in the loop with Freon-11. The flow was determined from the mass-decay curve given by the weight transducer on the supply vessel. K factors supplied by Cox showed better agreement with the weight measurement; the result is shown in Fig. I.3. Thus the result gave a good and confident check on the weight and flow measurements.

\section{Pressure Transducers}

Absolute pressure transducers were calibrated using pressurized nitrogen or air, and the pressure was read with a 100-in. (2.54-m) well-type mercury manometer [i.e., able to read below $\sim 65 \mathrm{psia}(0.45 \mathrm{MPa})$ ]. Hysteresis was less than $0.1 \%$ full scale for 1000 -psig $(6.9 \mathrm{MPa})$ transducer used at the upper plenum.

Differential pressure transducers were calibrated in more or less the same way on both high- and low-pressure sides. A 60-in. (152-cm) U-tube manometer with a 2.95 Meriam fluid was used to read any pressure less than 5 psi $(34 \mathrm{kPa})$. Calibrations of the high-and low-pressure sides of each DP cell agreed to within $1 \%$, and hysteresis in general was small (see Fig. I.4) for one calibration. Drift in the calibrations was also negligible during a test period of 4 months.

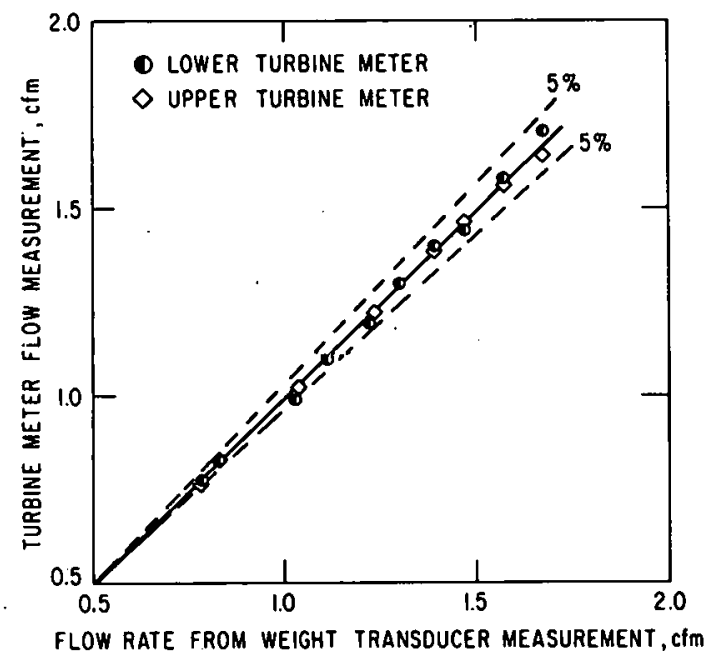

Fig. 1.3. Agreement. hetween Two Types of Flow Measurements. Conversion factor: $1 \mathrm{cfm}=4.719 \times 10^{-4} \mathrm{~m}^{3} / \mathrm{s}$. ANL Neg. No. 900-75-573.

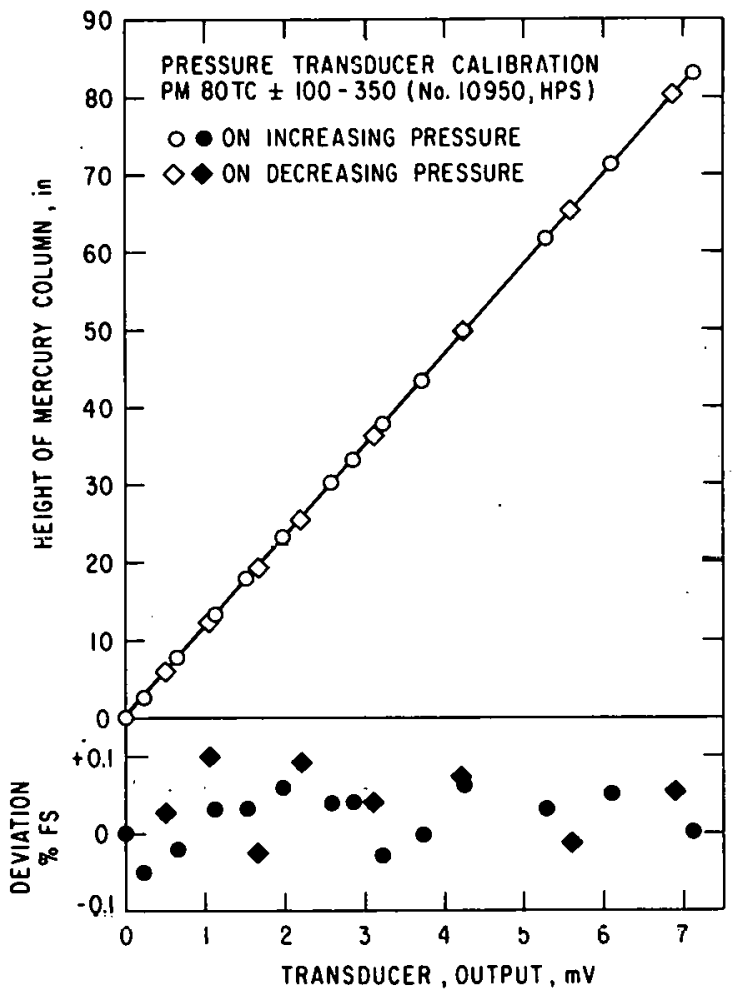

Fig. I.4. Calibration of a $100-p s i d(689.5-\mathrm{kPa})$ Transducer. Conversion factor: 1 in. $=2.54 \mathrm{~cm}$. ANL Neg. No. $900-75-572$ Rev. 1. 


\section{APPENDIX J}

\section{Freon-11-to-Water Scaling}

As mentioned in Sec. III.A.1, the use of Freon-water scaling for steadystate $\mathrm{CHF}$ has met with numerous success. Although such modeling techniques can be used to only a limited extent for a rapid depressurizing system as in the present study, it is quite educational to look into some existing scaling criteria.

A good review of the state of the art with an extensive bibliography appears in Refs. 143 and 144. Here three existing scaling laws are compared.

\section{Zuber and Ishii}

In the method of Zuher and Ishii, the coulinuity, momentum, and energy equations were linearized; these, together with seven constitutive equations, were integrated, and the steady-state values were subtracted to give a perturbed characteristic equation. If the rmodynamic-equilibrium flow is as sumed, the following dimensionless groups were obtained:

$$
\begin{aligned}
& \rho_{\mathrm{f}} / \rho_{\mathrm{g}}=\text { ratio of liquid to vapor density, } \\
& \mathrm{L}_{\mathrm{h}} / \mathrm{D}_{\mathrm{e}}=\text { ratio of heated length to diameter, } \\
& \mathrm{U}_{\mathrm{gj}} / \mathrm{U}_{\mathrm{fi}}=\text { ratio of vapor drift velocity to liquid inlet velocity; } \\
& \mathrm{RE}=\frac{\rho_{\mathrm{f}} \mathrm{U}_{\mathrm{fi}} \mathrm{D}}{\mu_{\mathrm{f}}}=\text { Reynolds number; } \\
& \mathrm{Fr}=\frac{g \mathrm{~L}_{\mathrm{h}}}{\mathrm{U}_{\mathrm{fi}}^{2}}=\mathrm{Froude} \text { number, } \\
& \quad . \\
& \mathrm{N}_{\mathrm{SUB}}=\frac{\Delta p}{\rho_{\mathrm{g}}} \frac{\Delta \mathrm{h}_{\mathrm{f}}}{\mathrm{h}_{\mathrm{fg}}}=\text { subcooling number, } \\
& \mathrm{N}_{\mathrm{PCH}}=\frac{\Gamma_{\mathrm{g}} \mathrm{v}_{\mathrm{fg}} \mathrm{L}}{U_{\mathrm{fi}}}=\text { phase-rhange numbcr, }
\end{aligned}
$$

where

$$
\begin{aligned}
\Gamma_{\mathrm{g}} & =\frac{\text { total heat generated at sirface }}{\text { latent heat of vaporization } \mathrm{x} \text { total volume }} \\
& =\text { rate of vapor generation/unit volume } \\
& =\frac{\varphi}{\mathrm{h}_{\mathrm{fg}}} \frac{4 \mathrm{D}_{\mathrm{i}}}{\mathrm{D}_{0}^{2}-\mathrm{D}_{\mathrm{i}}^{2}} \text { for annular channel. }
\end{aligned}
$$


Pressure is scaled via the density ratio (see Figs. J.1 and J.2); hence, the corresponding thermodynamic and transport properties are established,

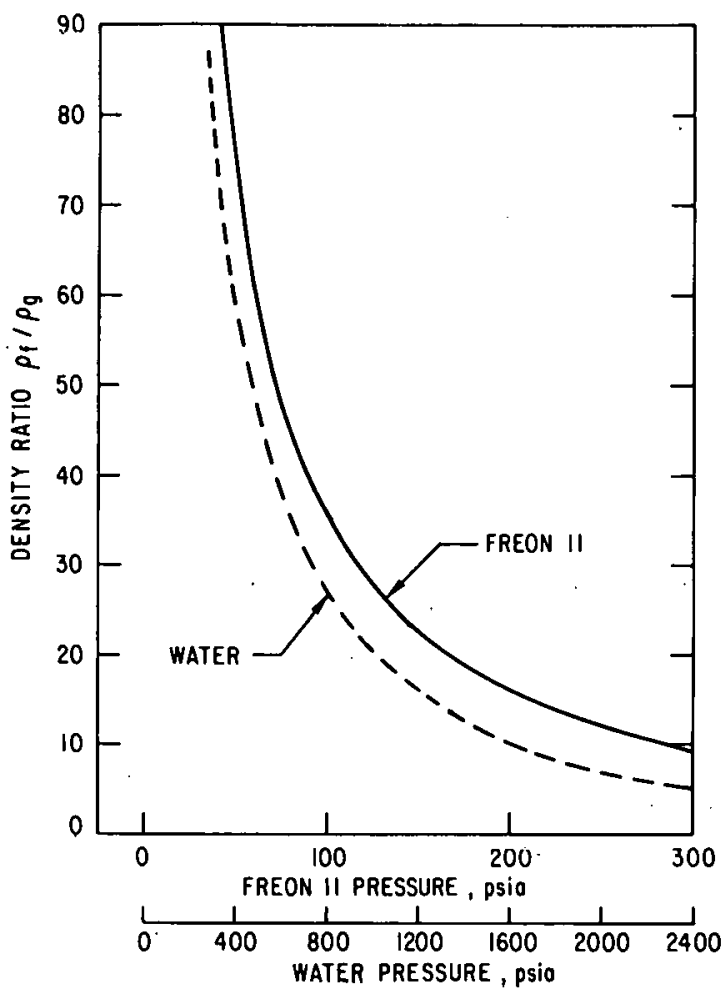

Fig. J.1. Density Ratio for Freon-11 and Water. Conversion factor: 1 psia $=6.895 \mathrm{kPa}$. ANL Neg. No. 900-75-368. as shown in Table XI. Freon conditions during the tests at steady state before initiation of blowdown were used.

Rearrangment of the groups $\mathrm{L}_{\mathrm{h}} / \mathrm{D}_{\mathrm{e}}$, $\mathrm{Re}$, and $\mathrm{Fr}$ leads to $g D_{\mathrm{e}}^{3} / \nu_{\mathrm{f}}^{2}$. Since the kine matic viscosity for Freon- 11 is $40 \%$ greater than that for water, the equivalent diameter in the water system is smaller, $\sim 25 \%$ in this case. For comparison, the geometry is made the same. Further, it would be inconvenient to change model geometry for each pressure level. But this leads to a problem in which both $\mathrm{Re}$ and $\mathrm{Fr}$ cannot be satisfied simultaneously. In the present approximate case, the Froude number rather than the Reynolds number has been maintained, since wide variations in $R e$ have little effect on the friction factor. ${ }^{147}$ The results are shown in Table XII.

2. Tong et a.1. ${ }^{144}$

Tong et al. suggested some dynamic scaling expressions in subcooled and lowquality flow. The physical model pictured

Fig. J.2

Density Ratio vs Reduced Pressure. Conversion factor: 1 psia $=6.895 \mathrm{kPa}$. ANL Neg. No. $900-75-914$.

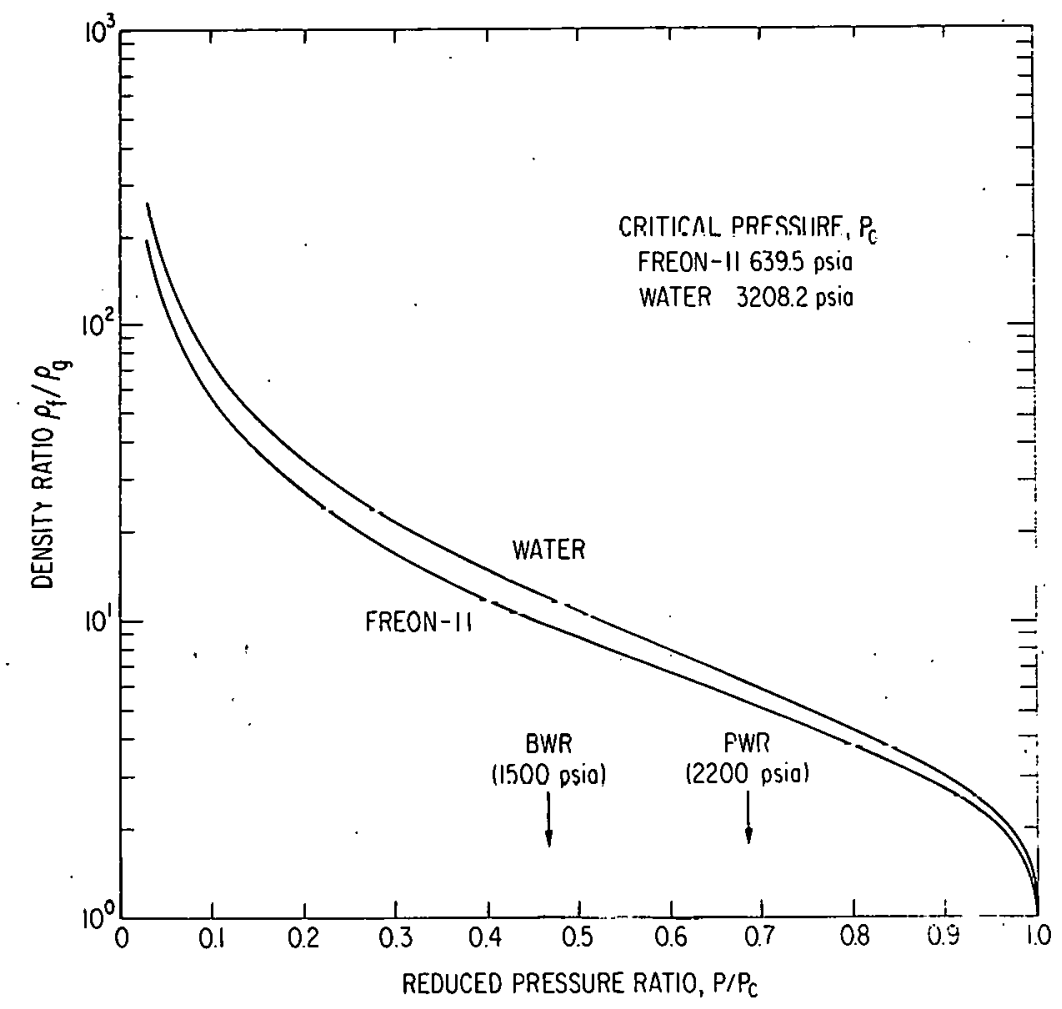


TABLE XI. Thermodynamic and Transport Properties ${ }^{a}$

\begin{tabular}{|c|c|c|}
\hline Parameter & Freon-11 & Water \\
\hline P.psia & 65 & 430 \\
\hline $\mathrm{T}_{\mathrm{SAT}},{ }^{\circ} \mathrm{F}$ & 165 & 452 \\
\hline$\rho_{\mathrm{f}}, 1 \mathrm{~b} \mathrm{~m} / \mathrm{ft}^{3}$ & 84.37 & 51.39 \\
\hline$\rho_{g}, 1 b_{m} / f^{3}$ & 1.485 & 0.93 \\
\hline$\rho_{f} / \rho_{g}$ & 56.0 & 55.5 \\
\hline$\mu_{\mathrm{f}}, 1 \mathrm{~b}_{\mathrm{m}} / \mathrm{hr} \cdot \mathrm{ft}$ & 0.68 & 0.29 \\
\hline$\mu_{\mathrm{g}}, \mathrm{lb}_{\mathrm{m}} / \mathrm{hr} \cdot \mathrm{ft}$ & 0.0311 & 0.0394 \\
\hline${ }^{h_{S A T}}$, Btu $/ 1 b_{m}$ & 42.73 & 432.2 \\
\hline $\mathrm{h}_{\mathrm{fg}}, \mathrm{Btu} / \mathrm{lb} \mathrm{m}$ & 68.68 & 772.6 \\
\hline$v \cdot p t^{2} / 1 b_{f}$ & $6.25 \times 10^{-3}$ & $1: 00 \times 10^{=3}$ \\
\hline $\mathrm{C}, \mathrm{hr} \cdot \mathrm{ft}^{5 / 3} / 1 \mathrm{~b} \mathrm{~m}$ & $9.40 \times 10^{-5}$ & $6.99 \times 10^{-5}$ \\
\hline \multicolumn{3}{|c|}{ 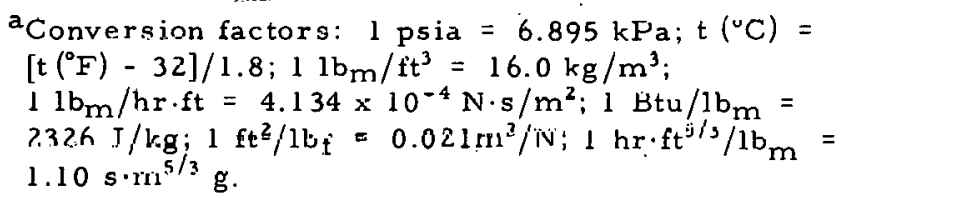 } \\
\hline
\end{tabular}

TABLE XII. Results of Freon-11 Water Scalinga

\begin{tabular}{|c|c|c|c|c|}
\hline & \multirow{2}{*}{$\begin{array}{c}\text { Freon }-11 \\
\text { (present study) }\end{array}$} & \multicolumn{2}{|c|}{ Water Equivalent Conditions } & \multirow[b]{2}{*}{ Redclur Eondition ( $P W R$ ) } \\
\hline & & Zuber's Criteria & Ahmad's Gritcria & \\
\hline$p$, psid & 65 & 430 & 430 & 2250 \\
\hline $\mathrm{D}_{\mathbf{e}}$, in. & 0.22 & 0.22 & 0.2 .2$. & 0.53 \\
\hline $\mathbf{L}_{h}, \mathrm{ft}$ & 2 & 2 & 2 & 12 \\
\hline $\mathrm{T}_{\mathrm{i}},{ }^{\circ} \mathrm{F}$ & 130 & 370 & 370 & 550 \\
\hline$\Delta \mathrm{h}_{\mathrm{i}}, \mathrm{Btu} / \mathrm{lb} \mathrm{m}$ & 7.71 & 89.2 & 86.5 & 151.0 \\
\hline$U_{f i}, f t / s e c$ & 7.5 & 7.5 & 17.3 & 15.0 \\
\hline $\mathrm{G}, 1 \mathrm{~b}_{\mathrm{m}} / \mathrm{hr} \cdot \mathrm{ft}^{2}$ & $2.37 \times 10^{6}$ & $1.39 \times 10^{6}$ & $3.20 \times 10^{6}$ & $2.5 \times 10^{6}(\mathrm{avg})$ \\
\hline$\varphi ;$ Dtu/lin $\cdot \mathrm{ft}^{?}$ & 45,000 & 316,000 & 684,000 & $\begin{array}{l}200,000(\mathrm{avg}) \\
580,000(\max )\end{array}$ \\
\hline $\begin{array}{l}\text { Reynolds } \\
\text { number }\end{array}$ & 63,900 & 87,700 & 202,300 & $5,02,000$ \\
\hline $\begin{array}{l}\text { Froude } \\
\text { number }\end{array}$ & 1.14 & 1.14 & 0.21 & 1.69 \\
\hline
\end{tabular}

${ }^{\mathrm{a}}$ Conversion factors: 1 psia $=6.895 \mathrm{kPa} ; 1 \mathrm{in} .=2.54 \mathrm{~cm} ; 1 \mathrm{ft}=30.48 \mathrm{~cm} ;{ }^{\circ}\left({ }^{\circ} \mathrm{G}\right)=$ $\left[\mathrm{t.}\left({ }^{\circ} \mathrm{F}\right)-32\right] / 1.8 ; 1 \mathrm{Btu} / 1 \mathrm{~b}_{\mathrm{m}}-2326 \mathrm{~J} / \mathrm{kg} ; 1 \mathrm{ft} / \mathrm{s}=0.305 \mathrm{~m} / \mathrm{s} ; 10^{6} \mathrm{lbm} / \mathrm{hr} \cdot \mathrm{ft}^{2}=$ $1356 \mathrm{~kg} / \mathrm{m}^{2} \cdot \mathrm{s} ; 1 \mathrm{Btu} / \mathrm{hr} \cdot \mathrm{ft}^{2}=3.155 \mathrm{~W} / \mathrm{m}^{2}$. 
the existence of a bubble boundary layer sliding between the subcooled core and the heating surface. First the ratio of the vapor mass velocity of vaporization and the liquid mass velocity $G_{f}$ in the subcooled core is defined as the boiling number:

$$
\cdot N_{B o}=\frac{\varphi}{h_{f g} \rho_{f} U_{f}}=\frac{\varphi}{h_{f g} G_{f}} .
$$

A hydrodynamic similitude requires a similar flow pattern, similar velocity, and shear distribution in the channel. The latter is a function of the Reynolds number

$$
R e=\frac{\rho_{f} U_{f} D_{e}}{\mu_{f}} .
$$

Based on Tong's two-phase-flow friction factor ${ }^{16}$

$$
f_{T P} \propto R^{-0.6}
$$

and his boundary-layer analysis at CHF (DNB), the following expression was derived:

$$
\left(\mathrm{N}_{\mathrm{Bo}}\right)_{\mathrm{CHF}}=\mathrm{CRe}^{-0.6}
$$

or .

$$
{ }^{\varphi}{ }_{\mathrm{CHF}}=\mathrm{Ch}_{\mathrm{fg}} G_{f}^{0.4}\left(\frac{\mu_{\hat{f}}}{D_{\mathrm{e}}}\right)^{0.6}
$$

where $C$ is a function of reduced pressure and the properties of the subcooled core. It is to be empirically determined.

Similar flow patterns can be ensured by having the same Froude number, void fraction, and density ratio. This was achieved by requiring geometrically similar channels and equivalent test pressure, giving the same $\rho_{\mathrm{f}} / \rho_{\mathrm{g}}$ value.

The scaling factor determined by an empirical graphical method for Freon-11 was reported only at a water-equivalent pressure of about 1400 psia. :

3. $\underline{\text { Ahmad }}^{143}$

In Ahmad's scaling, the following parameters were first identified: 


$$
\begin{gathered}
f n\left(\varphi, G, \Delta h_{i}, L_{h}, D_{e}, g, h_{f g}, \rho_{f}, \rho_{g}, \mu_{f}, \mu_{g}, C_{p f}, C_{p g}, k_{f},\right. \\
\left.k_{g}, \sigma,\left|\frac{\partial}{\partial \rho}\left(\rho_{f} / \rho_{g}\right)\right|,\left|\frac{\partial T}{\partial P}\right|\right)=0 .
\end{gathered}
$$

Applying the classical dimensional analysis and Buckingham's Pi theorem produced one possible set of 12 dimensionless groups.

Obviously all 12 conditions cannot be satisfied; therefore, some have to be distorted. The "Compensated Distortion Model" introduced a CHF modeling parameter $\psi$ :

$$
\psi=C G\left(D_{C}\right)^{1 / 3}
$$

wherc

$$
C=\left(\frac{\gamma}{\rho_{f} \mu_{f}}\right)^{1 / 3}\left(\frac{\mu_{f}}{\mu_{g}}\right)^{1 / 8}
$$

and

$$
Y=\left|\frac{\partial}{\partial \mathcal{P}}\left(\rho_{\mathrm{f}} / \rho_{\mathrm{g}}\right)\right| .
$$

This model then showed that if $\rho_{f} / \rho_{g}, \Delta h_{i} / h_{f g}$, and $L_{h} / D_{e}$ are made the same for model and prototype, both sets of CHF data drawn on a plot of $\varphi_{\mathrm{CHF}} / \mathrm{Gh}_{\mathrm{fg}}$ versus $\psi_{\text {C.HF }}$ were on the same curve. It was found to be successful with Freun $=12,-113,=11,-21$, and $-114, \mathrm{CO}_{2}$, dnd putassium for clrcular, annular, and rod-bundle geometries. 'I'he result using Ahmad's scaling is shown in Table XII.

\section{Conclusion}

Zuber's $U_{g j} / U_{f i}$ group does not enter into the scaling procedure. This group is characteristic of the flow regime and varies along the length. The expression for vapor-drift velocity is still being developed. Zuber's criteria had met with success in hydrodynamic stability studies in two-phase flow, ${ }^{146,147}$ but had not been attempted to scale steady-state CHF data. The power-reduction factors in Zuber and Ahmad's scaling are 7 and 15, respectively. The discrepancy is certainly due to different approaches used in scaling. However, Ahmad's model should be used for CHF scaling.

The effects of flashing and vapor expansion were brought to attention by Crowley and Bergles ${ }^{147}$ in a low-pressure system, e.g., Freons. At low pressure, where the pressure drop across the test section is large, and hence $\Delta \mathcal{P}_{\mathrm{TS}} / \mathcal{P}$ is significant, the flashing and vapor expansion increase the velocity gradient, which is dynamically different from that caused by heat flux. The problem of high air solubility, extremely good wetting characteristics, and low conductivity found in Freons has not been included in the scaling approach. 


\section{APPENDIX K}

\section{Calculation of Critical Flow Rate}

As a first approximation for low-quality critical flow, the following relation is used: $:^{15}$

$$
G_{C}^{2}=-g_{c}\left[x\left(\frac{d v_{g}}{d \mathcal{P}}\right)+v_{g}\left(\frac{d x}{d \mathcal{P}}\right)\right]^{-1},
$$

where if we set $x=x(p(z))$ the derivative $d x / d P$ may be expressed as the quotient $(\mathrm{dx} / \mathrm{d} \mathrm{z}) /(\mathrm{d} \mathcal{P} / \mathrm{dz})$ and approximated by $(\Delta \mathrm{x} / \Delta \mathrm{z}) /(\Delta \mathcal{P} / \Delta \mathrm{z})$. The derivative $\mathrm{dv} / \mathrm{d} \boldsymbol{P}$ may be evaluated using thermodynamic data.

The data of Run 6/9 at $200 \mathrm{~ms}$ were taken to make the following calculation since both pressure profile (see Fig. 46) and velocity (see Fig. 56) were available.

Time: $200 \mathrm{~ms}$

Pressure at upper channel: $\mathcal{P}_{i}=53.0 \mathrm{psia}(365 \mathrm{kPa})$

Pressure al $\mathrm{z}=6$ in. $(15 \mathrm{~cm}): \mathcal{P}=50.5 \mathrm{psia}(348 \mathrm{kPa})$

Pressure at lower channel: $P_{0}=48.0 \mathrm{psia}(331 \mathrm{kPa})$

Void at upper channel: $\alpha_{i} \approx 0.10$

Void at lower channel: $\alpha_{0} \simeq 0.80$

Velocity at lower channel: $U_{0} \simeq 22 \mathrm{ft} / \mathrm{s}(6.7 \mathrm{~m} / \mathrm{s})$

Uniform heat flux: $\varphi=46,300 \mathrm{Btu} / \mathrm{hr} \cdot \mathrm{ft}^{2}\left(146 \mathrm{~kW} / \mathrm{m}^{2}\right)$.

1. First, the inlet quality $x_{i}$ at the upper channel can be estimated in two ways.

a. If the homogeneous-flow model and $\alpha_{i} \approx 0.10$ are assumed,

$$
x_{i}=\frac{\alpha_{i}}{\left(1-\alpha_{i}\right) \frac{\rho_{f}}{\rho_{g}}+\alpha_{i}}
$$


and

$$
x_{i}=0.0015 \text {. }
$$

b. If an isentropic expansion as outlined in Appendix $F$ is assumed,

$$
S_{0}=S_{f}+x S_{f g}
$$

where

$$
\begin{aligned}
\mathrm{S}_{0}\left[151{ }^{\circ} \mathrm{F}\left(66^{\circ} \mathrm{C}\right)\right] & =0.07723 \mathrm{Btu} / 1 \mathrm{~b} \mathrm{~m} \cdot{ }^{\circ} \mathrm{R}\left(179.64 \mathrm{~J} / \mathrm{kg} \cdot{ }^{\circ} \mathrm{R}\right), \\
\mathrm{S}_{\mathrm{f}}[53 \mathrm{psia}(365 \mathrm{kPa})] & =0.07717 \mathrm{Btu} / 1 \mathrm{~b}_{\mathrm{m}} \cdot{ }^{\circ} \mathrm{R}\left(179.50 \mathrm{~J} / \mathrm{kg} \cdot{ }^{\circ} \mathrm{R}\right),
\end{aligned}
$$

a.rul

$$
\mathrm{S}_{\mathrm{fg}}[5.3 \text { Isia }(365 \mathrm{k.Pa})]-0.11512 \mathrm{Blu} / 1 \mathrm{~b}_{\mathrm{m}} \cdot 1 \mathrm{~K}\left(267.77 \mathrm{~J} / \mathrm{kg} \cdot{ }^{\circ} \mathrm{K}\right) .
$$

Then,

$$
x_{i}=0.0005 .
$$

Therefore the enthalpy at the inlet is

$$
\begin{aligned}
h_{i} & =h_{f}+x h_{f g} \\
& =h_{f} \\
& =39.50 \mathrm{Btu} / 1 b_{m}(91.88 \mathrm{~kJ} / \mathrm{kg}) .
\end{aligned}
$$

2. If a quasi-steady-state condition is as sumed, the heat balance between the inlet at the upper channel and the $z=6$-in. $(15-\mathrm{cm})$ location can be written as

$$
h_{i}+\frac{\pi D_{i} \varphi L}{W}=h_{f}+x h_{f g} \text {, }
$$

where the terms on the right-hand side are evaluated at the pressure corresponding to the $z=6$-in. $(15-\mathrm{cm})$ location $[\approx \equiv 50.5 \mathrm{psia}(34 \mathrm{kPa})]$.

Mass flow and velocity are estimated as

$$
W=A_{x} G
$$

and

$$
G=\rho_{2 \varphi} U \text {, }
$$


and $\rho_{2 \varphi}$-is the two-phase density, given by

$$
\rho_{2 \varphi}=\alpha \rho_{\mathrm{g}}+(1-\alpha) \rho_{\mathrm{f}} \text {. }
$$

From the measurement at the lower void probe

$$
\rho_{2 \varphi}=18.16 \mathrm{lb} / \mathrm{ft}^{3}\left(290.56 \mathrm{~kg} / \mathrm{m}^{3}\right) \text {; }
$$

thus,

$$
G=1.44 \times 10^{6} 1 b_{m} / \mathrm{hr} \cdot \mathrm{ft}^{2}\left(1953 \mathrm{~kg} / \mathrm{m}^{2} \cdot \mathrm{s}\right)
$$

and

$$
\mathrm{W}=3128 \mathrm{lb} \mathrm{m} / \mathrm{hr}(0.126 \mathrm{~g} / \mathrm{s}) \text {. }
$$

Equation K.4 then yields the quality at $z=6$ in. $(15 \mathrm{~cm})$ :

$$
x(z=6 \text { in. })=0.077 \text {. }
$$

By use of the same heat balance, the quality at the $z=0$ location is estimated to be

$$
\mathbf{x}(z=0 \text { in. })=0.113 .
$$

The derivatives in Eq. K.l can be approximated as

$$
\frac{\Delta x / \Delta z}{\Delta P / \Delta z}=\frac{0.077-0.113}{50.5-48.0}=-0.0144
$$

where $\Delta z$ is taken at the bottom 6 in. $(15 \mathrm{~cm})$ of the heated section and

$$
\frac{\Delta \mathrm{v}_{\mathrm{g}}}{\Delta \not D}=\frac{0.856-0.898}{50.5-48.0}=-0.0172
$$

Thus the critical mass velocity at $\mathrm{z}=0 \mathrm{in}$. is

$$
\begin{aligned}
G_{c} & =\left\{\frac{-32.2\left(1 b_{m} \cdot \mathrm{ft}\right) /\left(1 b_{\mathrm{f}} \cdot \mathrm{sec}^{2}\right) 144 \mathrm{in}^{2} / \mathrm{ft}^{2}}{[0.113(-0.0172)+0.898(-0.0144)]\left(\mathrm{ft}^{3} \cdot \mathrm{in}^{2}\right) /\left(1 \mathrm{~b}_{\mathrm{m}} \cdot 1 \mathrm{~b}_{\mathrm{f}}\right)}\right\}^{1 / 2} \\
& =2.01 \times 10^{6} \mathrm{lb} \mathrm{m} / \mathrm{hr} \cdot \mathrm{ft}^{2}\left(2725.56 \mathrm{~kg} / \mathrm{m}^{2} \cdot \mathrm{s}\right) \\
G / G_{c} & =0.72 .
\end{aligned}
$$

The values for $\alpha_{0}$ and $U_{0}$ were varied by $\pm 10 \%$ to study the sensitivity of the ratio $G / G_{c}$. In no case was this ratio calculated to be $>0.8$. 
A similar calculation was performed at the bottom $6-$ in. $(15-\mathrm{cm})$ unheated length. The quality of the exiting end was evaluated using an isentropic calculation, and the derivatives were estimated in the same manner. The critical mass velocity at $\mathrm{z}=-6 \mathrm{in} .(-15 \mathrm{~cm})$ is

$$
\begin{aligned}
G_{c} & =3.1 \times 10^{6} 1 b_{m} / h r \cdot \mathrm{ft}^{2}\left(4203.6 \mathrm{~kg} / \mathrm{m}^{2} \cdot \mathrm{s}\right) ; \\
G / G_{c} & =0.46 .
\end{aligned}
$$




\section{APPENDIX L}

\section{Calculation of Critical Heat Flux}

Two CHF modeling approaches, namely, those of Tong ${ }^{144}$ and Ahmad ${ }^{143}$ have been outlined in Appendix $J$. An attempt to use the former approach met with difficulty because the empirical scaling factor for Freon-1 l was given for pressures of greater than $250 \mathrm{psia}(1.72 \mathrm{MPa}),{ }^{144}$ which are much higher than those involved in the present investigation. The result of the latter approach was summarized in Table XII. By knowing the water-equivalent conditions, we can estimate the operating CHF level, using existing correlations developed for water. Unfortunately, to my knowledge, no water CHF data for annuli have been reported at around $400 \mathrm{psia}(2.76 \mathrm{MPa})$. However, a CHF correlation for annular geometries that is independent of fluid types was developed from Freon-12 data. ${ }^{148}$ On the basis of Ahmad's "Compensated Distortion Model," the following prediction equation was proposed:

$$
W^{*}=\left(1-e^{-\rho * E *}\right)
$$

where $W^{*}$, the reduced power number, is defined as

$$
\begin{aligned}
& W^{*}=\frac{4 L \varphi /\left(G h_{f g} D_{h}\right)}{1-x_{i}}, \\
& \rho^{*}=f n\left(\rho_{f} / \rho_{g}\right),
\end{aligned}
$$

and

$$
E^{*}=\operatorname{fn}\left(\psi_{\mathrm{CHF}}, \mathrm{L} / \mathrm{D}_{\mathrm{e}}, \mathrm{x}_{\mathrm{i}}\right)
$$

The resulting correlation obtained with Freon-12 data between 88 and 244 psia (0.61 and $1.68 \mathrm{MPa})\left(0.15<\mathrm{P}_{r}<0.41\right)$, is

$$
\mathrm{W}^{*}=1-\exp \left[-0.025\left(\rho_{\mathrm{f}} / \rho_{\mathrm{g}}-1\right)^{0.266} \mathrm{E}\left(1-\mathrm{x}_{\mathrm{i}}\right)^{3.9} / \sqrt{\mathrm{E}}\right]
$$

where

$$
E=\left(\frac{L}{D_{e}}\right)^{0.715} / \psi_{C H F}^{0.866}
$$

Equation L. 6 was used to calculate the critical heat flux during steady state and transient as summarized in Table XIII. The results, however, have to be regarded with caution, since the correlation was developed at a higher pressure range and at relatively constant pressure along the test section. During the blowdown, the fluid properties change more drastically along the test section due to large pressure drop; hence, the correlation, which is in terms of the inlet subcooling or quality, is bound to be less accurate. 
TABLE XIII. Summary of Estimations of Critical Heat Flux ${ }^{2}$

\begin{tabular}{|c|c|c|c|c|c|c|c|}
\hline Case & No.: & 1 & 2 & 3 & 4 & 5 & 6 \\
\hline Run & No.: & $\begin{array}{c}5 / 29, j / 4 \\
6 / 9, \text { anc } 6 / 12\end{array}$ & $5 ; 29$ & $j / 29$. & $5 / 29$ & $6 / 4$ and $6 / 9$ & $\begin{array}{c}5 / 29,6 / 4 \\
6 / 9, \text { and } 6 / 12\end{array}$ \\
\hline Time, $\mathrm{s}$ & & $<0$ & 3.0 & 20.0 & 35.0 & 3.0 & $\sim 0.3$ \\
\hline $\mathcal{P}$, psiab $^{\circ}$ & & 65 & 48 & 43 & 40 & 48 & 50 \\
\hline $\mathrm{T}_{\mathrm{SAT}},{ }^{\mathrm{c}} \mathrm{F}$ & & 165 & 144 & 13.7 & 132 & 144 & 147 \\
\hline$\rho_{f}, 1 b_{m} / \mathrm{ft}^{3}$ & & 84.37 & 86.32 & 86.96 & .87 .41 & 86.32 & 86.05 \\
\hline$p_{f} / p_{g}$ & & 56.0 & 77.63 & $8 \epsilon .48$ & 93.55 & 77.63 & 74.18 \\
\hline$\mu_{\mathrm{f}}, 1 b_{\mathrm{m}} / \mathrm{hr} \cdot \mathrm{ft}$ & & 0.68 & 0.743 & 0.765 & 0.782 & 0.743 & 0.730 \\
\hline$\mu_{\mathrm{g}}, \mathrm{lb}_{\mathrm{m}} / \mathrm{ax} \cdot \mathrm{ft}$ & & 0.031 & 0.0305 & 0.0301 & 10.0298 & 0.0305 & 0.0305 \\
\hline$h_{f g}=13 t u / 1 b_{m}$ & & 68.68 & 70.98 & $7 \mathrm{i} .69$ & 72.19 & 70.98 & 70.68 \\
\hline$\gamma, \mathrm{ft}^{2} / 1 \mathrm{~b}_{\mathrm{f}}$ & & 0.0063 & 0.0117 & 0.0145 & 0.0167 & 0.0117 & 0.0105 \\
\hline $\mathrm{C}, \mathrm{hr} \cdot \mathrm{ft}^{5, \mathrm{ij}} / \mathrm{lb} \mathrm{m}$ & & $9.4 \times 10^{-5}$ & $1.14=10^{-4}$ & $1.21 \times 10^{-4}$ & $1.26 \times 10^{-4}$ & $1.14 \times 10^{-4}$ & $1.10 \times 10^{-4}$ \\
\hline $\mathrm{G}, 1 \mathrm{~b}_{\mathrm{m}} / \mathrm{hr} \cdot \mathrm{ft}^{2}$ & & $2.4 \times 10^{6}$ & $1.55 \times 10^{3^{c}}$ & $1.06 \times 10^{6^{c}}$ & $0.55 \times 10^{6}=$ & $1.36 \times 10^{-6 \mathrm{C}}$ & $1.0 \times 10^{6 \mathrm{~d}}$ \\
\hline${ }^{\mathrm{CHFF}}$ & . & . $\quad 59.3$ & 46.54 & 33.67 & 18.1 & 42.08 & 29.0 \\
\hline$x_{i}$ & & -0.10 & $\sim 0.0^{\mathrm{e}}$ & $0.01^{\mathrm{e}}$ & $0.02 \mathrm{e}$ & $\sim 0.0^{\mathbf{e}}$ & -0.0 \\
\hline $\mathrm{w}^{*}$ & & 0.087 & 0.081 & 0.106 & 0.179 & 0.087 & 0.115 \\
\hline${ }^{\varphi} \mathrm{CHF}, \mathrm{Btu} / \mathrm{hr} \cdot \mathrm{ft}^{2}$ & & 30,500 & 45,820 & 41,400 & 36,000 & 43,450 & 41,760 \\
\hline$\dot{\mathrm{C}} \mathrm{HFR}^{\mathrm{f}}$ & & 1.75 & 1.01 & 0.91 & 0.79 & 0.94 & 0.91 \\
\hline Observation & & No $\mathrm{CHF}$ & No $C H F$ & No CHF & $\mathrm{CHF}$ & $\mathrm{CHF}$ & $\mathrm{CHF}$ \\
\hline
\end{tabular}

a Conversion factors: 1 psia $=6.895 \mathrm{kPa} ; \mathrm{t}\left({ }^{\circ} \mathrm{C}\right)=\left[\mathrm{t}\left({ }^{\mathrm{D}} \mathrm{F}\right)-32: / 1.8 ; 11 \mathrm{bm} / \mathrm{ft}^{3}=16 \mathrm{~kg} / \mathrm{m}^{3} ; 11 \mathrm{lb} \mathrm{m} / \mathrm{hr} \cdot \mathrm{ft}=4.134 \mathrm{x} 10^{-4} \mathrm{~N} \cdot \mathrm{s} / \mathrm{m}^{2}\right.$ $1 \mathrm{Btu} / 1 \mathrm{bm}=2326 \mathrm{~J} / \mathrm{kg} ; 1 \mathrm{ft}^{2} / 1 \mathrm{~b}_{\mathrm{f}}=0.021 \mathrm{~m}^{2} / \mathrm{N} ; 1 \mathrm{hr} \cdot \mathrm{t}^{5 / 3} / 1 \mathrm{bm}=1.10 \mathrm{~s} \cdot \mathrm{m}^{5 / 3} / \mathrm{g} ;: 0^{6} \mathrm{lbm} / \mathrm{mr} \cdot \mathrm{ft}^{2}=1356 \mathrm{~kg} / \mathrm{m}^{2} \cdot \mathrm{s}$.

bPressure is taken at the flow exit of the heated zone.

c The mass velocity is based on the vreight-transdice r signal of the blowdown vessel.

d Because sharp flow decay occurred about $300 \mathrm{~ms}$, is shown.in Figs. $55-57$, a rean value of $\mathrm{U}=15 \mathrm{ft} / \mathrm{s}$ at $80 \%$ void was used to calculate the mass velocity.

e The inlet quality is calculated based on isentropic expansion.

${ }^{\mathrm{f} C a l c u l a t e d C H F / o p e r a t i n g ~ h e a t ~ f l i x ; ~ C H F ~ o c c u r s ~ w h e n ~ C H F R ~}<1.0$. 


\section{ACKNOW LEDGMENTS}

I wish to express my gratitude to my co-advisors, Dr. Robert E. Henry, who introduced me to the two-phase-blowdown heat-transfer problem and gave me valuable suggestions and encouragement; Dr. Owen C. Jones, who gave freely of his time and knowledge; and Professor George Bankoff, who has been devoted to me as a teacher at Northwestern University and has stimulated my study in boiling heat transfer. Special thanks are due to Dr. Paul A. Lottes for his constant interest and support in the present work.

Personal thanks are extended to Mr. Elmer R. Gunchin, who aided in the construction, maintenance, and operation of the experimental apparatus. My sincere thanks are due to Mr. Edward A. Spleha and Mr. Daniel J. Quinn for their all-around assistance and technical advice. I wish also to thank Mr. Louis M. McUmber and Mr. Benigno T. Banez for helping with the highspeed photography and electronic components, respectively. Last, but not least, my thanks to Mr. Henry J. Shepelak, who performed the machining work.

Thanks are due to Professors J. C. Slattery and D. T. Eggen for serving as members of the thesis advisory committee and for reviewing this work.

This research was performed under the auspices of the U. S. Nuclear Regulatory Commission. The investigation was conducted at Argonne National Laboratory, Reactor Analysis and Safety Division, Argonne, Illinois. 


\section{REFERENCES}

1. L. J. Ybarrondo, C. W. Solbrig, and H. S. Isbin, The "Calculated" Lossof-Coolant Accident: A Review, AIChE Monograph Series No. 7 (1972).

2. I. Catton, J. 0. Cermak, Y. S. Kuo, Prajoto, and A. R. Wazzan, Swmary of the Evaluation of Several Aspects of the Hypothetical Loss of Coolant Accident for Light Water Reactors, Volumes I and II, UCLA-ENG-7450 (June 1974).

3. Interim Acceptance Criteria for Emergency Core Cooling Systems for LightWater Power Reactors, Federal Register 36(125), 12247 (1971).

4. H. D. Curet, J. A. Dearien, J. R. Larson, S. W. Solbrig, and

L. Y. Ybarrondo, Loss-of-Coolant Accident Analysis Progrom, IN-1382

(June 1970).

5. J. G. Collier, Ileat Transfer and Fluid Dynmice Research as Applied to Fog Cooled Power Reactors, AECL 1631 (1962).

6. F. E. Tippets, Critical Heat Fluxes and Flow Pattemo in High-Fressure Boiliniy Wule' Flowe, J. Heat 'I'ransfer 86, 12 (1964).

7. L. S. Tong, Boiling Crisis and Critical Heat Flux, TID-25887 (1972).

8. J. G. Collier, Convective Boiling and Condensation, McGraw-Hill Book Co., United Kingdom (1972).

9. Y. P. Chang, An Analysis of the Critical Conditions and Bumout in Boiling Heat Transfer, TID-14004 (1961).

10. S. G. Bankoff, On the Mechanism of Subcooled Nucleate Boiling. Part I, Preliminary Coneiderations. Part II, Sequential Kate Process Model, AIChE Reprints No. 19 and 20, Fourth Nat.. Heat Transfer Conf. (1960).

11. G. J. Kirby, R. Staniforth, and J. H. Kinneir, A Visual Study of Forced Convection Boizing, Part I, AEEW-R281 (1965).

12. G. J. Kirby, R. Staniforth, and J. H. Kinneir, A Visud, stady of Foreed Convection Boiling, Part II, AEEW-R506 (1967).

13. G. J. Kirby, R. Staniforth, and J. H. Kinneir, An Investigation into a Possible Mechanism of Subcooled Bumout, AEEW-M725 (1966).

14. M. P. Fiori and A. E. Bergles, "Model of Critical Heat Flux in Subcooled Flow Boiling," Fourth Int. Heat Transfer Conf., Paris, Paper B6.3 (1970).

15. S. S. Kutateladze and A. E. Leont'ev, "Some Applicalions of the Asymtotic Theory of the Turbulent Boundary Layer," Proc. Third Int. Heat Transfer Conf., AIChE Paper No. 81 5, 1 (1966).

16. L. 3. Tung, Buundary Layer Analysis of the Flow Boiling Crisis, Int. J. Heat Mass Transfer 11, 1208 (1968).

17. R. A. Dean, R. S. Dougal1, and L. S. Tong, "Effect of Vapor Injection on Critical Heat Flux in a Subcooled R-113 Flow," Int. Symp. on Two-Phase Flow Syctem, Haifa, Israel (1971).

18. J. C. Purcupile and S. W. Gouse, Reynolds Flux Model of Critical Heat Flux in Subcooled Forced Convection Boiling, ASME Paper No. 72-HT-4 (1972).

19. R. G. Vanderwater, An Analysis of Bumout in Two-Phase, Liquid-Vapor Flow, Ph.D. thesis, University of Minnesota (1956). 
20. H. S. Isbin, R. Vanderwater, H. K. Fauske, and S. Singh, A ModeZ for Correlating Two-Phase, Steam-Water, Bumout Heat-Transfer Fluxes,

J. Heat Transfer 83, 149 (1961).

21. T. M. Grace, The Mechanism of Bumout in Initially Subcooled Forced Convective Systems, Ph.D thesis, University of Minnesota (1964).

22. K. M. Becker and P. Persson, An Analysis of Bumout Conditions for Flow of Boiling Water in Vertical Round Ducts, J. Heat Transfer 86, 515 (1964).

23. K. Goldmann, H. Firstenberg, and C. Lombardi, Bumout in Turbulent Flow-A Droplet Diffusion Model, J. Heat Transfer 83, 158. (1961).

24. R. P. Stein, "Fog-Flow Models," Proc. 2nd Joint USAEC Euratom Two-Phase Flow Meeting, Germantown, p. 367 (1964).

25. F. E. Tippets, Analysis of Critical Heat-Flux Condition in High Pressure Boiling Water Flows, J. Heat Transfer 86, 23 (1964).

26. H. S. Chung, Theoretical Model for Burnout in Two-Phase Annular Dispersed Flow, ASME Paper No. 73-HT-36 (1973).

27. G. F. Hewitt, H. A. Kearsey, P. M. C. Lacey, and D. J. Pulling, Burmout and Nucleation in Climbing Film Flow, Int. J. Heat Mass Transfer 8, 793 (1965).

28. G. F. Hewitt, H. A. Kearsey, P. M. C. Lacey, and D. J. Pulling, Burnout and Film Flow in the Evaporation of Water in Tubes, Proc. Inst. Mech. Eng. 180(3C), 206 (1966).

29. C. S. Yih, Stability of Liquid Flow Down an Inclined Plane, Phys. Fluids $6(3), 321$ (1963).

30. T. B. Benjamin, Wave Formation in Lominar Flow Down an Inclined Plane, J. Fluid Mech. 2(6), 554 (1957).

31. S. G. Bankoff, Stability of Liquid Flow Down a Heated Inclined Plane, Int: J. Heat Mass Transfer 14, 377 (1971).

32. W. S. Norman and V. McIntyre, Heat Transfer to Liquid Film on a Vertical Surface, Trans. Inst. Chem. Eng. 38, 301 (1960).

33. V. A. Hallett, Surface Phenomena Causing Breakdown of Falling Liquid Films During Heat Triansfer, Int. J. Heal Mass Transfer 8, 283 (1966):

34. F. F. Simon and Y. Y. Hsu, ThermocapizZary Induced Breakdown of a Falling Liquid Film, NASA TN D-5624, Vo1. 30 (1970).

35. G. P. Dubrovskii, A. Y. Didenko, and I. S. Kokorev, Effect of Nonisothermicity on Stability of Free-Faliing Water Films, Atomnaya Energia $31(6)$, 621 (1971).

36. Acceptance Criteria for Emergency Core Cooling Systems for Light-Water Cooled Nucloar Power Renctors, Federal Register 39(3), 1001 (1974).

37. L. S. Tong, Prediction of DNB for Axially Non-uniform Heat Flux Distribution, J. Nucl. Energy 21, 241 (1967).

38. J. S. Gellerstedt et al., "Correlation of Critical Heat Flux in a Bundle Cooled by Pressurized Water," Two-Phase Flow and Heat Transfer in Rod Bund7es, ASME Publication, p. 63 (1969). 
39. R. V. Macbeth, Burmout Analysis. Part 4. Application of a Local Condition Hypothesis to World Data for Uniformly Heated Rounded Tubes and Rectangular Channels, AEEW-R-267 (1963).

40. B. C. Slifer, Loss-of-Coolant Accident and Emergency Core Cooling Models for General Electric Boiling Water Reactors, NED0-10329 (1971) NEDO-10329, Supplement 1 (1971).

41. R. Cole, Investigation of Transient Pool Boiling Due to Sudden Large Power Surge, NASA-TN-3885 (1956).

42. R. W. Graham, Expeximental Observations of Transient Boiling of Subcooled Water and Alcohol on a Horizontal Surface, NASA-TND-2507 (1964).

43. M. W. Rosenthal and R. L. Miller, An Experimental Study of Transient Boiling, ORNL-2294 (1957).

44. V. M. Borishanokiy and B. S. Foklr, Orlset of Heat lransfer Crisio with Unsteady Inerease in Heat Flux, Heat Transfer-Eoviet Res. 1(5), 27 (1969).

45. W. B. Hall and W. G. Harrison, "Transient Bniling of Water at Atmospheric Preoourc," Prace. Thiril Irlt. Heat l'ransfer C'onf'., Chicago, Vol. 3, p. 186 (1966).

46. F. Tachibana, M. Akiyama, and H. Kawamura, Heat Transfer and Critical Heat Flux in 'I'ransient Boiling, Part I, J. Nuc1. Sci. Technol. (Tokyo) $5(3), 117$ (1968).

47. H. A. Johnson, "Transient Boiling Heat Transfer," Fourth Int. Ileat Transfer Conf., Paris, Paper B3.1 (1970).

48. H. A. Johnson et al., Reactor Heat Transients Project, University of California, Berkeley, SAN-1001 (Jan 1961) to SAN-1013 (May 1966).

49. V. E. Schrock et al., Transient Boiling Phenomena, Vols. I and II, University of California, Berkeley, Report No. NE-66-2 (1966).

50. A. Sakura1, K. Mizukami, and M. Shiotsu, "Experimental Scudies on Transient Boiling Heat Transfer. and Burnout," Founth Int. Ileat Tpurlsfer conf", Paris, Paper B3.4 (1970).

51. J. R. Howell and K. J. Bell, An Experimental Investigation of the Effect of Pressure Transients on Pool Boiling Burnout, Chem. Eng. Prog. Symp. Series, No. 41, 59, 88 (1963).

52. L. S. Tong, J. E. Bishop, J. E. Casterline, and B. Matzner, Transient DNB Test on CVTR Fuel Assembly, ASME Paper No. 65-WA/NE-3 (1965).

53. L. S. Tong, H. Chelemer, J. E. Casterline, and B. Matzner, "Critical Heat Flux (DNB) in Square and Triangular Array Rod Bundles," JSME 1.967 SemiInleirlutional symposizm, Tokyo (1967).

54. D. Moxon and P. A. Edwards, Dryout During Flow and Power Transients, AEEW-R-553 (1967).

55. J. A. Redfield, CHICKIN: A Fortran Progrom for Intormediate and Fusl Transients in a Water Moderated Reactor, WAPD-TM-479 (Jan 1965).

56. A. Premoli, An Experimental Investigation on Voiding of Power Channels Cooled by Stecm-water Mixtures, Energia Nucleare 16(10), 625 (1969).

57. J. O. Cermak, R. F. Farman, L. S. Tong, J. E. Casterline, S. Kokolis, and B. Matzner, The DNB in Rod Bundles During Pressure Blowdown, J. Heat Transfer 92, 621 (1970). 
58. C. G. Lawson, Heat Transfer from Electrically Heated Rods During a Simulated LOCA, Chem. Eng. Prog. Symp. Ser. 19(119), 1 (1971).

59. ORNL Nuclear Safety R\&D Program, Bimonthly Report for Jan-Feb 1970 (1971).

60. C. G. Lawson, R. H. Chapman, and H. W. Hoffman, "PWR Blowdown Heat Transfer Separate-Effects Program," Water Reactor Safety Meeting, Salt Lake City, Mar 26-28, p. 380 (1973).

61. ORNL Quarterly Progress Report on Reactor Safety Progroms for JulySeptember 1974, ORNL-TM-4729, Vol. I (1974).

62. H. Kawamura, F. Tachibana, and M. Akiyama, "Heat Transfer and DNB Heat Flux in Transient Boiling," Fourth Int. Heat Transfer Conf., Paris, Paper No. B3.3 (1970).

63. R. T. Lahey et al., Deficient Cooling, 7th Quarterly Progress Report jan 1--Mar 31, 1971, GEAP-10221-7 (1971).

64. R. T. Lahey, B. S. Shiralkar, J. M. Gonzalez, and L. E. Schnebley, The Analysis of Transient Critical Heat Flux, GEAP-13249 (1972).

65. B. S. Shiralkar, E. E. Polomik, R. T. Lahey, J. M. Gonzalez, D. W. Radcliffe, and L. E. Schnebly, Transient Critical Heat Flux-Experimental Results, GEAP-13295 (1972).

66. R. F. Farman and J. O. Cermak, Post DNB Heat Transfer During Blowdown, WCAP-7837 (1972).

67. C. D. Morgan, D. H. Roy, R. A. Hedrick, R. H. Stoudt, L. A. Zielke, and J. S. Gellerstedt, "Analytical and Experimental Investigation of Heat Transfer During Simulated Cold-leg Blowdown Accidents," CREST Specialist Meeting on Emergency Core Cooling for Light. Water Reactors, Munich (1972).

68. 0. K. Smirnov, L. T. Pashkov, and V. N. Zaitsev, Investigation of CHF with Decrease in Flow Through a Heated Tube, Teploenergetika 19(9), 83 (1972), or Thermal Eng., p. 122 (Sept 1973).

69. G. Fritz and W. Riebold, "Experimental Investigation for the Post-Crisis Heat Transfer in a Subcooling Subchannel of a PWR During Depressurization," CREST Specialist Meet. on Emergency Core Cooling for Light Water Reactors, Munich (1972).

70. D. Hein and F. Mayinger, "Burnout Power in Transient Conditions," Seminar on Two-Phase Flow Thermohydraulics, Rome (1972).

71. E. Hicken, E. Koch, and O. Schad, "Heat Transfer During Blowdown with an Inside Cooled Tube as Test Section," CREST Specialist Meet. Emergency Core Cooling (ECC) for Light Water Reactors, Munich (1972).

72. M. Tokumitsu, "Full Scale Safety Experiments on FUGEN," CREST Specialist Meet. Emergency Core Cooling (ECC) for Light Water Reactors, Munich (1972).

73. ANC Annual Report of Nuclear Safety Research, Jan-Dec 1970, p. 155, ANCR-1089 (1972).

74. G. P. Gaspari, R. Granzini, and A. Hassid, Dryout Onset in Flow Stoppage, Depressurization, and Power Surge Transients, Energia Nucleare 20(10), 554 (1973).

75. G. P. Gaspari, R. Granzini, A. Premoli, and C. Sandri, "Mass Holdup, Pressure, and Time-to-Dryout Predictions under LOCA Conditions. Comparisons with Scaled-down Experimental Results," European Two-Phase Flow Group Meeting, Harwell, England (1974). 
76. L. A. Zielke and R. H. Wilson, Transient Critical Heat Flux and Spacer Grid Studies, Nucl. Tech. 24, 13 (1974).

77. S. Aoki, A. Inoue, Y. Kozawa, T. Furubayaski, M. Aritomi, T. Nakajima, and H. Okazaki, "Critical Heat Flux under Transient Condition (Case of Transient. Heat Input)," Int. Meet. Reactor Heat Transfer, Karlsruhe, Germany, Paper No. 2 (Oct 1973).

78. S. Aoki, A. Ionue, and Y. Kozawa, "Transient Boiling Crisis During Rapid Depressurization," Fifth Int. Heat Transfer Conf., Tokyo, Paper B6.3 (1974).

79. F. A. Price, Transient Critical Heat Flux During Flow Reversal, M.S. thesis, MW Dept., MIT (1975).

80. R. A. Smith, Critical Heat Flux in Flow Reversal Transients, Ph.D. thesis, ME Dept., MIT (May 1975).

81. S. Banerjee, R. B. Jeffries, H. Goulding, and T. Jaganothan, "Experiments and Analysis by the Method of Characteristics of Loss-of-Coolant Accidents," Int. Meet. Reactor Heat Transfer, Karlsruhe, Germany (ner 1.973).

82. S. Banerjee, W. T. Hancox, R. B. Jeffries, and M. T. Sulatisky, "Transient Two-Phase Flow and Heat Transfer During Blowdown from Subcooled Conditions with Heat Addition," 15th National Heat Tranofer Conf., San Francisco (Aug 1975).

83. D. Moxon, SLIP--A Dynamic Programme for the Thermal-hydraulic Behavior of Boiling Loops, AEEW-R-448 (1968).

84. A. Magni, TILT: A Digital Simulation Programme for the Study of Hydrodynomic Processes and core Heat-up of a Boiling Water Pressure Tube Reactor During Transient Corlitions, Energia Nucleare 20(5), 293 (1973).

85. A. Hassid and R. Rychlicki, An Attempt to Use Steady-State Data for Determining CHF in Transient Conditions, Energia Nuc1eare 18(6), 333 (1971).

86. J. A. Redfield, S. G. Margolis, J. H. Murphy, and G. A. Snyder, Losis of Coolant from a Simulated Reactor Loop, Nucl. Appl. 3, 206 (1967).

87. S. G. Margolis and J. A. Redfield, FLASH: A Program for Digital Simulation of the Loss-of-Coolant Accident, WAPD-TM-534 (May 1966).

88. CRAFT-DEscription of Mndel. for E'quilibrium LOCA Anul.ysi.s Froyrum (Proprietary), BAW-10030 (Oct 1971).

89. D. J. Olson, Semiscale BZowdown ECC Project Test Report, ANCR-1036 (1972).

90. J. A. Block and G. B. Wallis, "Heat Transfer and Fluid Flows Limited by Flooding," AIChE/ASME 15th Nat. Heat Transfer Conf., San Franciaco. (Aug 1975).

91. C. T. Avedisian and P. Griffith, Critical Heat Flux in, Counter-Current Flow, ME Dept., MIT, Report No. 80620-84 (Feb 1974).

92. F. F. Motley, F. F. Cade, J. O. Cermak, L. S. Tong, S. W. Gouse, F. Paul, and J. C. Purcupile, "CHF Data from Freon-11 Flow for Scaling CHF in Water," Int. Symposium on Two-Phase Systems, Haifa, Paper No. 1-3 (1971).

93. J. C. Purcupile, L. S. Tong, and S. W. Gouse, Refrigerant-Water Scaling of CHF in Round Tubes--Subcooled Forced Convection Boiling, J. Heat Transfer ASME 95, 279 (1973). 
94. G. F. Stevens and R. V. Macbeth, The Use of Freon-12 to Model Forced Convection Burnout in Water: The Restriction on the Size of the Model, J. Br. Nucl. Energy Soc. 9, 249 (1970; also ASME Paper 70-HT-20.

95. D. C. Groeneve1d, Similarity of Water and Freon Dryout Data for Uniformly Heated Tubes, ASME Paper 70-HT-27 (1970).

96. R. D. Coffield, W. M. Rohrer, and L. S. Tong, A Subcooled DNB Investigation of Freon-113 and Its Similarity to Subcooled Water DNB Data, Nuc1. Eng. Design 11, 143 (1969).

97. G. E. Dix, Freon-Water Modeling of CHF in Round Tubes, ASME Paper 70-HT-26 (1970).

98. F. W. Staub, Two-Phase Flow Modeling--The Critical Heat Flux, Nuc1. Sc1. Engr. 35, 190 (1969).

99. E. G. Hauptmann, V. Lee, and D. W. McAdam, "Two-Phase Fluid Modeling of the Critical Heat Flux," Int. Meeting on Reactor. Heat Transfer, Karlsruhe, Paper No. 78 (1973).

100. L. S. Tong, F. E. Motley, and J. 0. Cermak, "Scaling Law of Flow-boiling Crisis," Fourth Int. Heat Transfer Conf., Paris, Paper No. B6.12 (1970).

101. J. Grey, Transient Response of the Turbine Flowmeter, Jet Propulsion 26,98 (1956).

102. G. F. Popper, Lecture Notes on In-core Instrumentation for the Measurement of Hydrodynamic Parameters in Water-cooled Reactors, ANL-6452 (Nov 1961).

103. Z. Rouhani, "Application of the Turbine Type Flowmeters in the Measurement of Steam Quality and Void," Symposium on In-core Instrumentation, Oslo, Paper No. D-6 (1964).

104. M. N. Hutcherson, Contribution to the Theory of the Two-Phase Blowdown Phenomenon, Ph.D. thesis, University of Missouri at Columbia (1975); also ANL-75-82 (Dec 1975).

105. C. L. Spigt, A. J. J. Wamsteker, and H. F. van Vlaardingen, "The Application of the Impedance Method for Transient Void Fraction Measurement and Comparison with the $\gamma$-ray Attenuation Technique," Symposium on In-Core Instrumentation, Oslo, Paper No. D-2 (1964).

106. I. Orbeck, "The Impedance Void Meter," Symposizon on In-Core Instrumentation, Oslo, Paper No. D-8 (1964).

107. J..F. Lafferty and F. G. Hammitt, A Conductivity Probe for Measuring Local Void Fractions in Two-Phase Flow, Nucl. Appl. 3, 317 (1967).

108. L. Cimorelli and A. Premoli, Measurement of. Void Fraction with Impedance Gauge Technique, Energia Nucleare, 13(1), 12 (1966).

109. A. E. Dukler and 0. P. Bergelin, Characteristics of Flow in Falling Liquid Films, Chem. Eng. Prog. 48(11), 557 (1952).

110. F. W. Paul and K. J. Riedle, Experimental and Analytical Investigation of the Dynamic Behavior of Diabatic Two-Phase Flow in a Vertical Monotube Vapor Generator--Part I, ASME Paper No. 72-WA/HT-46 (1972).

111. R. E. Murphy and A. E. Bergles, Subcooled Flow Boiling of Fluorocarbons, MI'l Keport No. USR 71903-72, (1971). 
112. P. Sachs and R. A. K. Long, A Correlation for Heat Transfer in Stratified Two-Phase Flow with Vaporization, Int. J. Heat Mass Transfer 2, 222 (1961).

113. D. C. Groeneveld, The Thermal Behavior of a Heated Surface at and Beyond Dryout, AECL-4309 (1972).

114. A. E. Bergles, N. Bakhru, and J. W. Shires, Cooling of High-PowerDensity Computer Components, MIT Report No. DSR 70712-60 (1968).

115. R. E. Henry, A Study of One- and Two-component, Two-phase Critical Flows at Low Qualities, ANL-7430 (Mar 1968).

116: J. Leung, O. C. Jones, R. E. Henry, and S. G. Bankoff, "Critical Heat Flux During Blowdown with Reversed Flow, First European Nuclear Conf., April 21-25, Paris; Trans. ANS 20, 486 (1975).

117. L. W. Florschuetz and B. T. Chao. On the Mechanics of Vapor Bubble

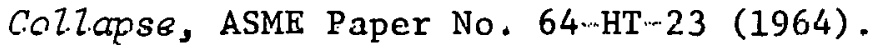

118. R. W. Murphy and A. E. Bergles, "Subcooled Flow Boiling of Fluorocarbono--Hyatcresis and Dissulved Gas Efferrs nn HeAt iranster," Hoat Transfer and Fluid Mechanics Institute, Stanford University Press, Paper 24, p. 400 (1972).

119. M. Behar, M. Conurtand, R. Bisque, and R. Scmeria, "Fundamental Aspects of Subcooled Boiling with and without Dissolved Gases," Proc. Third Int. Heat Transfer Conf., Vol. IV, p. 1 (1966).

120. W. H. McAdams, W. E. Kennel, C. S. L. Minden, R. Carl, P. M. Picornell, and J. E. Dew, Heat Transfer at High Rates to Water with Surface Boiling, Ind. Eng. Chem. 41(9), 1945-53 (1949).

121. N. Zuber, Hydrodynomics Aspects of Boiling Heat Transfer, AECU-4439 (1959).

122. J. P. Walkush, High Pressure Counterflow CHF, M.S. thesis, ME Dept.. MIT (Siept 14/4).

123. '1. s. 'l'hompson, An Analysis of the Wet-side Heat Transfer Coefficient During Rewetting of a Hot Dry Patch, Nuc1. Eng. Design 22, 212 (1972).

124. R. E. Henry and H. K. Fauske, The Two-Phase Critical Flow of OneComponent Mixtures in Nozzles, Orifires, and Short. Tubes, J. Heat Tranefer $03(2), 179$ (May 1971).

125. J. C. Slattery, Momention, Energy, and Masa Transfer in Continua, McGraw-Hill Book Co., Inc., New York p. 75 (1972).

126. J. K. Vennard EZementary Fluid Mechanics, John Wiley and Sons, New York (1954).

127. J. G. Knudsen and D. L. Katz, Fluid Dynomics and Heat Transfer, McGraw-Hill Book Co., Inc., New York (1,958).

128. 0. C. Jones and J. C. M. Leung, unpublished information (1975).

129. 0. C. Jones An Improvement in the Calculation of Turbulent Friction in Rectangular Ducts, presented at ASME Meeting, Nov. 30-Dec. 4, 1975, Paper No. 75-WA/FE-12 (1975).

130. C. C. Monrad and J. F. Pelton, Heat Transfer by Convection in Annular Spaces, Trans. AIChE 38, 593 (1942). 
131. J. H. Wiegand and E. M. Baker, Transfer Processes in AnnuZi, Trans. AIChE $38,569-588$ (1942).

132. R. J. Muzzy, J. H. Avila, and D. E. Root, Determination of Transient Heat 'iransfer Coefficients and the Resultant Surface Heat H'Zux from Internal Temperature Measurements, GEAP-20731 (Jan 1975).

133. J. V. Beck, NonZinear Estimation Applied to the NonZinear Inverse Heat Transfer Probiem, Int. J. Heat Mass Transfer 13, 703, (1970).

134. 0. R. Burggraf, An Exact Solution of the Inverse Problem in Heat Conduction Theory and Applications, J. Heat Transfer 86, 369 (1964).

135. G. Stoltz, Jr., Numerical Solutions to an Inverse Problem of Heat Conduction for Simple Shapes, J. Heat Transfer 82, 20 (1960).

136. E. M. Sparrow, A. Haji-Sheikh, and T. S. Lundgren, The Inverse Problem in Transient Heat Conduction, J. App1. Mech. 31, 369 (1964).

137. S. J. Green and T. W. Hunt, "Accuracy and Response of Thermocouples for Surface and Fluid Temperature Measurements," Symp. on Temp.: Its Measurement and Control in Science and Industry, Columbus, Ohio (Mar 1961).

138. J. P. Holman, Heat Transfer, McGraw-Hill Book Co., Inc., New York (1968).

139. Stainless Steel Handbook, The Allegheny Ludlum Steel Corp. (1959).

140. L. Cimorelli and R. Evangelisti, The Application of the Capacitance Method for Void Fraction Measurement in Bulk Boiling Conditions, Int. J. Heat Mass Transfer 10, 277 (1967).

141. J. C. Maxwe11, A Treatise on Electricity and Magnetism, Oxford University Press, Oxford (1873).

142. Du Pont Technical Bulletin X-11C (June 1975).

143. S. Y. Ahmad, Fluid to Fluid Modeling of Critical Heat Flux: A Compensated Distortion Model, Int. J. Heat Mass Transfer 16, 641 (1973).

144. L. S. Tong, F. E. Motley, and J. O. Cermak, "Scaling Law of Flow Boiling Crisis," Fourth Int. Heat Transfer Conf., Paris, Paper No. B6.12 (1970).

145. N. Zuber, "Two Phase Flow Stability in Rod Bundles," Two-Phase Flow and Heat Transfer. in Rod Bundles, ASME Winter Annual Mtg. (1969).

146. M. Ishii and N. Zuber, "Thermally Induced Flow Instabilities in Two Phase Mixtures," Fourth Int. Heat Transfer Conf., Paris, Paper No. B5.11 (1970).

147. J. D. Crowley and A. E. Bergles, Fluid-to-Fluid Modeling of the Hydrodynamic Stability of Flow in Boiling Channels, ASME Paper 70-HT-28 (1970).

148. S. Y. Ahmad and D. C. Groeneveld, "Fluid Modeling of Critical Heat Flux in Uniformly Heated Annuli," Int. Symp. on Two-Phase Systems, Haifa, Israel, Paper No. 1-8; also AECL-4070 (1971). 